\title{
Regulator of G Protein Signaling-12 (RGS12) in dopaminergic and kappa opioid receptor-dependent signaling and behavior
}

\author{
Joshua David Gross \\ jdgross@mix.wvu.edu
}

Follow this and additional works at: https://researchrepository.wvu.edu/etd

Part of the Behavioral Neurobiology Commons, Biochemistry Commons, and the Molecular and Cellular Neuroscience Commons

\section{Recommended Citation}

Gross, Joshua David, "Regulator of G Protein Signaling-12 (RGS12) in dopaminergic and kappa opioid receptor-dependent signaling and behavior" (2019). Graduate Theses, Dissertations, and Problem Reports. 4060.

https://researchrepository.wvu.edu/etd/4060

This Dissertation is protected by copyright and/or related rights. It has been brought to you by the The Research Repository @ WVU with permission from the rights-holder(s). You are free to use this Dissertation in any way that is permitted by the copyright and related rights legislation that applies to your use. For other uses you must obtain permission from the rights-holder(s) directly, unless additional rights are indicated by a Creative Commons license in the record and/ or on the work itself. This Dissertation has been accepted for inclusion in WVU Graduate Theses, Dissertations, and Problem Reports collection by an authorized administrator of The Research Repository @ WVU.

For more information, please contact researchrepository@mail.wvu.edu. 
2019

Regulator of G Protein Signaling-12 (RGS12) in dopaminergic and kappa opioid receptordependent signaling and behavior

Joshua David Gross

Follow this and additional works at: https://researchrepository.wvu.edu/etd

Part of the Behavioral Neurobiology Commons, Biochemistry Commons, and the Molecular and Cellular Neuroscience Commons 
Regulator of G Protein Signaling-12 (RGS12) in dopaminergic and kappa opioid receptordependent signaling and behavior

\author{
Joshua David Gross \\ Dissertation submitted to the School of Medicine \\ at West Virginia University \\ in partial fulfillment of the requirements for the degree of \\ Doctor of Philosophy in \\ Cellular \& Integrative Physiology
}

\author{
Bernard G. Schreurs, Ph.D., Chair \\ David P. Siderovski, Ph.D. \\ Vincent Setola, Ph.D. \\ Steven G. Kinsey, Ph.D. \\ Hanting Zhang, Ph.D.
}

Department of Physiology \& Pharmacology

Morgantown, West Virginia

2019

Keywords: regulator of G protein signaling-12 (RGS12), dopamine transporter, kappa opioid receptor, $\beta$-arrestin

Copyright 2019 Joshua David Gross 


\begin{abstract}
Regulator of G Protein Signaling-12 (RGS12) in dopaminergic and kappa opioid receptordependent signaling and behavior
\end{abstract}

Joshua David Gross

Dopaminergic neurotransmission is critically involved in the etiology and treatment of many psychiatric and neurological disorders. One modulator of dopaminergic neurotransmission is the kappa opioid receptor (KOR) -- a G protein-coupled receptor (GPCR) that is densely expressed within dopaminergic neurons and circuits. GPCRs are tightly regulated by a variety of intracellular signaling molecules, including Regulator of G Protein Signaling (RGS) proteins. Canonically, RGS proteins act as GTPase accelerating proteins (GAPs) on GTP-bound G $\alpha$ subunits following GPCR activation, thereby hastening the rate at which GPCR-mediated G protein signaling is terminated. However, some RGS proteins exhibit more complex mechanisms of action on cellular signaling. One such example is RGS12, which harbors the capacity to regulate both $G$ protein-dependent and -independent signaling cascades. RGS12 is widely expressed across the developing and adult brain; we show that expression levels are notably high within dopamine- and KOR-enriched regions. We also observed that Rgs12 mRNA exhibits marked expression overlap with Oprk1 mRNA encoding KOR, which potently regulates dopaminergic neurotransmission following environmental stress and pharmacological challenge with psychostimulants. We revealed that genetic ablation of Rgs12 in mice upregulates dopamine transporter (DAT) function and attenuates behavioral responses to psychostimulants via KORdependent mechanisms. Moreover, we showed that RGS12 differentially regulates G proteindependent versus $\mathrm{G}$ protein-independent signaling and behavior downstream of KOR activation. We also demonstrated that RGS12 displays region-specific effects in the striatum, and that RGS12 selectivity modulates KOR over other opioid receptors. Further studies are required to more completely elucidate the complex interaction between RGS12 and KOR, as well as to identify precisely the neuronal cell populations and brain regions mediating the effect of RGS12 on dopaminergic and KOR-dependent signal transduction and behavior. 


\section{ACKNOWLEDGEMENTS}

When I step back to reflect on my time as a Ph.D. student, it becomes immediately difficult to grasp how far l've come since entering the Biomedical Sciences program and the Siderovski/Setola lab(s). As my co-mentor Dr. Vincent Setola would say, I arrived at WVU as a "tabula rasa" -- barely able to hold a pipette. Through five years of sinusoidal challenges and the occasional eureka! moment, I was fortunate enough to construct a successful Ph.D. primarily because of the quality of mentorship I received, the optimal lab environment/culture I was immersed in every day, and the support of my family. It is quite difficult for me to conceive of a better set of conditions for my development as a scientist, and for that, I am deeply grateful to the following people:

To my mentor Dr. David Siderovski... You flawlessly walk the tenuous line of providing me direction without micromanagement, autonomy without absence (i.e., always catching my back when I need it), and encouragement to pursue my interests and ideas without allowing me to float off into the deep end. Of all that you have taught me about performing good science, writing and grantsmanship, and how to pursue a career as a scientist, you have perhaps most deftly shown me how mentorship ought to be practiced by the example you set every day. It is my hope, if I run my own lab someday, that I can employ at least a subset of these traits to students of my own.

To my mentor Dr. Vincent Setola... The scientific interest and drive that you instilled in me during my SURI stint (while still an undergrad at JMU) is the predominant reason that I decided to come back to WVU for my Ph.D. You took a big risk by investing so much time and effort into my early training as a scientist, especially after I showed up at WVU as 'green' as could be. You somehow identified a potential in me despite my naivety, perhaps buried deep down below my wildly over-the-top enthusiasm about neuropsychopharmacology (and music). You enabled me to build myself from the ground-up as a scientific thinker and experimenter, and for that I will always be very grateful to you. 
I would also like to thank the other members of my dissertation committee: my chairman Dr. Bernard Schreurs, Dr. Hanting Zhang, and especially Dr. Steven Kinsey. I am very fortunate to have selected a committee that has always provided me with constructive and helpful support.

To my past lab-mates Bryan, Adam, and Shane... I am certain that I could not have been luckier with the lab environment you have all created for me. You are each incredible scientists and even better friends. All the help you have given me in, and out of, lab has been a major reason that I have had success as a Ph.D. candidate. I would like to give a special shout-out to my officemate, Shane. It is pretty baffling how we could be around each other all day long and still decide to hang out outside of lab. The combination of our eerily similar intellectual interests (whether it be science, politics, philosophy, etc.), along with your superior IQ meant there was never a dull moment of conversation. When you run a clinic or institute someday, I hope that you will consider hiring me as your head of neuropsychopharmacology research.

To my wife Kate.... There is absolutely no chance any Ph.D. student could get as lucky as I have been to have such a supportive, encouraging, and understanding spouse. I am certain that my very positive experience as a Ph.D. student is largely due to your support. You have had to endure every one of the existential crises I have conjured up throughout my grad student career, and every single time I came out of the conversation knowing that everything was going to work out. You are a relentless voice of reason, the world's best listener, and so selfless that you push me to pursue my scientific interests and passions even further than I do on my own. My only hope is that I can provide you with even a fraction of the support that you have provided me as you progress in your own, very successful career.

To my parents, you have provided me with unwavering support throughout this entire process, even when you had no idea what I was actually doing on a daily basis or what kind of job I may get someday. Your encouragement to always pursue what you love, regardless of what that entails, is a value that I will always carry with me. You are model parents and you have made my navigation through graduate school much easier than it could have been. Thank you. 


\section{TABLE OF CONTENTS}

Cover Page

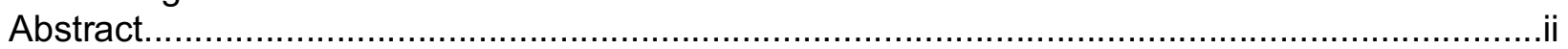

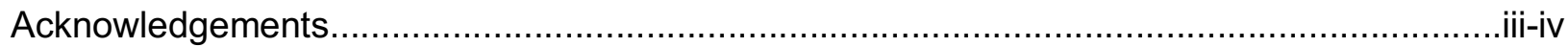

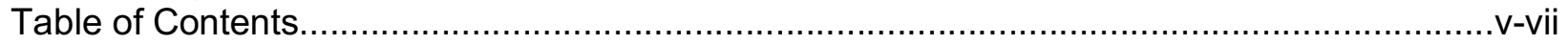

List of Figures.................................................................................................................

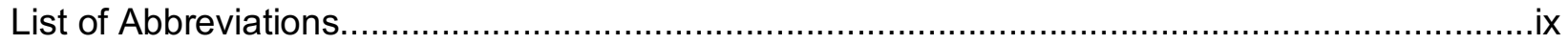

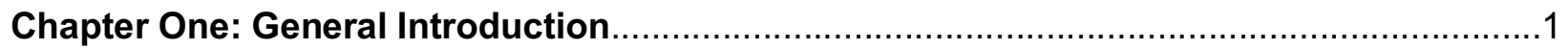

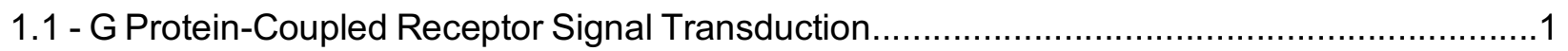

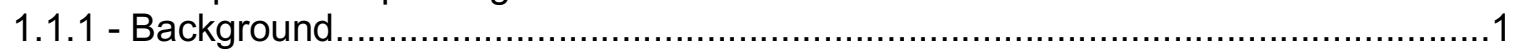

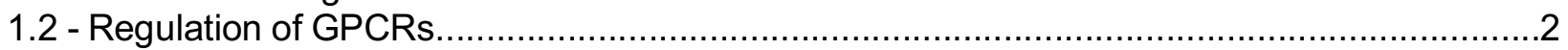

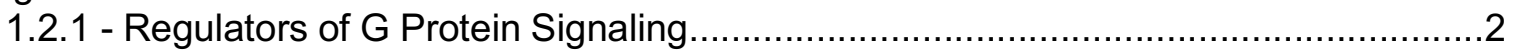

1.2.1a - RGS Proteins in Neuronal Physiology ..................................................5

1.2.1b - RGS Proteins and Opioidergic Signaling and Behavior...........................

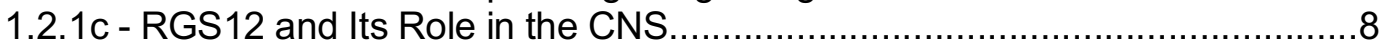

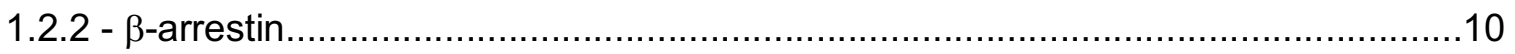

1.2.2a - $\beta$-arrestins in Neuronal Physiology ...............................................12

1.2.2b - $\beta$-arrestins and Opioidergic Signaling and Behavior..............................12

1.2.3 - GPCR Functional Selectivity (a.k.a. Biased Agonism)....................................13

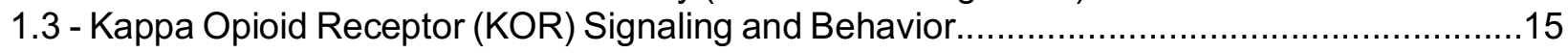

1.3.1 - Background: Opioid Receptor Signaling Transduction.....................................15

1.3.2 - KOR Expression in the Mouse Brain..........................................................16

1.3.3 - KOR and Dopaminergic Neurotransmission...............................................17

1.3.3a - Background: KOR in the Mesolimbic DA System..............................17

1.3.3b - Dopamine Release.....................................................................18

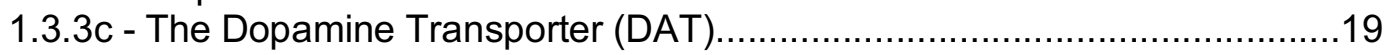

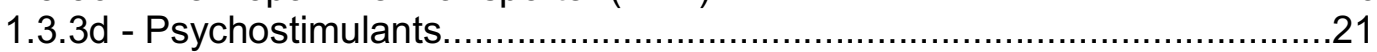

1.4 - 'Functionally Selective' Behavioral Outcomes of KOR Activation....................................23

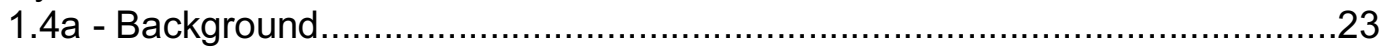

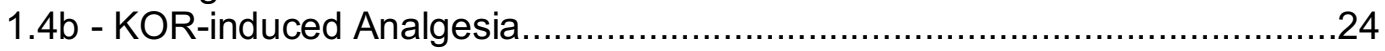

$1.4 \mathrm{c}$ - KOR-induced Dysphoria/Aversion...................................................25

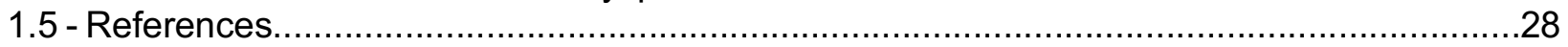

Chapter Two: Regulator of G protein signaling-12 (RGS12) modulates the dopamine transporter in ventral striatum and locomotor responses to psychostimulants (Gross et al., 2018, Journal of

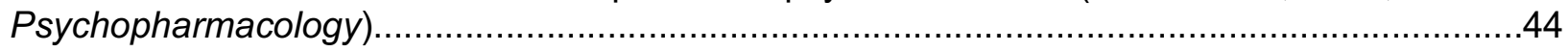

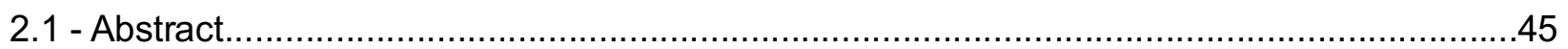

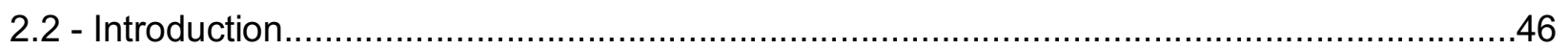

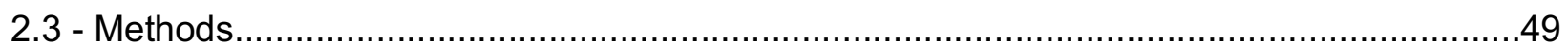

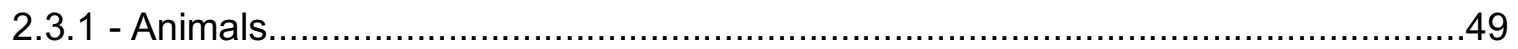

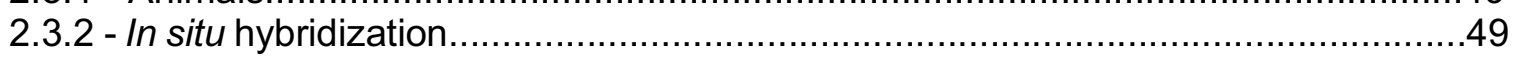

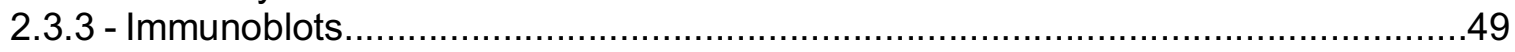

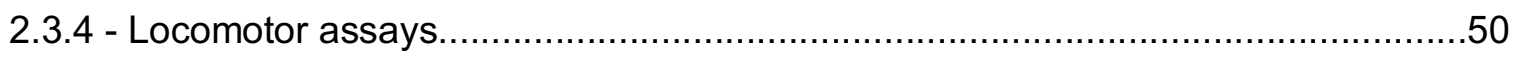

2.3.5 - Psychostimulant-induced locomotor sensitization...........................................51

2.3.6 - Conditioned place preference (CPP) .....................................................51

2.3.7 - Preparation of brain sections and immunohistochemistry for c-Fos.....................53

2.3.8 - Preparation of synaptosomes and measurement of $\left[{ }^{3} \mathrm{H}\right]$ dopamine uptake and release. 
2.3.9 - Preparation of brain tissue and measurement of $\left[{ }^{3} \mathrm{H}\right] \mathrm{WIN} 35428$ binding

2.3.10 - High-performance liquid chromatography (HPLC) with dual-cell electrochemical detection............................................................................................54

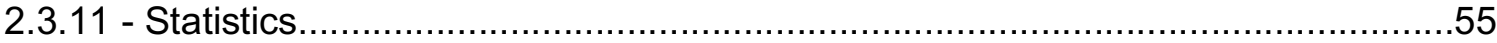

2.4 - Results. 56

2.4.1 - RGS12 protein is abundantly expressed in the ventral striatum of the mouse CNS. .56

2.4.2 - RGS12 loss blunts hyperlocomotion to low doses of amphetamine and

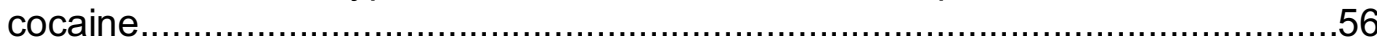

2.4.3 - RGS12 loss does not affect sensitization nor conditioned place preference...........58

2.4.4 - AMPH-elicited neuronal excitation is reduced in the NAc upon RGS12 loss..........60

2.4.5 - Dopamine uptake is enhanced in ventral striatal synaptosomes from

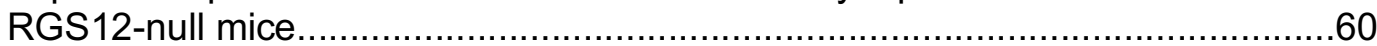

2.4.6 - DAT binding sites are significantly elevated in the ventral striatum......................61

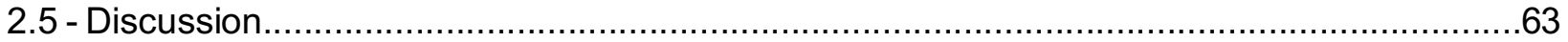

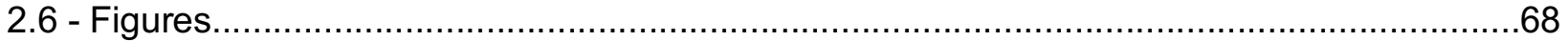

2.7 - References.

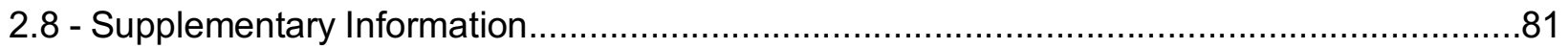

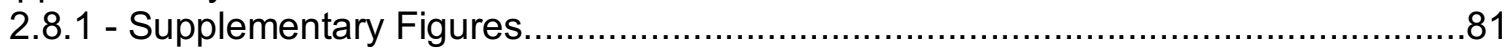

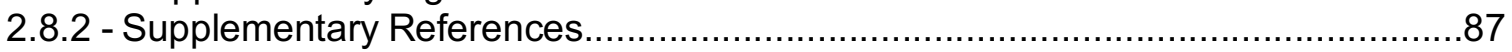

Chapter Three: The role of RGS12 in the differential regulation of kappa opioid receptordependent signaling and behavior (Gross et al., 2019, Neuropsychopharmacology)...................88

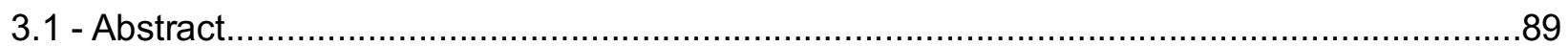

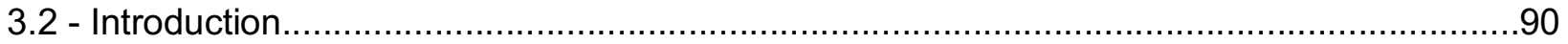

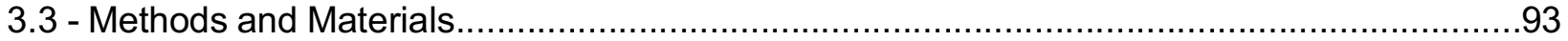

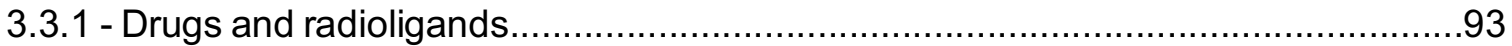

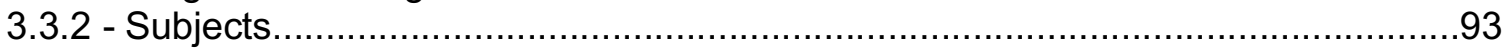

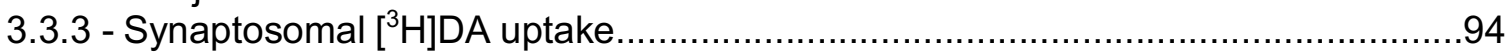

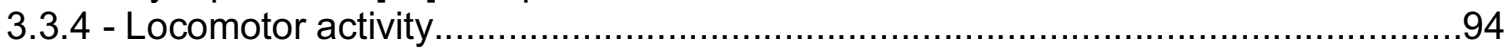

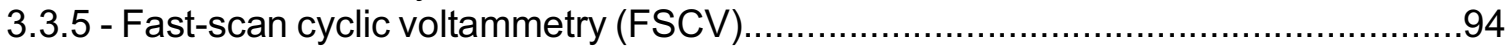

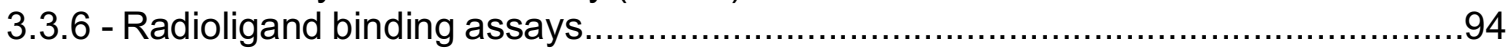

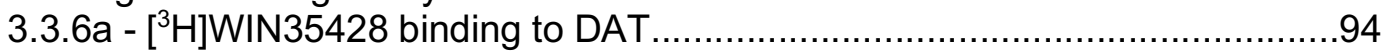

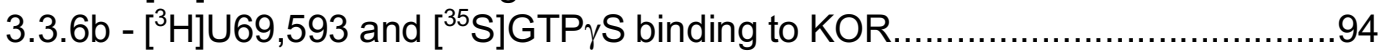

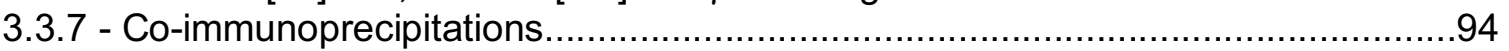

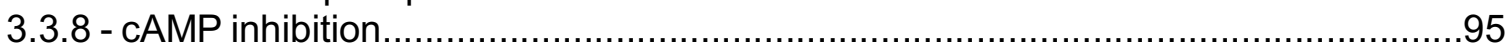

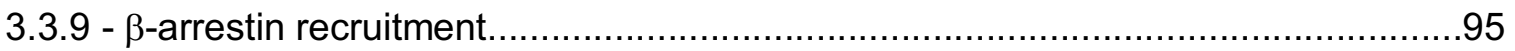

3.3.10 - Hot plate analgesia and conditioned place aversion (CPA) tests.......................95

3.4 - Results .96

3.4.1 - vSTR DAT dysfunction in RGS12-null mice is KOR-dependent.........................96

3.4.2 - RGS12 forms a protein complex with KOR in brain tissue and transfected cells..99

3.4.3 - KOR sensitivity and binding sites are increased in vSTR of RGS12-null mice......99

3.4.4 - RGS12 differentially regulates $G$ protein and $\beta$-arrestin signaling downstream of KOR. .101

3.4.5 - RGS12 differentially regulates G protein- and $\beta$-arrestin-dependent behaviors

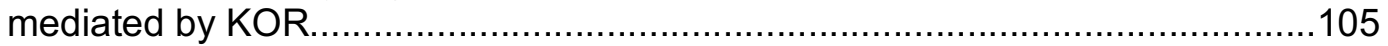

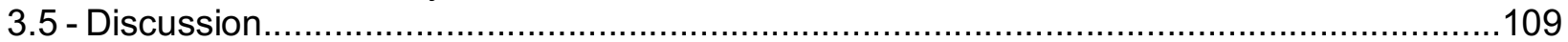

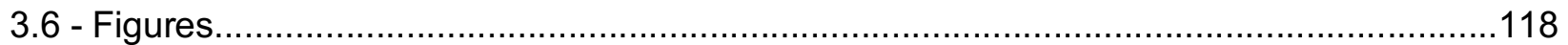

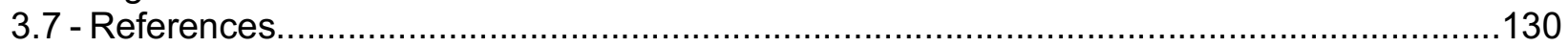

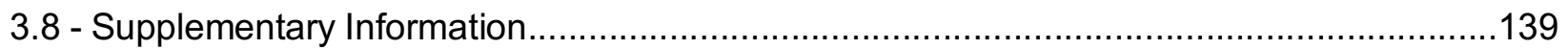




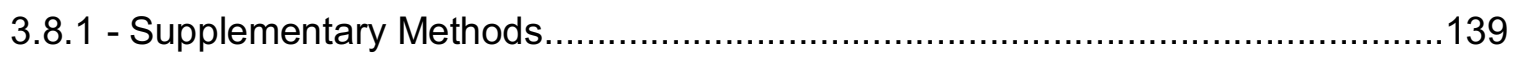

3.8.1a - $\beta$-arrestin-2 deficient animals.......................................................139

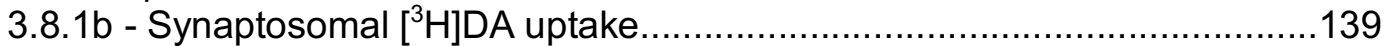

3.8.1c - Locomotor activity ..................................................................139

3.8.1d - Fast-scan cyclic voltammetry (FSCV) ...........................................140

3.8.1e - Radioligand binding assays.......................................................140

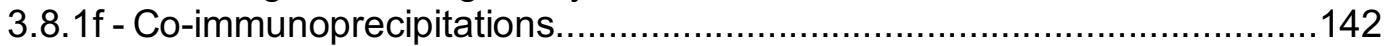

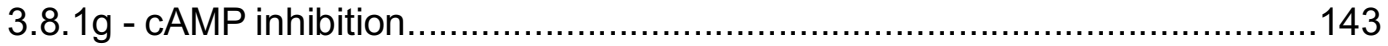

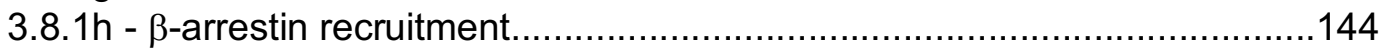

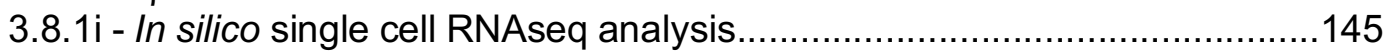

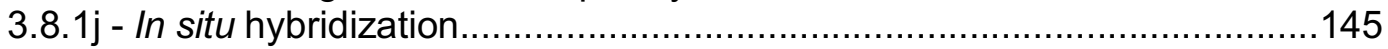

3.8.1k - Quantitative reverse transcription-polymerase chain reaction (qRT-PCR)

3.8.1I - Hot plate analgesia test..............................................................146

3.8.1m - Hot plate analgesia with KOR antagonist treatment.........................146

3.8.1n - Conditioned place aversion (CPA) ................................................147

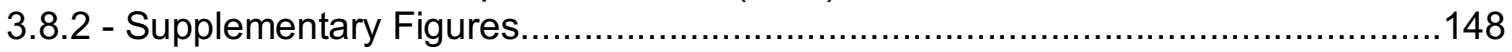

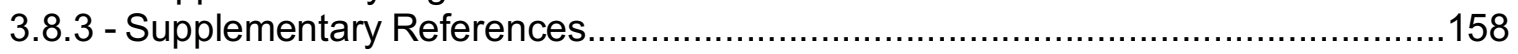

Chapter Four: General Conclusions and Future Directions..............................................159

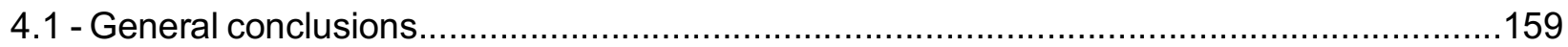

4.2 - Future Directions and Experimental Approaches....................................................160

4.2.1 - Question 1: Does RGS12 affect KOR signaling and behaviors solely in KORexpressing neurons? ............................................................................160

4.2.2 - Question 2: Does RGS12 loss of Rgs12 during neurodevelopment contribute to the observed biochemical and behavioral disruptions in adult RGS12-null mice? ..................................................................................161

4.2.3 - Question 3: Does RGS12 play a role in KOR-mediated signaling and behavioral

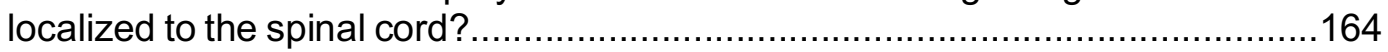

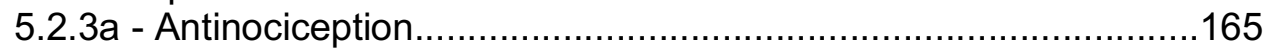

5.2.3b - Antinociception tolerance ...................................................166

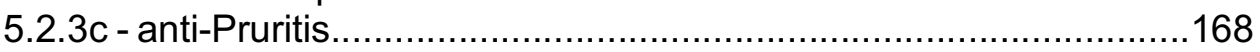

5.2.3d - Neuropathic pain............................................................170

4.2.4 - Question 4: Do RGS12 and KOR associate via a PDZ-mediated interaction? ....174

4.2.5 - Question 5: Which specific brain regions and protein domains are responsible for the disruptions to DA and KOR function observed with global RGS12-null mice? ..........................................................................................176

4.2.6 - Question 6: Does RGS12 regulate AMPH-evoked DA levels in vivo? ...............177

4.2.7 - Question 7: Does RGS12 after SERT and/or 5-HTergic behaviors via KOR-dependent mechanism(s)? ........................................................179

4.3 - References.

Appendix A: RGS12 Loss and Its Effect on Prepulse Inhibition of Acoustic Startle

Appx A.1 Deletion of schizophrenia-associated gene RGS12 in mice results in baseline prepulse inhibition deficiencies that are not reversed by antipsychotics.............189

Appx A.2 Deletion of schizophrenia-associated gene RGS6 in mice does not alter baseline prepulse inhibition or startle reactivity.........................................................191

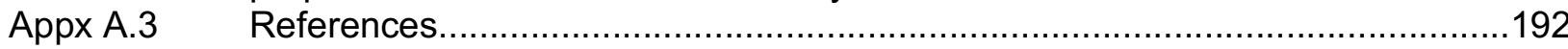




\section{LIST OF FIGURES}

Figure

2.6.1

2.6 .2

2.6.3

2.6.4

2.6 .5

2.8.1

2.8 .2

2.8 .3

2.8.4

3.6.1

3.6 .2

3.6 .3

3.6.4

3.6 .5

3.8.2a

3.8.2b

$3.8 .2 \mathrm{c}$

3.8.2d

3.8.2e

3.8.2f

$3.8 .2 \mathrm{~g}$

4.2.3a-1

4.2.3d-1 Appx A.1

Appx A.2

$\underline{\text { Title }}$

Targeting sites for Rgs12 gene locus deletion and expression patterns of Rgs12 mRNA and protein in the adult mouse brain.

RGS12-null mice exhibit reduced hyperlocomotor responses to the presynaptically-acting psychostimulants, d-amphetamine (AMPH) and cocaine..71 RGS12-null mice display normal locomotor sensitization and conditioned place preference to AMPH and cocaine.

AMPH-induced c-Fos immunoreactivity is reduced in the nucleus accumbens (NAc), but not dorsal striatum (dSTR), of RGS12-null mice.............................74 The number of DAT binding sites and [3H]dopamine (DA) uptake are increased in the ventral (vSTR), but not dorsal (dSTR), striatum of RGS12-null mice..........75 Generation and validation of two independent global RGS12-null strains.............81 Baseline levels of dopaminergic markers are normal in RGS12-null mice............84 AMPH-induced $\left[{ }^{3} \mathrm{H}\right]$ dopamine (DA) efflux is only mildly affected in ventral (vSTR), but not dorsal (dSTR), striatal synaptosomes.....................................85 Increased DAT binding sites and [3H]dopamine (DA) uptake are recapitulated in an independent, Cre-dependent RGS12-null mouse strain.

Ventral striatal DAT dysfunction in RGS12-null mice is kappa opioid receptor (KOR)-dependent

RGS12 interacts with KOR and RGS12 loss results in elevated KOR sensitivity and binding sites in the VSTR.

RGS12 differentially regulates KOR agonist-mediated $G$ protein versus $\beta$-arrestin signaling cascades and exerts considerable selectivity for KOR over other opioid

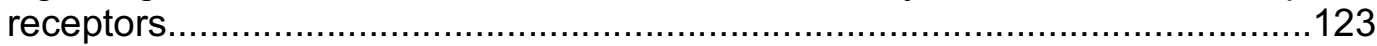

RGS12-null mice display differential behavioral responses to KOR agonists....126 Proposed model of RGS12 action in the differential outputs of KOR-activated

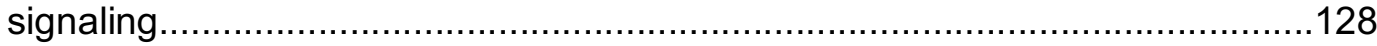
Rgs12 and Oprk1 (KOR) mRNAs show similar expression patterns in mouse brain........................................................................................................ 148

Baseline and KOR-dependent DA release and DA reuptake are normal in the dSTR of RGS12-null mice. 150 Oprk1 (KOR) and prodynorphin (Pdyn) mRNA levels are unchanged in the vSTR and midbrain of RGS12-null mice. 151 The selective effect of RGS12 on KOR-mediated G protein signaling is preserved in rodent RGS12 variants. 153 The analgesic effect of $30 \mathrm{mg} / \mathrm{kg} U 50,488$ is lost, in both RGS12-null mice and wildtype littermate controls, following pretreatment with nor-BNI. 155 Responses to morphine at doses of either $5 \mathrm{mg} / \mathrm{kg}(\mathrm{A})$ or $10 \mathrm{mg} / \mathrm{kg}$ (B) are similar in RGS12-null mice and wildtype littermate controls.............................156 $\beta$-arrestin-2 is not required for $\left[{ }^{3} \mathrm{H}\right] \mathrm{DA}$ uptake in the vSTR and dSTR.............157 RGS12-null mice exhibit augmented spinal antinociception to the KOR agonist in a dose-dependent manner.

RGS12-null mice exhibit attenuated allodynia after $\mathrm{CCl}$.

Deletion of schizophrenia-associated gene RGS12 in mice results in baseline prepulse inhibition deficiencies that are not reversed by antipsychotics.............189 Deletion of schizophrenia-associated gene RGS6 in mice does not alter baseline prepulse inhibition or startle reactivity. 


\section{ABBREVIATIONS}

\begin{tabular}{|c|c|}
\hline 5-HT & Serotonin \\
\hline AMPH & d-Amphetamine \\
\hline AMY & Amygdala \\
\hline $\mathrm{CCl}$ & Chronic Constriction Injury \\
\hline CLA & Claustrum \\
\hline CPA & Conditioned Place Aversion \\
\hline CPP & Conditioned Place Preference \\
\hline CTX & Cerebral Cortex \\
\hline DA & Dopamine \\
\hline DAT & Dopamine Transporter \\
\hline DOR & Delta Opioid Receptor \\
\hline DRG & Dorsal Root Ganglion \\
\hline DRN & Dorsal Raphe Nucleus \\
\hline dSTR & Dorsal Striatum \\
\hline ERK & Extracellular Signaling Regulated Kinase \\
\hline FSCV & Fast-Scan Cyclic Voltammetry \\
\hline GAP & GTPase Accelerating Protein \\
\hline GDI & Guanine Dissociation Inhibitor \\
\hline GDP & Guanosine Diphosphate \\
\hline GEF & Guanine Nucleotide Exchange Factor \\
\hline GPCR & G Protein-Coupled Receptor \\
\hline GRK & G Protein-Coupled Receptor Kinase \\
\hline GTP & Guanosine Triphosphate \\
\hline $\mathrm{HPC}$ & Hippocampus \\
\hline HPLC-ECD & High-Performance Liquid Chromatography with Electrochemical Detection \\
\hline JNK & c-Jun N-terminal Kinase \\
\hline KOR & Kappa Opioid Receptor \\
\hline MAPK & Mitogen-Activated Protein Kinase \\
\hline MB & Midbrain \\
\hline METH & Methamphetamine \\
\hline MOR & Mu Opioid Receptor \\
\hline MRN & Median Raphe Nucleus \\
\hline NAc & Nucleus Accumbens \\
\hline NGF & Nerve Growth Factor \\
\hline nor-BNI & Norbinaltorphimine \\
\hline PDZ & PSD-95/Dlg/ZO-1 domain \\
\hline PFC & Prefrontal Cortex \\
\hline $\mathrm{PH}$ & Pleckstrin Homology \\
\hline PPI & Prepulse Inhibition \\
\hline PTB & Phosphotyrosine Binding Domain \\
\hline PTX & Pertussis Toxin \\
\hline PWT & Paw Withdrawal Threshold \\
\hline RBD & Ras Binding Domain \\
\hline RGS & Regulator of G Protein Signaling \\
\hline RTK & Receptor Tyrosine Kinase \\
\hline SERT & Serotonin Transporter \\
\hline vSTR & Ventral Striatum \\
\hline VTA & Ventral Tegmental Area \\
\hline Barr & $\beta$-arrestin \\
\hline
\end{tabular}




\section{CHAPTER 1}

\section{General Introduction}

\section{1 - G Protein-Coupled Receptor Signal Transduction}

\subsection{1 - Background}

All organisms must convert extracellular stimuli into intracellular signals to enable physiological adaptation to the environment. A primary mechanism by which organisms transduce extracellular cues into cellular responses is via membrane-bound, cell surface-expressed receptor proteins (Gilman, 1987; Bockaert and Pin, 1999; Unwin, 1993; Ullrich and Schlessinger, 1990). The largest class of receptor proteins is G protein-coupled receptors (GPCRs), which constitute more than $1 \%$ of the protein-coding human genome (Bockaert and Pin, 1999; Fredriksson et al., 2003). GPCRs are ubiquitously expressed throughout the body, and they respond to a diverse array of external stimuli, including neurotransmitters, hormones, ions, and sensory cues, such as light and odor (Rosenbaum et al., 2009; Lagerstrom and Schioth, 2008;

Krishnan and Schioth, 2015). Accordingly, GPCRs represent the largest pharmacological drug target class (Hauser et al., 2017; Santos et al., 2017).

GPCRs (also referred to as 7TMRs) contain seven transmembrane $\alpha$-helices, with an extracellular $\mathrm{N}$-terminus, three extracellular loops, three intracellular loops, and an intracellular Cterminus (Geppetti et al., 2015; Rosenbaum et al., 2009). Inactive GPCRs couple to intracellular heterotrimeric $\mathrm{G}$ protein complexes composed of a GDP-bound $\mathrm{G} \alpha$ subunit and an obligate $\mathrm{G} \beta \gamma$ dimer (Hepler and Gilman, 1992; Gilman, 1987). Binding of a GPCR agonist (activating ligand) induces conformational changes in the GPCR that promote the exchange of GDP for GTP (the latter nucleotide in higher cytosolic concentrations) on $\mathrm{G} \alpha$ subunits, thereby acting as a guanine nucleotide exchange factor (GEF). GTP-bound $\mathrm{G} \alpha$ subunits exhibit reduced affinity for the G $\beta \gamma$ heterodimer and, thus, G $\alpha \cdot$ GTP dissociates from G $\beta \gamma$ heterodimers (Lambright et al., 1994; Neer, 1995; Oldham and Hamm, 2008). Heterotrimeric G protein complex dissociation reflects the 'on' 
state of the receptor, as freed G $\alpha \cdot G T P$ subunits and $G \beta \gamma$ heterodimers interact with various intracellular effectors, including adenylyl cyclase, isoforms of phospholipase C, ion channels, and many others. The engagement of specific effectors is predicated on the subtype of $\mathrm{G} \alpha$ subunit (Freissmuth et al., 1989; Simon et al., 1991; Hart et al., 1998; Siehler, 2009). For example, G $\alpha_{\text {s }}$ activates adenylyl cyclase, resulting in the formation of cyclic adenosine monophosphate (cAMP) (i.e., stimulatory activity) (Hausdorff et al., 1989), whereas $\mathrm{G}_{\mathrm{i} / \mathrm{o}}$ blocks this process (i.e., exerts inhibitory activity) (Gilman, 1984). Effector signaling leads to a wide array of biological responses over short- and long-term timespans, including neuronal excitation/inhibition, neurotransmitter/hormone release, and gene transcription (Clapham and Neer, 1997; Carman et al., 1999; Simonds, 1999; Kammermeier et al., 2000; Lutz et al., 2007). Free G $\alpha \cdot G T P$ and G $\beta \gamma$ subunits continue to impact intracellular effector molecules until GTP is hydrolyzed back to GDP via intrinsic GTPase catalytic activity of the G $\alpha$ subunit (Cassel et al., 1979; Vuong and Chabre, 1991). G $\alpha \cdot G D P$ has a higher affinity for $G \beta \gamma$ heterodimers, thus GTP hydrolysis drives restoration of heterotrimeric complex formation and receptor coupling (i.e., the 'off' state) until subsequent GPCR activation (Neubig and Siderovski, 2002; Kimple et al., 2011; Siderovski DP, 2008)

\section{2 - GPCR Regulation}

\subsection{1 - Regulators of G Protein Signaling}

The termination of GPCR signaling is tightly regulated by intracellular signaling molecules across a wide temporal scale (i.e., seconds to minutes to hours) (Berman and Gilman, 1998; Kimple et al., 2011; Smith and Rajagopal, 2016a). Although G $\alpha$ subunits harbor intrinsic GTP hydrolysis activity, the spontaneous rate of this reaction is too slow to account for the physiological processes engendered by GPCR activation (Vuong and Chabre, 1991; Angleson and Wensel, 1993; Breitwieser and Szabo, 1988). Regulators of G protein signaling (RGS) proteins serve as the primary mechanism by which GTP is rapidly hydrolyzed from active $\mathrm{G} \alpha$ subunits and thereby 
act as the chief short-term negative regulators of $G$ protein signaling in the cell. RGS proteins exhibit GTPase-accelerating protein (GAP) activity on GTP-bound G $\alpha$ subunits via a conserved 120 amino acid RGS domain (Berman and Gilman, 1998; McCudden et al., 2005; Dohlman and Thorner, 1997; Soundararajan et al., 2008). The RGS domain exhibits strong affinity for the

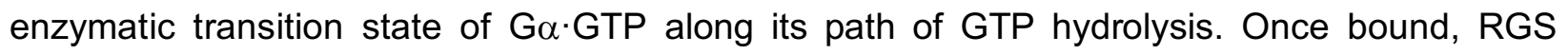
proteins stabilize the positioning of an essential glutamate residue within the intrinsic $\mathrm{G} \alpha$ catalytic region, thereby accelerating the rate of GTP hydrolysis to GDP + $\mathrm{P}_{\mathrm{i}}$ (Kimple et al., 2011). An extensive literature has demonstrated that loss of RGS protein expression in mice (e.g., RGS2, RGS4, RGS9-2) engenders increased GPCR sensitivity to agonist stimulation (e.g., (Heximer et al., 2003; Ruiz de Azua et al., 2010; Han et al., 2010; Zachariou et al., 2003; Psifogeorgou et al., 2007), thus highlighting the importance of RGS proteins in vivo.

There are 20 classical RGS proteins, and these can be partitioned into smaller subfamilies $(\mathrm{R} 4, \mathrm{R} 7, \mathrm{R} 12, \mathrm{RZ})$ on the basis of sequence and protein domain homology. Notably, many other protein classes contain an RGS domain, including G protein-coupled receptor kinases (GRKs), nexins, ankyrins, AKAPs, and Rho-GEFs, but these are considered non-canonical RGS proteins, as most of them do not exhibit G $\alpha$-directed GAP activity (Neubig and Siderovski, 2002; Sjogren, 2017). The largest (in number) and simplest RGS protein subfamily is the R4 family (e.g., RGS2, RGS4, RGS21), which contains only a central RGS domain between the $\mathrm{N}$ - and C-termini. Members of the RZ family exhibit a similar domain architecture, except that they each contain an $\mathrm{N}$-terminal post-cysteine segment that undergoes reversible palmitoylation. Members of other RGS subfamilies contain multi-domain architectures capable of mediating protein-protein interactions with adaptor proteins or regulating G protein-independent signaling. For example, stable expression of RGS proteins within the R7 subfamily (i.e., RGS6, RGS7, RGS9, RGS11) requires an obligatory physical interaction with $\mathrm{G} \beta 5$ subunits via the N-terminal GGL (G $\beta$-like) domain (Chen et al., 2003; Snow et al., 1998b). In contrast, RGS12 (a member of the R12 family) 
contains an N-terminal PDZ domain that enables physical interactions with GPCRs expressing C-terminal PDZ recognition motifs (Snow et al., 2002; Snow et al., 1998a). Another distinguishable feature of R12 family members (e.g., RGS12, RGS14) is that these proteins are capable of modulating G protein-independent signal transduction. Specifically, RGS12 and RGS14 both contain tandem Ras-binding domains (RBDs), which affect mitogen-activated protein kinase/extracellular-signaling regulated kinase (MAPK/ERK) cascades (Willard et al., 2009; Willard et al., 2007); furthermore, RGS12 (but not RGS14) contains an N-terminal phosphotyrosine-binding domain that can modulate receptor-tyrosine kinase (RTK)-mediated signaling (Willard et al., 2007). For a deeper discussion on the molecular mechanisms and physiological outcomes of RGS12-dependent signaling, please see 1.2.1c - RGS12 and Its Role in the CNS below. Comprehensive reviews on the sequence and biochemical differences between RGS protein subfamily members can be found elsewhere (Siderovski and Willard, 2005; Neubig and Siderovski, 2002; Siderovski DP, 2013).

RGS proteins can exhibit specificity for GPCRs on multiple levels. First, the RGS domain displays $\mathrm{G} \alpha$ subunit specificity, although some can act upon multiple $\mathrm{G} \alpha$ subunit subtypes (Xu et al., 1999; Soundararajan et al., 2008). However, to date, there are no identified RGS proteins capable of acting as a functional GAP on $\mathrm{G} \alpha_{\text {s }}$ subunits (cf., (Zheng et al., 2001). Second, RGS proteins can exhibit specificity for particular GPCRs via compatible amino acid sequences between the RGS protein and its cognate GPCR. For example, RGS12 contains a PDZ binding domain on its $\mathrm{N}$-terminus that enables selective GPCR interactions via direct physical association with GPCRs containing a C-terminal PDZ recognition motif (Snow et al., 1998a; Martemyanov et al., 2003; Snow et al., 2002; Sambi et al., 2006). Lastly, RGS proteins can exert specificity for GPCRs through differential and selective expression distributions across physiological systems and tissues. A stark example of this phenomenon is the RGS9 splice variants RGS9-1 and RGS9-2. The RGS9-1 isoform is exclusively expressed in rod and cone photoreceptors, where 
it serves as the critical GAP for rhodopsin (He et al., 1998), whereas RGS9-2 is almost exclusively expressed in the striatum, where it acts on neurotransmitter GPCRs (Mancuso et al., 2010).

\subsection{1a - RGS Proteins in Neuronal Physiology}

RGS proteins are widely expressed in the mammalian central nervous system (CNS) (Gold et al., 1997; Larminie et al., 2004) and have been extensively linked to a wide variety of neurological and psychiatric conditions (Rivero et al., 2012; Mirnics et al., 2001; Erdely et al., 2006; Tekumalla et al., 2001). The functional role of RGS proteins in neuronal physiology has been predominantly elucidated through the use of transgenic mice. Classically, constitutive and conditional RGS knockout mice provided a method by which to investigate the role of specific RGS proteins in vivo (Grillet et al., 2005; Zachariou et al., 2003; Oliveira-Dos-Santos et al., 2000; Lee et al., 2010). These efforts have been augmented by the development and use of RGSinsensitive $G \alpha$ subunit knockin mice. In these mice, specific $G \alpha$ subunits $\left(G \alpha_{o}, G \alpha_{i 2}\right)$ are incapable of functional coupling to RGS proteins (DiBello et al., 1998; Lan et al., 1998; Fu et al., 2004; Kaur et al., 2011; Lamberts et al., 2013). Studies utilizing these techniques have revealed the integral roles for RGS proteins in the modulation of GPCR signaling-driven neuroplasticity and behaviors via action within a variety of neuronal cell populations and circuits (Gerber et al., 2016; Roman and Traynor, 2011). A comprehensive summary of the mechanisms by which all CNS-expressed RGS proteins affect neuronal physiology is beyond the scope of this thesis. Therefore, I will focus specifically on the extant findings that strongly support a role for RGS proteins in the modulation of opioidergic signaling and behavior.

\subsection{1b - RGS Proteins and Opioidergic Signaling and Behavior}

Several groups have demonstrated that RGS proteins are critical determinants of opioidergic signaling and behavior (Traynor, 2012; Zachariou et al., 2003; Wang et al., 2009; Xie 
et al., 2007). There are three classical opioid receptors, the mu (MOR), delta (DOR), and kappa (KOR) opioid GPCRs (Waldhoer et al., 2004; Snyder and Pasternak, 2003). Historically, most work has focused on characterizing the functional relationship between several different RGS proteins and the MOR, which is the molecular target of opioid analgesics and drugs of abuse, such as morphine, hydrocodone, oxycodone, and heroin (Contet et al., 2004). Extensive prior work has demonstrated that RGS4 and RGS9-2 are required for the molecular and behavioral effects of MOR-directed drugs (for a comprehensive review, see (Traynor, 2012)).

RGS4 is one of the smallest RGS proteins, consisting only of a single RGS domain that promiscuously acts as a GAP on $\mathrm{G}_{\alpha_{i /}}$ and $\mathrm{G} \alpha_{q}$ subunits (Zheng et al., 1999; Zhong and Neubig, 2001). RGS4 is co-expressed with MOR in many brain regions, and Rgs4 mRNA is upregulated following spinal injury in rodents (Garnier et al., 2003; Mansour et al., 1995). In heterologous systems, RGS4 co-immunoprecipitates with MOR and acts as a GAP on MOR-mediated G protein signaling (Leontiadis et al., 2009; Georgoussi et al., 2006; Talbot et al., 2010). Although constitutive RGS4 knockout mice only display mild MOR-specific phenotypes, specific knockdown of Rgs4 in the nucleus accumbens (NAc -- a subregion of the ventral striatum) using lentiviral shRNA manifests more marked effects on MOR-induced reward (Han et al., 2010), suggesting that germline deletion of RGS4 may be compensated for by other related RGS proteins. Moreover, RGS4 has been shown to interact with DOR (Wang et al., 2009), supporting that permissive action of RGS4 on MOR-mediated signaling and behavior in vivo may relate to its redundant interactions with other opioid receptors.

In contrast to the relatively mild role that RGS4 plays in MOR-dependent outcomes, several groups have demonstrated that RGS9-2 exhibits considerably more robust and specific actions on MOR-mediated signaling and behavior (Xie and Palmer, 2005; Traynor, 2012). RGS9-2 is an alternative splice variant of the RGS9 gene that is nearly exclusively expressed in the striatum, but also exhibits low expression in the periaqueductal gray -- both brain regions being crucial for the effects of opioidergic drugs (Cowan et al., 1998; Granneman et al., 1998; 
Rahman et al., 1999). Extensive in vitro and in vivo findings indicate that RGS9-2 potently affects MOR-mediated signal transduction and clinically relevant behavioral outcomes, including analgesia, reward, and drug tolerance (Rahman et al., 2003; Zachariou et al., 2003; Traynor et al., 2009; Traynor, 2012). Like RGS4, RGS9-2 acts as a potent GAP for MOR agonist-mediated G protein signaling in over-expression systems (Psifogeorgou et al., 2011). Consistent with RGS9-2 as a negative regulator of MOR-mediated signaling, prior studies with constitutive RGS9 knockout mice demonstrated that RGS9 loss results in hypersensitivity to the rewarding and analgesic properties of morphine (Zachariou et al., 2003). These effects could be reversed upon virally mediated re-expression of RGS9 in the NAc (Zachariou et al., 2003), supporting a causal role for RGS9 in this striatal subregion in the regulation of morphine-induced reward. Further studies using antisense oligonucleotide-mediated knockdown of RGS9, or the obligate RGS9 partner $\mathrm{G} \beta 5$, recapitulated the enhanced analgesia and reward in response to morphine and DAMGO (a selective MOR agonist) observed with constitutive RGS9 knockout mice (SanchezBlazquez et al., 2003). Notably, RGS9 exerts opposing effects on DOR, with knockdown of RGS9 resulting in reduced DOR agonist-mediated analgesia (Sanchez-Blazquez et al., 2003). These findings, in contrast with prior findings using RGS4 loss, support that RGS proteins can exhibit selectivity for one opioid receptor over another. Furthermore, acute morphine administration to wildtype mice upregulates RGS9 protein in several analgesia- and reward-related brain regions, whereas chronic morphine downregulates RGS9 protein in these areas. Accordingly, RGS9 knockout mice display enhanced analgesia as induced by acute morphine treatment, despite expressing attenuated tolerance to chronic administrations of morphine (Zachariou et al., 2003). Given that the acute and chronic effects of MOR-directed agonists are mediated by independent signaling mechanisms ((Bohn et al., 2003; Bohn et al., 2000) -- for further discussion see 1.2.2a $\beta$-arrestins in Neuronal Physiology below), these findings and others (Psifogeorgou et al., 2007) support that RGS proteins can exert distinct effects on signal transduction cascades downstream 
of their cognate GPCRs and, consequently, perturbation of RGS protein expression can result in separable behavioral outcomes in response to opioidergic drug administration.

\subsubsection{C - RGS12 and Its Role in the CNS}

RGS12 is a $\mathrm{G}_{\mathrm{i} / \mathrm{o}}$-selective RGS protein originally cloned in 1997 by the Siderovski group from cultures of the rat C6 glioblastoma cell line treated with morphine (Snow et al., 1997). RGS12 is relatively widely expressed throughout mammalian tissues, although it does exhibit some cellular and regional specificity within certain physiological systems, especially the brain (Snow et al., 1998a; Lopez-Aranda et al., 2006). RGS12 is unique among RGS proteins in that it exhibits a complex domain architecture capable of independently modulating and coordinating across several signaling pathways beyond canonical RGS domain-mediated GAP activity; accordingly, RGS12 is considered a "signaling scaffold" (Willard et al., 2007; Sambi et al., 2006; Wang et al., 2017; Huang et al., 2014). RGS12 possesses an N-terminal PDZ domain, a phosphotyrosine binding domain (PTB), a central Go $\alpha_{\mathrm{i} / 0}$-specific RGS domain, tandem Ras binding domains (RBDs), and a C-terminal GoLoco motif (Siderovski and Willard, 2005). The GoLoco motif of RGS12 acts as a guanine nucleotide dissociation inhibitor (GDI) by sequestering inactive $\mathrm{G} \alpha$ subunits, thereby prolonging $\mathrm{G} \beta \gamma$ signaling (Kimple et al., 2001). Thus, RGS12 uniquely contains two $\mathrm{G}_{\mathrm{i}}$-interaction domains, the RGS domain and the GoLoco motif, which differentially affect $\mathrm{G} \alpha_{\mathrm{i}}$-dependent signaling. Moreover, RGS12 harbors $\mathrm{G} \alpha_{\mathrm{i}}$-independent domains that are common among signaling adaptors and scaffolds (e.g., PDZ, PTB, RBDs) (Romero et al., 2011; Yaffe, 2002; Willard et al., 2007). Together, the diverse domain architecture and biochemical properties of RGS12 support the notion that it coordinates complex and integrative regulation of signal transduction initiated by both $\mathrm{G}$ protein-dependent and -independent pathways. 
Two primary isoforms of RGS12 exist: a full-length variant containing N-terminal PDZ and PTB domains, and a truncated variant lacking these $\mathrm{N}$-terminal domains. The truncated variant of RGS12 exhibits a domain architecture identical to another R12 family member, RGS14 (Snow et al., 1997; Snow et al., 1998a). However, the expression distributions of RGS12 and RGS14 in the developing and adult brain differ considerably (Martin-McCaffrey et al., 2005; Lopez-Aranda et al., 2006), suggesting there is likely little, if any, genetic compensation of RGS14 upon transgenic deletion of RGS12.

RGS12 is required for nerve growth factor-mediated axonogenesis by dorsal root ganglion neurons via PTB domain-dependent mitogen-activated protein kinase (MAPK) scaffolding (Willard et al., 2007). These findings highlight at least one way in which RGS proteins can perform integral physiological functions independent of their canonical GAPmediated termination of $\mathrm{G}$ protein signaling. Consistent with its effects on neurodevelopmental processes, such as axonogenesis, RGS12 is highly expressed in CNS progenitor cell populations during early stages of brain development (Martin-McCaffrey et al., 2005), although the functional implications of this temporal and spatial expression pattern in the developing CNS remain to be determined. Consistent with the notion that RGS12 is important for neurodevelopmental processes, studies in both mice and humans have identified changes in RGS12 protein expression and mutations in the RGS12 gene, respectively, in neurodevelopmental disease models/states. In a whisker-trimming animal model of somatosensory cortical development, RGS12 was significantly down-regulated under conditions of early-life sensory deprivation (Butko et al., 2013). In a rat model of schizophrenia in which a non-mutant variant of the human disrupted-in-schizophrenia (DISC1) gene is overexpressed, RGS12 was found to be down-regulated in the striatum (Sialana et al., 2018). These findings are strengthened by exome sequencing analyses of humans diagnosed with schizoaffective disorder and schizophrenia (considered neurodevelopmental disorders of the CNS; (Owen et al., 2011; Birnbaum and Weinberger, 2017)), in which two independent groups 
identified de novo missense mutations in RGS12 (Xu et al., 2011; Guipponi et al., 2014). Collectively, these studies suggest that RGS12 likely plays a crucial role in neurodevelopmental processes and that perturbation of its function could manifest neurobiological disruptions consistent with psychiatric diseases, such as schizophrenia.

\subsection{2 - $\beta$-arrestin}

In addition to the homeostatic feedback exerted by RGS proteins, GPCRs are also negatively regulated by another class of proteins called $\beta$-arrestins ( $\beta$ arrs) (Pierce et al., 2002; Lohse et al., 1990). $\beta$ arrs are ubiquitously expressed and exist in two relatively homologous (78\%

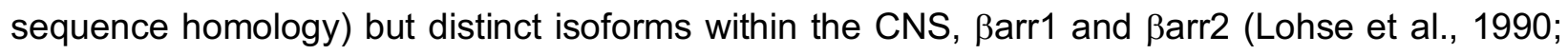
Attramadal et al., 1992). Initial work identified ßarrs as an essential mediator of GPCR desensitization following intense, repeated and/or prolonged receptor stimulation (Wilden et al., 1986; Lohse et al., 1990). However, a considerable number of studies since these initial observations have demonstrated that $\beta$ arrs also are essential modulators of other processes, such as GPCR internalization (i.e., receptor endocytosis), GPCR degradation/downregulation, signaling crosstalk/receptor transactivation (e.g., with RTKs), and that these proteins can even act as scaffolds of signal transduction cascades (e.g., MAPK/ERK signaling) independent of canonical G protein signaling. For comprehensive reviews on the myriad functional outcomes of GPCR-mediated ßarr signaling, see (Kang et al., 2014; Lefkowitz and Whalen, 2004; Shenoy and Lefkowitz, 2011; Smith and Rajagopal, 2016b).

ßarr-dependent signaling is engaged following GPCR activation by an agonist/activating ligand, or under conditions in which the GPCR is constitutively active (Scheerer and Sommer, 2017). Following receptor activation, cytosolic G protein receptor kinases (GRKs) are recruited to the GPCR, resulting in phosphorylation of serine/threonine residues on the receptor C-terminus or intracellular loop regions (Benovic et al., 1986a; Benovic et al., 1986b; Gurevich and Gurevich, 
2019). To date, there have been seven independent GRK isoforms identified (GRK1-7), and these are separated into subclasses based on sequence homology and function. GRK1 and GRK7 (GRK1-like subfamily) are found only in the visual system. The GRK4-like subfamily includes GRK4, which is expressed predominantly in the testes, as well as GRK5 and GRK6, which exhibit more ubiquitous expression. The GRK2-like subfamily includes GRK2 and GRK3, which are also ubiquitously expressed (Pitcher et al., 1998; Gainetdinov et al., 2004). The mechanisms by which GRKs are recruited to GPCRs varies across GRK subtypes/subfamilies (Gurevich and Gurevich, 2019). Given that the GRK2/3 subfamily has been the most extensively characterized in the brain (Gainetdinov et al., 2004; Evron et al., 2012), I will focus on outlining only GRK2/3-initated signaling cascades. Classical models indicate that GRK activation is directly stimulated by free $\mathrm{G} \beta \gamma$ subunits, which interact with the pleckstrin homology $(\mathrm{PH})$ domain of the GRK molecule (Koch et al., 1993; Touhara et al., 1994). However, more recent evidence suggests that GRK signaling can be initiated independent of G $\beta \gamma$ (i.e., G protein)-mediated mechanisms (Pack et al., 2018). GRK-mediated GPCR phosphorylation mobilizes cytoplasmic $\beta$ arr to the $2^{\text {nd }}$ or $3^{\text {rd }}$ intracellular loop regions of the GPCR, leading to functional uncoupling of the GPCR and heterotrimeric $\mathrm{G}$ protein complex by steric hindrance, thereby preventing further signaling (i.e., desensitization) (DeGraff et al., 2002; Marion et al., 2006). Additionally, ßarrs act as cellular scaffolds of AP-2, resulting in GPCR internalization via dynamin-dependent endocytosis in clathrin-coated pits (Ferguson et al., 1996; Kang et al., 2013; Claing et al., 2001). Internalized GPCRs either recycle back to the plasma membrane (via recycling endosomes) or undergo degradation/downregulation (via sorting into late endosomes targeted to lysosomes) (Kang et al., 2014; Oakley et al., 2000). Lastly, the scaffolding properties of $\beta$ arrs enable the nucleation of cellular signal transduction cascades, most notably of the MAPK/ERK family, that are distinct from signaling engendered by G proteins (Luttrell et al., 1999; Luo et al., 2008; Sun et al., 2002; Bruchas et al., 2006; Breitman et al., 2012). For example, some GPCRs will induce MAPK/ERK 
signaling in early (e.g., $\sim 5$ minutes) and late (e.g., $\sim 30$ minutes) phases via distinct $\mathrm{G}$ protein- and ßarr-dependent mechanisms (Gesty-Palmer et al., 2006; McLennan et al., 2008). Moreover, GPCR-mediated p38 MAPK activation has been shown to be $\beta$ arr-, but not G protein-, dependent (Bruchas et al., 2006), further highlighting that ßarr-mediated signaling cascades can be engendered independently of those evoked by $\mathrm{G}$ proteins following receptor activation.

\subsection{2a - $\beta$-arrestins in Neuronal Physiology}

The physiological importance of $\beta$ arrs has been elucidated predominantly through the use of transgenic knockout mice. Double knockout of $\beta$ arr1 and $\beta$ arr2 is embryonically lethal (DeWire et al., 2007), thus $\beta$ arrs play a prominent developmental role. However, knockout of either $\beta a r r 1$ or ßarr2 produces viable offspring that display grossly normal phenotypic profiles, suggesting that loss of a single $\beta$ arr isoform can result in, at least some, physiological compensation by the alternate $\beta$ arr. Despite relatively normal baseline phenotypes in $\beta$ arr1 and $\beta$ arr2 knockout mice, these strains often display perturbed physiological responses to environmental stressors or pharmacological challenge (Conner et al., 1997; Bohn et al., 1999).

\subsection{2b - $\beta$-arrestins and Opioidergic Signaling and Behavior}

One of the most widely recognized examples of the physiological importance of $\beta$ arr function is work performed by the Caron group, which demonstrated that constitutive $\beta$ arr2 knockout mice exhibit enhanced and prolonged morphine-induced analgesia (Bohn et al., 1999), despite marked reductions in morphine-induced tolerance and physical dependence (Bohn et al., 2000; Bohn et al., 2002). These findings were among the first to confirm that $\beta$ arrs play an important role in agonist-induced desensitization and/or internalization/downregulation of CNSexpressed GPCRs in vivo and suggested that specific behavioral outcomes (e.g., analgesia) could be mediated by distinct signal transduction cascades. Further work demonstrated that 
MOR-induced analgesia is lost following pertussis toxin (PTX) treatment (Parolaro et al., 1990; Bodnar et al., 1990), which abolishes G $\alpha_{\text {ilo }}$ signaling via irreversible ADP-ribosylation (Moss and Vaughan, 1988). These findings, when considered along with the aforementioned studies utilizing Barr2 knockout mice, support that MOR-induced analgesia is mediated specifically by $\mathrm{G}_{\mathrm{i} /}$ protein signaling. Continued work by Bohn, Caron, and others highlighted that $\beta$ arr2 loss also blunts some of the negative side effects produced by morphine and other MOR-directed opioids, including respiratory depression and constipation (Raehal et al., 2005; Raehal et al., 2011). Taken together, these seminal studies revealed that $\mathrm{G}$ protein and $\beta$ arr signaling downstream of opioidergic GPCRs can differentially determine behavioral outcomes.

\subsection{3 - GPCR Functional Selectivity (also known as Biased Agonism)}

More recent work has focused on applying the mechanistic insight obtained from $\beta$ arr knockout mice toward designing and characterizing novel pharmacological compounds that exhibit the capacity to differentially or preferentially engage G protein- or ßarr-dependent signaling downstream of GPCRs (Urban et al., 2007; Violin and Lefkowitz, 2007). In classical models of ligand-receptor interactions, ligands possess two properties: affinity and efficacy. Affinity reflects how tightly a ligand binds to a receptor, whereas efficacy refers to the capacity of the ligand to produce a biological response following receptor binding (Stephenson, 1956; Kenakin, 2004). Thus, classical models suggested that GPCRs exist in either an active or inactive conformation, contingent on whether an agonist was bound (active conformation) or unbound (inactive conformation) (De Lean et al., 1980; Violin and Lefkowitz, 2007). These models permitted the classification of ligands as full agonists, partial agonists, neutral antagonists, or inverse agonists across a continuum of affinities. Specifically, full agonists produce maximal biological responses (i.e., maximal efficacy) via stabilization of an active state conformation of the GPCR. Partial agonists also stabilize an active state conformation of the GPCR, but exhibit submaximal efficacy 
relative to full agonists. Inverse agonists stabilize an inactive state of the GPCR and exert an inhibitory effect on signal transduction that results from constitutive activity of the receptor (i.e., receptor activity that is independent of agonist binding). Lastly, ligands can be neutral antagonists, which prevent binding of other ligands and do not exhibit any efficacy at the receptor (Ariens, 1954; Kenakin, 1995). While these categories accurately described many ligands, classical models of ligand-receptor pharmacology did not account for the aberrant property of some GPCRdirected ligands to exhibit differential efficacy for distinct signal transduction cascades (e.g., G protein and $\beta$ arr signaling) within the same cellular system (Wei et al., 2003; Gesty-Palmer et al., 2006), a process previously described as "imbalanced efficacy." For example, a ligand can act as an antagonist of one signaling pathway (e.g., $\beta$ arr signaling), while simultaneously acting as an agonist at a distinct signaling pathway (e.g., G protein signaling), despite identical expression of signal transduction machinery (e.g., RGSs, GRKs, ßarrs) within that particular cellular milieu (Allen et al., 2011). This concept is now more commonly known as functional selectivity or biased agonism (Urban et al., 2007; Reiter et al., 2012; Kenakin, 2011). Under this principle, an agonist (full, partial, or inverse) may stabilize a conformation of its cognate GPCR that preferentially or, in some cases, exclusively drive G protein (a 'G protein-biased' agonist) or $\beta a r r$ (a 'ßarr-biased' agonist) signaling cascades.

The use of biased agonists in animal models has provided an additional strategy (i.e., along with transgenic manipulation) by which to further elucidate of how $\mathrm{G}$ protein or $\beta$ arr signaling mediates specific physiological or behavioral outcomes. Perhaps more importantly, biased agonists permit the opportunity to design a drug that can, in theory, produce enhanced therapeutic efficacy and/or mitigate disadvantageous side effects if these physiological/behavioral outcomes are independently induced by G protein versus $\beta$ arr signaling (Whalen et al., 2011). For example, the aforementioned work on the effects of morphine in $\beta$ arr2 knockout mice led to speculation that a MOR-selective G protein-biased agonist would be expected to preserve and/or enhance 
analgesia, while reducing or eliminating clinically undesired side effects, such as tolerance, dependence, respiratory depression, and constipation (Schmid et al., 2017; Madariaga-Mazon et al., 2017). Indeed, MOR-selective $G$ protein biased agonists have been synthesized and are considered to display a more clinically advantageous behavioral profile relative to unbiased, conventional MOR agonists, such as morphine (Manglik et al., 2016; DeWire et al., 2013; Koblish et al., 2017; Urits et al., 2019). These studies have led to a clinical trial of a MOR-selective G protein biased agonist called TRV-130 (oliceridine, brand name Olinvo) for severe pain (Singla et al., 2017), but the candidate compound failed due to weak efficacy and safety concerns related to QT interval prolongation, addiction, and tolerance liability (Research, 2018). Nonetheless, the design and characterization of biased agonists (directed against a wide variety of GPCRs) remains an encouraging and highly active pursuit that seeks to both deepen our mechanistic understanding of how GPCR signaling mediates a diverse array of physiological outcomes, as well as provide novel therapeutic candidates for clinical application across many different diseases and pathologies.

\section{3 - Kappa Opioid Receptor (KOR) Signaling and Behavior}

\subsection{1 - Background: Opioid Receptor Signal Transduction}

Each opioid receptor (MOR, DOR, and KOR) is a $\mathrm{G}_{\mathrm{i} / 0}$-coupled GPCR and thus activation leads to adenylyl cyclase inhibition and reduced cAMP production (Al-Hasani and Bruchas, 2011). Via freed $G \beta \gamma$ subunits, opioid receptor activation also leads to the activation of $G$ protein inwardly rectifying potassium channels (GIRKs) (Luscher and Slesinger, 2010; Nockemann et al., 2013) and inhibition of P/Q-, N-, and L-type $\mathrm{Ca}^{2+}$ channels (Wang et al., 2010; Tedford and Zamponi, 2006), thereby reducing neuronal excitation (via hyperpolarization) and decreasing neurotransmitter/neuropeptide release, respectively. Opioid receptors also recruit $\beta$ arr via activation-dependent receptor phosphorylation by GRK2/3, primarily at the C-terminal tail of the 
receptor; thus, opioid receptors undergo $\beta$ arr-dependent desensitization and internalization in an agonist-dependent manner (Al-Hasani and Bruchas, 2011). The recruitment of $\beta$ arr also promotes G protein-independent signaling cascades, including the activation of kinases, such as ERK1/2, MAPK p38, and c-Jun N-terminal kinase (JNK) (Appleyard et al., 1999; Bruchas et al., 2006; McDonald et al., 2000; Wagley et al., 2013). MOR, DOR, and KOR show approximately 50-70\% sequence similarity (Katritch et al., 2013), but display distinct neuroanatomical distributions and behavioral outcomes upon activation (Pan, 1998; Al-Hasani and Bruchas, 2011). In this section, I will focus on the mechanisms by which KOR signal transduction manifests specific behavioral outcomes following endogenous or exogenous activation.

\subsection{2 - KOR Expression in the Mouse Brain}

The endogenous ligands of KOR are dynorphins, a class of neuropeptides derived from the precursor preprodynorphin (Sohn et al., 2014; Draisci and ladarola, 1989). Dynorphin is released under conditions of stress and mediates a variety of acutely adaptive behavioral responses that chiefly serve to enable escape, and later avoidance, of environmental threats and/or aversive stimuli. Specifically, dynorphin-stimulated KOR activation can produce behavioral states of dysphoria (displeasure and unease), anhedonia (reduced responses to rewarding stimuli), anxiety, cognitive disruption, psychosis, analgesia, neuroendocrine dysfunction, and withdrawal following drug abuse (Chavkin and Koob, 2016). Continued or severe acute exposure to stressors upregulates dynorphin and often produces hypersensitization of the dynorphin/KOR system, which can promote the manifestation of disease-related physiological and behavioral states (Van't Veer and Carlezon, 2013; Vien et al., 2009; Karkhanis et al., 2016; Yorgason et al., 2016). As one would expect based on this notion, KOR expression is densely distributed throughout the stress-sensitive limbic system of the brain, including the mesolimbic dopamine (DA) system (the reward system; the VTA and NAc), the dorsal raphe nucleus (DRN; the site of most serotonergic neurons innervating the forebrain), the prefrontal cortex (PFC), the amygdala 
(AMY), the hippocampus (HPC), and the hypothalamus (Yasuda et al., 1993; Crowley and Kash, 2015; Lalanne et al., 2014). A comprehensive review of the known actions of KOR activation within each of these brain regions can be found elsewhere (Crowley and Kash, 2015; Knoll and Carlezon, 2010; Van't Veer and Carlezon, 2013) and is beyond the scope of this thesis. Given the critical importance of KOR in regulating the mesolimbic DA system and the robust expression of RGS12 within mesolimbic substructures, I will focus on the specific mechanisms by which KOR affects mesolimbic DAergic neurotransmission and behavior.

\subsection{3 - KOR and Dopaminergic Neurotransmission}

\subsection{3a - Background: KOR in the Mesolimbic DA System}

KOR is enriched on presynaptic terminals of the NAc (a subregion of the ventral striatum [VSTR]), which originate from VTA DAergic projection neurons (Crowley and Kash, 2015; Bruijnzeel, 2009; Britt and McGehee, 2008). KORs are also expressed on VTA cell bodies, but these receptors preferentially regulate subpopulations of DAergic neurons that project to the prefrontal cortex (the mesocortical DA tract) (Margolis et al., 2006). Under conditions of elevated synaptic DA tone in the NAc, extracellular DA stimulates post-synaptic DA receptors (e.g., dopamine D1 receptor [D1R] and dopamine D2 receptor [D2R]) expressed on the cell bodies of GABAergic medium spiny neurons (MSNs), which comprise $\sim 95 \%$ of the cells making up the striatum (Gerfen et al., 1990). Activation of D1R-expressing MSNs stimulates the release of dynorphin in a retrograde fashion to act upon presynaptic KORs expressed on DAergic terminals, leading to reductions in extracellular DA. Thus, KOR serves an important role in the negative feedback of mesolimbic DAergic neurotransmission (Trifilieff and Martinez, 2013). KOR-mediated decreases in DA occur by two primary, PTX-sensitive (i.e., $\mathrm{G}_{\mathrm{i} / \mathrm{o}}$ heterotrimer signaling-dependent), mechanisms; (1) inhibition of exocytotic DA release (Di Chiara and Imperato, 1988; Donzanti et al., 1992) and (2) increased dopamine transporter (DAT)-mediated DA uptake (Thompson et al., 2000; Kivell et al., 2014). KOR-mediated reductions in DAergic neurotransmission are proposed 
to underlie the dysphorigenic effects of KOR agonists in mice and humans (Pfeiffer et al., 1986; Shippenberg et al., 1993) and, accordingly, conditioned place aversion produced in mice by KOR agonists is lost upon ablation of KORs in DAergic neurons (Chefer et al., 2013). Furthermore, many drugs of abuse exert their rewarding effects by increasing mesolimbic DA (Nestler, 2001); thus, either acute administration of KOR agonists or endogenous activation of KOR by dynorphin effectively reduces behavioral responses to addictive substances (e.g., such psychostimulants as amphetamine and cocaine), and this reduction is dependent on KOR action in VSTR (Thompson et al., 2000; Gray et al., 1999).

\subsection{3b - Dopamine Release}

Extensive prior evidence supports the notion that activation of KOR on presynaptic mesolimbic DA neurons reduces exocytotic DA release. Systemic administration of KOR agonists (e.g., U50,488, U69,593), or their direct infusion into the NAc, reduces extracellular DA in vivo (Spanagel et al., 1992; Chefer et al., 2005). Moreover, direct application of KOR agonists to NAccontaining brain slices attenuates electrically-evoked, depolarization-dependent release of exogenously applied [ $\left.{ }^{3} \mathrm{H}\right] \mathrm{DA}$ and endogenous DA stores (Heijna et al., 1990; Grilli et al., 2009; Rose et al., 2016). More recent studies using optogenetics demonstrate that the inhibitory effect of KOR on DA is preserved following the selective activation of DA terminals (i.e., absent the recruitment of local striatal microcircuitry, such as GABAergic MSNs or cholinergic interneurons) (Melchior and Jones, 2017), supporting the idea that KOR reduces DA release via a direct, cellautonomous mechanism. KOR-mediated inhibition of DA release is PTX-and $\mathrm{Ca}^{2+}$-sensitive (Grilli et al., 2009; Dalman and O'Malley, 1999), supporting the notion that reduced DA exocytosis by KOR activation is $\mathrm{G}_{\mathrm{i} / \mathrm{o}}$ heterotrimer signaling-dependent and likely mediated by $\mathrm{G} \beta \gamma$-dependent inhibition of $\mathrm{Ca}^{2+}$ channels. KOR is also expressed, albeit at relatively low levels, in local striatal cholinergic interneurons. Cholinergic interneurons constitute only $\sim 1 \%$ of the cell populations making up the striatum; however, they densely innervation DAergic terminals and serve an 
integral role in the modulation of DA release via stimulatory release of acetylcholine (ACh) (Bolam et al., 1984; Contant et al., 1996). Accordingly, prior work supports that KOR-dependent regulation of DA release is, in part, related to the activation of KORs on striatal cholinergic interneurons (Threlfell and Cragg, 2011; Karkhanis et al., 2017). Perhaps the most compelling support for the notion that KOR regulates DA release via action within cholinergic interneurons comes from work by the Jones lab, which has demonstrated that KOR activation more potently inhibits DA release in the NAc following electrical stimulation (which directly recruits cholinergic interneurons) than after selective DAergic terminal activation (using optogenetics) (Rose et al., 2016; Melchior and Jones, 2017). The most parsimonious explanation for these findings is that the activation of DA terminal-expressed KORs is necessary, but not sufficient, to account for the inhibitory effect that KOR exerts on striatal DA release and that cholinergic interneuron-expressed KORs contribute, in part, to this effect.

\subsection{3c - The Dopamine Transporter (DAT)}

A central determinant of striatal DA tone (extracellular DA concentration) is the dopamine transporter (DAT). DAT is a 12-transmembrane protein with cytosolic $\mathrm{N}$ - and $\mathrm{C}$-termini and is expressed exclusively within presynaptic and somatodendritic compartments of DAergic neurons (Chen and Reith, 2000; Ciliax et al., 1995). Under normal physiological conditions, DAT recaptures released DA back into DA neurons via a $\mathrm{Na}^{+} / \mathrm{Cl}^{-}$-dependent mechanism, thereby terminating DAergic neurotransmission (Kuhar et al., 1990; Amara and Sonders, 1998). DAT can also display reverse transport, and thereby elevate extracellular DA via the non-exocytotic efflux of free cytosolic DA, in response to several psychostimulants (e.g., amphetamine [AMPH], methamphetamine $[\mathrm{METH}]$ ), which are aptly characterized as releasing agents (Rothman et al., 2001). Releasing agents are substrates for DAT; thus, in addition to their action as releasers, they also increase extracellular DA levels via competitive reuptake inhibition with endogenous DA (Rothman et al., 2001). In contrast, psychostimulants such as cocaine and methylphenidate 
(Ritalin ${ }^{\mathrm{TM}}$ ) are not DAT substrates: they bind directly to the extracellular face of DAT and preclude the reuptake of DA, thereby augmenting extracellular DA levels predominantly via noncompetitive DAT inhibition (Beuming et al., 2008). Mice genetically engineered to lack DAT expression (i.e., DAT KO mice) exhibit markedly elevated extracellular DA tone at baseline and display remarkable levels of spontaneous hyperactivity; moreover, these mice do not exhibit locomotor activation or DA release to such psychostimulant drugs as AMPH and cocaine (Giros et al., 1996), highlighting the integral role that DAT plays in mediating the effects of psychostimulant drugs (Gainetdinov et al., 2002). Under both basal and psychostimulantstimulated conditions, DAT expression, subcellular trafficking, and uptake/efflux functions are all tightly regulated by a host of direct and indirect interactants, including receptors (e.g., GPCRs), kinases, and scaffolds (Torres et al., 2003; Vaughan and Foster, 2013).

KORs are robustly expressed on the plasma membrane of NAc DA neurons in direct apposition to DAT (Svingos et al., 2001), and KOR forms an oligomeric complex with DAT in transfected cells (Kivell et al., 2014). Activation of KOR leads to increased DAT-mediated DA uptake (Thompson et al., 2000; Kivell et al., 2014), likely by increasing the translocation of DAT to the plasma membrane (Kivell et al., 2014). However, at least one report found that KOR agonism (using the KOR agonist mesyl Sal B) induced an augmentation of DAT-mediated DA uptake with no change in cell surface DAT levels (Simonson et al., 2015). Thus, the effects of KOR activation on DAT, particularly with respect to DAT trafficking, are likely ligand-dependent. KOR activation-mediated increases in DA uptake are PTX-sensitive, supporting that these processes are mediated by a $\mathrm{G}_{\mathrm{i} / \mathrm{o}}$ heterotrimer signaling-dependent mechanism (Kivell et al., 2014). DAT expression and function are both altered following either acute or chronic KOR activation (Chefer et al., 2005), thereby providing, at least in part, a mechanistic explanation for the observation that both acute and prolonged stress (e.g., via environmental stress-induced dynorphin upregulation or pharmacological activation of KOR) results in mesolimbic hypoDAergia 
and disrupted responses to DAT-dependent psychostimulants (Walker and Koob, 2008; Karkhanis et al., 2016).

\subsection{3d - Psychostimulants}

Ample prior evidence supports that KOR activation strongly regulates the behavioral and biochemical responses to psychostimulants such as AMPH and cocaine. Acute administration of the KOR-selective agonist U69,593 attenuates AMPH-induced behavioral activation and AMPHinduced elevations in ventral striatal DA, while local application of the KOR-selective antagonist nor-BNI into the vSTR reverses these effects (Gray et al., 1999). These data strongly support that KOR signaling within the VSTR is able to regulate the DA-dependent behavioral effects of AMPH. However, repeated administration of U69,593 has no effect on locomotor sensitization to AMPH following repeated administration (Escobar Adel et al., 2012), suggesting that KOR signaling may play a more important role in modulating the acute effects of AMPH. Indeed, acute administration of AMPH potently stimulates the release of endogenous dynorphin, which can result in the desensitization of striatal KORs (Xia et al., 2008). These findings provide at least one explanation for why KORs may not be as important under conditions of chronically administered AMPH.

Considerably more work has been performed to elucidate the role that KOR plays in the behavioral and biochemical effects of cocaine. Administration of KOR agonists blocks acute cocaine-induced locomotor activation (Heidbreder et al., 1993; Vanderschuren et al., 2000). In contrast to AMPH, some work has shown that KOR agonists also blunt locomotor sensitization and conditioned place preference to cocaine (Heidbreder et al., 1993; Shippenberg et al., 1996; Zhang et al., 2004), measures of repeated/chronic cocaine administration. Moreover, chronic cocaine adminstration upregulates KOR protein levels (Collins et al., 2002). Together, prior evidence supports that cocaine and KOR exhibit a reciprocally functional interaction, particularly within the mesolimbic DA system (Trifilieff and Martinez, 2013). 
However, some work has shown that KOR agonists do not affect cocaine-induced locomotor sensitization (Vanderschuren et al., 2000), and the effect of KOR on cocaine selfadministration is similarly mixed (Karkhanis et al., 2017). More recent work convincingly reconciles these mixed findings by demonstrating the nuanced temporal dependence of KOR activity on the chronic effects of cocaine. For example, the Chavkin group has shown that systemic administration of the KOR-selective agonist U50,488 15 minutes prior to cocaine administration in a conditioned place preference paradigm decreases cocaine preference, and these effects correlate with traditionally observed KOR-mediated reductions in the elevation of extracellular DA (in the NAc) evoked by cocaine (Zhang et al., 2004). However, when U50,488 is administered 60 minutes prior to cocaine administration, cocaine preference is markedly increased with concomitantly augmented DA levels in the NAc relative to baseline conditions. The authors conclude that 60 -minute pretreatment with a KOR agonist initially results in reduced synaptic DA levels, thereby resetting baseline DAergic tone to a lower starting point, and thus permitting a greater effect of cocaine (i.e., an enhanced effect size of cocaine-stimulated DAergic tone relative to baseline) (Ehrich et al., 2014). Notably, potentiation of cocaine-induced CPP is also observed following chronic stress (using a chronic forced swim paradigm), a process that increases dynorphin release and KOR activation (McLaughlin et al., 2006; Schindler et al., 2010; Ehrich et al., 2014). This biphasic, time-dependent effect of KOR activation on cocaine-induced DA tone has been observed by other groups, even when employing different KOR agonists and behavioral paradigms (Chartoff et al., 2016). Together, these findings support that KOR dynamically responds to, and can determine, the overall effects of cocaine and perturbations in mesolimbic DA neurotransmission. 


\section{4 - 'Functionally Selective' Behavioral Outcomes of KOR Activation}

\section{4a - Background}

Consistent with the aforementioned studies demonstrating that functional selectivity at MOR can produce profoundly distinct molecular and behavioral outcomes (Bohn et al., 1999; Bohn et al., 2000; Bohn et al., 2002), recent work has shown that similar processes occur with KOR (Bohn and Aube, 2017; Schmid et al., 2013; White et al., 2015; Brust et al., 2016; Dunn et al., 2018). KOR activation results in a wide array of clinically relevant effects, including analgesia (Kivell and Prisinzano, 2010), anti-addiction/reward (Bruijnzeel, 2009), anxiety/depressive-like behaviors (Van't Veer and Carlezon, 2013), anti-pruritus (anti-itch) (Brust et al., 2016), diuresis (DeHaven-Hudkins and Dolle, 2004), sedation (Vonvoigtlander et al., 1983), dysphoria/aversion (Ehrich et al., 2015), and psychotomimesis (Pfeiffer et al., 1986). Clearly, a subset of these outcomes are clinically advantageous (e.g., analgesia, anti-itch, anti-reward), while others are disadvantageous (anxiety/depression, dysphoria, psychotomimesis). To date, the only approved KOR-directed ligand, nalfurafine (Remitch), is used in Japan for the treatment of intractable itch in patients with uremic pruritus related to chronic kidney disease (Kumagai et al., 2010). However, most work with animal models has focused on leveraging the notion that KOR agonists produce analgesia, but lack addictive potential; thus, many have proposed that KOR agonists could represent a viable replacement (or adjuvant) for highly addictive MOR-directed pain relievers (e.g., oxycodone, hydrocodone, etc.) (Bohn and Aube, 2017; Vanderah, 2010).

The clinical viability of KOR agonists has been largely hampered by an inability to identify KOR-selective drugs that preserve clinically beneficial outcomes, while mitigating (or abolishing) detrimental outcomes. This issue may be addressable by exploiting functional selectivity at KOR, as the prevailing notion in the literature supports that the analgesic properties of KOR agonists are mediated by $\mathrm{G}$ protein signaling-dependent mechanisms, whereas the dysphoric/aversive effects of KOR agonists are mediated by Barr-dependent processes (Bruchas et al., 2007; Brust et al., 2016). Considerably less work has sought to identify the functional selectivity underlying 
other clinically relevant KOR-mediated behaviors (e.g., anxiety/depression). Therefore, in this section, I will focus on the extant findings related to the $G$ protein- and $\beta$ arr-dependent mechanisms underlying KOR-induced analgesia and dysphoria/aversion.

\section{4b - KOR-induced Analgesia}

KOR is expressed within many ascending sensory and descending inhibitory painassociated cell types/regions within the spinal cord and brain (Mansour et al., 1994; Ji et al., 1995). Accordingly, KOR activation in both the CNS and periphery reduces inflammatory, visceral, neuropathic, and acute pain (Kivell and Prisinzano, 2010; Vanderah, 2010; Simonin et al., 1998; Cunha et al., 2012). The upregulation of dynorphin and/or KOR is an important mechanism underlying the negative affective response experienced under conditions of chronic pain (Cahill et al., 2014; Liu et al., 2019; Massaly et al., 2019), further highlighting the diverse and integrative role that KOR signaling plays in pain processing. The signaling mechanisms underlying KORmediated analgesia have largely been elucidated using assays of supraspinal (hot plate assay) and spinal (tail immersion/withdrawal assay) analgesia in rodents. Using these assays, it has been shown that KOR agonist-induced analgesia is abolished with PTX pretreatment (Hernandez et al., 1995) and is unaffected in mice lacking GRK3 or ßarr expression (McLaughlin et al., 2004; White et al., 2015). Moreover, several G protein-biased KOR agonists retain analgesic efficacy comparable to conventional unbiased agonists (White et al., 2015; Brust et al., 2016; Schattauer et al., 2017). Collectively, these findings strongly support that KOR agonist-induced supraspinal analgesia is mediated by $G$ protein signaling downstream of receptor activation. Similar mechanistic underpinnings have been ascribed to the anti-pruritic effects of KOR agonists (Morgenweck et al., 2015; Brust et al., 2016), although these effects are mediated by KORs within the dorsal root ganglion (DRG) (Kardon et al., 2014). Under conditions of chronic pain (e.g., neuropathic injury), dynorphin and KOR are upregulated, enabling an analgesic compensation in 
response to injury (Xu et al., 2004; Wagner et al., 1993; Wang et al., 2001). However, prolonged dynorphin release desensitizes KOR via a GRK/ßarr-dependent mechanism (Xu et al., 2004), thereby reducing the analgesic effects of KOR activation. Thus, the acute analgesic effects of KOR activation are mediated via G protein-dependent signaling, whereas the efficacy of KORmediated analgesia in chronic pain states may rely predominantly on ßarr-dependent signaling.

\section{4c - KOR-induced Dysphoria/Aversion}

Early investigation into the effects of KOR agonists in humans revealed KOR activation can result in profound dysphoria and psychotomimesis (Pfeiffer et al., 1986). The dysphoric and hallucinogenic effects in humans have been derived predominantly from observations with the KOR-selective agonist salvinorin A, the psychoactive constituent of the plant Salvia divinorum. The Mazatec peoples of Oaxaca, Mexico have traditionally used Salvia divinorum for religious practices, while the general recreational use of salvinorin $A$ extracts has become more widespread over the last few decades (Roth et al., 2002; Mahendran et al., 2016). Salvinorin A administration produces profound effects of mind-body dissociation and cognitive disruption (MacLean et al., 2013; Maqueda et al., 2015), although participants do not always rate these experiences as dysphoric or anxiety-inducing (Johnson et al., 2011; Ranganathan et al., 2012; MacLean et al., 2013). However, some speculate that the absence of dysphoria or negative affect in some participants may be confounded by prior use of other hallucinogens/psychedelics and/or expectation(s) of experience (Gonzalez et al., 2006).

In contrast to the mixed affective responses observed in humans, KOR agonists administered to rodents very reliably induce aversion, a behavioral response considered to be a measure of dysphoria (Al-Hasani and Bruchas, 2011; Valentino and Volkow, 2018). The standard assay employed for measuring aversion in rodents is the conditioned place aversion (CPA) paradigm, which employs Pavlovian conditioning to determine the aversive properties of drugs 
and/or the actions of neural circuits or neurotransmitter systems. Early work (Shippenberg and Herz, 1986) identified KOR agonists as potently aversive agents using the CPA paradigm. The dysphoric effects of KOR agonists were later reinforced by independent results from behavioral tasks less reliant on learning, such as intracranial self-stimulation (ICSS) (Todtenkopf et al., 2004). Aversion produced by systemic KOR agonist administration is abolished following 6hydroxydopamine (6-OHDA)-induced lesioning of DAergic neurons or pharmacological DA receptor inhibition in the mesolimbic (i.e., NAc), but not mesocortical (i.e., PFC), system (Shippenberg et al., 1993). Moreover, microinjection of the KOR agonist U50,488 into the NAc is sufficient to produce CPA, and this behavioral outcome correlates with KOR agonist-induced reductions in DAergic tone (Bals-Kubik et al., 1993). Additionally, more recent work demonstrated that KOR agonist-induced CPA is lost upon DA neuron-specific knockout of KOR (Chefer et al., 2013). Together, these findings support the idea that KOR agonist-induced aversion is mediated by reductions in DA within the NAc, a biological process consistent with a state of negative affect. However, not all studies support this model. For example, DA-deficient mice still exhibit KOR agonist-induced CPA (Land et al., 2009). Although this finding is compelling, it is confounded by the fact that CPA assays with DA-deficient mice required caffeine administration (Land et al., 2009) in order to reverse the marked inactivity exhibited by these mice at baseline. Perhaps more convincing are experiments demonstrating that selective inactivation of KOR expressed within serotonergic dorsal raphe nucleus (DRN) neurons (specifically those projecting to the NAc) prevents KOR agonist-induced CPA; moreover, selective re-expression of KOR within serotonergic DRN neurons of KOR knockout mice was sufficient to produce KOR agonist-induced aversion (Land et al., 2009). Thus, in contrast to prior studies supporting KOR's effects on mesolimbic DA as being required for agonist-induced aversion, this study supports an integral role of serotonin in these processes.

The intracellular signaling determinants underlying KOR-induced aversion have also been controversial, although the traditional theory within the field supports that the dysphoric/aversive 
properties of KOR agonists are mediated by $\beta$ arr-dependent processes. This notion is predominantly predicated on extensive work by the Chavkin group utilizing pharmacologic and genetic manipulations of upstream (GRK3) and downstream (p38 MAPK) signaling molecules of ßarr following KOR activation (Bruchas et al., 2006; Ehrich et al., 2015; Al-Hasani and Bruchas, 2011). The dependence of $\beta$ arr in mediating KOR-induced aversion is further bolstered by the lack of dysphoria/aversion produced by some G protein-biased KOR agonists (Brust et al., 2016; Kivell et al., 2018). However, a study by the Roth group (White et al., 2015) provided conflicting evidence to this theory when the authors evaluated KOR agonist-induced CPA in ßarr-2 knockout mice. These experiments showed that the CPA induced by the conventional KOR agonist U69,593 was unaffected in mice constitutively lacking ßarr-2. Notably, the authors recognize the possibility that compensation of $\beta$ arr-1 could underlie these results, especially given their overlapping expression (White et al., 2015). Moreover, ßarr-2 plays an integral role in neurodevelopmental processes (Philipp et al., 2013); thus, it is highly plausible that constitutive loss of $\beta$ arr-2 from conception could engender disruptions to neuronal cell and circuit function, thereby confounding a determination of whether KOR agonist-induced aversion is mediated by a direct $\beta$ arr-2-dependent mechanism. Future studies employing selective ablation of $\beta$ arr within KOR neurons (e.g., progeny from KOR::Cre mice crossed with Barr2 floxed mice) may provide the best model to determine whether $\beta$ arr is absolutely required for KOR agonist-induced aversion, as this would obviate issues of genetic compensation and off-target effects (i.e., loss of ßarr in non-KOR-expressing cell populations). 


\section{5 - References}

Al-Hasani R and Bruchas MR. (2011) Molecular mechanisms of opioid receptor-dependent signaling and behavior. Anesthesiology 115: 1363-1381.

Allen JA, Yost JM, Setola V, et al. (2011) Discovery of beta-arrestin-biased dopamine D2 ligands for probing signal transduction pathways essential for antipsychotic efficacy. Proc Natl Acad Sci U S A 108: 18488-18493.

Amara SG and Sonders MS. (1998) Neurotransmitter transporters as molecular targets for addictive drugs. Drug Alcohol Depend 51: 87-96.

Angleson JK and Wensel TG. (1993) A GTPase-accelerating factor for transducin, distinct from its effector cGMP phosphodiesterase, in rod outer segment membranes. Neuron 11: 939949.

Appleyard SM, Celver J, Pineda V, et al. (1999) Agonist-dependent desensitization of the kappa opioid receptor by $\mathrm{G}$ protein receptor kinase and beta-arrestin. J Biol Chem 274: 2380223807.

Ariens EJ. (1954) Affinity and intrinsic activity in the theory of competitive inhibition. I. Problems and theory. Arch Int Pharmacodyn Ther 99: 32-49.

Attramadal H, Arriza JL, Aoki C, et al. (1992) Beta-arrestin2, a novel member of the arrestin/betaarrestin gene family. J Biol Chem 267: 17882-17890.

Bals-Kubik R, Ableitner A, Herz A, et al. (1993) Neuroanatomical sites mediating the motivational effects of opioids as mapped by the conditioned place preference paradigm in rats. $J$ Pharmacol Exp Ther 264: 489-495.

Benovic JL, Mayor F, Jr., Somers RL, et al. (1986a) Light-dependent phosphorylation of rhodopsin by beta-adrenergic receptor kinase. Nature 321: 869-872.

Benovic JL, Strasser RH, Caron MG, et al. (1986b) Beta-adrenergic receptor kinase: identification of a novel protein kinase that phosphorylates the agonist-occupied form of the receptor. Proc Natl Acad Sci U S A 83: 2797-2801.

Berman DM and Gilman AG. (1998) Mammalian RGS proteins: barbarians at the gate. J Biol Chem 273: 1269-1272.

Beuming T, Kniazeff J, Bergmann ML, et al. (2008) The binding sites for cocaine and dopamine in the dopamine transporter overlap. Nat Neurosci 11: 780-789.

Birnbaum R and Weinberger DR. (2017) Genetic insights into the neurodevelopmental origins of schizophrenia. Nat Rev Neurosci 18: 727-740.

Bockaert J and Pin JP. (1999) Molecular tinkering of G protein-coupled receptors: an evolutionary success. EMBO J 18: 1723-1729.

Bodnar RJ, Paul D, Rosenblum M, et al. (1990) Blockade of morphine analgesia by both pertussis and cholera toxins in the periaqueductal gray and locus coeruleus. Brain Res 529: 324328.

Bohn LM and Aube J. (2017) Seeking (and Finding) Biased Ligands of the Kappa Opioid Receptor. ACS Med Chem Lett 8: 694-700.

Bohn LM, Gainetdinov RR, Lin FT, et al. (2000) Mu-opioid receptor desensitization by betaarrestin-2 determines morphine tolerance but not dependence. Nature 408: 720-723. 
Bohn LM, Gainetdinov RR, Sotnikova TD, et al. (2003) Enhanced rewarding properties of morphine, but not cocaine, in beta(arrestin)-2 knock-out mice. J Neurosci 23: 1026510273.

Bohn LM, Lefkowitz RJ and Caron MG. (2002) Differential mechanisms of morphine antinociceptive tolerance revealed in (beta)arrestin-2 knock-out mice. J Neurosci 22: 10494-10500.

Bohn LM, Lefkowitz RJ, Gainetdinov RR, et al. (1999) Enhanced morphine analgesia in mice lacking beta-arrestin 2. Science 286: 2495-2498.

Bolam JP, Wainer BH and Smith AD. (1984) Characterization of cholinergic neurons in the rat neostriatum. A combination of choline acetyltransferase immunocytochemistry, Golgiimpregnation and electron microscopy. Neuroscience 12: 711-718.

Breitman M, Kook S, Gimenez LE, et al. (2012) Silent scaffolds: inhibition OF c-Jun N-terminal kinase 3 activity in cell by dominant-negative arrestin-3 mutant. J Biol Chem 287: 1965319664.

Breitwieser GE and Szabo G. (1988) Mechanism of muscarinic receptor-induced K+ channel activation as revealed by hydrolysis-resistant GTP analogues. J Gen Physiol 91: 469-493.

Britt JP and McGehee DS. (2008) Presynaptic opioid and nicotinic receptor modulation of dopamine overflow in the nucleus accumbens. J Neurosci 28: 1672-1681.

Bruchas MR, Land BB, Aita M, et al. (2007) Stress-induced p38 mitogen-activated protein kinase activation mediates kappa-opioid-dependent dysphoria. J Neurosci 27: 11614-11623.

Bruchas MR, Macey TA, Lowe JD, et al. (2006) Kappa opioid receptor activation of p38 MAPK is GRK3- and arrestin-dependent in neurons and astrocytes. J Biol Chem 281: 18081-18089.

Bruijnzeel AW. (2009) kappa-Opioid receptor signaling and brain reward function. Brain Res Rev 62: 127-146.

Brust TF, Morgenweck J, Kim SA, et al. (2016) Biased agonists of the kappa opioid receptor suppress pain and itch without causing sedation or dysphoria. Sci Signal 9: ra117.

Butko MT, Savas JN, Friedman B, et al. (2013) In vivo quantitative proteomics of somatosensory cortical synapses shows which protein levels are modulated by sensory deprivation. Proc Natl Acad Sci U S A 110: E726-735.

Cahill CM, Taylor AM, Cook C, et al. (2014) Does the kappa opioid receptor system contribute to pain aversion? Front Pharmacol 5: 253.

Carman CV, Parent JL, Day PW, et al. (1999) Selective regulation of Galpha(q/11) by an RGS domain in the G protein-coupled receptor kinase, GRK2. J Biol Chem 274: 34483-34492.

Cassel D, Eckstein F, Lowe M, et al. (1979) Determination of the turn-off reaction for the hormone-activated adenylate cyclase. J Biol Chem 254: 9835-9838.

Chartoff EH, Ebner SR, Sparrow A, et al. (2016) Relative Timing Between Kappa Opioid Receptor Activation and Cocaine Determines the Impact on Reward and Dopamine Release. Neuropsychopharmacology 41: 989-1002.

Chavkin C and Koob GF. (2016) Dynorphin, Dysphoria, and Dependence: the Stress of Addiction. Neuropsychopharmacology 41: 373-374.

Chefer VI, Backman CM, Gigante ED, et al. (2013) Kappa opioid receptors on dopaminergic neurons are necessary for kappa-mediated place aversion. Neuropsychopharmacology 38: 2623-2631. 
Chefer VI, Czyzyk T, Bolan EA, et al. (2005) Endogenous kappa-opioid receptor systems regulate mesoaccumbal dopamine dynamics and vulnerability to cocaine. J Neurosci 25: 50295037.

Chen CK, Eversole-Cire P, Zhang H, et al. (2003) Instability of GGL domain-containing RGS proteins in mice lacking the G protein beta-subunit Gbeta5. Proc Natl Acad Sci U S A 100: 66046609.

Chen N and Reith ME. (2000) Structure and function of the dopamine transporter. Eur J Pharmacol 405: 329-339.

Ciliax BJ, Heilman C, Demchyshyn LL, et al. (1995) The dopamine transporter: immunochemical characterization and localization in brain. J Neurosci 15: 1714-1723.

Claing A, Chen W, Miller WE, et al. (2001) beta-Arrestin-mediated ADP-ribosylation factor 6 activation and beta 2-adrenergic receptor endocytosis. J Biol Chem 276: 42509-42513.

Clapham DE and Neer EJ. (1997) G protein beta gamma subunits. Annu Rev Pharmacol Toxicol 37: 167-203.

Collins SL, Kunko PM, Ladenheim B, et al. (2002) Chronic cocaine increases kappa-opioid receptor density: lack of effect by selective dopamine uptake inhibitors. Synapse 45: 153-158.

Conner DA, Mathier MA, Mortensen RM, et al. (1997) beta-Arrestin1 knockout mice appear normal but demonstrate altered cardiac responses to beta-adrenergic stimulation. Circ Res 81: 1021-1026.

Contant C, Umbriaco D, Garcia S, et al. (1996) Ultrastructural characterization of the acetylcholine innervation in adult rat neostriatum. Neuroscience 71: 937-947.

Contet C, Kieffer BL and Befort K. (2004) Mu opioid receptor: a gateway to drug addiction. Curr Opin Neurobiol 14: 370-378.

Cowan CW, Fariss RN, Sokal I, et al. (1998) High expression levels in cones of RGS9, the predominant GTPase accelerating protein of rods. Proc Natl Acad Sci U S A 95: 5351-5356.

Crowley NA and Kash TL. (2015) Kappa opioid receptor signaling in the brain: Circuitry and implications for treatment. Prog Neuropsychopharmacol Biol Psychiatry 62: 51-60.

Cunha TM, Souza GR, Domingues AC, et al. (2012) Stimulation of peripheral kappa opioid receptors inhibits inflammatory hyperalgesia via activation of the PI3Kgamma/AKT/nNOS/NO signaling pathway. Mol Pain 8: 10.

Dalman FC and O'Malley KL. (1999) kappa-Opioid tolerance and dependence in cultures of dopaminergic midbrain neurons. J Neurosci 19: 5750-5757.

De Lean A, Stadel JM and Lefkowitz RJ. (1980) A ternary complex model explains the agonistspecific binding properties of the adenylate cyclase-coupled beta-adrenergic receptor. $J$ Biol Chem 255: 7108-7117.

DeGraff JL, Gurevich VV and Benovic JL. (2002) The third intracellular loop of alpha 2-adrenergic receptors determines subtype specificity of arrestin interaction. J Biol Chem 277: 4324743252.

DeHaven-Hudkins DL and Dolle RE. (2004) Peripherally restricted opioid agonists as novel analgesic agents. Curr Pharm Des 10: 743-757.

DeWire SM, Ahn S, Lefkowitz RJ, et al. (2007) Beta-arrestins and cell signaling. Annu Rev Physiol 69: 483-510. 
DeWire SM, Yamashita DS, Rominger DH, et al. (2013) A G protein-biased ligand at the mu-opioid receptor is potently analgesic with reduced gastrointestinal and respiratory dysfunction compared with morphine. J Pharmacol Exp Ther 344: 708-717.

Di Chiara G and Imperato A. (1988) Opposite effects of mu and kappa opiate agonists on dopamine release in the nucleus accumbens and in the dorsal caudate of freely moving rats. J Pharmacol Exp Ther 244: 1067-1080.

DiBello PR, Garrison TR, Apanovitch DM, et al. (1998) Selective uncoupling of RGS action by a single point mutation in the G protein alpha-subunit. J Biol Chem 273: 5780-5784.

Dohlman HG and Thorner J. (1997) RGS proteins and signaling by heterotrimeric G proteins. J Biol Chem 272: 3871-3874.

Donzanti BA, Althaus JS, Payson MM, et al. (1992) Kappa agonist-induced reduction in dopamine release: site of action and tolerance. Res Commun Chem Pathol Pharmacol 78: 193-210.

Draisci G and ladarola MJ. (1989) Temporal analysis of increases in c-fos, preprodynorphin and preproenkephalin mRNAs in rat spinal cord. Brain Res Mol Brain Res 6: 31-37.

Dunn AD, Reed B, Guariglia C, et al. (2018) Structurally Related Kappa Opioid Receptor Agonists with Substantial Differential Signaling Bias: Neuroendocrine and Behavioral Effects in C57BL6 Mice. Int J Neuropsychopharmacol 21: 847-857.

Ehrich JM, Messinger DI, Knakal CR, et al. (2015) Kappa Opioid Receptor-Induced Aversion Requires p38 MAPK Activation in VTA Dopamine Neurons. J Neurosci 35: 12917-12931.

Ehrich JM, Phillips PE and Chavkin C. (2014) Kappa opioid receptor activation potentiates the cocaine-induced increase in evoked dopamine release recorded in vivo in the mouse nucleus accumbens. Neuropsychopharmacology 39: 3036-3048.

Erdely HA, Tamminga CA, Roberts RC, et al. (2006) Regional alterations in RGS4 protein in schizophrenia. Synapse 59: 472-479.

Escobar Adel P, Cornejo FA, Andres ME, et al. (2012) Repeated treatment with the kappa opioid receptor agonist $\mathrm{U} 69593$ reverses enhanced $\mathrm{K}+$ induced dopamine release in the nucleus accumbens, but not the expression of locomotor sensitization in amphetamine-sensitized rats. Neurochem Int 60: 344-349.

Evron T, Daigle TL and Caron MG. (2012) GRK2: multiple roles beyond G protein-coupled receptor desensitization. Trends Pharmacol Sci 33: 154-164.

Ferguson SS, Downey WE, 3rd, Colapietro AM, et al. (1996) Role of beta-arrestin in mediating agonist-promoted $G$ protein-coupled receptor internalization. Science 271: 363-366.

Fredriksson R, Lagerstrom MC, Lundin LG, et al. (2003) The G-protein-coupled receptors in the human genome form five main families. Phylogenetic analysis, paralogon groups, and fingerprints. Mol Pharmacol 63: 1256-1272.

Freissmuth M, Casey PJ and Gilman AG. (1989) G proteins control diverse pathways of transmembrane signaling. FASEB J 3: 2125-2131.

Fu Y, Zhong H, Nanamori M, et al. (2004) RGS-insensitive G-protein mutations to study the role of endogenous RGS proteins. Methods Enzymol 389: 229-243.

Gainetdinov RR, Premont RT, Bohn LM, et al. (2004) Desensitization of G protein-coupled receptors and neuronal functions. Annu Rev Neurosci 27: 107-144.

Gainetdinov RR, Sotnikova TD and Caron MG. (2002) Monoamine transporter pharmacology and mutant mice. Trends Pharmacol Sci 23: 367-373. 
Garnier M, Zaratin PF, Ficalora G, et al. (2003) Up-regulation of regulator of G protein signaling 4 expression in a model of neuropathic pain and insensitivity to morphine. J Pharmacol Exp Ther 304: 1299-1306.

Georgoussi Z, Leontiadis L, Mazarakou G, et al. (2006) Selective interactions between G protein subunits and RGS4 with the C-terminal domains of the mu- and delta-opioid receptors regulate opioid receptor signaling. Cell Signal 18: 771-782.

Geppetti P, Veldhuis NA, Lieu T, et al. (2015) G Protein-Coupled Receptors: Dynamic Machines for Signaling Pain and Itch. Neuron 88: 635-649.

Gerber KJ, Squires KE and Hepler JR. (2016) Roles for Regulator of G Protein Signaling Proteins in Synaptic Signaling and Plasticity. Mol Pharmacol 89: 273-286.

Gerfen CR, Engber TM, Mahan LC, et al. (1990) D1 and D2 dopamine receptor-regulated gene expression of striatonigral and striatopallidal neurons. Science 250: 1429-1432.

Gesty-Palmer D, Chen M, Reiter E, et al. (2006) Distinct beta-arrestin- and G protein-dependent pathways for parathyroid hormone receptor-stimulated ERK1/2 activation. J Biol Chem 281: 10856-10864.

Gilman AG. (1984) G proteins and dual control of adenylate cyclase. Cell 36: 577-579.

Gilman AG. (1987) G proteins: transducers of receptor-generated signals. Annu Rev Biochem 56: 615-649.

Giros B, Jaber M, Jones SR, et al. (1996) Hyperlocomotion and indifference to cocaine and amphetamine in mice lacking the dopamine transporter. Nature 379: 606-612.

Gold SJ, Ni YG, Dohlman HG, et al. (1997) Regulators of G-protein signaling (RGS) proteins: regionspecific expression of nine subtypes in rat brain. J Neurosci 17: 8024-8037.

Gonzalez D, Riba J, Bouso JC, et al. (2006) Pattern of use and subjective effects of Salvia divinorum among recreational users. Drug Alcohol Depend 85: 157-162.

Granneman JG, Zhai Y, Zhu Z, et al. (1998) Molecular characterization of human and rat RGS 9L, a novel splice variant enriched in dopamine target regions, and chromosomal localization of the RGS 9 gene. Mol Pharmacol 54: 687-694.

Gray AM, Rawls SM, Shippenberg TS, et al. (1999) The kappa-opioid agonist, U-69593, decreases acute amphetamine-evoked behaviors and calcium-dependent dialysate levels of dopamine and glutamate in the ventral striatum. J Neurochem 73: 1066-1074.

Grillet N, Pattyn A, Contet C, et al. (2005) Generation and characterization of Rgs4 mutant mice. Mol Cell Biol 25: 4221-4228.

Grilli M, Neri E, Zappettini S, et al. (2009) Salvinorin A exerts opposite presynaptic controls on neurotransmitter exocytosis from mouse brain nerve terminals. Neuropharmacology 57: 523-530.

Guipponi M, Santoni FA, Setola V, et al. (2014) Exome sequencing in 53 sporadic cases of schizophrenia identifies 18 putative candidate genes. PLoS One 9: e112745.

Gurevich VV and Gurevich EV. (2019) GPCR Signaling Regulation: The Role of GRKs and Arrestins. Front Pharmacol 10: 125.

Han $\mathrm{MH}$, Renthal W, Ring RH, et al. (2010) Brain region specific actions of regulator of $\mathrm{G}$ protein signaling 4 oppose morphine reward and dependence but promote analgesia. Biol Psychiatry 67: 761-769.

Hart MJ, Jiang X, Kozasa T, et al. (1998) Direct stimulation of the guanine nucleotide exchange activity of p115 RhoGEF by Galpha13. Science 280: 2112-2114. 
Hausdorff WP, Bouvier M, O'Dowd BF, et al. (1989) Phosphorylation sites on two domains of the beta 2-adrenergic receptor are involved in distinct pathways of receptor desensitization. J Biol Chem 264: 12657-12665.

Hauser AS, Attwood MM, Rask-Andersen M, et al. (2017) Trends in GPCR drug discovery: new agents, targets and indications. Nat Rev Drug Discov 16: 829-842.

He W, Cowan CW and Wensel TG. (1998) RGS9, a GTPase accelerator for phototransduction. Neuron 20: 95-102.

Heidbreder CA, Goldberg SR and Shippenberg TS. (1993) The kappa-opioid receptor agonist U69593 attenuates cocaine-induced behavioral sensitization in the rat. Brain Res 616: 335338.

Heijna MH, Padt M, Hogenboom F, et al. (1990) Opioid receptor-mediated inhibition of dopamine and acetylcholine release from slices of rat nucleus accumbens, olfactory tubercle and frontal cortex. Eur J Pharmacol 181: 267-278.

Hepler JR and Gilman AG. (1992) G proteins. Trends Biochem Sci 17: 383-387.

Hernandez A, Soto-Moyano R, Mestre C, et al. (1995) Intrathecal pertussis toxin but not cyclic AMP blocks kappa opioid-induced antinociception in rat. Int J Neurosci 81: 193-197.

Heximer SP, Knutsen RH, Sun X, et al. (2003) Hypertension and prolonged vasoconstrictor signaling in RGS2-deficient mice. J Clin Invest 111: 1259.

Huang J, Nalli AD, Mahavadi S, et al. (2014) Inhibition of Galphai activity by Gbetagamma is mediated by PI 3-kinase-gamma- and cSrc-dependent tyrosine phosphorylation of Galphai and recruitment of RGS12. Am J Physiol Gastrointest Liver Physiol 306: G802-810.

Ji RR, Zhang Q, Law PY, et al. (1995) Expression of mu-, delta-, and kappa-opioid receptor-like immunoreactivities in rat dorsal root ganglia after carrageenan-induced inflammation. $J$ Neurosci 15: 8156-8166.

Johnson MW, MacLean KA, Reissig CJ, et al. (2011) Human psychopharmacology and dose-effects of salvinorin A, a kappa opioid agonist hallucinogen present in the plant Salvia divinorum. Drug Alcohol Depend 115: 150-155.

Kammermeier PJ, Ruiz-Velasco V and Ikeda SR. (2000) A voltage-independent calcium current inhibitory pathway activated by muscarinic agonists in rat sympathetic neurons requires both Galpha q/11 and Gbeta gamma. J Neurosci 20: 5623-5629.

Kang DS, Tian X and Benovic JL. (2013) beta-Arrestins and G protein-coupled receptor trafficking. Methods Enzymol 521: 91-108.

Kang DS, Tian X and Benovic JL. (2014) Role of beta-arrestins and arrestin domain-containing proteins in G protein-coupled receptor trafficking. Curr Opin Cell Biol 27: 63-71.

Kardon AP, Polgar E, Hachisuka J, et al. (2014) Dynorphin acts as a neuromodulator to inhibit itch in the dorsal horn of the spinal cord. Neuron 82: 573-586.

Karkhanis A, Holleran KM and Jones SR. (2017) Dynorphin/Kappa Opioid Receptor Signaling in Preclinical Models of Alcohol, Drug, and Food Addiction. Int Rev Neurobiol 136: 53-88.

Karkhanis AN, Rose JH, Weiner JL, et al. (2016) Early-Life Social Isolation Stress Increases Kappa Opioid Receptor Responsiveness and Downregulates the Dopamine System. Neuropsychopharmacology 41: 2263-2274.

Katritch V, Cherezov V and Stevens RC. (2013) Structure-function of the G protein-coupled receptor superfamily. Annu Rev Pharmacol Toxicol 53: 531-556. 
Kaur K, Kehrl JM, Charbeneau RA, et al. (2011) RGS-insensitive Galpha subunits: probes of Galpha subtype-selective signaling and physiological functions of RGS proteins. Methods Mol Biol 756: 75-98.

Kenakin T. (1995) Agonist-receptor efficacy. II. Agonist trafficking of receptor signals. Trends Pharmacol Sci 16: 232-238.

Kenakin T. (2004) Principles: receptor theory in pharmacology. Trends Pharmacol Sci 25: 186-192.

Kenakin T. (2011) Functional selectivity and biased receptor signaling. J Pharmacol Exp Ther 336: 296-302.

Kimple AJ, Bosch DE, Giguere PM, et al. (2011) Regulators of G-protein signaling and their Galpha substrates: promises and challenges in their use as drug discovery targets. Pharmacol Rev 63: 728-749.

Kimple RJ, De Vries L, Tronchere H, et al. (2001) RGS12 and RGS14 GoLoco motifs are G alpha(i) interaction sites with guanine nucleotide dissociation inhibitor Activity. J Biol Chem 276: 29275-29281.

Kivell B and Prisinzano TE. (2010) Kappa opioids and the modulation of pain. Psychopharmacology (Berl) 210: 109-119.

Kivell B, Uzelac Z, Sundaramurthy S, et al. (2014) Salvinorin A regulates dopamine transporter function via a kappa opioid receptor and ERK1/2-dependent mechanism. Neuropharmacology 86: 228-240.

Kivell BM, Paton KF, Kumar N, et al. (2018) Kappa Opioid Receptor Agonist Mesyl Sal B Attenuates Behavioral Sensitization to Cocaine with Fewer Aversive Side-Effects than Salvinorin A in Rodents. Molecules 23.

Knoll AT and Carlezon WA, Jr. (2010) Dynorphin, stress, and depression. Brain Res 1314: 56-73.

Koblish M, Carr R, 3rd, Siuda ER, et al. (2017) TRV0109101, a G Protein-Biased Agonist of the micro-Opioid Receptor, Does Not Promote Opioid-Induced Mechanical Allodynia following Chronic Administration. J Pharmacol Exp Ther 362: 254-262.

Koch WJ, Inglese J, Stone WC, et al. (1993) The binding site for the beta gamma subunits of heterotrimeric $\mathrm{G}$ proteins on the beta-adrenergic receptor kinase. J Biol Chem 268: 82568260.

Krishnan A and Schioth HB. (2015) The role of G protein-coupled receptors in the early evolution of neurotransmission and the nervous system. J Exp Biol 218: 562-571.

Kuhar MJ, Sanchez-Roa PM, Wong DF, et al. (1990) Dopamine transporter: biochemistry, pharmacology and imaging. Eur Neurol 30 Suppl 1: 15-20.

Kumagai H, Ebata T, Takamori K, et al. (2010) Effect of a novel kappa-receptor agonist, nalfurafine hydrochloride, on severe itch in 337 haemodialysis patients: a Phase III, randomized, double-blind, placebo-controlled study. Nephrol Dial Transplant 25: 1251-1257.

Lagerstrom MC and Schioth HB. (2008) Structural diversity of G protein-coupled receptors and significance for drug discovery. Nat Rev Drug Discov 7: 339-357.

Lalanne L, Ayranci G, Kieffer BL, et al. (2014) The kappa opioid receptor: from addiction to depression, and back. Front Psychiatry 5: 170.

Lamberts JT, Smith CE, Li MH, et al. (2013) Differential control of opioid antinociception to thermal stimuli in a knock-in mouse expressing regulator of G-protein signalinginsensitive Galphao protein. J Neurosci 33: 4369-4377. 
Lambright DG, Noel JP, Hamm HE, et al. (1994) Structural determinants for activation of the alpha-subunit of a heterotrimeric $G$ protein. Nature 369: 621-628.

Lan KL, Sarvazyan NA, Taussig R, et al. (1998) A point mutation in Galphao and Galphai1 blocks interaction with regulator of $G$ protein signaling proteins. J Biol Chem 273: 12794-12797.

Land BB, Bruchas MR, Schattauer S, et al. (2009) Activation of the kappa opioid receptor in the dorsal raphe nucleus mediates the aversive effects of stress and reinstates drug seeking. Proc Natl Acad Sci U S A 106: 19168-19173.

Larminie C, Murdock P, Walhin JP, et al. (2004) Selective expression of regulators of G-protein signaling (RGS) in the human central nervous system. Brain Res Mol Brain Res 122: 24-34.

Lee SE, Simons SB, Heldt SA, et al. (2010) RGS14 is a natural suppressor of both synaptic plasticity in CA2 neurons and hippocampal-based learning and memory. Proc Natl Acad Sci U S A 107: 16994-16998.

Lefkowitz RJ and Whalen EJ. (2004) beta-arrestins: traffic cops of cell signaling. Curr Opin Cell Biol 16: 162-168.

Leontiadis L, Papakonstantinou MP and Georgoussi Z. (2009) Regulator of G protein signaling 4 confers selectivity to specific $\mathrm{G}$ proteins to modulate mu- and delta-opioid receptor signaling. Cell Signal 21: 1218-1228.

Liu SS, Pickens S, Burma NE, et al. (2019) Kappa Opioid Receptors Drive a Tonic Aversive Component of Chronic Pain. J Neurosci.

Lohse MJ, Benovic JL, Codina J, et al. (1990) beta-Arrestin: a protein that regulates betaadrenergic receptor function. Science 248: 1547-1550.

Lopez-Aranda MF, Acevedo MJ, Carballo FJ, et al. (2006) Localization of the GoLoco motif carrier regulator of G-protein signalling 12 and 14 proteins in monkey and rat brain. Eur J Neurosci 23: 2971-2982.

Luo J, Busillo JM and Benovic JL. (2008) M3 muscarinic acetylcholine receptor-mediated signaling is regulated by distinct mechanisms. Mol Pharmacol 74: 338-347.

Luscher C and Slesinger PA. (2010) Emerging roles for G protein-gated inwardly rectifying potassium (GIRK) channels in health and disease. Nat Rev Neurosci 11: 301-315.

Luttrell LM, Ferguson SS, Daaka Y, et al. (1999) Beta-arrestin-dependent formation of beta2 adrenergic receptor-Src protein kinase complexes. Science 283: 655-661.

Lutz S, Shankaranarayanan A, Coco C, et al. (2007) Structure of Galphaq-p63RhoGEF-RhoA complex reveals a pathway for the activation of RhoA by GPCRs. Science 318: 1923-1927.

MacLean KA, Johnson MW, Reissig CJ, et al. (2013) Dose-related effects of salvinorin A in humans: dissociative, hallucinogenic, and memory effects. Psychopharmacology (Berl) 226: 381392.

Madariaga-Mazon A, Marmolejo-Valencia AF, Li Y, et al. (2017) Mu-Opioid receptor biased ligands: A safer and painless discovery of analgesics? Drug Discov Today 22: 1719-1729.

Mahendran R, Lim HA, Tan JY, et al. (2016) Salvia divinorum: An overview of the usage, misuse, and addiction processes. Asia Pac Psychiatry 8: 23-31.

Mancuso JJ, Qian Y, Long C, et al. (2010) Distribution of RGS9-2 in neurons of the mouse striatum. J Neurochem 112: 651-661.

Manglik A, Lin H, Aryal DK, et al. (2016) Structure-based discovery of opioid analgesics with reduced side effects. Nature 537: 185-190. 
Mansour A, Fox CA, Burke S, et al. (1995) Immunohistochemical localization of the cloned mu opioid receptor in the rat CNS. J Chem Neuroanat 8: 283-305.

Mansour A, Fox CA, Burke S, et al. (1994) Mu, delta, and kappa opioid receptor mRNA expression in the rat CNS: an in situ hybridization study. J Comp Neurol 350: 412-438.

Maqueda AE, Valle M, Addy PH, et al. (2015) Salvinorin-A Induces Intense Dissociative Effects, Blocking External Sensory Perception and Modulating Interoception and Sense of Body Ownership in Humans. Int J Neuropsychopharmacol 18.

Margolis EB, Lock H, Chefer VI, et al. (2006) Kappa opioids selectively control dopaminergic neurons projecting to the prefrontal cortex. Proc Natl Acad Sci U S A 103: 2938-2942.

Marion S, Oakley RH, Kim KM, et al. (2006) A beta-arrestin binding determinant common to the second intracellular loops of rhodopsin family $\mathrm{G}$ protein-coupled receptors. J Biol Chem 281: 2932-2938.

Martemyanov KA, Hopp JA and Arshavsky VY. (2003) Specificity of G protein-RGS protein recognition is regulated by affinity adapters. Neuron 38: 857-862.

Martin-McCaffrey L, Hains MD, Pritchard GA, et al. (2005) Differential expression of regulator of G-protein signaling R12 subfamily members during mouse development. Dev Dyn 234: 438-444.

Massaly N, Copits BA, Wilson-Poe AR, et al. (2019) Pain-Induced Negative Affect Is Mediated via Recruitment of The Nucleus Accumbens Kappa Opioid System. Neuron 102: 564-573 e566.

McCudden CR, Hains MD, Kimple RJ, et al. (2005) G-protein signaling: back to the future. Cell Mol Life Sci 62: 551-577.

McDonald PH, Chow CW, Miller WE, et al. (2000) Beta-arrestin 2: a receptor-regulated MAPK scaffold for the activation of JNK3. Science 290: 1574-1577.

McLaughlin JP, Land BB, Li S, et al. (2006) Prior activation of kappa opioid receptors by U50,488 mimics repeated forced swim stress to potentiate cocaine place preference conditioning. Neuropsychopharmacology 31: 787-794.

McLaughlin JP, Myers LC, Zarek PE, et al. (2004) Prolonged kappa opioid receptor phosphorylation mediated by G-protein receptor kinase underlies sustained analgesic tolerance. J Biol Chem 279: 1810-1818.

McLennan GP, Kiss A, Miyatake M, et al. (2008) Kappa opioids promote the proliferation of astrocytes via Gbetagamma and beta-arrestin 2-dependent MAPK-mediated pathways. J Neurochem 107: 1753-1765.

Melchior JR and Jones SR. (2017) Chronic ethanol exposure increases inhibition of optically targeted phasic dopamine release in the nucleus accumbens core and medial shell ex vivo. Mol Cell Neurosci 85: 93-104.

Mirnics K, Middleton FA, Stanwood GD, et al. (2001) Disease-specific changes in regulator of Gprotein signaling 4 (RGS4) expression in schizophrenia. Mol Psychiatry 6: 293-301.

Morgenweck J, Frankowski KJ, Prisinzano TE, et al. (2015) Investigation of the role of betaarrestin2 in kappa opioid receptor modulation in a mouse model of pruritus. Neuropharmacology 99: 600-609.

Moss J and Vaughan M. (1988) ADP-ribosylation of guanyl nucleotide-binding regulatory proteins by bacterial toxins. Adv Enzymol Relat Areas Mol Biol 61: 303-379. 
Neer EJ. (1995) Heterotrimeric G proteins: organizers of transmembrane signals. Cell 80: 249257.

Nestler EJ. (2001) Molecular neurobiology of addiction. Am J Addict 10: 201-217.

Neubig RR and Siderovski DP. (2002) Regulators of G-protein signalling as new central nervous system drug targets. Nat Rev Drug Discov 1: 187-197.

Nockemann D, Rouault M, Labuz D, et al. (2013) The K(+) channel GIRK2 is both necessary and sufficient for peripheral opioid-mediated analgesia. EMBO Mol Med 5: 1263-1277.

Oakley RH, Laporte SA, Holt JA, et al. (2000) Differential affinities of visual arrestin, beta arrestin1, and beta arrestin2 for $G$ protein-coupled receptors delineate two major classes of receptors. J Biol Chem 275: 17201-17210.

Oldham WM and Hamm HE. (2008) Heterotrimeric G protein activation by G-protein-coupled receptors. Nat Rev Mol Cell Biol 9: 60-71.

Oliveira-Dos-Santos AJ, Matsumoto G, Snow BE, et al. (2000) Regulation of T cell activation, anxiety, and male aggression by RGS2. Proc Natl Acad Sci U S A 97: 12272-12277.

Owen MJ, O'Donovan MC, Thapar A, et al. (2011) Neurodevelopmental hypothesis of schizophrenia. Br J Psychiatry 198: 173-175.

Pack TF, Orlen MI, Ray C, et al. (2018) The dopamine D2 receptor can directly recruit and activate GRK2 without G protein activation. J Biol Chem 293: 6161-6171.

Pan ZZ. (1998) mu-Opposing actions of the kappa-opioid receptor. Trends Pharmacol Sci 19: 9498.

Parolaro D, Patrini G, Giagnoni G, et al. (1990) Pertussis toxin inhibits morphine analgesia and prevents opiate dependence. Pharmacol Biochem Behav 35: 137-141.

Pfeiffer A, Brantl V, Herz A, et al. (1986) Psychotomimesis mediated by kappa opiate receptors. Science 233: 774-776.

Philipp M, Evron T and Caron MG. (2013) The role of arrestins in development. Prog Mol Biol Transl Sci 118: 225-242.

Pierce KL, Premont RT and Lefkowitz RJ. (2002) Seven-transmembrane receptors. Nat Rev Mol Cell Biol 3: 639-650.

Pitcher JA, Freedman NJ and Lefkowitz RJ. (1998) G protein-coupled receptor kinases. Annu Rev Biochem 67: 653-692.

Psifogeorgou K, Papakosta P, Russo SJ, et al. (2007) RGS9-2 is a negative modulator of mu-opioid receptor function. J Neurochem 103: 617-625.

Psifogeorgou K, Terzi D, Papachatzaki MM, et al. (2011) A unique role of RGS9-2 in the striatum as a positive or negative regulator of opiate analgesia. J Neurosci 31: 5617-5624.

Raehal KM, Schmid CL, Groer CE, et al. (2011) Functional selectivity at the mu-opioid receptor: implications for understanding opioid analgesia and tolerance. Pharmacol Rev 63: 10011019.

Raehal KM, Walker JK and Bohn LM. (2005) Morphine side effects in beta-arrestin 2 knockout mice. J Pharmacol Exp Ther 314: 1195-1201.

Rahman Z, Gold SJ, Potenza MN, et al. (1999) Cloning and characterization of RGS9-2: a striatalenriched alternatively spliced product of the RGS9 gene. J Neurosci 19: 2016-2026.

Rahman Z, Schwarz J, Gold SJ, et al. (2003) RGS9 modulates dopamine signaling in the basal ganglia. Neuron 38: 941-952. 
Ranganathan M, Schnakenberg A, Skosnik PD, et al. (2012) Dose-related behavioral, subjective, endocrine, and psychophysiological effects of the kappa opioid agonist Salvinorin $A$ in humans. Biol Psychiatry 72: 871-879.

Reiter E, Ahn S, Shukla AK, et al. (2012) Molecular mechanism of beta-arrestin-biased agonism at seven-transmembrane receptors. Annu Rev Pharmacol Toxicol 52: 179-197.

Research FDADACfDE. (2018) Oliceridine Briefing Document. FDA.

Rivero G, Gabilondo AM, Garcia-Fuster MJ, et al. (2012) Differential regulation of RGS proteins in the prefrontal cortex of short- and long-term human opiate abusers. Neuropharmacology 62: 1044-1051.

Roman DL and Traynor JR. (2011) Regulators of G protein signaling (RGS) proteins as drug targets: modulating G-protein-coupled receptor (GPCR) signal transduction. J Med Chem 54: 74337440.

Romero G, von Zastrow M and Friedman PA. (2011) Role of PDZ proteins in regulating trafficking, signaling, and function of GPCRs: means, motif, and opportunity. Adv Pharmacol 62: 279314.

Rose JH, Karkhanis AN, Chen R, et al. (2016) Supersensitive Kappa Opioid Receptors Promotes Ethanol Withdrawal-Related Behaviors and Reduce Dopamine Signaling in the Nucleus Accumbens. Int J Neuropsychopharmacol 19.

Rosenbaum DM, Rasmussen SG and Kobilka BK. (2009) The structure and function of G-proteincoupled receptors. Nature 459: 356-363.

Roth BL, Baner K, Westkaemper R, et al. (2002) Salvinorin A: a potent naturally occurring nonnitrogenous kappa opioid selective agonist. Proc Natl Acad Sci U S A 99: 11934-11939.

Rothman RB, Baumann MH, Dersch CM, et al. (2001) Amphetamine-type central nervous system stimulants release norepinephrine more potently than they release dopamine and serotonin. Synapse 39: 32-41.

Ruiz de Azua I, Scarselli M, Rosemond E, et al. (2010) RGS4 is a negative regulator of insulin release from pancreatic beta-cells in vitro and in vivo. Proc Natl Acad Sci U S A 107: 79998004.

Sambi BS, Hains MD, Waters CM, et al. (2006) The effect of RGS12 on PDGFbeta receptor signalling to p42/p44 mitogen activated protein kinase in mammalian cells. Cell Signal 18: 971-981.

Sanchez-Blazquez P, Rodriguez-Diaz M, Lopez-Fando A, et al. (2003) The GBeta5 subunit that associates with the R7 subfamily of RGS proteins regulates mu-opioid effects. Neuropharmacology 45: 82-95.

Santos R, Ursu O, Gaulton A, et al. (2017) A comprehensive map of molecular drug targets. Nat Rev Drug Discov 16: 19-34.

Schattauer SS, Kuhar JR, Song A, et al. (2017) Nalfurafine is a G-protein biased agonist having significantly greater bias at the human than rodent form of the kappa opioid receptor. Cell Signal 32: 59-65.

Scheerer P and Sommer ME. (2017) Structural mechanism of arrestin activation. Curr Opin Struct Biol 45: 160-169.

Schindler AG, Li S and Chavkin C. (2010) Behavioral stress may increase the rewarding valence of cocaine-associated cues through a dynorphin/kappa-opioid receptor-mediated 
mechanism without affecting associative learning or memory retrieval mechanisms. Neuropsychopharmacology 35: 1932-1942.

Schmid CL, Kennedy NM, Ross NC, et al. (2017) Bias Factor and Therapeutic Window Correlate to Predict Safer Opioid Analgesics. Cell 171: 1165-1175 e1113.

Schmid CL, Streicher JM, Groer CE, et al. (2013) Functional selectivity of 6'-guanidinonaltrindole (6'-GNTI) at kappa-opioid receptors in striatal neurons. J Biol Chem 288: 22387-22398.

Shenoy SK and Lefkowitz RJ. (2011) beta-Arrestin-mediated receptor trafficking and signal transduction. Trends Pharmacol Sci 32: 521-533.

Shippenberg TS, Bals-Kubik R and Herz A. (1993) Examination of the neurochemical substrates mediating the motivational effects of opioids: role of the mesolimbic dopamine system and D-1 vs. D-2 dopamine receptors. J Pharmacol Exp Ther 265: 53-59.

Shippenberg TS and Herz A. (1986) Differential effects of mu and kappa opioid systems on motivational processes. NIDA Res Monogr 75: 563-566.

Shippenberg TS, LeFevour A and Heidbreder C. (1996) kappa-Opioid receptor agonists prevent sensitization to the conditioned rewarding effects of cocaine. J Pharmacol Exp Ther 276: 545-554.

Sialana FJ, Wang AL, Fazari B, et al. (2018) Quantitative Proteomics of Synaptosomal Fractions in a Rat Overexpressing Human DISC1 Gene Indicates Profound Synaptic Dysregulation in the Dorsal Striatum. Front Mol Neurosci 11: 26.

Siderovski DP KA. (2013) Regulator of G-Protein Signaling (RGS) Protein Family. In: S C (ed) Encyclopedia of signaling molecules. . New York, New York: Springer, 3.

Siderovski DP KA, Willard FS. . (2008) Large G-Proteins. . In: Begley TP e (ed) Wiley Encyclopedia of Chemical Biology. . Hoboken, New Jersey: John Wiley \& Sons, Inc.

Siderovski DP and Willard FS. (2005) The GAPs, GEFs, and GDIs of heterotrimeric G-protein alpha subunits. Int J Biol Sci 1: 51-66.

Siehler S. (2009) Regulation of RhoGEF proteins by G12/13-coupled receptors. Br J Pharmacol 158: 41-49.

Simon MI, Strathmann MP and Gautam N. (1991) Diversity of G proteins in signal transduction. Science 252: 802-808.

Simonds WF. (1999) G protein regulation of adenylate cyclase. Trends Pharmacol Sci 20: 66-73.

Simonin F, Valverde O, Smadja C, et al. (1998) Disruption of the kappa-opioid receptor gene in mice enhances sensitivity to chemical visceral pain, impairs pharmacological actions of the selective kappa-agonist U-50,488 $\mathrm{H}$ and attenuates morphine withdrawal. EMBO J 17: 886-897.

Simonson B, Morani AS, Ewald AW, et al. (2015) Pharmacology and anti-addiction effects of the novel kappa opioid receptor agonist Mesyl Sal B, a potent and long-acting analogue of salvinorin A. Br J Pharmacol 172: 515-531.

Singla N, Minkowitz HS, Soergel DG, et al. (2017) A randomized, Phase llb study investigating oliceridine (TRV130), a novel micro-receptor G-protein pathway selective (mu-GPS) modulator, for the management of moderate to severe acute pain following abdominoplasty. J Pain Res 10: 2413-2424.

Sjogren B. (2017) The evolution of regulators of $G$ protein signalling proteins as drug targets - 20 years in the making: IUPHAR Review 21. Br J Pharmacol 174: 427-437. 
Smith JS and Rajagopal S. (2016a) The beta-Arrestins: Multifunctional Regulators of G Proteincoupled Receptors. 291: 8969-8977.

Smith JS and Rajagopal S. (2016b) The beta-Arrestins: Multifunctional Regulators of G Proteincoupled Receptors. J Biol Chem 291: 8969-8977.

Snow BE, Antonio L, Suggs S, et al. (1997) Molecular cloning and expression analysis of rat Rgs12 and Rgs14. Biochem Biophys Res Commun 233: 770-777.

Snow BE, Brothers GM and Siderovski DP. (2002) Molecular cloning of regulators of G-protein signaling family members and characterization of binding specificity of RGS12 PDZ domain. Methods Enzymol 344: 740-761.

Snow BE, Hall RA, Krumins AM, et al. (1998a) GTPase activating specificity of RGS12 and binding specificity of an alternatively spliced PDZ (PSD-95/DIg/ZO-1) domain. J Biol Chem 273: 17749-17755.

Snow BE, Krumins AM, Brothers GM, et al. (1998b) A G protein gamma subunit-like domain shared between RGS11 and other RGS proteins specifies binding to Gbeta5 subunits. Proc Natl Acad Sci U S A 95: 13307-13312.

Snyder SH and Pasternak GW. (2003) Historical review: Opioid receptors. Trends Pharmacol Sci 24: 198-205.

Sohn J, Hioki H, Okamoto S, et al. (2014) Preprodynorphin-expressing neurons constitute a large subgroup of somatostatin-expressing GABAergic interneurons in the mouse neocortex. $J$ Comp Neurol 522: 1506-1526.

Soundararajan M, Willard FS, Kimple AJ, et al. (2008) Structural diversity in the RGS domain and its interaction with heterotrimeric G protein alpha-subunits. Proc Natl Acad Sci U S A 105: 6457-6462.

Spanagel R, Herz A and Shippenberg TS. (1992) Opposing tonically active endogenous opioid systems modulate the mesolimbic dopaminergic pathway. Proc Natl Acad Sci U S A 89: 2046-2050.

Stephenson RP. (1956) A modification of receptor theory. Br J Pharmacol Chemother 11: 379393.

Sun Y, Cheng Z, Ma L, et al. (2002) Beta-arrestin2 is critically involved in CXCR4-mediated chemotaxis, and this is mediated by its enhancement of p38 MAPK activation. $J$ Biol Chem 277: 49212-49219.

Svingos AL, Chavkin C, Colago EE, et al. (2001) Major coexpression of kappa-opioid receptors and the dopamine transporter in nucleus accumbens axonal profiles. Synapse 42: 185-192.

Talbot JN, Roman DL, Clark MJ, et al. (2010) Differential modulation of mu-opioid receptor signaling to adenylyl cyclase by regulators of $G$ protein signaling proteins 4 or 8 and 7 in permeabilised C6 cells is Galpha subtype dependent. J Neurochem 112: 1026-1034.

Tedford HW and Zamponi GW. (2006) Direct G protein modulation of Cav2 calcium channels. Pharmacol Rev 58: 837-862.

Tekumalla PK, Calon F, Rahman Z, et al. (2001) Elevated levels of DeltaFosB and RGS9 in striatum in Parkinson's disease. Biol Psychiatry 50: 813-816.

Thompson AC, Zapata A, Justice JB, Jr., et al. (2000) Kappa-opioid receptor activation modifies dopamine uptake in the nucleus accumbens and opposes the effects of cocaine. $J$ Neurosci 20: 9333-9340. 
Threlfell S and Cragg SJ. (2011) Dopamine signaling in dorsal versus ventral striatum: the dynamic role of cholinergic interneurons. Front Syst Neurosci 5: 11.

Todtenkopf MS, Marcus JF, Portoghese PS, et al. (2004) Effects of kappa-opioid receptor ligands on intracranial self-stimulation in rats. Psychopharmacology (Berl) 172: 463-470.

Torres GE, Gainetdinov RR and Caron MG. (2003) Plasma membrane monoamine transporters: structure, regulation and function. Nat Rev Neurosci 4: 13-25.

Touhara K, Inglese J, Pitcher JA, et al. (1994) Binding of G protein beta gamma-subunits to pleckstrin homology domains. J Biol Chem 269: 10217-10220.

Traynor J. (2012) mu-Opioid receptors and regulators of G protein signaling (RGS) proteins: from a symposium on new concepts in mu-opioid pharmacology. Drug Alcohol Depend 121: 173-180.

Traynor JR, Terzi D, Caldarone BJ, et al. (2009) RGS9-2: probing an intracellular modulator of behavior as a drug target. Trends Pharmacol Sci 30: 105-111.

Trifilieff $P$ and Martinez D. (2013) Kappa-opioid receptor signaling in the striatum as a potential modulator of dopamine transmission in cocaine dependence. Front Psychiatry 4: 44.

Ullrich A and Schlessinger J. (1990) Signal transduction by receptors with tyrosine kinase activity. Cell 61: 203-212.

Unwin N. (1993) Neurotransmitter action: opening of ligand-gated ion channels. Cell 72 Suppl: 31-41.

Urban JD, Clarke WP, von Zastrow M, et al. (2007) Functional selectivity and classical concepts of quantitative pharmacology. J Pharmacol Exp Ther 320: 1-13.

Urits I, Viswanath O, Orhurhu V, et al. (2019) The Utilization of Mu-Opioid Receptor Biased Agonists: Oliceridine, an Opioid Analgesic with Reduced Adverse Effects. Curr Pain Headache Rep 23: 31.

Valentino RJ and Volkow ND. (2018) Untangling the complexity of opioid receptor function. Neuropsychopharmacology 43: 2514-2520.

Van't Veer A and Carlezon WA, Jr. (2013) Role of kappa-opioid receptors in stress and anxietyrelated behavior. Psychopharmacology (Berl) 229: 435-452.

Vanderah TW. (2010) Delta and kappa opioid receptors as suitable drug targets for pain. Clin J Pain 26 Suppl 10: S10-15.

Vanderschuren L, Schoffelmeer AN, Wardeh G, et al. (2000) Dissociable effects of the kappaopioid receptor agonists bremazocine, U69593, and U50488H on locomotor activity and long-term behavioral sensitization induced by amphetamine and cocaine. Psychopharmacology (Berl) 150: 35-44.

Vaughan RA and Foster JD. (2013) Mechanisms of dopamine transporter regulation in normal and disease states. Trends Pharmacol Sci 34: 489-496.

Vien TN, Gleason CA, Hays SL, et al. (2009) Effects of neonatal stress and morphine on kappa opioid receptor signaling. Neonatology 96: 235-243.

Violin JD and Lefkowitz RJ. (2007) Beta-arrestin-biased ligands at seven-transmembrane receptors. Trends Pharmacol Sci 28: 416-422.

Vonvoigtlander PF, Lahti RA and Ludens JH. (1983) U-50,488: a selective and structurally novel non-Mu (kappa) opioid agonist. J Pharmacol Exp Ther 224: 7-12.

Vuong TM and Chabre M. (1991) Deactivation kinetics of the transduction cascade of vision. Proc Natl Acad Sci U S A 88: 9813-9817. 
Wagley Y, Hwang CK, Lin HY, et al. (2013) Inhibition of c-Jun NH2-terminal kinase stimulates mu opioid receptor expression via p38 MAPK-mediated nuclear NF-kappaB activation in neuronal and non-neuronal cells. Biochim Biophys Acta 1833: 1476-1488.

Wagner R, DeLeo JA, Coombs DW, et al. (1993) Spinal dynorphin immunoreactivity increases bilaterally in a neuropathic pain model. Brain Res 629: 323-326.

Waldhoer M, Bartlett SE and Whistler JL. (2004) Opioid receptors. Annu Rev Biochem 73: 953990.

Walker BM and Koob GF. (2008) Pharmacological evidence for a motivational role of kappaopioid systems in ethanol dependence. Neuropsychopharmacology 33: 643-652.

Wang HB, Zhao B, Zhong YQ, et al. (2010) Coexpression of delta- and mu-opioid receptors in nociceptive sensory neurons. Proc Natl Acad Sci U S A 107: 13117-13122.

Wang Q, Liu-Chen LY and Traynor JR. (2009) Differential modulation of mu- and delta-opioid receptor agonists by endogenous RGS4 protein in SH-SY5Y cells. J Biol Chem 284: 1835718367.

Wang Y, Wang J, Zhang L, et al. (2017) RGS12 Is a Novel Tumor-Suppressor Gene in African American Prostate Cancer That Represses AKT and MNX1 Expression. Cancer Res 77: 4247-4257.

Wang Z, Gardell LR, Ossipov MH, et al. (2001) Pronociceptive actions of dynorphin maintain chronic neuropathic pain. J Neurosci 21: 1779-1786.

Wei H, Ahn S, Shenoy SK, et al. (2003) Independent beta-arrestin 2 and G protein-mediated pathways for angiotensin II activation of extracellular signal-regulated kinases 1 and 2 . Proc Natl Acad Sci U S A 100: 10782-10787.

Whalen EJ, Rajagopal S and Lefkowitz RJ. (2011) Therapeutic potential of beta-arrestin- and G protein-biased agonists. Trends Mol Med 17: 126-139.

White KL, Robinson JE, Zhu H, et al. (2015) The G protein-biased kappa-opioid receptor agonist RB-64 is analgesic with a unique spectrum of activities in vivo. J Pharmacol Exp Ther 352: 98-109.

Wilden U, Wust E, Weyand I, et al. (1986) Rapid affinity purification of retinal arrestin (48 kDa protein) via its light-dependent binding to phosphorylated rhodopsin. FEBS Lett 207: 292295.

Willard FS, Willard MD, Kimple AJ, et al. (2009) Regulator of G-protein signaling 14 (RGS14) is a selective H-Ras effector. PLoS One 4: e4884.

Willard MD, Willard FS, Li X, et al. (2007) Selective role for RGS12 as a Ras/Raf/MEK scaffold in nerve growth factor-mediated differentiation. EMBO J 26: 2029-2040.

Xia YF, He L, Whistler JL, et al. (2008) Acute amphetamine exposure selectively desensitizes kappa-opioid receptors in the nucleus accumbens. Neuropsychopharmacology 33: 892900.

Xie GX and Palmer PP. (2005) RGS proteins: new players in the field of opioid signaling and tolerance mechanisms. Anesth Analg 100: 1034-1042.

Xie Z, Li Z, Guo L, et al. (2007) Regulator of G protein signaling proteins differentially modulate signaling of mu and delta opioid receptors. Eur J Pharmacol 565: 45-53.

Xu B, Roos JL, Dexheimer P, et al. (2011) Exome sequencing supports a de novo mutational paradigm for schizophrenia. Nat Genet 43: 864-868. 
Xu M, Petraschka M, McLaughlin JP, et al. (2004) Neuropathic pain activates the endogenous kappa opioid system in mouse spinal cord and induces opioid receptor tolerance. $J$ Neurosci 24: 4576-4584.

Xu X, Zeng W, Popov S, et al. (1999) RGS proteins determine signaling specificity of Gq-coupled receptors. J Biol Chem 274: 3549-3556.

Yaffe MB. (2002) Phosphotyrosine-binding domains in signal transduction. Nat Rev Mol Cell Biol 3: 177-186.

Yasuda K, Raynor K, Kong H, et al. (1993) Cloning and functional comparison of kappa and delta opioid receptors from mouse brain. Proc Natl Acad Sci U S A 90: 6736-6740.

Yorgason JT, Calipari ES, Ferris MJ, et al. (2016) Social isolation rearing increases dopamine uptake and psychostimulant potency in the striatum. Neuropharmacology 101: 471-479.

Zachariou V, Georgescu D, Sanchez N, et al. (2003) Essential role for RGS9 in opiate action. Proc Natl Acad Sci U S A 100: 13656-13661.

Zhang Y, Butelman ER, Schlussman SD, et al. (2004) Effect of the kappa opioid agonist R-84760 on cocaine-induced increases in striatal dopamine levels and cocaine-induced place preference in C57BL/6J mice. Psychopharmacology (Berl) 173: 146-152.

Zheng B, De Vries L and Gist Farquhar M. (1999) Divergence of RGS proteins: evidence for the existence of six mammalian RGS subfamilies. Trends Biochem Sci 24: 411-414.

Zheng B, Ma YC, Ostrom RS, et al. (2001) RGS-PX1, a GAP for GalphaS and sorting nexin in vesicular trafficking. Science 294: 1939-1942.

Zhong $\mathrm{H}$ and Neubig RR. (2001) Regulator of G protein signaling proteins: novel multifunctional drug targets. J Pharmacol Exp Ther 297: 837-845. 


\section{CHAPTER TWO}

RGS12 modulates the dopamine transporter in ventral striatum and locomotor responses to psychostimulants

Original Article - Journal of Psychopharmacology (2018) vol. 32, issue 2, pgs 191-203

Joshua D. Gross ${ }^{1}$, Shane W. Kaski ${ }^{1}$, Adam B. Schroer ${ }^{1}$, Kimberley A. Wix ${ }^{1}$, David P. Siderovski ${ }^{1}$, Vincent Setola ${ }^{1,2}$

${ }^{1}$ Department of Physiology, Pharmacology \& Neuroscience, and

2 Department of Behavioral Medicine \& Psychiatry,

West Virginia School of Medicine, One Medical Center Drive, PO Box 9229, Morgantown WV 26506-9229 USA 


\section{1 - Abstract}

Regulators of $G$ protein Signaling (RGS) are proteins that accelerate the termination of effector stimulation after G protein-coupled receptor (GPCR) activation. Many RGS proteins are highly expressed in the brain and therefore considered potential drug discovery targets for CNS pathologies; for example, here we show that RGS12 is highly expressed in microdissected mouse ventral striatum. Given a role for the ventral striatum in psychostimulant-induced locomotor activity, we tested whether Rgs12 genetic ablation affected behavioral responses to amphetamine and cocaine. RGS12 loss significantly decreased hyperlocomotion to lower doses of both amphetamine and cocaine; however, other outcomes of administration (sensitization and conditioned place preference) were unaffected, suggesting that RGS12 does not function in support of the rewarding properties of these psychostimulants. To test whether observed response changes upon RGS12 loss were caused by changes to dopamine transporter (DAT) expression and/or function, we prepared crude membranes from the brains of wild type and RGS12-null mice and measured DAT-selective $\left[{ }^{3} \mathrm{H}\right]$ WIN 35428 binding, revealing an increase in DAT levels in the ventral-but not dorsal-striatum of RGS12-null mice. To address DAT function, we prepared striatal synaptosomes and measured $\left[{ }^{3} \mathrm{H}\right]$ dopamine uptake. Consistent with increased $\left[{ }^{3} \mathrm{H}\right]$ WIN 35428 binding, DAT-specific $\left[{ }^{3} \mathrm{H}\right]$ dopamine uptake in RGS12-null ventral striatal synaptosomes was found to be increased. Decreased amphetamine-induced locomotor activity and increased [ $\left.{ }^{3} \mathrm{H}\right]$ WIN 35428 binding were recapitulated with an independent RGS12-null mouse strain. Thus, we propose that RGS12 regulates DAT expression and function in the ventral striatum, affecting amphetamine- and cocaine-induced increases in dopamine levels that specifically elicit acute hyperlocomotor responses. 


\section{2 - Introduction}

Psychostimulant drugs of abuse such as (+)-amphetamine (AMPH) and cocaine are among the most widely abused substances in the United States (Quality., 2015). These psychostimulants impose severe liabilities of high abuse potential, capacity to induce psychoses, considerable neurotoxicity, and mortality (Heal et al., 2013; Ciccarone, 2011). The locomotor-activating and rewarding properties of these psychostimulants are dependent on the mesolimbic dopamine (DA) system of the brain (Adinoff, 2004; Kauer and Malenka, 2007; Thomas et al., 2008; Nutt et al., 2015), defined as the projections from DAergic cell bodies in the ventral tegmental area (VTA) to presynaptic terminals in the nucleus accumbens (NAc) of the ventral striatum (vSTR). Dopaminergic signaling within the VSTR is central to psychostimulant-induced locomotor activity (Ikemoto, 2002): lesioning of DAergic terminals within the NAc-but not in the dorsal striatum (dSTR) - by local injection of 6-hydroxydopamine markedly reduces the hyperlocomotor responses to the dopaminergic indirect agonists AMPH and cocaine (Kelly and Iversen, 1976). Similarly, microinjections of AMPH or cocaine into the NAc-but not dSTR-increase locomotion and rearing behavior in rodents (Staton and Solomon, 1984; Carr and White, 1987; Kelley et al., 1989; Delfs et al., 1990).

AMPH and cocaine exert their effects by increasing extracellular DA levels in the vSTR via their action at the dopamine transporter (DAT; refs. (Giros et al., 1996; Federici et al., 2014)), which acts to translocate released DA back into the presynaptic DA terminal, thus terminating neurotransmission at post-synaptic DA receptors. However, the mechanisms by which AMPH and cocaine modulate DAT are mechanistically distinct. AMPH acts as an indirect dopaminergic agonist in two ways: first, the drug acts as a substrate for (and hence, a competitive inhibitor of) DAT (Sitte and Freissmuth, 2010), whose role is to reuptake dopamine after its release (Ramsey et al., 2008). Upon entry into dopaminergic terminals, AMPH also acts as a substrate for the vesicular monoamine transporter, whose role is to transport synaptoplasmic dopamine into vesicles for release (Sulzer, 2011). Once inside dopaminergic vesicles, AMPH causes release, through reverse transport of 
the vesicular monoamine transporter, of free dopamine into the synaptoplasm (Sitte and Freissmuth, 2010). In addition, amphetamine causes release of that free dopamine through DAT, thereby increasing synaptic levels of dopamine (Sitte and Freissmuth, 2010). Cocaine acts more simply: it is not a DAT substrate rather, it is a competitive inhibitor of the protein (Rothman, 1990). Cocaine blocks the ability of DAT to re-uptake released dopamine, thereby increasing levels of dopamine in the synapse (Nestler, 2005). Thus, each drug (AMPH and cocaine) ultimately yields increased levels of synaptic dopamine in dopaminergic (dopamine transporter-expressing) synapses. These increased levels of dopamine in response to AMPH or cocaine act on post-synaptic, dopamine-responsive, G protein-coupled receptors (GPCRs) to elicit responses postsynaptically (Schultz, 2002).

DAT expression, subcellular trafficking, and DA uptake function are all tightly regulated by a host of protein interactants (Torres, 2006), such as receptors, kinases, and scaffolds. In particular, several groups have identified presynaptic GPCRs and scaffolding proteins that directly and/or functionally interact with DAT (Torres, 2006), suggesting that GPCR-dependent, multiprotein networks are critical to DAT function. RGS12, a member of the 'Regulator of G protein Signaling' (RGS) protein superfamily (Snow et al., 1998; Snow et al., 1997), has not previously been associated with DAT regulation. RGS proteins are known

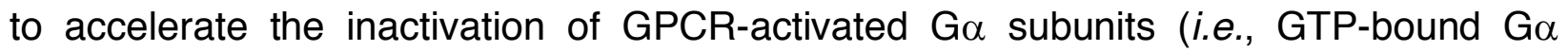
subunits) by stimulating their intrinsic GTPase activity (Berman et al., 1996). This inactivation is followed by the reassociation of GDP-bound (i.e., inactive) Go subunits with $\mathrm{G} \beta \gamma$ subunits, thereby terminating signaling originally evoked by free GTP-bound $\mathrm{G} \alpha$ subunits (e.g., inhibition of adenylyl cyclase; (Clark and Traynor, 2004)) and/or free G $\beta \gamma$ subunits (e.g., stimulation of G protein-coupled inwardly rectifying potassium (GIRK) channels; (Zhou et al., 2012)).

As many RGS proteins are expressed in the CNS (e.g., ref. (Gold et al., 1997)), they are suspected to play key roles in neuronal function and behavior (Neubig and Siderovski, 2002). For example, RGS14, the closest related paralog to RGS12, is integral to hippocampal 
synaptic plasticity underlying learning and memory (Lee et al., 2010). Several RGS proteins, including RGS12 and RGS14, are endowed with functional domains other than the RGS domain (Kimple et al., 2011). In addition to being a Ga-directed GTPaseaccelerating protein (GAP) (Snow et al., 1998), RGS12 contains four additional functional motifs: a PDZ binding domain (common among scaffolding proteins), a phosphotyrosine binding domain, tandem Ras binding domains, and a GoLoco motif (which sequesters

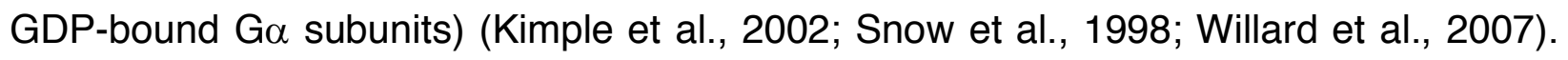
Thus, the function of RGS12 in vivo need not be restricted to Ga-directed GAP activity in opposition to GPCR activation; for example, we have shown that RGS12 acts as a scaffold for Ras, Raf, and MEK in prolonging NGF-stimulated ERK signaling and stimulating axonogenesis by dorsal root ganglion neurons, as detailed in (Willard et al., 2007).

To explore more deeply the potential roles for RGS12 function in the CNS, we created both conventional and conditional mouse knockout strains and conducted subsequent behavioral (locomotion, sensitization, conditioned place preference) and biochemical (tissue radioligand binding, synaptosome uptake and release) studies. Based on our findings, we propose that RGS12 modulates the expression and function of DAT in the ventral striatum, thus explaining decreased hyperlocomotor responses in RGS12-null mice to AMPH or cocaine compared with wild type littermates. Our findings are compatible with a robust literature indicating that DAT function is modulated by a number of accessory proteins/enzymes (Torres, 2006). Thus, we have identified RGS12 as a novel regulator of DAT and suggest that the locomotor-activating effects of psychostimulants are dependent, in part, on RGS12 function. 


\subsection{Methods}

\subsection{1 - Animals}

Generation of two independent strains of RGS12-null mice (constitutive $R g s 12^{\Delta 5-8 / \Delta 5-8}$ and Cre-dependent $\operatorname{Rgs} 12^{\Delta 5-6 / \Delta 5-\sigma}$ ) is described in Figure 1 and Supplementary Figure S1. Both mouse strains are in the C57BL/6J background. Mice were housed under standard temperature, humidity, and lighting conditions (12 hours light / 12 hours dark). All behavioral experiments performed during the light cycle using mice between 8-10 weeks of age. All mice were provided food and water ad libitum. All experiments were conducted in accordance with West Virginia University Animal Care and Use Committee and followed the National Institute of Health guidelines for use of animals in research. The procedures of the behavioral assays are described below and were conducted according to previously published methods (as cited); mice were used for only one behavioral assay involving either acute or chronic drug dosing (i.e., all drug-based studies were performed with drug-naïve mice; there is no sequence of multiple, drug-based experimental trials to define for individual mice used in this study).

\subsection{2 - In situ hybridization}

In situ hybridization with an antisense riboprobe directed against Rgs12 was performed in order to assess the distribution of Rgs 12 mRNA in brain. cDNA from the mouse Rgs12 open reading frame (full-length) was subcloned into a pBluescript II SK vector by restriction enzyme digestion. In vitro transcription with T7 RNA polymerase was conducted to produce a digoxigenin-labeled antisense riboprobe. In situ hybridization was then performed by the University of North Carolina Neuroscience Center In Situ Hybridization Core using standardized protocols (UNC-Chapel Hill).

\subsection{3 - Immunoblots}

Immunoblot analyses of microdissected dopaminergic brain regions (frontal cortex, dorsal and ventral striatum, and midbrain) were performed in order to identify which regions 
contained RGS12 protein, to compare the relative abundances of RGS12 protein across selected regions, and to verify complete knockout of RGS12 protein in $R g s 12^{45-8 / \Delta 5-8}$ mice. Mice were injected with a lethal dose of pentobarbital (200 mg/kg, ip), decapitated, rapidly dissected, and frozen on dry ice. Dorsal striatum, ventral striatum, and midbrain were sonicated in 10 volumes of RIPA buffer containing $25 \mathrm{mM}$ Tris- $\mathrm{HCl}(\mathrm{pH} 7.6), 150 \mathrm{mM}$ $\mathrm{NaCl}, 1 \% \mathrm{NP}-40,1 \%$ sodium deoxycholate, $0.1 \%$ SDS (Pierce) supplemented with protease inhibitors (Halt ${ }^{\mathrm{TM}}$ protease inhibitor cocktail, Thermo Fisher). Lysates were cleaned by centrifugation at $20,800 \mathrm{~g}$ for $20 \mathrm{~min}$ and pellets were discarded. Proteins were then separated by SDS-PAGE on a gradient $4-15 \%$ gel (BioRad), electrotransferred to nitrocellulose membranes, and incubated overnight $\left(4^{\circ} \mathrm{C}\right)$ with a monoclonal primary antibody directed against the N-terminus of RGS12 (generated in-house) or beta-actin (Thermo Fisher). Blots were then probed with HRP-conjugated goat anti-mouse secondary antibodies and visualized by chemiluminescence (Pierce). Data were derived from a sample size of $n=6-9$ per genotype per experiment.

\subsection{4 - Locomotor assays}

AMPH- or cocaine-induced locomotor activity assessments were carried out in order to evaluate behavioral phenotypes in RGS12-null mice. Open field locomotor activity was evaluated in a $16 \times 16$ photobeam activity system (PAS) under standard environmental conditions (San Diego Instruments, San Diego, CA). Horizontal locomotor activity was measured as the sum of the total $X$ and $Y$ coordinate beam breaks collected every 5 minutes. Acute psychostimulant-induced locomotor activity experiments were carried out over 3 days. On day 1, mice were habituated to locomotor chambers over 150 minutes to reduce the influence of novelty. On day 2, all mice we allowed to habituate to locomotor chambers for 30 min before intraperitoneal (ip) administration of saline $(0.9 \% \mathrm{NaCl})$ at a volume $10 \mathrm{~mL} / \mathrm{kg}$ and locomotor activity was measured over 110 minutes. On day 3 , mice were habituated to locomotor chambers for $30 \mathrm{~min}$ and then injected with d-amphetamine (1, 3, or $5 \mathrm{mg} / \mathrm{kg}$, ip) (Salahpour et al., 2008; Tzschentke, 2007) or 
cocaine $(10,20$, or $40 \mathrm{mg} / \mathrm{kg}$, ip) (Ramsey et al., 2008; Jung et al., 2013) dissolved in saline (ip, at a final volume of $10 \mathrm{~mL} / \mathrm{kg}$ ). Psychostimulant-induced hyperlocomotion was then measured over 110 minutes. All drugs were obtained from Sigma-Aldrich (St. Louis, MO). Data were derived from a sample size of $n=7-23$ per genotype per experiment.

\subsection{5 - Psychostimulant-induced locomotor sensitization}

Sensitization experiments were performed in order to assess whether RGS12-null mice exhibited reduced responsiveness to repeated administration of AMPH or cocaine as was observed with acute hyperlocomotion induced by these psychostimulants. Experiments were performed as previously described (Steinkellner et al., 2014) with minor modifications. Briefly, mice were habituated to locomotor chambers on day 1 and 2 as described in acute psychostimulant-induced locomotor activity experiments. Mice were then administered d-amphetamine (2 mg/kg, ip) or cocaine (20 mg/kg, ip) (Ramsey et al., 2008) for 6 consecutive days (d1-d6) to induce sensitization under the conditions described for day 3 of acute psychostimulant-induced locomotor activity experiments. After the sixth day of psychostimulant administration, drug was withdrawn for 14 days. Following washout (d20), mice were challenged with d-amphetamine (2 mg/kg, ip) or cocaine (20 mg/kg, ip) and horizontal locomotor activity was evaluated. Data were analyzed by two-way, repeated measures ANOVA. Data were derived from a sample size of $n=6-9$ per genotype per experiment.

\subsection{6 - Conditioned place preference (CPP)}

CPP was conducted with RGS12-null mice in order to evaluate whether RGS12 influences the rewarding properties of AMPH or cocaine. CPP studies were performed in a two-chambered apparatus (Med Associates, ENV-3013-2, Georgia, VA) with the paradigm described by Ramsey and colleagues (Ramsey et al., 2008) with minor modifications. The two chambers of the CPP apparatus contained distinguishable floor grating (grid floor vs rod floor) and colored walls (white vs black). Each experiment consisted of habituation, preconditioning, conditioning, and post-conditioning phases. 
Habituation (day 1 ) was carried out to reduce the influence of apparatus novelty. Mice were allowed free access to either chamber for $30 \mathrm{~min}$ and measurements of time spent in each chamber was measured. For the preconditioning phase (day 2), mice were again allowed free access to either chamber for $30 \mathrm{~min}$ and time spent in each chamber was measured to determine the least-preferred chamber of each mouse. Preference on days 1 and 2 were comparable (data not shown). The next day (day 3) began the conditioning phase. Mice were injected with either d-amphetamine $(2 \mathrm{mg} / \mathrm{kg}$, ip) or cocaine $(20 \mathrm{mg} / \mathrm{kg}$, ip) and were restricted to the least preferred chamber for $30 \mathrm{~min}$. On day 4, mice were injected with saline $(0.9 \% \mathrm{NaCl}, \mathrm{ip})$ and restricted to the other chamber for $30 \mathrm{~min}$. The remainder of the conditioning phase consisted of two more repetitions of alternating drug (days 5 and 7 ) and saline (days 6 and 8 ). For the postconditioning test phase, conditioned place preference was determined by allowing mice free access to either chamber and measuring the time spent for $30 \mathrm{~min}$. No differences in chamber preference were identified between habituation (day 1 ) and preconditioning day (day 2). Preconditioning and postconditioning were calculated by subtracting the time spent (seconds) in the preferred chamber (as determined on day 2) from the least preferred chamber (as determined on day 2). Data were analyzed by two-way, repeated measures ANOVA. Data were derived from a sample size of $n=7-8$ per genotype per experiment.

\subsection{7 - Preparation of brain sections and immunohistochemistry for c-Fos}

Psychostimulant-induced c-Fos immunohistochemistry was performed in order to determine whether RGS12-null mice showed a reduction in neural activity specifically within the NAc of the vSTR. Mice received ip injection of saline or d-amphetamine (3 $\mathrm{mg} / \mathrm{kg}$ ). Following $90 \mathrm{~min}$, mice were anesthetized with pentobarbital $(200 \mathrm{mg} / \mathrm{kg})$ and transcardially perfused with $4 \%$ paraformaldehyde. Perfused brains were post-fixed overnight and then placed in $30 \%$ sucrose solution until brains sank. Cryoprotected brains were then frozen overnight at $-80^{\circ} \mathrm{C}$ and $40-\mu \mathrm{m}$ free-floating sections were prepared. Sections were incubated with a polyclonal anti-c-Fos primary antibody (1:100; Santa 
Cruz, Dallas, TX) overnight at $4^{\circ} \mathrm{C}$, followed by incubation of a flurophore-conjugated goat anti-rabbit secondary antibody (Thermo Fisher Sci.) for $2 \mathrm{hr}$ at RT. Psychostimulantinduced c-Fos expression was visualized on an Evos epifluorescent microscope and cFos-positive nuclei were counted in a $0.16-\mathrm{mm}^{2}$ field of dorsal and ventral striatum. Anatomical landmarks, such as the anterior commissure, corpus callosum, and septum, were utilized to demarcate the dorsal and ventral striatum. Three independent sections separated by $200 \mu \mathrm{m}$ were counted per mouse, and presented data were determined by computing the average number of c-Fos-positive nuclei per field in 3-4 mice per genotype.

2.3.8 - Preparation of synaptosomes and measurement of $\left[{ }^{3} \mathrm{H}\right]$ dopamine uptake and release These biochemical experiments were performed to assess whether the observed reductions in acute psychostimulant-induced hyperlocomotion were correlated with changes in DA uptake and/or AMPH-induced DA release. For $\left[{ }^{3} \mathrm{H}\right]$ dopamine uptake experiments, dorsal and ventral striatal synaptosomes were prepared by homogenizing brain tissue from 3-4 mice per genotype in 10 volumes ice-cold sucrose buffer (10\% sucrose, $5 \mathrm{mM}$ HEPES, $\mathrm{pH}$ 7.4) with a Potter-Elvehjem homogenizer (10 strokes). Homogenates were then centrifuged at $1,000 \mathrm{~g}$ for $10 \mathrm{~min}$ and supernatants containing crude synaptosomes were maintained on ice. Synaptosomes were then added to tubes containing Krebs-Ringer uptake buffer (120 mM NaCl, $20 \mathrm{mM}$ Tris- $\mathrm{HCl}, 5 \mathrm{mM} \mathrm{KCl}, 1.2$ $\mathrm{mM} \mathrm{MgSO}_{4}, 2.5 \mathrm{mM} \mathrm{CaCl}_{2}, 10 \mathrm{mM}$ glucose, $1 \mathrm{mM}$ ascorbic acid, and $0.1 \mathrm{mM}$ pargyline) plus $\left[{ }^{3} \mathrm{H}\right]$ dopamine $(33.5 \mu \mathrm{Ci}$, Perkin-Elmer, Bridgeville, $\mathrm{PA})$ and incubated for $10 \mathrm{~min}$ at RT for uptake to occur. Non-specific $\left[{ }^{3} \mathrm{H}\right]$ dopamine uptake was determined in the presence of $10 \mu \mathrm{M}$ cocaine and subtracted from total uptake. Uptake was terminated by rapid filtration (Brandel harvester) through $0.1 \% \mathrm{PEI}$-soaked Whatman GF/B filters with ice-cold Krebs-Ringer buffer and washed three times before radioactivity measurement via liquid scintillation counting. Data were analyzed with nonlinear fitting software (GraphPad Prism 7) to determine $\mathrm{V}_{\max }$ and $\mathrm{K}_{\mathrm{m}}$. AMPH-induced $\left[{ }^{3} \mathrm{H}\right]$ dopamine release assays were performed as previously described (Rothman et al., 2001) with minor 
modifications. Briefly, dorsal and ventral striatal synaptosomes were prepared as described above but with ice-cold sucrose buffer supplemented with $1 \mu \mathrm{M}$ reserpine. Synaptosomes were then incubated to steady-state with $5 \mathrm{nM}\left[{ }^{3} \mathrm{H}\right]$ dopamine (30 min) in Krebs-Ringer buffer supplemented with $1 \mu \mathrm{M}$ reserpine. Following incubation, $900 \mu \mathrm{L}$ of preloaded synaptosomes were added to $12 \times 75 \mathrm{~mm}$ polystyrene tubes containing $\mathrm{d}$ amphetamine $\left(1 \times 10^{-8.5}\right.$ to $\left.1 \times 10^{-5} \mathrm{M}\right)$ in Krebs-Ringer buffer. The release reaction proceeded for $5 \mathrm{~min}$, then terminated by rapid filtration over Whatman GF/B filters with ice-cold Krebs-Ringer buffer, washed three times, and radioactivity was measured via liquid scintillation counting. Data were analyzed with nonlinear fitting software (GraphPad Prism 7) to determine $\mathrm{EC}_{50}$. Data were derived from a sample size of $\mathrm{n}=6-12$ per genotype per experiment.

\subsection{9 - Preparation of brain tissue and measurement of [ $\left.{ }^{3} \mathrm{H}\right] \mathrm{WIN} 35428$ binding}

DAT saturation binding experiments were conducted in order to determine whether the increased DA uptake in RGS12-null mice was associated with elevated DAT protein levels. Dorsal and ventral striatal brain regions were rapidly dissected and frozen on dry ice. Tissue was then homogenized with a Polytron homogenizer with 10 volumes of transporter binding buffer (50 mM Tris- $\mathrm{HCl}, 120 \mathrm{mM} \mathrm{NaCl}$, and $5 \mathrm{mM} \mathrm{MgCl}_{2}, \mathrm{pH}$ 7.4). Homogenates were then centrifuged at $20,800 \mathrm{~g}$ for $20 \mathrm{~min}$. The resulting pellet was then resuspended in transporter binding buffer and added to tubes containing $\left[{ }^{3} \mathrm{H}\right]$ WIN 35428 (1.75 to $52.5 \mathrm{nM}$ ) and incubated for $1 \mathrm{hr}$ at RT. Nonspecific binding was determined in the presence of 10 GBR12909. Binding was terminated by rapid filtration over Whatman GF/B filters with ice-cold transporter binding buffer, washed three times, and radioactivity was measured via liquid scintillation counting. Data were analyzed with nonlinear fitting software (GraphPad Prism 7) to determine $B_{\max }$ and $K_{d}$. Data were derived from a sample size of $n=6-9$ per genotype per experiment. 
2.3.10 - High-performance liquid chromatography (HPLC) with dual-cell electrochemical detection

HPLC on microdissected dopaminergic brain regions was carried out to assess whether tissular DA levels differed between RGS12-null and wild type mice. Dorsal and ventral striatal brain regions were rapidly dissected and frozen on dry ice. Tissue was then sonicated in 10 volumes of $0.3 \mathrm{~N}$ perchloric acid and homogenates were centrifuged at $12,000 \times g$ for $15 \mathrm{~min}$. Supernatants were collected, passed through a $0.22 \mu \mathrm{m}$ filter, and dopamine levels in the homogenates were determined by HPLC with dual-cell electrochemical detection. Cleared lysates underwent automated direct injection of $10 \mu \mathrm{L}$ into a Dionex Ultimate 3000 HPLC system equipped with a pump (ISO-3100BM, Thermo Scientific, Waltham, WA) linked to an autosampler (WPS-3000TBRS, Thermo Scientific), ESA HPLC column (MD-150 x 3.2) and dual coulometric/amperometric electrochemical detectors (ECD-3000RS, Thermo Scientific) set at $-170 \mathrm{mV}$ and $+400 \mathrm{mV}$, respectively. Mobile phase (MD-TM; Thermo Scientific) was pumped at a flow rate of $0.6 \mathrm{~mL} / \mathrm{min}$. Chromatograms were analyzed using Chromeleon software and dopamine peak height (concentration) was determined from a standard curve. The identity of the dopamine peak in the sample was confirmed by standard addition.

\subsubsection{1 - Statistics}

All data are presented as the mean \pm SEM. Statistical significance was set at $p<0.05$ for all experiments, and data were analyzed by student's t-test or two-way ANOVA followed by Sidak's post hoc test where appropriate. 


\subsection{Results}

2.4.1 - RGS12 protein is abundantly expressed in the ventral striatum of the mouse CNS Our study was initiated by the generation of two independent strains of RGS12-null mice on the C57BL/6J background (Figure 1A-C). Rgs12 mRNA was detected within the brain by in situ hybridization in wild type, but not in RGS12-null, mice (Figure 1D-E). Rgs12 is expressed in the ventral tegmental area (VTA) and the substantia nigra pars compacta (SNc) (Figure 1D); there was also clear labeling of Rgs12 in the dentate gyrus and the $\mathrm{CA}$ regions of the hippocampus (HPC). As shown in Figure 1E, there was also diffuse labeling of Rgs12 in the striatum (STR) and cortex (CTX), as well as marked labeling of Rgs12 in the claustrum (CLA). RGS12 protein immunoreactivity was detected in the midbrain (the seat of the VTA and SNc) (Figure 1F); however, midbrain RGS12 protein content was low in comparison to the high abundance of Rgs12 mRNA. There was also detectable RGS12 immunoreactivity in the frontal cortex and dorsal striatum (dSTR) (Figure 1F). RGS12 immunoreactivity was greater in the ventral striatum (vSTR) than in frontal cortex, dSTR, or midbrain (Figure 1G). Quantification of immunoblots is presented as the mean \pm SEM ( $n=6$ per group), and statistical significance was assessed by oneway ANOVA with Tukey's multiple comparisons post-hoc analysis: e.g., frontal cortex vs $\operatorname{dSTR}\left({ }^{*}, P<0.05\right)$; dSTR vs vSTR $\left({ }^{* *}, P<0.01\right)$; midbrain vs dSTR (ns, $\left.P=0.72\right)$. Despite dense RGS12 immunoreactivity, Rgs12 mRNA labeling in the ventral striatum is quite sparse (Figure 1E).

\subsection{2 - RGS12 loss blunts hyperlocomotion to low doses of amphetamine and cocaine}

Given marked RGS12 expression in the vSTR, and an established role for the vSTR in psychostimulant actions, as a next step we evaluated RGS12-null mice in psychostimulant-induced behavioral assays. Both RGS12-null mouse strains exhibited a markedly reduced response to a standard hyperlocomotive-inducing dose (3 mg/kg) of AMPH compared with wild type littermates (Figure 2A-C). Data indicating lack of a saline 
effect (Fig. 2A) are displayed as the mean \pm SEM ( $n=7-8$ per group) and analyzed by two-way ANOVA: genotype effect, $\mathrm{F}(1,13)=0.04, P=0.84$; time, $\mathrm{F}(21,273)=5.4, P<$ 0.0001; genotype $x$ time, $F(21,273)=1.1, P=0.40$. Data indicating reduced hyperlocomotion of conditional RGS12-null mice to $3 \mathrm{mg} / \mathrm{kg}$ AMPH (Fig. 2B) are displayed as the mean \pm SEM ( $n=7-8$ per group) and analyzed by two-way ANOVA: genotype effect, $F(1,12)=8.9, P=0.011 ;$ time, $F(21,252)=11.3, P<0.0001$; genotype $x$ time, $F$ $(21,252)=3.2, P<0.0001$. Data indicating reduced hyperlocomotion of constitutive RGS12-null mice (Fig. 2 C) are the mean \pm SEM ( $n=9-23$ per group) and analyzed by two-way ANOVA: genotype effect, $F(1,41)=18.6, P<0.0001 ;$ time, $\mathrm{F}(21,861)=42.3, P<0.0001$; genotype $x$ time, $\mathrm{F}(21,861)=9.6, P<0.0001$.

An initial dose of $3 \mathrm{mg} / \mathrm{kg}$ AMPH was selected because it has been extensively characterized as eliciting robust locomotor responses in wild type C57BL/6 mice (Salahpour et al., 2008; Ramsey et al., 2008; Medvedev et al., 2013). We next assessed whether RGS12-null mice exhibit reduced locomotor responses to lower doses of AMPH. We found that $\mathrm{AMPH}$ at $1 \mathrm{mg} / \mathrm{kg}$ was sufficient to observe hyperlocomotion in wild type mice relative to saline injection (Figure 2D); however, there was only a trend towards reduced $\mathrm{AMPH}$-stimulated hyperlocomotion in RGS12-null mice at this lower dose (Figure 2D). At a high dose of AMPH (5 mg/kg), the hyperlocomotive responses of wild type and Rgs12-null mice were identical (Figure 2D). Data from these additional AMPH doses are displayed as the mean \pm SEM ( $n=8-23$ per group) and analyzed by multiple t-test analysis: saline, $P=0.52 ; 1 \mathrm{mg} / \mathrm{kg}, P=0.057 ; 3 \mathrm{mg} / \mathrm{kg}, P<0.0001\left(^{\star \star \star \star}\right) ; 5 \mathrm{mg} / \mathrm{kg}: P=$ 0.086 .

Having obtained the described results with $\mathrm{AMPH}$, we proceeded to determine whether the response to another dopaminergic psychostimulant, cocaine, was similarly affected upon RGS12 loss. As shown in Figure 2E, $10 \mathrm{mg} / \mathrm{kg}$ cocaine elicited a hyperlocomotive response in wild type mice that was markedly reduced in Rgs12-null mice. Data indicating reduced hyperlocomotion to cocaine in RGS12-null mice are displayed as the mean \pm SEM ( $n=9-10$ per group) and analyzed by two-way ANOVA: 
genotype effect, $\mathrm{F}(1,17)=17.2, P=0.016 ;$ time, $\mathrm{F}(21,357)=8.8, P<0.0001$; genotype $x$ time, $F(21,357)=2.4, P=0.0006$. In follow-up studies with $20 \mathrm{mg} / \mathrm{kg}$ and $40 \mathrm{mg} / \mathrm{kg}$ of cocaine, doses established by others' studies (Salahpour et al., 2008; Ramsey et al., 2008; Elliot, 2002; Reith et al., 1991), we observed no genotype-dependent differences in drug-induced hyperlocomotion (Figure 2F). Data from these additional cocaine doses are displayed as the mean \pm SEM ( $n=7-20$ per group) and analyzed by multiple t-test analysis: saline, $\left.P=0.99 ; 10 \mathrm{mg} / \mathrm{kg}, P=0.02,{ }^{\star *}, P<0.01\right) ; 20 \mathrm{mg} / \mathrm{kg}, P=0.84 ; 40$ $\mathrm{mg} / \mathrm{kg}, P=0.72$.

Both AMPH and cocaine are well known to exert their actions via the neurotransmitter dopamine (Ciccarone, 2011). One possible explanation for these observations of reduced hyperlocomotion is that, in RGS12-null mice, post-synaptic dopamine receptor sensitivity is decreased. SKF 81927 is a selective D1-like (D1/D5) dopamine receptor full agonist (Weed et al., 1993; Desai et al., 2005), which has been extensively characterized as eliciting robust horizontal locomotor activity in mice (Desai et al., 2005; Scott et al., 2005; Medvedev et al., 2013). However, we found no differences in hyperlocomotion between the two genotypes at each of the three different doses of SKF 81927 tested (Figure 2G), suggesting a pre-synaptic, rather than a post-synaptic, effect of RGS12 loss on dopaminergic psychostimulant action. Data on SKF 81927-mediated hyperlocomotion are displayed as the mean \pm SEM ( $n=8$ per group) and analyzed by multiple t-test analysis: saline, $P=0.73 ; 1 \mathrm{mg} / \mathrm{kg}, P=0.64 ; 3 \mathrm{mg} / \mathrm{kg}, P=0.59 ; 5 \mathrm{mg} / \mathrm{kg}, P=0.71$.

\subsection{3 - RGS12 loss does not affect sensitization nor conditioned place preference} Having established a phenotype based on acute administration of AMPH or cocaine, we next tested the effects of repeated dosings of these psychostimulants on RGS12-null mice with doses known to elicit robust sensitization in wild type C57BL/6 mice (Ramsey et al., 2008; Eisener-Dorman et al., 2011). Despite recapitulating the reduced acute locomotor responses to AMPH by RGS12-null mice (Figure 3A), sensitization to repeated administration of $\mathrm{AMPH}-\mathrm{a}$ measure of neuronal plasticity of the mesolimbic dopamine 
system (Steketee and Kalivas, 2011; Berg and Olsson, 2004)-was intact in RGS12-null mice compared to wild type littermates (Figure 3B-C). Locomotion observations from the first day of acute $2 \mathrm{mg} / \mathrm{kg} \mathrm{AMPH}$ administration (Fig. 3A) were analyzed by two-way ANOVA: genotype effect, $\mathrm{F}(1,308)=10.3, P=0.002\left(^{(*}\right)$; time, $\mathrm{F}(21,308)=1.7, P=$ 0.03 ; genotype $x$ time, $F(21,308)=7.6, P=0.75$. Locomotion observations from the sixth day of acute $2 \mathrm{mg} / \mathrm{kg} \mathrm{AMPH}$ administration (Fig. 3B) were analyzed by two-way ANOVA: genotype effect, $\mathrm{F}(1,14)=0.45, P=0.52$; time, $\mathrm{F}(21,294)=36.2, P<0.0001$; genotype $x$ time, $F(21,294)=1.1, P=0.36$. AMPH sensitization time-course data (Fig. $3 C)$ were analyzed by two-way, repeated-measures ANOVA: genotype effect, $F(1,14)=2.7, P=$ 0.6 ; time, $\mathrm{F}(6,84)=25.4, P<0.0001$; genotype $\mathrm{x}$ time, $\mathrm{F}(6,84)=25.4, P=0.95$. Similarly, sensitization to cocaine was not affected in RGS12-null mice (Figure 3D-F). Locomotion observations from the first day of acute $20 \mathrm{mg} / \mathrm{kg}$ cocaine administration (Fig. 3D) were analyzed by two-way ANOVA: genotype effect, $F(1,10)=0.31, P=0.59$; time, $\mathrm{F}(21,210)=14.2, P<0.0001$; genotype $x$ time, $\mathrm{F}(21,210)=3.6, P<0.0001$. Locomotion observations from the sixth day of acute $20 \mathrm{mg} / \mathrm{kg}$ cocaine administration (Fig. 3E) were analyzed by two-way ANOVA: genotype effect, $\mathrm{F}(1,10)=0.08, P=0.78$; time, $\mathrm{F}(21$, $210)=17.7, P<0.0001$; genotype $x$ time, $F(21,210)=0.61, P=0.91$. Cocaine sensitization time-course data (Fig. 3F) were analyzed by two-way, repeated-measures ANOVA: genotype effect, $\mathrm{F}(1,10)=1.0, P=0.33$; time, $\mathrm{F}(21,210)=17.4, P<0.0001$; genotype $\mathrm{x}$ time, $\mathrm{F}(21,210)=0.73, P=0.80$.

In another behavioral paradigm elicited by repeated psychostimulant administrationconditioned place preference (CPP), which measures the 'rewarding' properties of drugs (Tzschentke, 2007) - we observed no differences in the effects of either AMPH or cocaine in RGS12-null vs wild type mice (Figure 3G-H). CPP as induced by $2 \mathrm{mg} / \mathrm{kg}$ doses of AMPH was analyzed by two-way, repeated-measures ANOVA: genotype effect, $F(1,12)$ $=0.23, P=0.64$; time, $\mathrm{F}(1,12)=54.1, P<0.0001$; genotype $\mathrm{x}$ time, $\mathrm{F}(1,12)=0.04, P=$ 0.84 . CPP as induced by $10 \mathrm{mg} / \mathrm{kg}$ doses of cocaine was analyzed by two-way, repeatedmeasures ANOVA: genotype effect, $F(1,14)=3.43, P=0.09$; time, $F(1,14)=41.4, P<$ 
0.0001; genotype $x$ time, $F(1,14)=0.04, P=0.84$. All CPP data are presented as the mean \pm SEM ( $n=6-9$ per group).

\subsection{4 - AMPH-elicited neuronal excitation is reduced in the NAC upon RGS12 loss} In light of the locomotor data and RGS12 expression data, we suspected that RGS12 loss might affect psychostimulant-dependent neuronal activation in at least one locus within the ventral striatum: namely, the nucleus accumbens (NAc). Therefore, we addressed this hypothesis by measuring c-Fos induction in AMPH-treated RGS12-null and wild type mice. c-Fos immunoreactivity (measured as c-Fos-positive nuclei per field; Figure 4A) was pronounced in the NAc (i.e., ventro-lateral to the anterior commissure [ac]) after an acute dose of $3 \mathrm{mg} / \mathrm{kg} \mathrm{AMPH}$. Consistent with the reduced hyperlocomotion of RGS12null mice to acute, low-dose AMPH, c-Fos immunoreactivity was significantly reduced in the NAc of AMPH-treated RGS12-null mice compared with wild type littermates (Figure 4B). Conversely, in the dorsal striatum, the number of C-Fos-positive nuclei was not different between AMPH-treated RGS12-null mice and wild type littermates (Figure 4B). c-Fos immunoreactivity data are presented as the mean \pm SEM ( $n=3-4$ mice per group) and were analyzed by two-way ANOVA with Sidak's multiple comparisons: vSTR, $P<$ $\left.0.0001{ }^{(* \star \star *}\right)$; dSTR, $P=0.85$.

2.4.5 - Dopamine uptake is enhanced in ventral striatal synaptosomes from RGS12-null mice

The reduced effects of psychostimulants on RGS12-null mice could be explained by increased dopamine transporter (DAT)-mediated uptake in the ventral striatum of dopamine, the major neurotransmitter affected by AMPH and cocaine (Ciccarone, 2011). Thus, to test this hypothesis, we next prepared ventral and dorsal striatal synaptosomes from RGS12-null mice to measure $\left[{ }^{3} \mathrm{H}\right]$ dopamine uptake. A significant increase in the $V_{\max }$ (maximal rate of $\left[{ }^{3} \mathrm{H}\right]$ dopamine uptake) of RGS12-null ventral striatal synaptosomes was observed as compared with wild type ventral striatal synaptosomes (Figure 5A and 5B 
inset); however, no genotype-specific differences in $V_{\text {max }}$ were observed for dorsal striatal synaptosomes (Figure 5B). $K_{m}$ values were equivalent between genotypes in both ventral and dorsal striatal synaptosomes (Figure 5A-B). [ $\left.{ }^{3} \mathrm{H}\right]$ Dopamine uptake $V_{\max }$ data are presented in Fig. 5B as the mean \pm SEM ( $n=9-12$ per group) and were analyzed by genotype using two-way ANOVA with Sidak's multiple comparisons: vSTR, $P=0.0054$ $\left({ }^{* *}\right)$; dSTR, $P=0.91$ (ns, no significant difference). [ $\left.{ }^{3} \mathrm{H}\right]$ Dopamine uptake $K_{\mathrm{m}}$ values were as follows: vSTR, wild type mice $=0.36 \pm 0.16 \mu \mathrm{M}$, RGS12-null mice $=0.33 \pm 0.16 \mu \mathrm{M}$; dSTR, wild type mice $=0.86 \pm 0.32 \mu \mathrm{M}$, RGS12-null mice $=0.80 \pm 0.32 \mu \mathrm{M}$; two-way ANOVA with Sidak's multiple comparisons: vSTR, $P=0.99$; dSTR: $P=0.49$.

To evaluate whether the observed increase in $\left[{ }^{3} \mathrm{H}\right]$ dopamine uptake in the ventral striata of RGS12-null mice was mediated specifically by DAT, we also performed $\left[{ }^{3} \mathrm{H}\right]$ dopamine uptake studies using RGS12-null ventral striatal synaptosomes in the presence of the DAT-selective re-uptake inhibitor GBR12935 in order to quantify (and subtract out) non-specific uptake. A significant increase in the $V_{\max }$ of DAT-specific $\left[{ }^{3} \mathrm{H}\right]$ dopamine uptake was observed in RGS12-null vSTR synaptosomes as compared with those derived from wild type littermates (Figure $5 \mathrm{C}$ ). DAT-specific $\left[{ }^{3} \mathrm{H}\right]$ dopamine uptake data are presented as the mean \pm SEM ( $n=6$ per group) and were analyzed by unpaired t-test: $\left.P=0.001{ }^{(*}\right)$.

\subsection{6 - DAT binding sites are significantly elevated in the ventral striatum}

Data indicating increased dopamine uptake by ventral striatal synaptosomes prompted us next to probe the expression levels of DAT in striatal tissue from RGS12null mice. Radioligand saturation binding assays were performed with $\left[{ }^{3} \mathrm{H}\right] \mathrm{WIN} 35428$ (a DAT-selective radioligand) to determine the maximal number of DAT binding sites in wild type and Rgs12-null crude membrane fractions of ventral and dorsal striatal tissue. A marked increase was seen in $\left[{ }^{3} \mathrm{H}\right] \mathrm{WIN} 35428$ binding to ventral striatal membrane fractions from Rgs12-null mice compared with wild type mice (Figure 5D and 5E inset). Although unable to accurately determine $B_{\max }$ given the absence of saturation binding, 
we were able to establish relative expression levels of DAT by comparing the binding of wild type and RGS12-null ventral and dorsal striatal crude membrane fractions at the maximal concentration of $\left[{ }^{3} \mathrm{H}\right] \mathrm{WIN} 35428$ tested $(52.5 \mathrm{nM})$. As shown in the bar graph inset within Figure 5E, [ $\left.{ }^{3} \mathrm{H}\right] \mathrm{WIN} 35428$ binding to RGS12-null ventral striatal crude membrane fractions was markedly greater than radioligand binding to wild type ventral striatal crude membrane fractions; however, there was no statistically significant, genotype-specific effect on [ $\left.{ }^{3} \mathrm{H}\right]$ WIN 35428 binding to dorsal striatal crude membrane fractions. Data for $\left[{ }^{3} \mathrm{H}\right]$ WIN 35428 binding in Fig. 5E (inset) are presented as the mean \pm SEM ( $n=6-9$ per group) and analyzed by genotype using two-way ANOVA with Sidak's multiple comparisons: vSTR, $\left.P=0.0051{ }^{* *}\right)$; dSTR, $P=0.11$ (ns).

To assess whether the observed increase in vSTR DAT binding sites in Rgs 12 $25-8 / \Delta 5-8$ mice was recapitulated in an independent mouse strain lacking RGS12 expression, we next performed [ $\left.{ }^{3} \mathrm{H}\right] \mathrm{WIN} 35428$ binding assays on crude membrane fractions from Crerecombinase dependent RGS12-null (Rgs12 ${ }^{\Delta 5-6 / \Delta 5-6)}$ mice (Figure $1 \mathrm{C}$ and Figure S1E; i.e., Rgs $12^{t / f t}$ mice expressing an ubiquitously-expressed, CMV-driven Cre transgene). We found that maximal DAT binding sites are also elevated in this $R g s 12^{\Delta 5-6 / \Delta 5-6}$ mouse strain relative to wild type (Rgs12++; CMV::Cre) littermate controls (Figure 5F). Data for $\left[{ }^{3} \mathrm{H}\right]$ WIN 35428 binding in Fig. $5 \mathrm{~F}$ are presented as the mean \pm SEM ( $n=6$ per group) and were analyzed by genotype using unpaired t-test: $\left.P<0.0001{ }^{(* \star *}\right)$. 


\section{5 - Discussion}

Our major finding from these analyses is that the loss of RGS12 engenders reduced acute responses (hyperlocomotion and c-Fos induction) in response to the psychoactive drugs AMPH or cocaine. This reduction is likely caused by increased dopamine uptake in the ventral striatum-in particular, the nucleus accumbens-due to elevated levels of surface-exposed (and, hence, functional) DAT. The presence of RGS12, in one (or more) brain region(s), must in some way negatively regulate DAT expression levels and/or activity, given that RGS12 loss has been observed in this study to increase DAT expression and activity, at least in the ventral striatum.

The expression pattern of Rgs12 mRNA compared with the distribution of RGS12 protein renders it tempting to speculate that RGS12 is being synthesized in the dopaminergic projections from the midbrain (i.e., the VTA and SNc; e.g., Figure 1D) and trafficked to striatal terminals (e.g., Figure 1F) Put another way, RGS12 appears to be a pre-synaptic protein in the striatum. Furthermore, the lack of genotype-dependent differences in locomotor responses to a post-synaptically active dopaminergic agonist (i.e., SKF 81927; Figure 2G) suggests RGS12 acts pre-synaptically. Biochemical data are also in line with this notion: the expression and function of DAT, a pre-synaptic protein (Torres and Amara, 2007), are both increased upon RGS12 loss (Figure 5). However, baseline dopamine levels in the ventral and dorsal striatum of wild type and RGS12-null mice are identical, as measured by HPLC with dual-cell electrochemical detection (Supplementary Figure S2). In addition, no changes were observed in the levels of tyrosine hydroxylase, the rate-limiting enzyme for dopamine synthesis (Daubner et al., 2011) (Supplementary Figure S2). Thus, the observed changes in DAT expression levels and function are likely a direct result of RGS12 loss, and not necessarily caused indirectly by a compensatory upregulation (Kimmel et al., 2001; Jakowec et al., 2004; Salvatore et al., 2016) in response to altered dopamine synthesis or basal levels upon RGS12 loss perse. 
Despite reduced locomotor responses to acute administration of AMPH and cocaine, RGS12-null mice developed locomotor sensitization and CPP to each drug in a manner similar to wild type mice. Although these latter behaviors are mediated by mesolimbic dopamine (Steketee and Kalivas, 2011; Henry et al., 1989; Baik, 2013), their expression is found to be dependent on neuroplastic changes (i.e., increased VTA excitability and firing rate) to postsynaptic NMDA glutamate and dopamine receptor signaling/expression levels, as well as to somatodendritic dopamine autoreceptors located on VTA neurons (Henry et al., 1989; White and Wang, 1984; Neisewander et al., 1998; Tanabe et al., 2004; Ramsey et al., 2008). These findings also support the notion that RGS12 is acting pre-synaptically and thus why only acute behavioral responses to AMPH and cocaine are affected.

Biochemical assays revealed no significant differences in DAT levels or activity in the dorsal striatum. Thus, the phenomenon of RGS12 regulation of DAT appears to be region specific; i.e., RGS12 affects DAT in the mesolimbic system (i.e., VTA to the nucleus accumbens -- a major effector of locomotor behavior). Notably, the levels of RGS12 are greater in the ventral striatum than in the dorsal striatum (Figure 1). One possible explanation for this enrichment could be a functional and/or physical interaction with pre-synaptic GPCR(s) in the ventral striatum that is not expressed or relevant in the dorsal striatum. For example, striatal DAT expression and function are potently regulated by two Goi-coupled GPCRs expressed on striatal presynaptic membranes: $\mathrm{D}_{2}$ dopamine receptors and -opioid receptors (KORs). Activation of these receptors serves as a negative feedback mechanism upon elevated striatal dopamine tone, thus augmenting dopamine uptake and increasing surface DAT expression (Bolan et al., 2007; Kivell et al., 2014) in a region-specific manner. Acute administration of KOR agonists increases dopamine uptake in ventral, but not dorsal, striatum (Thompson et al., 2000). Additionally, $D_{2}$ receptor agonists decrease DAT expression in the dorsal striatum, but increase DAT expression in the ventral striatum (Kimmel et al., 2001). Thus, removal of RGS12 as a negative regulator of G protein-mediated signaling downstream of either GPCR may feasibly lead to augmented pre-synaptic $D_{2}$ receptor and/or KOR-mediated signaling, resulting in elevated DAT surface expression and dopamine uptake. 
There are several possible mechanisms by which RGS12 could impact DAT trafficking and/or function, given the multiple protein-protein interaction domains present within RGS12 (Kimple et al., 2002; Snow et al., 1998; Willard et al., 2007). One simple explanation for involvement of RGS12 in curtailing DAT function evokes the C-terminal GoLoco motif of RGS12 -- a guanine nucleotide dissociation inhibitor (GDI) activity that results in the sequestration of inactive $\mathrm{G} \alpha$ subunits (Kimple et al., 2002), which normally re-associate with $\mathrm{G} \beta \gamma$ subunits. This re-association blocks any signaling that is mediated by $G \beta \gamma$. Thus, by sequestering inactive Go subunits, the GoLoco motif of RGS12 may extend the lifetime of free $G \beta \gamma$ subunits, which are known to, among other things, inhibit DAT activity (Garcia-Olivares et al., 2013).

Another plausible explanation for RGS12 affecting DAT function in the ventral striatum lies in the ability of RGS12 to interact with components of the MAPK/MEK/ERK cascade, the activity of which supports DAT trafficking to the cell surface (Moron et al., 2003; Willard et al., 2007). We speculate that RGS12, as a MAPK/MEK/ERK scaffold, diverts this signaling cascade from facilitating the trafficking of DAT to the synaptic plasma membrane in the ventral striatum. Another possibility that cannot be excluded is that RGS12, through its established interactions with Ras, Raf, MEK, and/or other as-yet unidentified proteins, regulates transcription factors that negatively modulate the transcription of DAT. To explore this possibility, we performed immunoblot analyses on whole lysates of ventral striatum using a validated DAT antibody (Garcia-Olivares et al., 2013; Chen et al., 2006; Foster et al., 2012; Steinkellner et al., 2012); total DAT levels were seen to be comparable in wild type and RGS12-null ventral striatum (Supplemental Figure S2), arguing against any transcriptional effect (e.g., in VTA-to-NAc projection neurons). Thus, we are currently assessing whether RGS12 regulates the trafficking of DAT to the synaptic membrane in the ventral striatum.

There is a clear dose dependence to the differences seen in acute responses to AMPH and cocaine between RGS12-null and wild type mice (Figure 2). We suspect that this is due to a saturation of DAT by the uptake inhibitors AMPH and cocaine at higher 
concentrations. We propose that, at lower doses of DAT inhibitor ( 1 and $3 \mathrm{mg} / \mathrm{kg} \mathrm{AMPH}$; $10 \mathrm{mg} / \mathrm{kg}$ cocaine), the excess DAT that is expressed in RGS12-null ventral striatum is available to clear more synaptic dopamine, reducing the acute locomotor responses of RGS12-null mice vs those of wild type mice. However, at higher doses of DAT inhibitor (5 mg/kg AMPH; $20 \mathrm{mg} / \mathrm{kg}$ and $40 \mathrm{mg} / \mathrm{kg}$ cocaine), even the extra DAT expressed in RGS12-null mice becomes saturated by drug, so all DAT molecules in the ventral striatum of both genotypes are blocked, thereby eliminating any difference in acute locomotor responses between RGS12-null and wild type mice.

This hypothesis of extra, unsaturated DAT in RGS12-null mice would suggest that DAT levels would become saturated at lower doses in wild type mice. Yet, in both genotypes, locomotor response is seen to increase with $20 \mathrm{mg} / \mathrm{kg}$ cocaine over that of 10 $\mathrm{mg} / \mathrm{kg}$, and again with $40 \mathrm{mg} / \mathrm{kg}$ cocaine over that of $20 \mathrm{mg} / \mathrm{kg}$ (Figure 2F). Therefore, an additional possibility is that RGS12 loss affects the regulation of autoreceptors on DATpositive terminals, thereby lowering the threshold for pre-synaptic feedback by synaptic dopamine and resulting in curtailed DA release at low drug concentrations. On the other hand, it has been reported that $20 \mathrm{mg} / \mathrm{kg}$ cocaine increases locomotor response even in mice lacking vesicular monoamine transporter 2 (VMAT2), critical for dopamine transport into synaptic vesicular stores (Wang et al., 1997). Thus, another possibility to consider is a role for RGS12 in VMAT2 function affecting DA release - a role absent in RGS12-null mice but dependent on DAT inhibitor dose for full elaboration and observation in behavioral outcomes.

It is also notable that AMPH acts not only as an antagonist of DAT, but also as a releaser of dopamine. This dual effect explains the increased locomotor activity elicited by AMPH compared with cocaine, which is solely a DAT antagonist (Figure 2D vs 2F, note the difference in y-axis scales). We propose that, at higher doses of AMPH (5 mg/kg), due to saturation of DAT, the maximum quantity possible of dopamine is released (i.e., at $5 \mathrm{mg} / \mathrm{kg}$, dopamine is completely depleted from the pre-synaptic terminals of both wild type and RGS12-null mice), potentially explaining why there is no difference between the 
genotypes. Moreover, in ventral striatal synaptosomal preparations, the ability of AMPH to enhance the release of $\left[{ }^{3} \mathrm{H}\right]$ dopamine is not markedly different between wild type and RGS12-null mice (Supplemental Figure S3). This latter observation suggest that RGS12 somehow modulates the uptake functionality - but not the release functionality - of DAT. Molecular studies to address this issue are currently underway.

In summary, our studies have uncovered a novel regulator of ventral striatal DAT expression and activity: namely, RGS12. The neuroanatomical site(s) of RGS12 action and the mechanism(s) by which it regulates ventral striatal DAT expression and function remain to be identified. However, the observed functional interaction between RGS12 and DAT clearly impacts acute mesolimbic-dependent responses to dopaminergic psychostimulants. Future work is required to establish the molecular determinants within both proteins that underlie this regulation, be it direct (e.g., via possible RGS12/DAT interactions) or indirect via the presynaptic regulation of $G$ protein subunits or other intermediates.

\section{Acknowledgments}

Funding for these studies was supported in part by the WVU E.J. Van Liere Medicine Professorship (to D.P.S.). J.D.G. acknowledges early predoctoral support from the WVU Behavioral \& Biomedical Sciences T32 training grant (NIH 5T32GM081741) and current support from a NIDA predoctoral fellowship (NIH 1F31DA043331). The monoclonal antibody UNC60-80.4.1, originally developed by D.P.S., was re-obtained from the Developmental Studies Hybridoma Bank, created by the $\mathrm{NICHD}$ of the $\mathrm{NIH}$ and maintained at The University of lowa, Department of Biology, lowa City, IA 52242. 


\section{6 - Figures}

2.6.1 - Targeting sites for Rgs12 gene locus deletion and expression patterns of Rgs 12 mRNA and protein in the adult mouse brain.
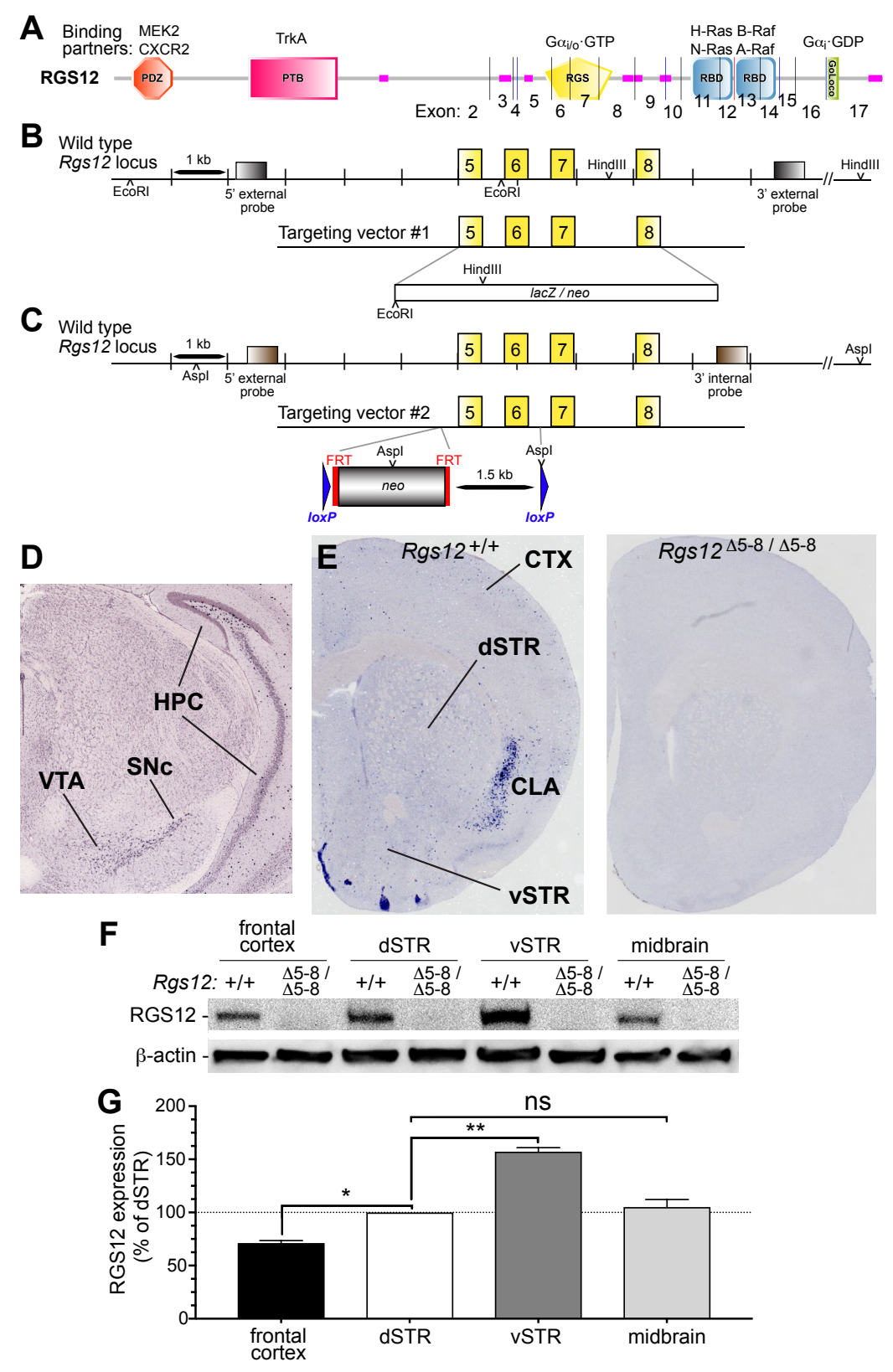

Figure 1. Independent targeting of two separate ablations to the mouse Rgs12 locus.

(A) Multiple, protein-protein interaction domain architecture of the encoded RGS12 protein, including a PSD-95/Dlg/ZO-1 (PDZ; orange) domain capable of binding the 
C-termini of the MAPK middle-tier kinase MEK2 and the interleukin-8 receptor CXCR2 (Willard et al., 2007; Snow et al., 1998), a phosphotyrosine-binding (PTB; pink) domain thought to bind the NGF receptor TrkA (Willard et al., 2007), an RGS domain (yellow) which binds and inactivates heterotrimeric $\mathrm{G}$ protein $\mathrm{G} \alpha$ subunits of the Gi/o subfamily (Snow et al., 1998), a tandem repeat of Ras-binding domains (RBDs; cyan) that bind indicated members of the Ras GTPase and MAPK first-tier (Raf) kinases (ref. (Willard et al., 2007)), a GoLoco motif which binds inactive $\mathrm{G} \alpha$ subunits of the Gi subfamily (ref. (Kimple et al., 2002)), and regions of predicted low complexity (rose). Vertical lines indicate exon-exon junctions within the open-reading frame encoded by the Rgs12 mRNA. (B) Mice lacking functional RGS12 (Rgs12 $\left.2^{45-8 / 45-8}\right)$ were obtained from the Texas A\&M Institute of Genomic Medicine (TIGM) in a 129/Sv x C57BL/6 mixed background. Because congenic C57BL/6 mice are standard for neuropsychopharmacological behavioral assays, we back-crossed the TIGM Rgs12 $15-8 / 45-8$ mice with C57BL/6J mice for more than ten generations. Henceforth, $R g s 12^{45-8 / 45-8}$ mice will refer to congenic $R g s 12^{45-8 / 45-8}$ mice on the C57BL/6J background. Exons 5-8, encoding the entire polypeptide sequence of the RGS domain of RGS12 (yellow; panel A), were targeted for replacement with a neomycin resistance, drug-selectable marker. $(D)$ Coronal in situ hybridization (Allen Brain Atlas) reveals marked Rgs12 mRNA labeling in the ventral tegmental area (VTA) and substantia nigra pars compacta (SNc), beds of the mesolimbic and nigrostriatal dopaminergic soma. Analyses also reveal hippocampal (HPC) Rgs12 mRNA, particularly in the dentate gyrus. (E) Coronal in situ hybridization from our group shows sparse Rgs12 mRNA in dorsal (dSTR) and ventral (vSTR) striatum and cortex (CTX). Marked labeling was observed in 
the claustrum (CLA). ( $F$ ) Immunoblotting for RGS12 protein levels in microdissected frontal cortex, dorsal striatum (dSTR), ventral striatum (vSTR), and midbrain in WT and RGS12-null mice. $\beta$-actin immunoreactivity served as a loading control. (G) Densitometric analysis demonstrates that RGS12 in vSTR is higher than frontal cortex, dSTR, and midbrain and, specifically is $157 \%$ more abundant than in dSTR. Data are the mean \pm SEM ( $n=6$ mice per group) relative to dSTR set to $100 \%$. One-way ANOVA with Tukey's multiple comparisons: dSTR vs frontal cortex $P=0.018\left({ }^{*}, P<0.05\right)$, dSTR vs vSTR $P=$ $0.0014\left({ }^{* *}, P<0.01\right.$ ), dSTR vs midbrain $P=0.724$ (not significant [ns], $P>0.05$ ). 
2.6.2 - RGS12-null mice exhibit reduced hyperlocomotor responses to the presynaptically-acting psychostimulants d-amphetamine (AMPH) and cocaine.
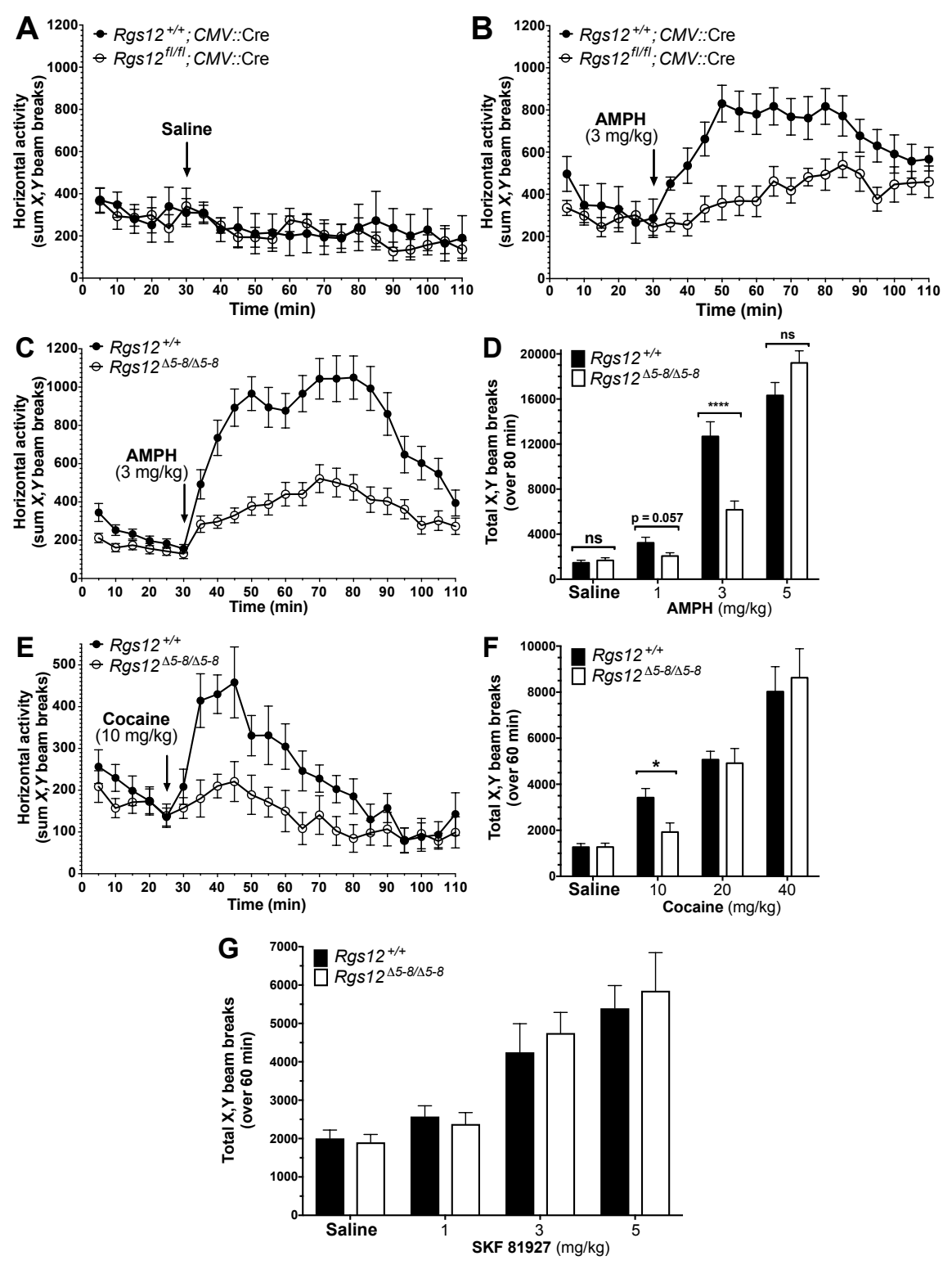

Figure 2. Acute psychostimulant-induced locomotion in Rgs12-null mice. $(A)$ Locomotor activity in $R g s 12^{\Delta 5-6 / \Delta 5-6}$ mice (i.e., conditional $R g s 12^{f / / f l}$ mice cross-bred with an ubiquitous $C M V:$ :Cre transgene) following 30 min acclimation to activity chambers and then saline (at a final volume of $10 \mathrm{~mL} / \mathrm{kg})$ administration. Data are the mean \pm SEM $(n=7-8$ per 
group). (B) AMPH (3 mg/kg)-induced hyperlocomotion in $R g s 12^{45-6 / 45-6}$ mice for 80 min following 30 min acclimation to activity chambers. Data are the mean \pm SEM $(n=7-8$ per group). (C) AMPH (3 mg/kg)-induced hyperlocomotion in constitutive $R g s 12^{45-8 / 45-8}$ mice for 80 min following 30 min acclimation to activity chambers. Data are the mean \pm SEM ( $n=9-23$ per group). (D) Cocaine (10 mg/kg)-induced hyperlocomotion in constitutive Rgs $12^{45-8 / 45-8}$ mice for 60 min following 30 min acclimation to activity chambers. Data are the mean \pm SEM ( $n=9-10$ per group). ( $E$ ) Total locomotion by constitutive $R g s 12^{45-8 / 45-}$ ${ }^{8}$ mice over 80 min following ip injection of saline or various doses of AMPH after 30 min acclimation to activity chambers. Data are the mean \pm SEM $(n=8-23$ per group). ( $F)$ Total locomotion by constitutive Rgs $12^{45-8 / 45-8}$ mice over 60 min following ip injection of saline or various doses of cocaine after 30 min acclimation to activity chambers. Data are the mean \pm SEM ( $n=7-20$ per group). (G) Total locomotion by constitutive $R g s 12^{\Delta 5-8 / 45-8}$ mice over 60 min following ip injection of saline or indicated doses of SKF 81927 after 30 min acclimation to activity chambers. Data are the mean \pm SEM ( $n=8$ per group). 


\subsection{3 - RGS12-null mice display normal locomotor sensitization and conditioned place preference to AMPH and cocaine.}
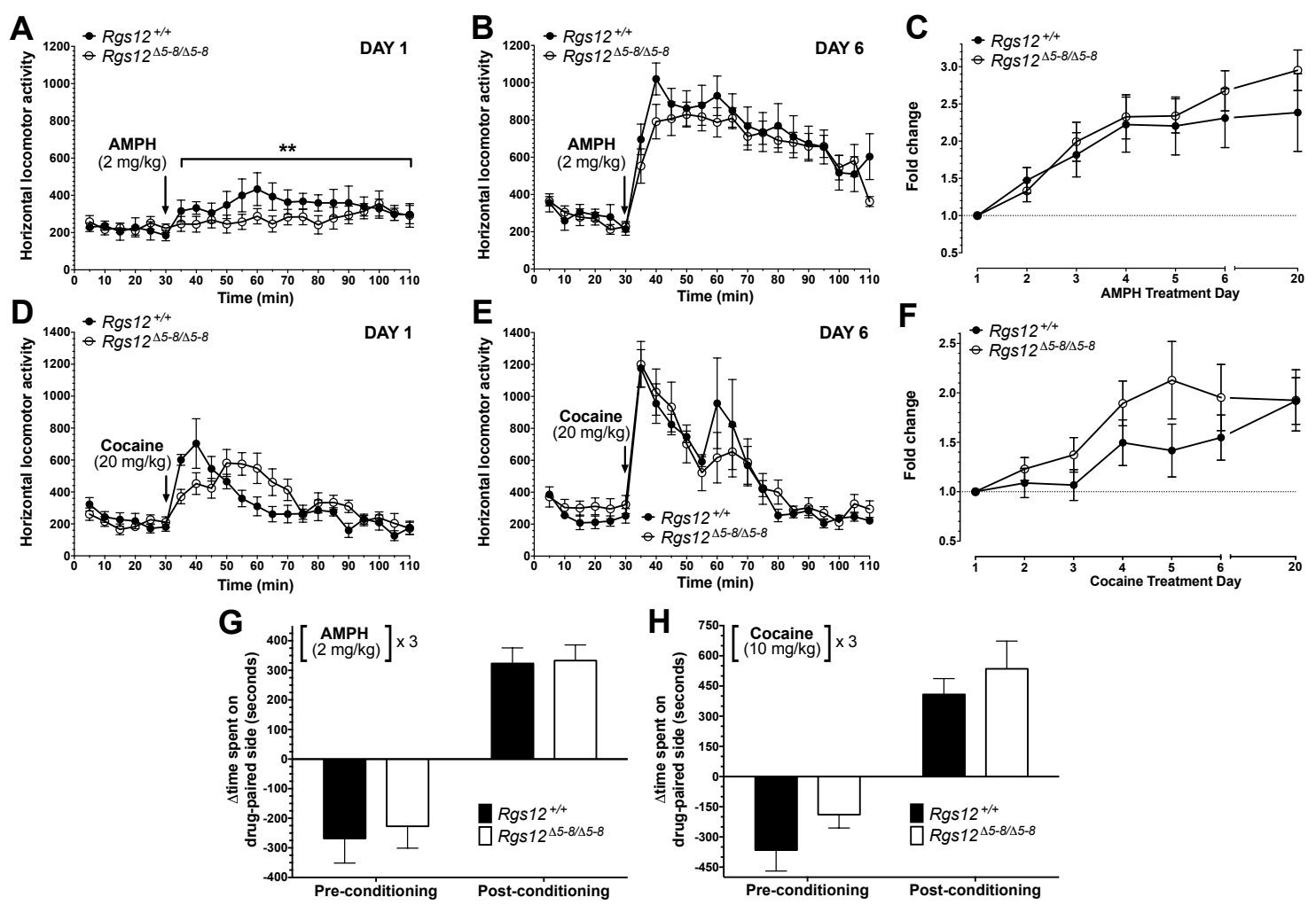

Figure 3. Psychostimulant-induced locomotor sensitization and conditioned place preference in RGS12-null mice. Total locomotion over 80 min following AMPH (2 mg/kg; $A-B)$ or $60 \mathrm{~min}$ following cocaine $(20 \mathrm{mg} / \mathrm{kg} ; D-E)$. Total locomotion normalized to day 1 total locomotion plotted as fold change across drug treatment days $(C, F)$. Data are the mean \pm SEM ( $n=6-9$ per group). Psychostimulant-induced conditioned place preference in Rgs12-null mice. Data shown are the difference in the time spent between AMPH (2 $\mathrm{mg} / \mathrm{kg}$ ) (panel G)- or cocaine (10 mg/kg) (panel H)-paired and saline-paired chamber for pre-conditioning (day 2) and post-conditioning (day 9). Data are the mean \pm SEM $(n=7$ 8 per group). 
2.6.4 - AMPH-induced c-Fos immunoreactivity is reduced in the nucleus accumbens (NAc), but not dorsal striatum (dSTR), of RGS12-null mice.
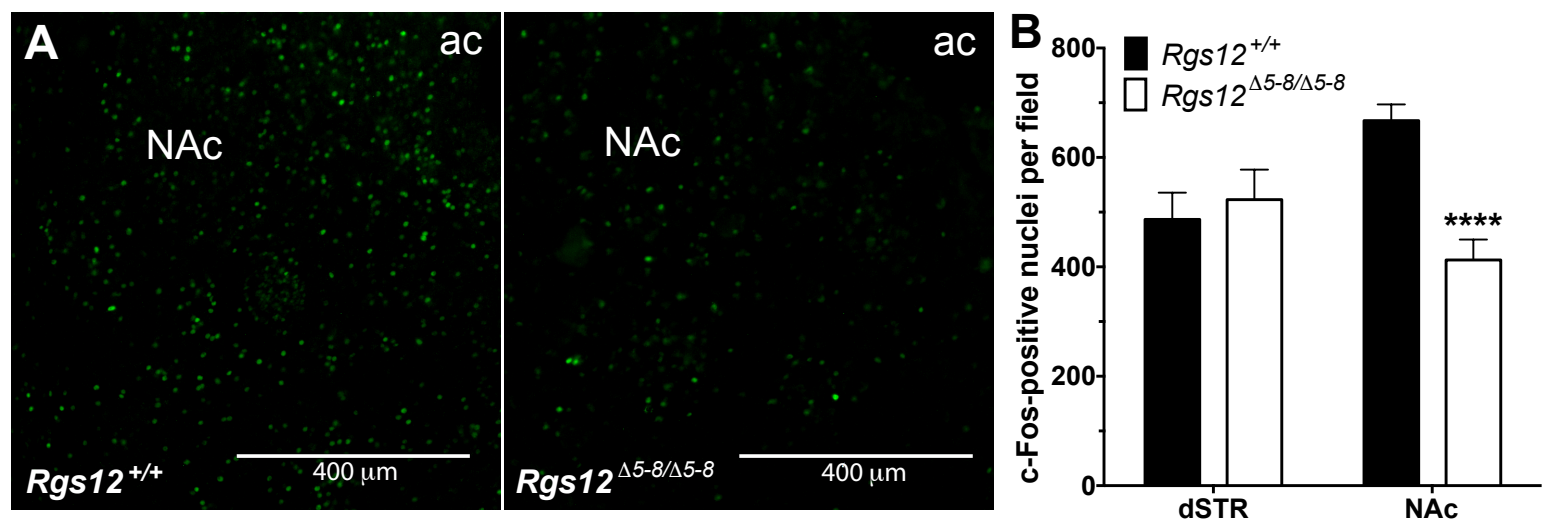

Figure 4. AMPH-stimulated c-Fos induction in RGS12-null mice. (A) Immunohistochemical analysis of c-Fos in the NAc of RGS12-null and WT mice injected with AMPH (3 mg/kg). (B) Quantification of the number of c-Fos-positive neurons per field in RGS12-null vs wild type dSTR and vSTR (3-4 matched sections per genotype). Data are the mean \pm SEM. ( $n=3-4$ mice per group). 


\subsection{5 - The number of DAT binding sites and $\left[{ }^{3} \mathrm{H}\right]$ dopamine (DA) uptake are} increased in the ventral (vSTR), but not dorsal (dSTR), striatum of RGS12-null mice.
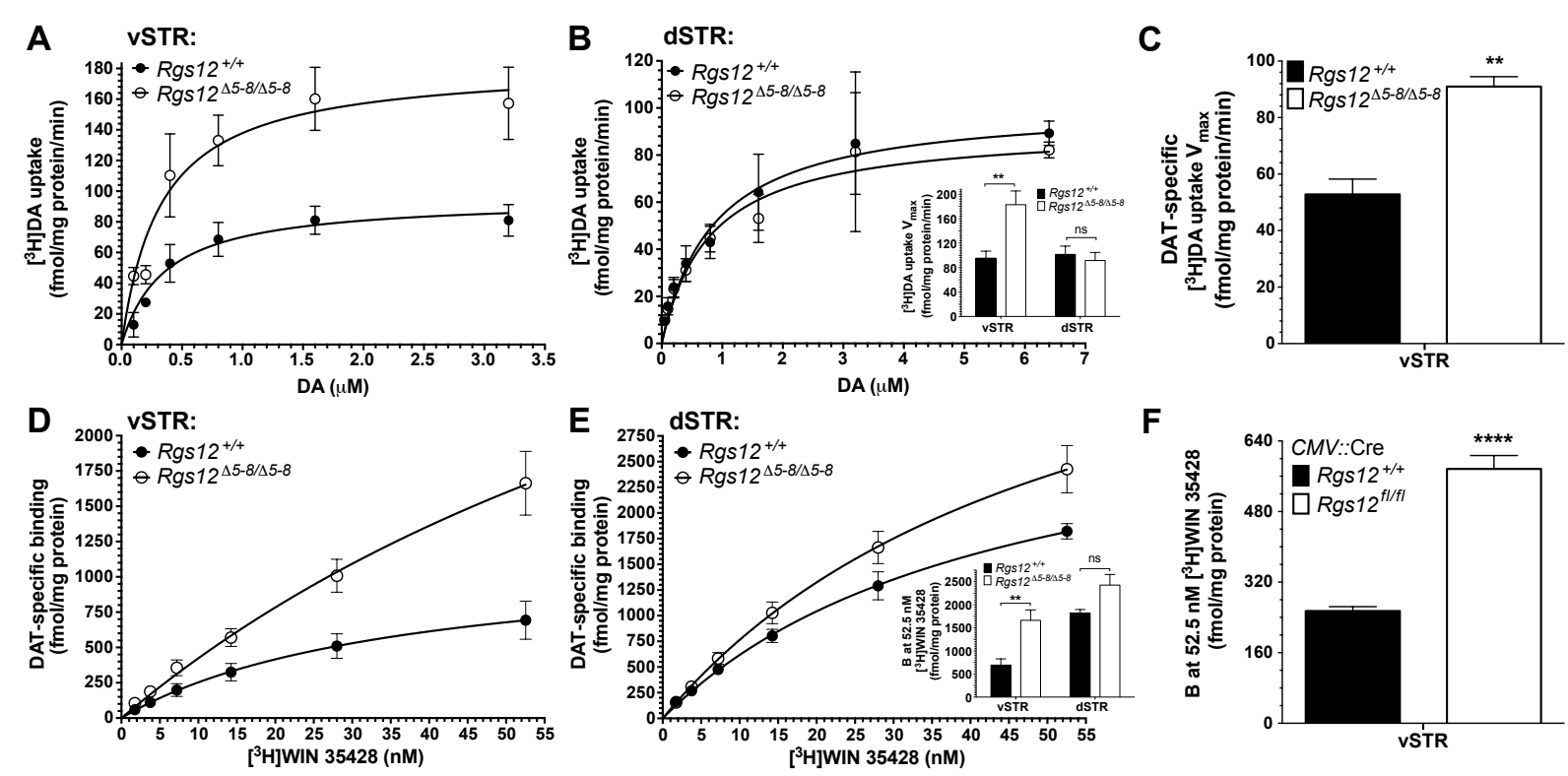

Figure 5. Analysis of DAT function and expression in RGS12-null mice. $\left[{ }^{3} \mathrm{H}\right]$ Dopamine uptake in ventral $(A)$ and dorsal $(B)$ striatal synaptosomes prepared from RGS12-null and wild type mice. $(B$, inset $)$ Uptake rates $\left(V_{\max }\right)$ of $\left[{ }^{3} \mathrm{H}\right]$ dopamine in ventral and dorsal striatal synaptosomes derived from data in panels $A$ and $B$; non-specific uptake determined in the presence of $10 \mu \mathrm{M}$ cocaine. Data are the mean \pm SEM ( $n=9-12$ per group). $(C)$ Uptake rates $\left(V_{\max }\right)$ by DAT of $\left[{ }^{3} \mathrm{H}\right]$ dopamine in ventral striatal synaptosomes derived from data in Supplementary Figure S4; non-specific uptake determined in the presence of 10 $\mu \mathrm{M}$ GBR12935 (a selective dopamine reuptake inhibitor). Data are the mean \pm SEM $(n=$ 6 per group). (D, E) Levels of DAT determined from $\left[{ }^{3} \mathrm{H}\right] \mathrm{WIN} 35428$ saturation binding analysis of ventral $(D)$ and dorsal $(E)$ striatal crude membrane fractions. Non-specific binding was determined in the presence of $10 \mu \mathrm{M}$ GBR12935. ( $E$, inset) Maximal DAT binding sites at $52.5 \mathrm{nM}\left[{ }^{3} \mathrm{H}\right] \mathrm{WIN} 35428$ in ventral and dorsal striatal membranes derived 
from data in $D$ and $E$. Data are the mean \pm SEM ( $n=6-9$ per group). $(F)$ Maximal DAT binding sites at $52.5 \mathrm{nM}\left[{ }^{3} \mathrm{H}\right] \mathrm{WIN} 35428$ in ventral striatal membranes derived from data in Supplementary Figure S4. Data are the mean \pm SEM ( $n=6$ per group). 


\section{7 - References}

Adinoff B. (2004) Neurobiologic processes in drug reward and addiction. Harv Rev Psychiatry 12: 305-320.

Baik JH. (2013) Dopamine signaling in reward-related behaviors. Front Neural Circuits 7: 152.

Berg P and Olsson U. (2004) Intra-articular injection of non-animal stabilised hyaluronic acid (NASHA) for osteoarthritis of the hip: a pilot study. Clin Exp Rheumatol 22: 300-306.

Berman DM, Wilkie TM and Gilman AG. (1996) GAIP and RGS4 are GTPase-activating proteins for the Gi subfamily of $\mathrm{G}$ protein alpha subunits. Cell 86: 445-452.

Bolan EA, Kivell B, Jaligam V, et al. (2007) D2 receptors regulate dopamine transporter function via an extracellular signal-regulated kinases 1 and 2-dependent and phosphoinositide 3 kinase-independent mechanism. Mol Pharmacol 71: 1222-1232.

Carr GD and White NM. (1987) Effects of systemic and intracranial amphetamine injections on behavior in the open field: a detailed analysis. Pharmacol Biochem Behav 27: 113-122.

Chen R, Tilley MR, Wei $\mathrm{H}$, et al. (2006) Abolished cocaine reward in mice with a cocaineinsensitive dopamine transporter. Proc Natl Acad Sci U S A 103: 9333-9338.

Ciccarone D. (2011) Stimulant abuse: pharmacology, cocaine, methamphetamine, treatment, attempts at pharmacotherapy. Prim Care 38: 41-58, v-vi.

Clark MJ and Traynor JR. (2004) Assays for G-protein-coupled receptor signaling using RGSinsensitive Galpha subunits. Methods Enzymol 389: 155-169.

Daubner SC, Le T and Wang S. (2011) Tyrosine hydroxylase and regulation of dopamine synthesis. Arch Biochem Biophys 508: 1-12.

Delfs JM, Schreiber L and Kelley AE. (1990) Microinjection of cocaine into the nucleus accumbens elicits locomotor activation in the rat. J Neurosci 10: 303-310.

Desai RI, Terry P and Katz JL. (2005) A comparison of the locomotor stimulant effects of D1-like receptor agonists in mice. Pharmacol Biochem Behav 81: 843-848.

Eisener-Dorman AF, Grabowski-Boase L and Tarantino LM. (2011) Cocaine locomotor activation, sensitization and place preference in six inbred strains of mice. Behav Brain Funct 7: 29.

Elliot EE. (2002) Cocaine sensitization in the mouse using a cumulative dosing regime. Behav Pharmacol 13: 407-415.

Federici M, Latagliata EC, Ledonne A, et al. (2014) Paradoxical abatement of striatal dopaminergic transmission by cocaine and methylphenidate. J Biol Chem 289: 264-274.

Foster JD, Yang JW, Moritz AE, et al. (2012) Dopamine transporter phosphorylation site threonine 53 regulates substrate reuptake and amphetamine-stimulated efflux. J Biol Chem 287: $29702-29712$.

Garcia-Olivares J, Torres-Salazar D, Owens WA, et al. (2013) Inhibition of dopamine transporter activity by $G$ protein $\beta \gamma$ subunits. PLOS One 8: e59788.

Giros B, Jaber M, Jones SR, et al. (1996) Hyperlocomotion and indifference to cocaine and amphetamine in mice lacking the dopamine transporter. Nature 379: 606-612.

Gold SJ, Ni YG, Dohlman HG, et al. (1997) Regulators of G-protein signaling (RGS) proteins: regionspecific expression of nine subtypes in rat brain. J Neurosci 17: 8024-8037.

Heal DJ, Smith SL, Gosden J, et al. (2013) Amphetamine, past and present--a pharmacological and clinical perspective. J Psychopharmacol 27: 479-496. 
Henry DJ, Greene MA and White FJ. (1989) Electrophysiological effects of cocaine in the mesoaccumbens dopamine system: repeated administration. J Pharmacol Exp Ther 251: 833-839.

Ikemoto S. (2002) Ventral striatal anatomy of locomotor activity induced by cocaine, Damphetamine, dopamine and D1/D2 agonists. Neuroscience 113: 939-955.

Jakowec MW, Nixon K, Hogg E, et al. (2004) Tyrosine hydroxylase and dopamine transporter expression following 1-methyl-4-phenyl-1,2,3,6-tetrahydropyridine-induced neurodegeneration of the mouse nigrostriatal pathway. J Neurosci Res 76: 539-550.

Jung ES, Lee HJ, Sim HR, et al. (2013) Cocaine-induced behavioral sensitization in mice: effects of microinjection of dopamine $\mathrm{d} 2$ receptor antagonist into the nucleus accumbens. Exp Neurobiol 22: 224-231.

Kauer JA and Malenka RC. (2007) Synaptic plasticity and addiction. Nat Rev Neurosci 8: 844-858.

Kelley AE, Gauthier AM and Lang CG. (1989) Amphetamine microinjections into distinct striatal subregions cause dissociable effects on motor and ingestive behavior. Behav Brain Res 35: 27-39.

Kelly PH and Iversen SD. (1976) Selective 6OHDA-induced destruction of mesolimbic dopamine neurons: abolition of psychostimulant-induced locomotor activity in rats. Eur J Pharmacol 40: 45-56.

Kimmel HL, Joyce AR, Carroll Fl, et al. (2001) Dopamine D1 and D2 receptors influence dopamine transporter synthesis and degradation in the rat. J Pharmacol Exp Ther 298: 129-140.

Kimple AJ, Bosch DE, Giguère PM, et al. (2011) Regulators of G-protein signaling and their G $\alpha$ substrates: promises and challenges in their use as drug discovery targets. Pharmacol Rev 63: 728-749.

Kimple RJ, Kimple ME, Betts L, et al. (2002) Structural determinants for GoLoco-induced inhibition of nucleotide release by Galpha subunits. Nature 416: 878-881.

Kivell B, Uzelac Z, Sundaramurthy S, et al. (2014) Salvinorin A regulates dopamine transporter function via a kappa opioid receptor and ERK1/2-dependent mechanism. Neuropharmacology 86: 228-240.

Lee SE, Simons SB, Heldt SA, et al. (2010) RGS14 is a natural suppressor of both synaptic plasticity in CA2 neurons and hippocampal-based learning and memory. Proc Natl Acad Sci U S A 107: 16994-16998.

Medvedev IO, Ramsey AJ, Masoud ST, et al. (2013) D1 dopamine receptor coupling to PLCbeta regulates forward locomotion in mice. $J$ Neurosci 33: 18125-18133.

Moron JA, Zakharova I, Ferrer JV, et al. (2003) Mitogen-activated protein kinase regulates dopamine transporter surface expression and dopamine transport capacity. J Neurosci 23: 8480-8488.

Neisewander JL, Fuchs RA, O'Dell LE, et al. (1998) Effects of SCH-23390 on dopamine D1 receptor occupancy and locomotion produced by intraaccumbens cocaine infusion. Synapse 30: 194-204.

Nestler EJ. (2005) The neurobiology of cocaine addiction. Sci Pract Perspect 3: 4-10.

Neubig RR and Siderovski DP. (2002) Regulators of G-protein signalling as new central nervous system drug targets. Nat Rev Drug Discov 1: 187-197.

Nutt DJ, Lingford-Hughes A, Erritzoe D, et al. (2015) The dopamine theory of addiction: 40 years of highs and lows. Nat Rev Neurosci 16: 305-312. 
Quality. CfBHSa. (2015) Behavioral Health Trend in the United States: Results from the 2014 National Survey on Drug Use and Health. In: SAMHSA (ed) HHS Publication No. SMA 154927 ed.: SAMHSA, U.S. Department of Health and Human Services (HHS).

Ramsey AJ, Laakso A, Cyr M, et al. (2008) Genetic NMDA receptor deficiency disrupts acute and chronic effects of cocaine but not amphetamine. Neuropsychopharmacology 33: 27012714.

Reith ME, Wiener HL and Fischette CT. (1991) Sertraline and cocaine-induced locomotion in mice. I. Acute studies. Psychopharmacology (Berl) 103: 297-305.

Rothman RB. (1990) High affinity dopamine reuptake inhibitors as potential cocaine antagonists: a strategy for drug development. Life Sci 46: PL17-21.

Salahpour A, Ramsey AJ, Medvedev IO, et al. (2008) Increased amphetamine-induced hyperactivity and reward in mice overexpressing the dopamine transporter. Proc Natl Acad Sci U S A 105: 4405-4410.

Salvatore MF, Calipari ES and Jones SR. (2016) Regulation of Tyrosine Hydroxylase Expression and Phosphorylation in Dopamine Transporter-Deficient Mice. ACS Chem Neurosci 7: 941-951.

Schultz W. (2002) Getting formal with dopamine and reward. Neuron 36: 241-263.

Scott L, Forssberg H, Aperia A, et al. (2005) Locomotor effects of a D1R agonist are DARPP-32 dependent in adult but not weanling mice. Pediatr Res 58: 779-783.

Sitte $\mathrm{HH}$ and Freissmuth $\mathrm{M}$. (2010) The reverse operation of $\mathrm{Na}(+) / \mathrm{Cl}(-)$-coupled neurotransmitter transporters--why amphetamines take two to tango. J Neurochem 112: 340-355.

Snow BE, Antonio L, Suggs S, et al. (1997) Molecular cloning and expression analysis of rat Rgs12 and Rgs14. Biochem Biophys Res Commun 233: 770-777.

Snow BE, Hall RA, Krumins AM, et al. (1998) GTPase activating specificity of RGS12 and binding specificity of an alternatively spliced PDZ (PSD-95/Dlg/ZO-1) domain. J Biol Chem 273: 17749-17755.

Staton DM and Solomon PR. (1984) Microinjections of d-amphetamine into the nucleus accumbens and caudate-putamen differentially affect stereotypy and locomotion in the rat. Physiol. Psycol. 12: 159-162.

Steinkellner T, Mus L, Eisenrauch B, et al. (2014) In vivo amphetamine action is contingent on alphaCaMKII. Neuropsychopharmacology 39: 2681-2693.

Steinkellner T, Yang JW, Montgomery TR, et al. (2012) Ca(2+)/calmodulin-dependent protein kinase II $\alpha$ ( $\alpha \mathrm{CaMKII})$ controls the activity of the dopamine transporter: implications for Angelman syndrome. J Biol Chem 287: 29627-29635.

Steketee JD and Kalivas PW. (2011) Drug wanting: behavioral sensitization and relapse to drugseeking behavior. Pharmacol Rev 63: 348-365.

Sulzer D. (2011) How addictive drugs disrupt presynaptic dopamine neurotransmission. Neuron 69: 628-649.

Tanabe LM, Suto N, Creekmore E, et al. (2004) Blockade of D2 dopamine receptors in the VTA induces a long-lasting enhancement of the locomotor activating effects of amphetamine. Behav Pharmacol 15: 387-395.

Thomas MJ, Kalivas PW and Shaham Y. (2008) Neuroplasticity in the mesolimbic dopamine system and cocaine addiction. Br J Pharmacol 154: 327-342. 
Thompson AC, Zapata A, Justice JB, Jr., et al. (2000) Kappa-opioid receptor activation modifies dopamine uptake in the nucleus accumbens and opposes the effects of cocaine. $J$ Neurosci 20: 9333-9340.

Torres GE. (2006) The dopamine transporter proteome. J Neurochem 97 Suppl 1: 3-10.

Torres GE and Amara SG. (2007) Glutamate and monoamine transporters: new visions of form and function. Curr Opin Neurobiol 17: 304-312.

Tzschentke TM. (2007) Measuring reward with the conditioned place preference (CPP) paradigm: update of the last decade. Addict Biol 12: 227-462.

Wang YM, Gainetdinov RR, Fumagalli F, et al. (1997) Knockout of the vesicular monoamine transporter 2 gene results in neonatal death and supersensitivity to cocaine and amphetamine. Neuron 19: 1285-1296.

Weed MR, Vanover KE and Woolverton WL. (1993) Reinforcing effect of the D1 dopamine agonist SKF 81297 in rhesus monkeys. Psychopharmacology (Berl) 113: 51-52.

White FJ and Wang RY. (1984) Electrophysiological evidence for A10 dopamine autoreceptor subsensitivity following chronic D-amphetamine treatment. Brain Res 309: 283-292.

Willard MD, Willard FS, Li X, et al. (2007) Selective role for RGS12 as a Ras/Raf/MEK scaffold in nerve growth factor-mediated differentiation. EMBO J 26: 2029-2040.

Zhou H, Chisari M, Raehal KM, et al. (2012) GIRK channel modulation by assembly with allosterically regulated RGS proteins. Proc Natl Acad Sci U S A 109: 19977-19982. 


\section{8 - Supplementary Information}

\subsection{1 - Supplementary Figures}

\subsection{1a - Validation of two independent RGS12-null mouse strains.}
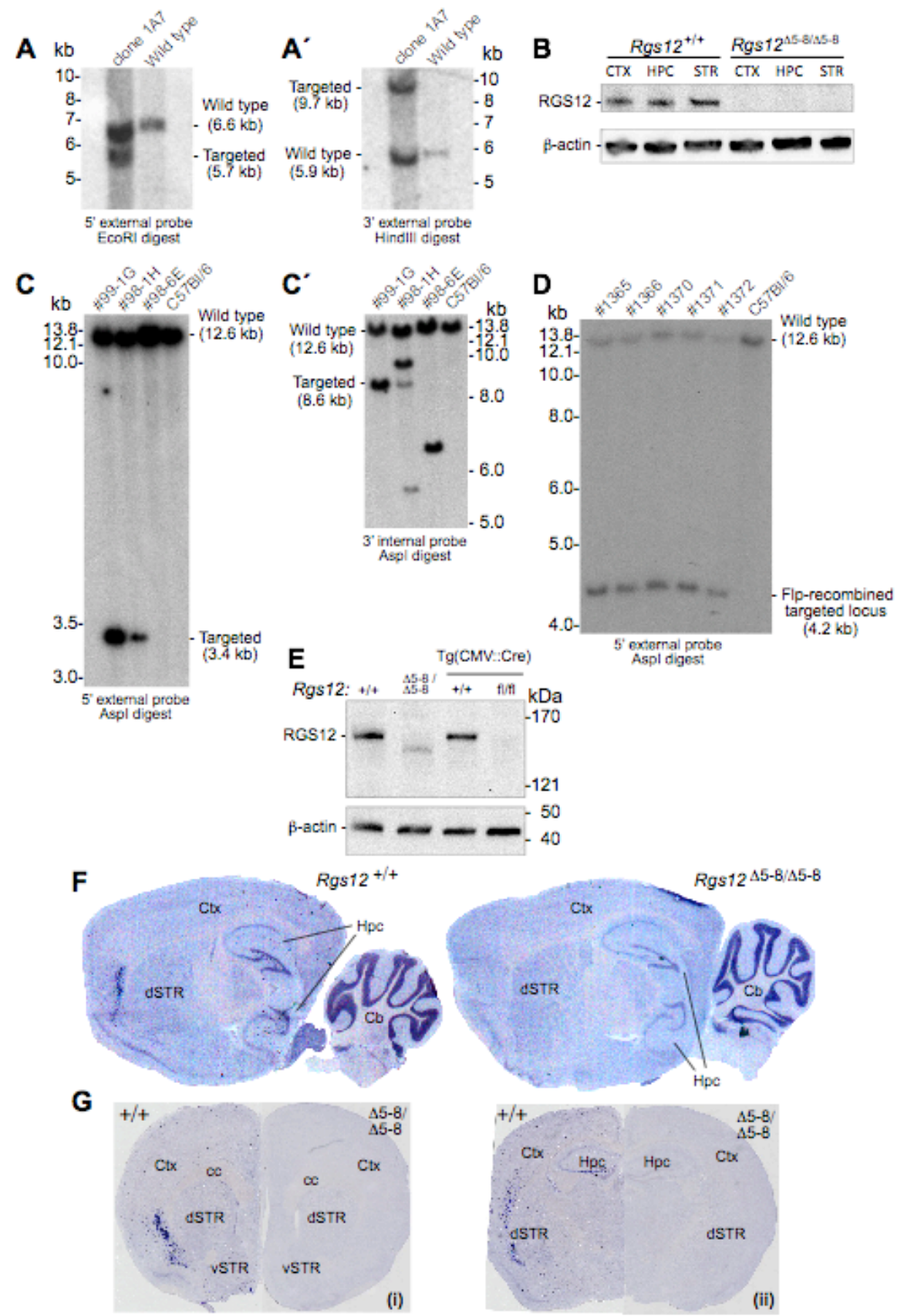

(i)

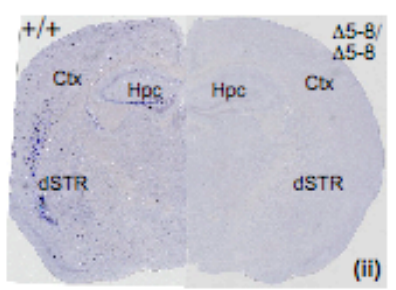

Supplementary Figure S1. Validation of the independent targeting of two separate ablations to the mouse Rgs12 locus. ( $A, A)$ Southern blot analyses using 5' and 3' 
external probes that flank the Rgs12 gene region targeted for homologous recombination (see Figure 1B), indicating that embryonic stem cell clone $1 \mathrm{~A} 7$ harbors the predicted homologous recombination event. (B) Immunoblotting for RGS12 and $\beta$-actin expression within lysates of brain cortex (CTX), hippocampus (HPC), and striatum (STR) from wild type $(+/+)$ and RGS12-null (Rgs12 $15-8 / 45-8)$ mice, indicating the loss of RGS12 expression in the latter mouse strain. (C) Mice engineered to harbor a loxP-and FRT-site flanked Rgs12 gene were obtained from genOway (France) in the C57BI/6 background. Exons 5-6, encoding the initial third of the RGS domain of RGS12 (see Figure 1A), were targeted for replacement with a FRT-flanked neomycin resistance, drugselectable marker and flanking loxP recombination sites. $(C, C)$ Southern blot analyses using 5' external (panel C) and 3' internal (panel C') probes that flank the Rgs12 gene region targeted for homologous recombination (see Figure 1C), indicating that embryonic stem cell clone \#99-1G harbors the predicted homologous recombination event. $(D)$ Southern blot analysis using 5' external probe to verify that mice \#1365, \#1366, \#1370, \#1371, and \#1372, derived from breeding germ-line transmitted mice from clone \#99-1G with an ubiquitous Flp recombinase-expressing driver strain, have the correct $R g s 12$ gene locus $\left(R g s 12^{f}\right)$ lacking the FRT-site flanked neo cassette but retaining the loxP sites flanking exons 5 and 6. (E) Immunoblotting for RGS12 and $\beta$-actin expression within whole brain lysates of wild type mice $(+/+)$, RGS12-null (Rgs12 $15-8 / 45-8)$ mice, and both wild type mice and Rgs12f/ffl mice bred to a ubiquitously-expressed Cre recombinase driver strain, leading the latter mouse to be deleted in exons 5 and 6 of Rgs12 (i.e., Rgs12 $15-6 / 45-\vartheta) .(F)$ Sagittal sections of wild type $\left(R g s 12^{+/+}\right)$and RGS12-null $\left(R g s 12^{15-8 / 45-}\right.$ 
8) mouse brain sections probed by in situ hybridization. Note the dense expression of Rgs12 mRNA in the claustrum in the wild type section. Also notable is the labeling in the hippocampus $(\mathrm{Hpc})$, which is denser in the dentate gyrus than in the CA regions in the wild type section. In addition, sparse labeling was observed in the caudate putamen $(\mathrm{CPu})$ and the cortex $(\mathrm{Ctx})$ in the wild type section. Also notable is the absence of labeling in the Rgs $12^{\Delta 5-8 / \Delta 5-8}$ section in all of these regions. (G) i. (Left half) Frontal coronal section demonstrating dense Rgs12 mRNA labeling in the claustrum and sparse labeling in the ventral and dorsal striatum (vSTR, dSTR) and cortex (Ctx). (Right half) Note the absence of labeling in these regions in the Rgs12 $2^{45-8 / 45-8}$ section. $(G)$ ii. (Left half) Marked labeling of the deep, lateral layers of the cortex (Ctx) and sparse labeling in the dorsal striatum (dSTR) and hippocampus (Hpc) are shown. (Right half) Note the absence of labeling in these regions in the $\mathrm{Rgs} 12^{45-8 / 45-8}$ section. 
2.8.2 - Baseline levels of dopaminergic markers are normal in RGS12-null mice.
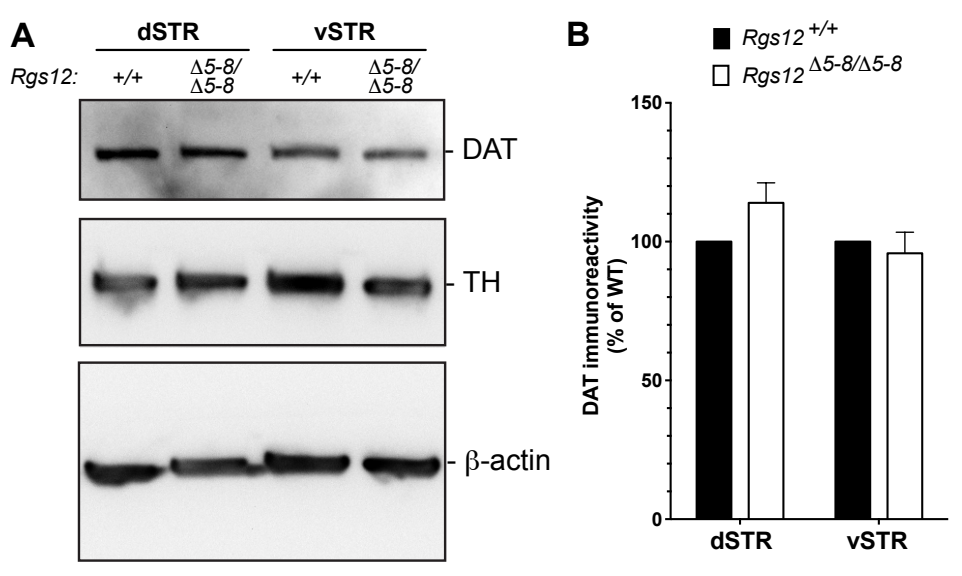

C
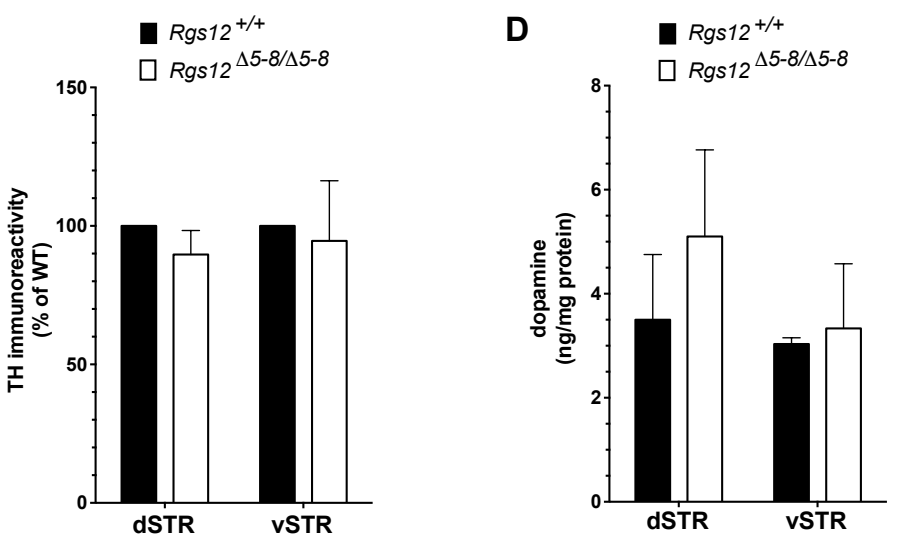

Supplementary Figure S2. Baseline dopamine levels and dopaminergic marker expression in RGS12-null mice. $(A)$ Immunoblot analysis of DAT and tyrosine hydroxylase (TH) immunoreactivity in dorsal striatum (dSTR) and ventral striatum (vSTR) of RGS12null and wild type mice. Densitometric analysis of $(B)$ DAT and $(C)$ TH immunoreactivity normalized to average DAT or TH levels detected in wild type mice. Data are the mean \pm S.E.M ( $n=6$ per group). Data were analyzed by two-way ANOVA with Sidak's multiple comparisons. (D) Total tissue levels of dopamine detected by HPLC with dual-cell electrochemical detection in dorsal striatal and ventral striatal homogenates from RGS12-null and wild type mice. Data were analyzed by two-way ANOVA with Sidak's multiple comparisons. 


\subsection{3 - AMPH-induced $\left[{ }^{3} \mathrm{H}\right]$ dopamine (DA) efflux is only mildly affected in ventral} (vSTR), but not dorsal (dSTR), striatal synaptosomes.

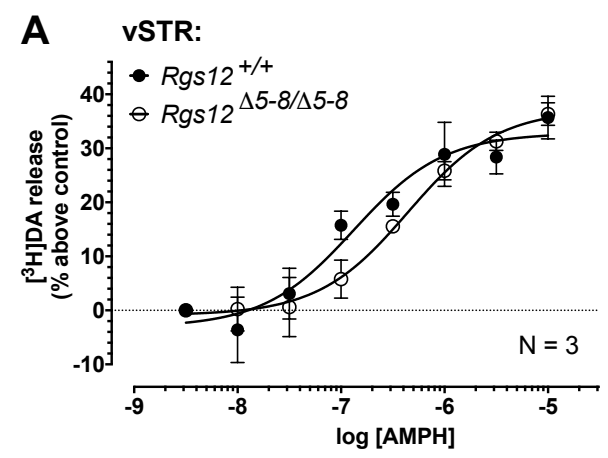

B dSTR:

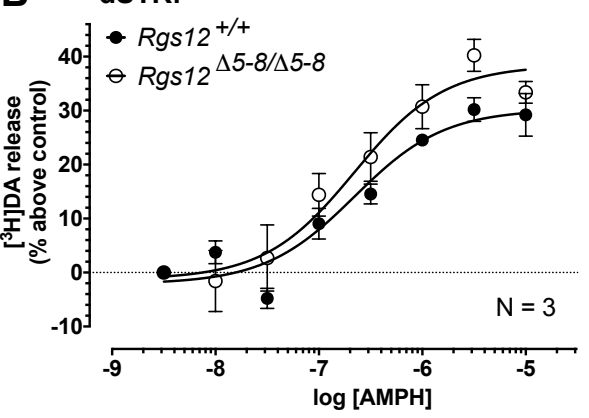

C

\begin{tabular}{|c|c|c|c|}
\hline & vSTR & dSTR & \\
\hline \multicolumn{4}{|l|}{ DAT release $\mathrm{pEC}_{50}$} \\
\hline Rgs12 $2^{+/+}$ & $6.9 \pm 0.2$ & $6.5 \pm 0.2$ & value \pm s.e.m \\
\hline$R g s 12^{\Delta 5-8 / \Delta 5-8}$ & $6.4 \pm 0.1$ & $6.8 \pm 0.2$ & value \pm s.e.m \\
\hline \multicolumn{4}{|l|}{ DAT release $E_{\max }$} \\
\hline Rgs12 ${ }^{+/+}$ & $32.8 \pm 2.7$ & $31.8 \pm 2.3$ & $\% \pm$ s.e.m. \\
\hline${\operatorname{Rgs} 12^{\Delta 5-8 / \Delta 5-8}}^{\Delta}$ & $37.2 \pm 2.4$ & $37.5 \pm 3.0$ & $\% \pm$ s.e.m. \\
\hline
\end{tabular}

Supplementary Figure S3. AMPH-stimulated $\left[{ }^{3} \mathrm{H}\right]$ dopamine release in preloaded synaptosomes. Release assays were performed as previously described (Rothman et al., 2001) with minor modifications. Briefly, dorsal and ventral striatal synaptosomes were prepared as described in the main text but with ice-cold sucrose buffer supplemented with $1 \mu \mathrm{M}$ reserpine. Synaptosomes were then incubated to steady-state with $5 \mathrm{nM}$ $\left[{ }^{3} \mathrm{H}\right]$ dopamine $(30 \mathrm{~min})$ in Krebs-Ringer buffer supplemented with $1 \mu \mathrm{M}$ reserpine. Following incubation, $900 \mu \mathrm{L}$ of preloaded synaptosomes were added to $12 \times 75 \mathrm{~mm}$ polystyrene tubes containing $(+)$-amphetamine $\left(1 \times 10^{-8.5}\right.$ to $\left.1 \times 10^{-5} \mathrm{M}\right)$ in Krebs-Ringer buffer. The release reaction proceeded for $5 \mathrm{~min}$, and was then terminated by rapid filtration over $0.5 \% \mathrm{PEI}-$ soaked Whatman GF/B filters with ice-cold Krebs-Ringer buffer, washed three times, and remaining radioactivity in the filtered synaptosomes was measured via liquid scintillation counting. 


\subsection{4 - Increased DAT binding sites and $\left[{ }^{3} \mathrm{H}\right]$ dopamine (DA) uptake are recapitulated} in an independent, Cre-dependent RGS12-null mouse strain.
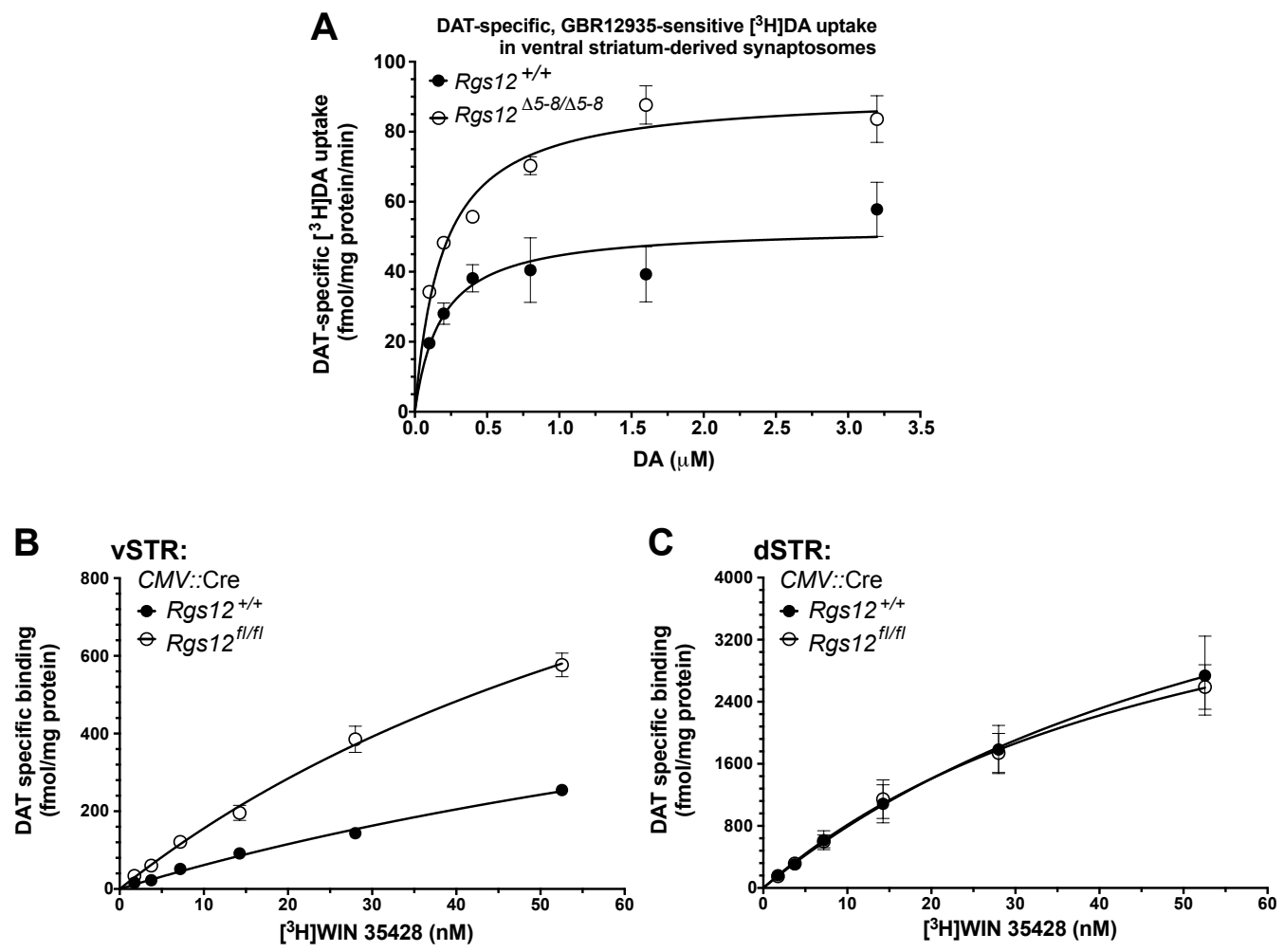

Supplementary Figure S4. DAT-specific $\left[{ }^{3} \mathrm{H}\right]$ dopamine uptake in vSTR-derived synaptosomes of $\operatorname{Rgs} 12^{45-8 / 45-8}$ mice and DAT binding in striatal tissue samples from Cre recombinase-dependent $R g s 12^{\Delta 5-6 / \Delta 5-6}$ mice. $(A)\left[{ }^{3} \mathrm{H}\right]$ Dopamine uptake in ventral striatal synaptosomes prepared from $\operatorname{Rgs} 12^{45-8 / 45-8}$ and wild type mice. Non-specific uptake was determined in the presence of $10 \mu \mathrm{M}$ GBR12935 (a selective dopamine reuptake inhibitor). ( $B, C)$ Levels of DAT determined from $\left[{ }^{3} \mathrm{H}\right] \mathrm{WIN} 35428$ saturation binding analysis of ventral $(E)$ and dorsal $(F)$ striatal crude membrane fractions from $R g s 12^{45-6 / 45-}$ ${ }^{6}$ and wild type mice (i.e., Rgs $12^{f / f t}$ and $R g s 12^{+/+}$mice additionally expressing the CMVdriven Cre recombinase transgene). Non-specific binding was determined in the presence of $10 \mu \mathrm{M}$ GBR12935. 


\subsection{2 - Supplemental Reference:}

Rothman RB, Baumann MH, Dersch CM, et al. (2001) Amphetamine-type central nervous system stimulants release norepinephrine more potently than they release dopamine and serotonin. Synapse 39(1): 32-41. 


\section{CHAPTER THREE}

\section{Role of RGS12 in the differential regulation of kappa opioid receptor-dependent signaling and behavior}

Original Article - Neuropsychopharmacology (2019) DOI: 10.1038/s41386-019-0423-7

Joshua D. Gross ${ }^{1,2,3}$, Shane W. Kaski 1,2,3, Karl T. Schmidt ${ }^{4}$, Elizabeth S. Cogan ${ }^{4}$, Kristen M. Boyt ${ }^{4}$, Kim Wix ${ }^{1}$, Adam B. Schroer ${ }^{1}$, Zoe A. McElligott ${ }^{4}$, David P. Siderovski ${ }^{1,2}$, and Vincent Setola ${ }^{1,2,3}$

1 Department of Physiology \& Pharmacology,

2 Department of Neuroscience, and

3 Department of Behavioral Medicine \& Psychiatry,

West Virginia University, Morgantown WV 26506-9229 USA;

${ }^{4}$ Bowles Center for Alcohol Studies and Department of Psychiatry, University of North Carolina at Chapel Hill, Chapel Hill NC 27599 USA 


\section{1 - Abstract}

Kappa opioid receptor (KOR) agonists show promise in ameliorating disorders, such as addiction and chronic pain, but are limited by dysphoric and aversive side effects. Clinically beneficial effects of KOR agonists (e.g., analgesia) are predominantly mediated by heterotrimeric $G$ protein signaling, whereas $\beta$-arrestin signaling is considered central to their detrimental side effects (e.g., dysphoria/aversion). Here we show that Regulator of $G$ protein Signaling-12 (RGS12), via independent signaling mechanisms, simultaneously attenuates $G$ protein signaling and augments $\beta$-arrestin signaling downstream of KOR, exhibiting considerable selectivity in its actions for KOR over other opioid receptors. We previously reported that RGS12-null mice exhibit increased dopamine transporter-mediated dopamine (DA) uptake in the ventral (vSTR), but not dorsal striatum (dSTR), as well as reduced psychostimulant-induced hyperlocomotion; in the current study, we found that these phenotypes are reversed following KOR antagonism. Fast-scan cyclic voltammetry studies of dopamine (DA) release and reuptake suggest that striatal disruptions to KOR-dependent DAergic neurotransmission in RGS12-null mice are restricted to the nucleus accumbens. In both ventral striatal tissue and transfected cells, RGS12 and KOR are seen to interact within a protein complex. Ventral striatal-specific increases in KOR levels and KOR-induced G protein activation are seen in RGS12-null mice, as well as enhanced sensitivity to KOR agonist-induced hypolocomotion and analgesia -- G protein signaling-dependent behaviors; a ventral striatal-specific increase in KOR levels was also observed in $\beta$-arrestin-2-deficient mice, highlighting the importance of $\beta$-arrestin signaling to establishing steady-state KOR levels in this particular brain region. Conversely, RGS12-null mice exhibited attenuated KORinduced conditioned place aversion (considered a $\beta$-arrestin signaling-dependent behavior), consistent with the augmented KOR-mediated $\beta$-arrestin signaling seen upon RGS12 over-expression. Collectively, our findings highlight a role for RGS12 as a novel, differential regulator of both $G$ protein-dependent and -independent signaling downstream of KOR activation. 


\section{2 - Introduction}

KOR is highly expressed in mood- and pain-related CNS regions and is involved in such pathologies as addiction, depression, anxiety, and chronic pain (Crowley and Kash, 2015; Chavkin and Koob, 2016). During stress, KOR activation by endogenous dynorphins results in analgesia, depressive / anxiety-like behaviors, and altered drug reward (Chavkin and Koob, 2016; Schindler et al., 2012; Van't Veer and Carlezon, 2013; Schenk et al., 1999; Chartoff et al., 2016). KOR antagonists have shown promise in preclinical models of stress-related psychiatric diseases including addiction (Chavkin, 2011; Carlezon and Krystal, 2016). In contrast, acute administration of KOR agonists has been shown to exert utility specifically in reducing pain and drug reward - behavioral outcomes particularly relevant to the current United States opioid epidemic (Kolodny et al., 2015; Koh, 2015; Volkow and Collins, 2017; Kaski et al., 2019). However, the advantageous effects of KOR agonists are limited by dysphoric sideeffects (Van't Veer and Carlezon, 2013; Chavkin and Koob, 2016; Bohn and Aube, 2017). Behaviors produced by KOR agonists depend upon which signaling cascade(s) is/are activated (Ehrich et al., 2015; White et al., 2015; Brust et al., 2016; Liu et al., 2018) - an example of biased agonism (a.k.a. functional selectivity) (Urban et al., 2007; Rankovic et al., 2016). Agonists induce KOR conformational change (Che et al., 2018), driving G protein dissociation (Siderovski and Willard, 2005). Freed G protein subunits then induce biological responses, including cAMP reduction, potassium channel activation, and inhibition of calcium influx (Karkhanis et al., 2017; Schoffelmeer et al., 1988; Tallent et al., 1994; Henry et al., 1995). KOR activation also recruits GPCR kinases (GRKs) and $\beta$-arrestin to trigger desensitization, internalization, and activation of other pathways (McLaughlin et al., 2003; Bruchas et al., 2006). Pharmacological or genetic inhibition of the KOR-stimulated $\beta$-arrestin signaling pathway abolishes KOR agonist-induced conditioned place aversion (CPA) - a metric of dysphoria (Ehrich et 
al., 2015; Chavkin et al., 2014). Thus, KOR-induced CPA is considered $\beta$-arrestindependent. Conversely, KOR-mediated analgesia is considered G protein-dependent and $\beta$-arrestin-independent (Brust et al., 2016; Hernandez et al., 1995; Chavkin, 2011; Schattauer et al., 2017).

GPCR signaling is tightly controlled by Regulators of G protein Signaling, which contain an RGS domain (Soundararajan et al., 2008), serving as a GTPase-accelerating protein (GAP) for Ga (Snow et al., 1998a) and thereby inhibiting G protein signaling (Lambert et al., 2010). Loss of RGS expression increases GPCR sensitivity to agonist stimulation (e.g., (Han et al., 2010; Traynor, 2012)). Some RGS proteins contain additional domains that modulate signaling independent of GAP activity (Anderson et al., 2009; Shu et al., 2010). For example, RGS12 contains a PDZ domain, a phosphotyrosine binding (PTB) domain, Ras binding domains (RBDs) (Willard et al., 2007), and a GoLoco

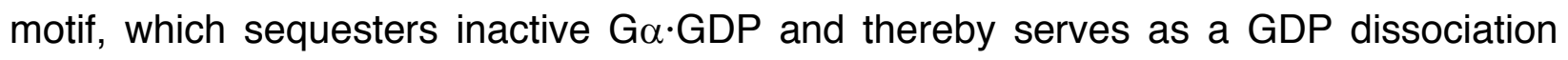
inhibitor (GDI) (Webb et al., 2005).

We recently found (Gross et al., 2018) that RGS12 is enriched in the ventral striatum (vSTR) of the mesolimbic dopamine (DA) system which contributes to reward and affect (Chao and Nestler, 2004; Russo and Nestler, 2013). RGS12 loss reduces psychostimulant-induced hyperlocomotion and elevates dopamine transporter (DAT) expression and DA uptake in the vSTR, but not dorsal striatum (dSTR) (Gross et al., 2018). We hypothesized that RGS12 loss could elevate vSTR KOR activity/sensitivity, as KOR is highly expressed in the mesolimbic DA system and enriched on presynaptic terminals of the nucleus accumbens (NAc) (terminals that originate from ventral tegmental area (VTA) DAergic projections (Crowley and Kash, 2015; Bruijnzeel, 2009)). Mesolimbic KOR activation reduces extracellular DA - an action proposed to underlie dysphoric effects (Knoll and Carlezon, 2010; Chefer et al., 2013). KOR-mediated DA decrease occurs by inhibition of exocytotic DA release (Di Chiara and Imperato, 1988; Donzanti et 
al., 1992) and increased DAT-mediated DA reuptake via Gai/o- and MAPK-dependent signaling (Thompson et al., 2000; Kivell et al., 2014). Here, we examined whether augmented VSTR DA uptake and reduced psychostimulant-induced hyperlocomotion in RGS12-null mouse strains (Gross et al., 2018) results from enhanced KOR action, given that RGS12 is an established inhibitor of Godi/o signaling (Snow et al., 1998a). Our investigation revealed that RGS12 more robustly affects KOR-mediated signaling than it does other opioid receptors, RGS12 differentially modulates G protein-dependent versus -independent KOR signaling, and RGS12 loss differentially affects KOR-mediated behaviors, likely contingent upon which KOR-initiated signaling cascade is required to elicit the particular behavioral outcome. 


\section{3 - Materials and Methods}

\subsection{1 - Drugs and radioligands}

The opioid receptor agonists U50,488 hydrochloride (Cat. no. 0495), DAMGO (Cat. no. 1171), and DADLE (Cat. no. 3790) were purchased from Tocris Bioscience (Minneapolis, $\mathrm{MN}$ ). For all in vitro experiments with opioid receptor agonists, $10 \mathrm{mM}$ stocks were prepared with dimethyl sulfoxide (DMSO), then diluted to the appropriate final working concentrations in assay buffer. The KOR antagonist nor-Binaltorphimine dihydrochloride (nor-BNI; Cat. no. 0347) was also purchased from Tocris Bioscience, and was dissolved in sterile $0.9 \%$ sodium chloride (saline) for all experiments. D-Amphetamine hemisulfate salt and morphine sulfate salt pentahydrate were both purchased from Sigma Aldrich (St. Louis, MO) and dissolved in sterile saline for all experiments. For all animal experiments, drugs were administered intraperitoneally (ip). [ $\left.{ }^{3} \mathrm{H}\right]$ Dihydroxyphenylethylamine ([ $\left.{ }^{3} \mathrm{H}\right]$ dopamine; Cat. no. NET673250UC), $\left[{ }^{3} \mathrm{H}\right] \mathrm{WIN} 35593$ (Cat. no. NET1033250UC), and $\left[{ }^{3} \mathrm{H}\right] \mathrm{U}-69,593$ (Cat. no. NET952250UC) were purchased from Perkin-Elmer (Waltham, WA).

\subsection{2 - Subjects}

Rgs12 ${ }^{\Delta 5-8 / \Delta 5-8}$ mice (a.k.a. Rgs12/- or RGS12-null) (Gross et al., 2018) and wildtype $\left(R_{\left.g s 12^{+/+}\right)}\right.$littermates, both $\mathrm{C} 57 \mathrm{BL} / 6 \mathrm{~J}$ and of both sexes, were housed under conventional lighting (12 hours light / 12 hours dark), humidity, and temperature, with food and water ad libitum. Behaviors were tested within the light cycle. All mice used were 812 weeks of age. Experiments were in accordance with WVU Animal Care and Use Committee and NIH guidelines. 


\subsection{3 - Synaptosomal [3H]DA uptake}

Synaptosomal [ $\left.{ }^{3 \mathrm{H}}\right] \mathrm{DA}$ uptake was performed as described (Gross et al., 2018), with modifications described in Supplementary Methods.

\subsection{4 - Locomotor activity}

AMPH-induced locomotor activity was measured as described (Gross et al., 2018) with modifications denoted in Supplementary Methods.

\subsection{5 - Fast-scan cyclic voltammetry (FSCV)}

RGS12-null and wildtype littermates were injected with $10 \mathrm{mg} / \mathrm{kg}$ nor-BNI or saline (i.p.). 24 hours later, brain slices were prepared and FSCV performed as described (Schmidt et al., 2018), with modifications detailed in Supplementary Methods.

\subsection{6 - Radioligand binding assays}

\subsection{6a - $\left[{ }^{3} H\right]$ WIN35428 binding to DAT}

DAT binding sites were quantified as described (Gross et al., 2018), with modifications detailed in Supplementary Methods.

3.3.6b - $\left[{ }^{3} H\right] \cup 69,593$ binding to KOR and $\left[{ }^{35} S\right] G T P \gamma S$ incorporation upon KOR activation

KOR saturation binding and GTPYS incorporation assays were performed as described (Zhou et al., 2015), with modifications detailed in Supplementary Methods.

\subsection{7 - Co-immunoprecipitations}

Co-immunoprecipitations (co-IPs) from brain tissue were performed with the Pierce co-IP Kit (Waltham, MA) according to manufacturer's instructions, with modifications described in Supplementary Methods. Co-IP analyses in HEK293T cells were performed with the 
Pierce HA-Tag IP/Co-IP Kit according to manufacturer's instructions, with modifications detailed in Supplementary Methods.

\subsection{8 - cAMP inhibition}

HEK293T cells were transfected via $\mathrm{CaPO}_{4}$ (Jordan et al., 1996) with GloSensor-22F cAMP biosensor (Promega) and HA-tagged opioid receptor (3XHA-hKOR, 3XHA-hMOR, or 3XHA-hDOR; www.cdna.org), with or without wildtype human RGS12, RGS domain loss-of-function RGS12 (Rgs12E740K), or GoLoco motif loss-of-function RGS12 (Rgs12 $\left.{ }^{R 1206 F}\right)$. Additional procedures are detailed in Supplementary Methods.

\subsection{9 - $\beta$-arrestin recruitment}

Agonist-induced $\beta$-arrestin recruitment was determined using 'Tango' assay (Barnea et al., 2008; Allen et al., 2011). HTLA cells expressing $\beta$-arrestin-TEV protease fusion and tetracycline transactivator-driven luciferase reporter (Barnea et al., 2008) were transfected via $\mathrm{CaPO}_{4}$ (Jordan et al., 1996) with opioid receptor-Tango vectors (FLAGKOR-Tango, FLAG-MOR-Tango, or FLAG-DOR-Tango; contributed to Addgene by Dr. Bryan Roth) with or without WT hRGS12, Rgs12E740K, or Rgs12 ${ }^{R 1206 F}$ vectors. Additional procedures are detailed in Supplementary Methods.

\subsubsection{0 - Hot plate analgesia and conditioned place aversion (CPA) tests}

To detect sensitivity to painful stimuli, the hot plate test of nociception was performed as previously described (Bohn et al., 1999) with modifications detailed in Supplementary Information. CPA was performed as described (Schindler et al., 2012) with modifications denoted in Supplemental Methods. 


\section{4 - Results}

\subsection{1 - vSTR DAT dysfunction in RGS12-null mice is KOR-dependent}

Rgs12 mRNA is detected in multiple Oprk1-expressing neuronal populations in the mouse brain (Fig. S1), including the VTA and substantia nigra pars compacta (SNc), the anatomical loci of DAergic projection neurons; within the striatum, RGS12 protein is seen (Gross et al., 2018) to be particularly enriched within the ventral striatum. To evaluate whether increased KOR activity is responsible for elevated DAT-mediated DA uptake observed (Gross et al., 2018) in the vSTR of RGS12-null mice, [ $\left.{ }^{3} \mathrm{H}\right] \mathrm{DA}$ uptake by vSTR synaptosomes was measured following systemic pretreatment with the KOR-selective antagonist nor-BNI (Fig. 1A). Omnibus analyses revealed an effect of genotype, antagonist treatment, and a genotype $\mathrm{x}$ treatment interaction (genotype, $F(1,9)=13.5, \mathrm{p}$ $=0.005 ;$ treatment, $F(1,9)=13.4, p=0.005$; interaction, $F(1,9)=7.0, p=0.026$ ). Synaptosomes from saline-pretreated RGS12-null mice exhibited increased DATmediated [ $\left.{ }^{3} \mathrm{H}\right] \mathrm{DA}$ uptake compared with wildtype mice $(\mathrm{p}=0.001)$ (Fig. $\left.1 \mathrm{~A}\right)$. nor-BNI pretreatment $(10 \mathrm{mg} / \mathrm{kg}$, ip) reversed this effect $(p=0.002)$; nor-BNI pretreatment did not affect $\left[{ }^{3} \mathrm{H}\right] \mathrm{DA}$ uptake in wildtype controls $(\mathrm{p}=0.768)$. All data from $\left[{ }^{3} \mathrm{H}\right] \mathrm{DA}$ uptake analyses are the mean \pm SEM and analyzed by two-way ANOVA followed by Sidak's post hoc test ( $n=4-8$ mice/group).

To test whether increased DAT binding sites in the vSTR of RGS12-null mice (Gross et al., 2018) was due to increased KOR expression/sensitivity, we systemically pretreated RGS12-null and wildtype mice with nor-BNI (10 mg/kg, ip) or saline over 14 days and assessed $\left[{ }^{3} \mathrm{H}\right]$ WIN35428 binding to DAT (Fig. 1B). Omnibus analyses revealed an effect of genotype and a genotype $\mathrm{x}$ antagonist treatment interaction (genotype, $F(1,16)=19.5, \mathrm{p}<0.001$; treatment $\mathrm{x}$ genotype interaction, $F(1,16)=8.0, \mathrm{p}=0.011)$. 
Multiple comparisons analysis showed that saline-treated RGS12-null mice display increased $\left[{ }^{3} \mathrm{H}\right]$ WIN35428 binding to DAT relative to saline-treated wildtype mice $(p<$ 0.001). Prolonged nor-BNI pretreatment reversed this effect $(p=0.048)$ to levels comparable to saline-treated wildtype mice $(p=0.149)$. nor-BNI treatment did not significantly affect DAT binding in wildtype mice $(p=0.673)$. All data from DAT binding analyses are the mean \pm SEM and analyzed by two-way ANOVA followed by Sidak's post hoc test ( $n=6$ mice/group).

Augmented DA uptake and DAT binding sites in RGS12-null mice were previously correlated with decreased hyperlocomotor response to the DA-dependent psychostimulant d-amphetamine (AMPH) (Gross et al., 2018). To assess whether this blunted hyperlocomotion is due to increased KOR activity, RGS12-null mice were pretreated with nor-BNI (10 mg/kg, ip) 24 hours prior to AMPH treatment. Omnibus analyses revealed an effect of genotype and antagonist treatment (genotype, $F(1,44)=$ $7.5, p=0.009 ;$ treatment, $F(1,44)=7.0, p=0.011)$. Attenuated AMPH-induced hyperlocomotion in RGS12-null mice ( $p=0.039$ ) was reversed following nor-BNI pretreatment $(p=0.045)$ (Fig. $1 C)$; in contrast, nor-BNI pretreatment did not affect AMPHinduced hyperlocomotion of wildtype mice $(p=0.305)$. Hyperlocomotion data are the mean \pm SEM and analyzed by two-way ANOVA followed by a Sidak's post hoc test $(\mathrm{n}=$ 10-13 mice/group).

FSCV analyses of DA release and reuptake revealed significant effects of genotype and nor-BNI treatment within the NAc core, but not the NAc shell nor dSTR, in mice lacking RGS12 expression (Fig. 1D-G and Fig. S2). Examining peak DA release in the NAc core, we found significant main effects of stimulation amplitude $(F(62,2)=34.439$, $\mathrm{p}<0.001)$ and genotype $(F(1,31)=4.875, \mathrm{p}=0.035)$, and a non-significant genotype $\mathrm{x}$ antagonist treatment interaction $(F(1,31)=3.206, p=0.083)(F i g .1 D)$. Furthermore, $a$ 
significant main effect of antagonist treatment $(F(1,31)=6.089, \mathrm{p}=0.019)$ was seen on DA reuptake dynamics (Fig. 1F) as measured by $t_{1 / 2}$ (Yorgason et al., 2011). Within the NAc shell (Fig. 1E), a significant main effect of stimulation amplitude was observed $(F(1.4,43.3)=38.2, p<0.0001)$, as well as a non-significant stimulation $\mathrm{x}$ genotype $\mathrm{x}$ antagonist treatment interaction $(F(2,62)=2.5, \mathrm{p}=0.089)$; however, there was no significant effect of genotype, antagonist treatment, or genotype $\mathrm{x}$ treatment interaction $(p>0.05)$ regarding peak DA concentration. In the dSTR, we observed only an effect of stimulation amplitude $(F(1.2,38.3)=2, p<0.0001)$ and no effect of genotype, antagonist treatment, nor any interaction $(p>0.05)$ (Fig. S2A). There were no significant effects, in the NAc shell or the dSTR, on $t_{1 / 2}$ measures of DA reuptake $(p>0.05)$ (Shell: Fig. 1G; dSTR: Fig. S2B). All data are mean \pm SEM and were analyzed by general linear mixed model with stimulation amplitude as a repeated factor and genotype and antagonist treatment as between-subject factors ( $n=6-11$ mice/group). It is important to note that electrical stimulation of striatal brain slices during FSCV also recruits local microcircuitry, including cholinergic interneurons, which can strongly influence DA release magnitude via acetylcholine release and subsequent activation of nicotinic cholinergic receptors expressed on DA terminals (Threlfell et al., 2012; Melchior et al., 2015). Given high Rgs12 expression in ChAT+ (cholinergic) interneurons, yet relatively low expression of $K O R$ in these neurons (e.g., Fig. S1C), it is possible that the KOR-independent reductions in accumbal DA release seen in RGS12-null mice may be due, in part, to RGS12 loss within ChAT+ striatal interneurons. Future studies will be required to parse out the relative contributions of this specific interneuron population. 


\subsection{2 - RGS12 forms a protein complex with KOR in brain tissue and transfected cells}

Endogenous KOR co-immunoprecipitates with endogenous RGS12 in vSTR tissue from wildtype mice (Fig. 2). KOR immunoreactivity was absent in immunoprecipitated samples from RGS12-null vSTR (Fig. 2A), suggesting that KOR immunoreactivity from the wildtype mouse vSTR sample was not due to non-specific KOR binding. Consistent with this finding from vSTR (Fig. 2A), we found robust RGS12 immunoreactivity in immunoprecipitates of HA-tagged KOR expressed in transfected HEK293T cells (Fig. 2B). Notably, co-expression of RGS12 with the mu opioid receptor (3XHA-MOR) resulted in only a weak, non-specific signal (relative to RGS12 alone-transfected cells; Fig. 2B), supporting the notion of a selective interaction of RGS12 with KOR and not MOR.

\subsection{3 - KOR sensitivity and binding sites are increased in vSTR of RGS12-null mice}

Given the effect of KOR antagonism in reversing the DAT-mediated DA dysfunction of RGS12-null mice, we probed for changes in KOR signaling and/or levels upon RGS12 loss. Systemic administration of KOR agonists, including U50,488, reduces mouse locomotion (Castellano et al., 1988) -- an index of KOR sensitivity in vivo. Following 2.5 mg/kg U50,488, RGS12-null, but not wildtype, mice displayed hypolocomotion relative to vehicle-treated controls (Fig. 2C; RGS12-null: $p=0.012$; wildtype: $p=0.892$ ), indicating increased KOR sensitivity in RGS12-null mice. A higher dose (5 mg/kg) significantly reduced locomotion in both genotypes (Fig. 2C; RGS12-null: $p=0.000$; wildtype: $p=$ 0.0007). All data are the mean \pm SEM and analyzed by two-way ANOVA ( $\mathrm{n}=7-13$ mice/group). Omnibus analyses of summed data (Fig. 2C) revealed an effect of genotype, 
U50,488 treatment, and a trend for a genotype $\mathrm{x}$ treatment interaction (genotype, $F(1,55)$ $=4.4, \mathrm{p}=0.040$; treatment, $F(2,55)=20.1, \mathrm{p}<0.0001$; interaction, $F(2,55)=2.8, \mathrm{p}=$ 0.072). Multiple comparisons were analyzed by a Sidak's post hoc test and performed with each dose of U50,488 statistically compared to saline-treated controls.

We also measured $\left[{ }^{35} \mathrm{~S}\right] \mathrm{GTP} \gamma \mathrm{S}$ incorporation upon U50,488-elicited $\mathrm{G}$ protein activation in vSTR and dSTR membranes. At $1 \mu \mathrm{M}$ U50,488, RGS12-null, but not wildtype, mice displayed significant GTP $\gamma$ S incorporation in vSTR membranes (Fig. 2D) relative to vehicle control (RGS12-null [1 $\mu \mathrm{M}]: \mathrm{p}=0.015$; wildtype $[1 \mu \mathrm{M}]: \mathrm{p}=0.996$ ), supporting the notion of enhanced KOR-stimulated G protein activation in the vSTR upon RGS12 loss. A two-way ANOVA of the data across multiple U50,488 dosings (Fig. 2D) revealed omnibus effects of genotype, U50,488 treatment, and a genotype $\mathrm{x}$ treatment interaction (genotype: $p=0.005$; treatment: 0.004 , interaction: $p=0.015$ ).

vSTR and dSTR preparations from wildtype mice, as well as dSTR preparations from RGS12-null mice, only displayed significant $\left.{ }^{35} \mathrm{~S}\right] \mathrm{GTP} \gamma \mathrm{S}$ incorporation at the highest concentration tested (Fig. 2D: e.g., vSTR of wildtype mice at $100 \mu \mathrm{M} U 50,488: \mathrm{p}=0.028$ ). Low signal window (e.g., $\sim 0.2$-fold max) in assays of [ $\left.{ }^{35} \mathrm{~S}\right] \mathrm{GTP} \gamma \mathrm{S}$ binding to endogenous receptors in native brain tissue has been previously noted (Bohn et al., 2015). U50,488induced $\left[{ }^{35} \mathrm{~S}\right] \mathrm{GTP} \gamma \mathrm{S}$ binding was not differentially elevated in dSTR preparations from RGS12-null vs wildtype mice (Fig. $2 \mathrm{D}$ inset: Student's t-test $t(7)=0.06 ; \mathrm{p}=0.946$ ). All data from $\left[{ }^{35} \mathrm{~S}\right] \mathrm{GTP} \gamma \mathrm{S}$ incorporation are the mean $\pm \mathrm{SEM}(\mathrm{n}=13-19$ mice/group $)$.

We next assessed whether increased KOR levels/binding sites, in addition to augmented KOR signaling, could account for KOR antagonism-mediated reversal of increased DA uptake in RGS12-null mice. We performed saturation binding with the KOR- 
selective agonist $\left[{ }^{3} \mathrm{H}\right] \mathrm{U} 69,593$ on vSTR and dSTR membranes from RGS12-null mice vs wildtype controls. With loss of RGS12, KOR binding sites $\left(B_{\max }\right)$ were increased in vSTR (Fig. 2E) $(F(1,87)=12.9, \mathrm{p}=0.0005)$, but not dSTR $(F(1,62)=0.3, p=0.618 ;)$; in contrast, $\mathrm{K}_{d}$ values were equivalent between RGS12-null and wildtype mice in both vSTR $(F(1,87)$ $=0.008, p=0.931)$ and dSTR $(F(1,62)=0.3, p=0.610)$ preparations. All data from $\left[{ }^{3} \mathrm{H}\right] \cup 69,593$ saturation binding are the mean $\pm \mathrm{SEM}$, and the inset of Fig. $2 \mathrm{E}$ was analyzed by two-way ANOVA ( $\mathrm{n}=9-12$ mice/group), revealing an effect of genotype, brain region, and a genotype $\mathrm{x}$ brain region interaction (genotype, $F(1,24)=10.0, \mathrm{p}=$ 0.004; region, $F(1,24)=4.6, p=0.043$; interaction, $F(1,24)=6.1, p=0.021)$; multiple comparisons were analyzed by Sidak's post hoc test (multiple comparisons: vSTR, RGS12-null vs wildtype, $\mathrm{p}<0.0001$; dSTR, RGS12-null $v s$ wildtype, $\mathrm{p}=0.879$ ). To ascertain whether increased KOR protein levels/binding sites in RGS12-null mice was due to KOR (Oprk1) transcriptional upregulation, we performed qRT-PCR on vSTR and midbrain tissue. RGS12-null and wildtype mice exhibited similar Oprk1 mRNA levels in both regions (Fig. S3A), suggesting that enhanced KOR activation observed in RGS12null mice is not likely due to elevated KOR expression.

\subsection{4 - RGS12 differentially regulates G protein and $\beta$-arrestin signaling downstream of KOR}

KOR belongs to the GPCR family that includes mu- (MOR) and delta- (DOR) opioid

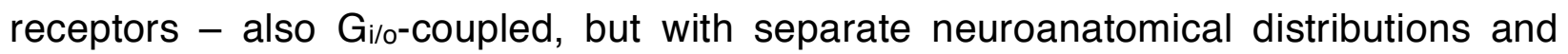
functions relative to KOR (Pan, 1998; Al-Hasani and Bruchas, 2011). To determine whether RGS12 regulates G protein signaling downstream of opioid receptor activation, 
we used a cAMP-based readout in HEK293T cells (Allen et al., 2011) to measure receptor-mediated, Goxilo-dependent inhibition of isoproterenol-induced cAMP increases (Fig. 3A-F). PTX pretreatment abolished KOR agonist-stimulated cAMP inhibition (Fig. $3 \mathrm{~A}$ inset: $t(3)=18.1, \mathrm{p}<0.001)$, validating the luciferase assay as a measure of $\mathrm{G}_{\mathrm{i} / \mathrm{o}^{-}}$ mediated signaling. Wildtype (WT) RGS12 expression reduced U50,488 potency by at least 20-fold (Fig. 3A: $F(1,245)=56.8, p<0.0001$; also Fig. S4A), but only affected agonism of MOR by $\sim$-fold (Fig. 3B: $F(1,216)=13.1, p=0.0004$; also Fig. S4B) and DOR by 2.5 -fold (Fig. 3C: $F(1,136)=7.6, p=0.007$ ). The effect of RGS12 expression on KOR-mediated G protein signaling relied on both the GAP and GDI activities of RGS12, as loss-of-function mutations to either element within RGS12 curtailed the observed decrease in pIC 50 from 20-fold (RGS12 WT) to less than 4-fold (Fig. 3A: RGS12E740K: $F(1$, $205)=7.1, p=0.008 ;$ RGS12 $\left.{ }^{R 1206 F}: F(1,173)=5.7, p=0.018\right)$. We previously established that the E740K charge-reversal mutation to RGS12 eliminates RGS domain GAP activity (Sambi et al., 2006), whereas the R1206F mutation eliminates GoLoco motif GDI activity (Kimple et al., 2002; Sambi et al., 2006).

The PDZ domain of RGS12 exhibits a high degree of similarity (Snow et al., 1998a) to the first PDZ domain of NHERF1 ("Na+/H+ exchanger regulatory factor-1"). NHERF1 is known (Li et al., 2002) to employ its first PDZ domain to bind directly to a PDZ docking site at the KOR C-terminus (aa 376-380: -NKPV-cooh), but does not bind MOR nor DOR (which both lack this C-terminal sequence). As RGS12 co-immunoprecipitates with KOR, but not MOR, in transfected cells (Fig. 2B), we tested whether such binding specificity was determined by a potential PDZ domain / GPCR C-terminal tail interaction. We mutated the last four amino acids of the KOR C-terminus (i.e., NKPV) to four alanine 
residues and, conversely, mutated the last four amino acids of the MOR C-terminus to that found in the wildtype KOR sequence (i.e., NKPV) (Fig. 3D). Co-expression of hRGS12-WT with hKORAAA diminished the RGS12-mediated reduction in U50,488 potency from 20-fold down to 4-fold (Fig. $3 \mathrm{~A}$ vs $\mathrm{E}: F(1,272)=5.0, p=0.024)$. Conversely, substitution of the last four amino acids of MOR to the C-terminal PDZ docking site of KOR (i.e., MOR ${ }^{N K P V}$ ) was seen to enhance the RGS12-mediated reduction of DAMGO potency from 3-fold to 6-fold (Fig. 3B vs $F: F(1,271)=32.1, p<0.0001)$, constituting a $2-$ fold gain-of-function from the effect of RGS12 on wildtype MOR. Together, these data suggest that the PDZ docking site of KOR is necessary, but not sufficient in its entirety, to account for the selectivity RGS12 exerts on opioid agonist potency for KOR over the other opioid receptors.

To determine whether RGS12 also regulates G protein-independent signaling from opioid receptors, we examined $\beta$-arrestin recruitment following receptor activation (Allen et al., 2011; Barnea et al., 2008). Expression of wildtype RGS12 augmented KOR agonist-dependent $\beta$-arrestin recruitment by 3 -fold (Fig. 3G: $F(1,410)=211, p<0.0001$ ), but only mildly elevated MOR agonist-dependent $\beta$-arrestin recruitment (Fig. 3I: 1.2-fold; $F(1,314)=11.5, p=0.0008$ ) and DOR agonist-dependent $\beta$-arrestin recruitment (Fig. 3J: 1.1-fold; $F(1,250)=17.6, p<0.0001)$; no potency changes $\left(E C_{50}\right)$ were observed for any opioid receptor agonist used: KOR/U50,488: $F(1,410)=0.3, p=0.598$; MOR/DAMGO: $F(1,314)=0.3, p=0.561 ;$ and DOR/DADLE: $F(1,250)=1.6, p=0.205)(F i g .3 G, I, J)$.

RGS domain and GoLoco motif loss-of-function mutants did not reverse the RGS12dependent increase in $\beta$-arrestin recruitment downstream of KOR activation (Fig. 3G). RGS $12^{E 740 K}$ elicited no change in the maximal efficacy $\left(E_{\max }\right)$ of KOR agonist-dependent $\beta$-arrestin recruitment relative to wildtype RGS12 (RGS12 ${ }^{E 740 K}: F(1,410)=2.1, p=0.148$ ), 
whereas RGS12 ${ }^{\mathrm{R} 1206 \mathrm{~F}}$ co-transfection resulted in a slight, but statistically significant, increase in KOR agonist-dependent $\beta$-arrestin recruitment relative to wildtype protein (RGS12 $\left.{ }^{\mathrm{R} 1206 \mathrm{~F}}: F(1,410)=20.9, \mathrm{p}<0.0001\right)$. Together, these data indicate that RGS12 requires a functional RGS domain and GoLoco motif for its full effects on KOR-mediated G protein signaling (Fig. 3A), but not for enhancing $\beta$-arrestin translocation to activated KOR (Fig. 3G), suggesting that RGS12 increases $\beta$-arrestin recruitment in a G proteinindependent manner. To confirm this idea, we evaluated KOR agonist-stimulated $\beta$ arrestin translocation following PTX pretreatment. Overnight PTX pretreatment had no effect on the RGS12-mediated increase in $\beta$-arrestin recruitment to activated KOR (Fig. $3 \mathrm{H} ; \mathrm{p}=0.696)$ nor an effect on $\mathrm{U} 50,488$-induced $\beta$-arrestin recruitment efficacy in control cells expressing KOR-only (Fig. $3 \mathrm{H} ; \mathrm{p}=0.540$ ). Omnibus analyses revealed only an effect of RGS12 expression (RGS12, $F(1,8)=1160.0, p<0.001$ ). Data in Fig. $3 \mathrm{H}$ are the mean \pm SEM ( $N=3$ independent experiments) and were analyzed by two-way ANOVA with Sidak's post hoc test.

We hypothesized that the increased KOR binding sites seen in the VSTR of RGS12null mice (Fig. 2E) might be due to attenuated $\beta$-arrestin-2-dependent internalization and/or downregulation of KOR in the absence of RGS12 expression. To test this idea, we performed $\left[{ }^{3} \mathrm{H}\right]$ U69,593 saturation binding assays in vSTR and dSTR membranes of $\beta$ arrestin-2 knockout ( $\beta$ arr2 $^{\mathrm{KO}}$ ) (Bohn et al., 1999) and wildtype control mice. $\beta$-arrestin-2 knockout mice exhibited increased KOR $B_{\max }$ in the vSTR compared to wildtype controls (Fig. 3K,L: $F(1,66)=4.1, \mathrm{p}=0.044)$; in contrast, $\mathrm{Kd}$ values for KOR radioligand binding were equivalent between $\beta$ arr2 ${ }^{\mathrm{KO}}$ and wildtype mice in both vSTR $(F(1,66)=0.1, \mathrm{p}=$ $0.701)$ and $\operatorname{dSTR}(F(1,68)=0.1, \mathrm{p}=0.678)$ preparations (Fig. 3K,L). Analysis of KOR binding $B_{\max }$ revealed that KOR levels were increased in the vSTR, but not the dSTR (Fig. $3 \mathrm{~L}: F(1,68)=0.018, p=0.6674)$. Omnibus analysis revealed effects of genotype, brain 
region, and a trend for a genotype $\mathrm{x}$ brain region interaction (genotype, $F(1,20)=5.8, \mathrm{p}$ $=0.025$; treatment, $F(1,20)=14.9, p=0.001$; interaction, $F(1,20)=4.0, p=0.057)$. These findings support the notion that increased KOR levels/binding sites in RGS12-null mice is related to reduced KOR-mediated $\beta$-arrestin-2 function upon RGS12 loss. All data are the mean \pm SEM ( $n=12$ mice per group); data displayed in Fig. 3K-L were analyzed by twoway ANOVA with Sidak's post hoc test.

\subsection{5 - RGS12 differentially regulates G protein- and $\beta$-arrestin-dependent behaviors mediated by KOR}

RGS12 expression selectively reduces KOR agonist-induced cAMP inhibition via its RGS domain and GoLoco motif (Fig. 3); these data are consistent with findings of KOR antagonism-mediated reversal of elevated DA uptake and DAT binding sites (Fig. 1A,B) and attenuated $\mathrm{AMPH}$-induced hyperlocomotion (Fig. 1C), increased KOR-stimulated [35S]GTP $\gamma$ S binding (Fig. 2D), and increased sensitivity to KOR-stimulated hypolocomotion (Fig. 2C) upon RGS12 loss. Together, these findings suggest that RGS12 normally reduces G protein-dependent KOR signaling, and RGS12 loss results in hypersensitivity of KOR-mediated G protein signaling. To assess this hypothesis with an integrated, behavioral output, we interrogated supraspinal nociception using the hot plate assay (Sora et al., 1997); prior studies have determined that KOR-induced analgesia represents a $G$ protein-dependent and $\beta$-arrestin-independent outcome of KOR agonism (Chavkin, 2011; White et al., 2015; Schattauer et al., 2017). Here, we tested whether RGS12-null mice exhibit enhanced sensitivity to the analgesic effect of U50,488 (Fig. 4A-C). RGS12-null mice displayed significantly increased analgesia by U50,488 at $5 \mathrm{mg} / \mathrm{kg}$ (within-subjects comparisons: RGS12-null saline vs U50,488: $\mathrm{p}=0.033$ ) and $22.5 \mathrm{mg} / \mathrm{kg}$ (RGS12-null saline vs U50,488: $\mathrm{p}=0.005$ ), whereas wildtype littermates 
exhibited no statistically significant analgesia to either dose (within-subjects comparisons: WT saline vs $5 \mathrm{mg} / \mathrm{kg}$ U50,488: $\mathrm{p}=0.815$; WT saline $v s 22.5 \mathrm{mg} / \mathrm{kg}$ U50,488: $\mathrm{p}=0.199$ ). Omnibus ANOVA revealed only a significant effect of treatment at these two doses of U50,488 $(5 \mathrm{mg} / \mathrm{kg}$ treatment, $F(1,18)=5.2, \mathrm{p}=0.036 ; 22.5 \mathrm{mg} / \mathrm{kg}$ treatment, $F(1,15)=$ $13.8, p=0.002$ ). These results suggest that $R G S 12-n u l l$ mice have enhanced sensitivity

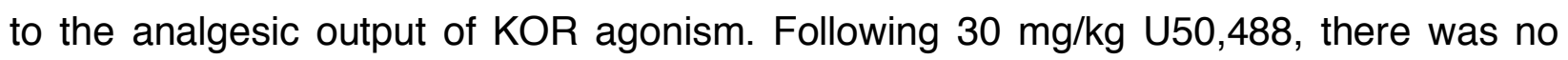
difference in analgesia between genotypes (Fig. 4C: RGS12-null saline vs U50,488: $p<$ 0.0001; WT saline vs U50,488: $\mathrm{p}=0.0003$ ); omnibus ANOVA revealed only a significant effect of treatment at this $30 \mathrm{mg} / \mathrm{kg}$ dose of U50,488 (treatment, $F(1,16)=57.6, \mathrm{p}<$ 0.0001). RGS12-null and wildtype mice pretreated with the KOR antagonist nor-BNI (10 $\mathrm{mg} / \mathrm{kg}$, ip) 24 hours prior to $\mathrm{U} 50,488$ administration exhibited no analgesic responses (Fig. S5), indicating that the supraspinal anti-nociceptive effects of U50,488 (Fig. 4A-C) are mediated by KOR activation. Supporting a selective function of RGS12 on KOR signaling over that of other opioid receptors, RGS12-null mice were seen to exhibit normal analgesia to morphine (Fig. S6) - a response dependent on MOR activation (Sora et al., 1997; Pasternak, 2010). All data from hot plate analgesia experiments are the mean \pm SEM ( $n=7-14$ mice per group) and analyzed by two-way ANOVA followed by Sidak's post hoc test.

While RGS12 is known to suppress G protein-dependent signaling (Snow et al., 1998a; Kimple et al., 2002), RGS12 expression was also seen to augment $\beta$-arrestin recruitment independent of its heterotrimeric G protein-modulating domains (Fig. 3G). These data suggest that RGS12 loss may lead to decreased G protein-independent (i.e., $\beta$-arrestin) signaling downstream of KOR activation. Therefore, we examined conditioned place aversion (CPA) to $\mathrm{U} 50,488$, given that aversion to KOR-induced dysphoria is considered a $\beta$-arrestin-dependent behavior (Land et al., 2009; Chavkin et al., 2014; 
Ehrich et al., 2015). Wildtype mice exhibited CPA following $2.5 \mathrm{mg} / \mathrm{kg}$ U50,488 ( $\mathrm{p}=$ $0.011)$; in contrast, RGS12-null mice did not express aversion at this dose $(p=0.548)$. Omnibus ANOVA analysis revealed only an effect of U50,488 treatment $(F(1,25)=7.7, p$ $=0.010$ ) (Fig. 4D). These data suggest that RGS12 loss reduces the ability of KOR agonism to produce aversion/dysphoria. At $5 \mathrm{mg} / \mathrm{kg}$ U50,488, both RGS12-null and wildtype mice exhibited aversion (Fig. 4E) (within-subjects comparison: RGS12-null mice: $p=0.021$; WT mice: $p<0.0001)$; the aversion exhibited by RGS12-null mice was attenuated relative to that of wildtype littermates (between-subjects comparison: RGS12null vs WT: $\mathrm{p}=0.006)$. Omnibus ANOVA analysis revealed an effect of treatment at this higher U50,488 dose (treatment, $F(1,22)=44.7, \mathrm{p}<0.0001$ ) and a genotype $\mathrm{X}$ treatment interaction $(F(1,22)=10.7, \mathrm{p}=0.004)$. All data from CPA experiments are the mean \pm SEM ( $\mathrm{n}=9-15$ mice per group) and analyzed by two-way ANOVA followed by a Sidak's post hoc test.

A summary of the interpretation of all these findings, derived from our interrogations of adult RGS12-null mice, is presented in Figure 5. Constitutive loss of RGS12 may alternatively (or additionally) engender disruptions to KOR signaling in the vSTR via perturbation of neurodevelopmental processes. In response to neonatal or early life stress, the KOR/dynorphin system becomes hypersensitive to endogenous and exogenous activation, resulting in mesolimbic hypodopaminergia and behavioral disruption in adulthood, including altered psychostimulant responsiveness (Van't Veer and Carlezon, 2013; Vien et al., 2009; Karkhanis et al., 2016; Yorgason et al., 2016). Thus, loss of RGS12 from birth may increase pre- and/or post-natal stress susceptibility such that the KOR system becomes upregulated. This hypothesis is supported by previous work from our group and others demonstrating that (i) RGS12 is strongly 
expressed throughout CNS regions integral to the early embryonic stages of neurodevelopment (Martin-McCaffrey et al., 2005), (ii) RGS12 is required for neurodevelopmental processes such as nerve growth factor-stimulated axonogenesis by sensory neurons (Willard et al., 2007), and (iii) RGS12 levels are altered during synaptogenesis by sensory deprivation (Butko et al., 2013) and in transgenic models of neurodevelopmental diseases such as schizophrenia (Sialana et al., 2018). Future studies will be required to elucidate whether RGS12 loss early in neurodevelopment contributes to the disruptions of KOR signaling and behavior observed in constitutive RGS12-null adult mice. 


\section{5 - Discussion}

RGS12 as an important regulator of vSTR DA homeostasis via KOR signaling effects on DAT

RGS12 exhibits selective effects on KOR signaling in at least one region of the CNS - the ventral striatum - via a mechanism dependent on an interaction with KOR that is at least functional and likely direct. Single cell RNAseq data (Saunders et al., 2018) reveals that $R g s 12$ is expressed in several Oprk1 (KOR)-expressing neuronal populations within the corticostriatal circuit (Fig. S1C). Thus, disruptions to KOR signaling and behavior upon global Rgs12 deletion may, at least in part, reflect an integrated response across several corticostriatal brain regions and may not necessarily be restricted to abrogated functional interaction solely within the vSTR. For example, loss of Rgs12 in striatal dopamine receptor D1R+ and/or D2R+ medium spiny neurons (MSNs) seen to co-express Oprk1 and Rgs12 in wildtype mice (e.g., Fig. S1C) could contribute to the RGS12-null mouse phenotypes observed, especially given the known roles these MSNs play in rewarding and aversive responses (e.g., to psychostimulant-drugs) (Calipari et al., 2016; Tejeda et al., 2017).

KOR activation results in hypodopaminergia in the vSTR/NAc by (i) decreasing DA release (Di Chiara and Imperato, 1988; Donzanti et al., 1992) and (ii) increasing DATmediated DA reuptake (Thompson et al., 2000; Kivell et al., 2014) in a G proteindependent manner. As RGS12-null mice exhibit augmented DAT-mediated DA uptake reversible by KOR blockade, and display increased KOR-mediated G protein signaling (Figs. 1, 2), we hypothesized that RGS12 loss would also reduce DA release in the 
vSTR/NAc due to increased KOR-mediated G protein signaling. Indeed, RGS12-null mice exhibited attenuated DA release in the NAc core (Fig. 1); in addition, a notable trend towards reduced DA release was also observed in the NAc shell, but this latter result was not statistically different from wildtype controls. Evoked DA release is considerably lower in the NAc shell than the core (Melchior and Jones, 2017), which may account for our inability to attain statistically significant differences between genotypes when performing FSCV in the shell. No differences of DA release nor in nor-BNI pretreatment effects were detected in the dSTR (Fig. S2), further supporting that RGS12 selectively exerts DAmodulatory effects in the vSTR, but not dSTR.

KOR blockade via nor-BNI pretreatment did not rescue the deficient DA release seen in the NAc core of RGS12-null mice (Fig. 1), suggesting that this release defect is KORindependent or reliant on long-term neurodevelopmental maladaptation to RGS12 loss rather than acute KOR signaling upregulation per se. We identified a trend for nor-BNI pretreatment to increase DA release in RGS12-null, but not wildtype, mice within the NAc shell at select stimulation amplitudes (Fig. 1), although this did not reach statistical significance. KOR agonists have been reported to reduce DA release more potently in the NAc shell than the core (Melchior and Jones, 2017), and this effect may relate to the higher level of KOR expression in the NAc shell relative to the core seen in rodents (Mansour et al., 1995a; Resendez et al., 2016). Therefore, the observed trend for increased DA release by nor-BNI in the NAc shell, but not NAc core, of RGS12-null mice may have emerged given enhanced expression and function of KOR in the NAc shell over the core.

Wildtype mice did not exhibit altered DA reuptake in the NAc core, NAc shell, nor dSTR following nor-BNI pretreatment (Fig. 1 and S2); these observations support the 
notion that, under normal conditions, there is a lack of basal KOR tone (i.e., the presence of dynorphin-stimulated and/or constitutive activity of KOR) in these regions. However, augmented $\left[{ }^{3} \mathrm{H}\right] \mathrm{DA}$-uptake in the vSTR synaptosomes of RGS12-null-mice was reversed by systemic nor-BNI pretreatment (Fig. 1); moreover, RGS12-null mice display a trend for enhanced sensitivity to the effect of nor-BNI on DA reuptake in the NAc-core relative to wildtype controls (Fig. 1). Together, these data support the idea that KOR sensitivity/activity in the vSTR is enhanced in the absence of RGS12-expression. This effect is unlikely to be related to elevated dynorphin tone, given normal Prodyn mRNA expression in RGS12-null mice (Fig. S3B). RGS12-null mice may not exhibit KORdependent effects on DA reuptake in the NAc shell given that this region expresses considerably less DAT than the NAc core (Nirenberg et al., 1997). Moreover, the minimal levels of extracellular DA that arise following evoked DA release in the NAc shell, especially in RGS12-null mice, may be insufficient to drive DAT-mediated DA reuptake at thresholds sufficient to engage KOR, thereby masking any modulatory effects that RGS12 may have on KOR-dependent processes. Irrespective of the relative paucity of engagement within the NAc shell leading to a lack of observable signal, our data from brain-slice FSCV and synaptosomal [ $\left.{ }^{3} \mathrm{H}\right] \mathrm{DA}$ uptake support that (i) RGS12 loss affects DAergic neurotransmission in vSTR, but not the dSTR, and (ii) RGS12 modulates vSTRKOR signaling that affects DAT function, but does not appreciably affect KOR signaling that specifically regulates DA release.

vSTR synaptosomes derived from RGS12-null mice exhibit elevated $V_{\max }$ of [ $\left.{ }^{3} \mathrm{H}\right] \mathrm{DA}$ uptake (Gross et al., 2018). In contrast, DA reuptake in the NAc is similar in saline-treated RGS12-null mice and saline-treated wildtype controls (Fig. 1). Such differences between measurements of endogenous DA reuptake (e.g., via FSCV) vs exogenous DA uptake (e.g., via synaptosomal $\left[{ }^{3} \mathrm{H}\right] \mathrm{DA}$-uptake) have been demonstrated previously (Chen and 
Reith, 2007). FSCV evaluates DA reuptake by quantifying the clearance rate ( $\left.t_{1 / 2}\right)$ of endogenous DA released into the extracellular space following stimulation of release (e.g., electrical) (Robinson et al., 2003; Yorgason et al., 2011). Thus, FSCV-derived reuptake rates are predicated, in part, on the absolute quantity of DA released from presynaptic DA neurons. Given that RGS12-null mice exhibit markedly reduced DA release in the NAc following electrical stimulation (Fig. 1), these mice may consequently display lower rates of DA reuptake than expected (relative to observed synaptosomal $\left[{ }^{3} \mathrm{H}\right] \mathrm{DA}$-uptake rates) simply due to the considerably lower levels of extracellular DA present during the experiment. Unlike in brain-slice FSCV (Phillips et al., 2002; McGinnis et al., 2016), in vitro synaptosomal [ $\left.{ }^{3} \mathrm{H}\right] \mathrm{DA}$-uptake experiments employ high levels of both $\left[{ }^{3} \mathrm{H}\right]$-labeled and unlabeled DA to achieve DAT saturation (e.g., refs. (Bermingham and Blakely, 2016; Gross et al., 2018)). Consequently, this high load of exogenous DA produces a distinctly different measure of DA uptake capacity relative to FSCV (Richardson et al., 2016; Gowrishankar et al., 2018) given that it drives activation of endogenously expressed receptors and thereby engages negative feedback systems (e.g., ref. (Gowrishankar et al., 2018)). Thus, RGS12-null mice may require elevated DA tone in the vSTR/NAc to manifest observable differences in DAT-mediated DA uptake.

Our finding that RGS12 modulates KOR function (this study) and DAT function (Gross et al., 2018) in the vSTR, but not dSTR, supports previous findings that KOR effects on DAT function and AMPH-induced neuronal activation are restricted to the vSTR (Gray et al., 1999; Thompson et al., 2000). Regio-specific RGS12 action on KOR and DAT function might be, at least in part, related to the greater RGS12 expression seen in vSTR relative to dSTR (Gross et al., 2018). An alternative (or additive) explanation might be differential expression of some G-protein-signaling element(s) between the vSTR and dSTR. For 
example, DA signaling via the dopamine $\mathrm{D}_{2}$ receptor is reported as being more potent in the NAc (vSTR) than the dSTR (Marcott et al., 2018), given preferential coupling of $D_{2} R$ to $\mathrm{G} \alpha_{0}$, which is more highly expressed in the NAc than dSTR relative to $\mathrm{G}_{\mathrm{i}}$ (Lein et al., 2007). While the RGS12 RGS domain increases the GTPase activity of both G $\alpha_{0}$ and Godi proteins (Snow et al., 1998a), the GoLoco-motif binds only to Goi1/i2/i3 subunits and not to $G \alpha_{o}$ (Kimple et al., 2002). Such differential engagement of $G \alpha_{i}$ vs $G \alpha_{o}$ by RGS12 might thereby underlie a vSTR specific action of RGS12 on KOR signaling and, consequently, on DAT function.

\section{RGS12 as a potential target for inhibition to help direct KOR agonism toward beneficial analgesia and away from anti-therapeutic aversion/dysphoria?}

Neuroanatomical loci mediating supraspinal opioid-induced analgesia are located throughout the brain (Lipp, 1991; Jensen, 1997), with the mesolimbic dopamine-system playing an integral role (Altier and Stewart, 1999; Gear et al., 1999). Thus, the enhanced analgesic effect of U50,488 in RGS12-null mice (Fig. 4) is consistent with the augmented KOR agonist potency and KOR levels observed in the vSTR of these mice (Fig. 2). RGS12 may also regulate KOR-mediated spinal analgesia via similar mechanisms: RGS12 and KOR are both expressed in spinal neurons that mediate analgesia (Willard et al., 2007; Hylden et al., 1991; Cai et al., 2016). Dorsal root ganglion (DRG) neurons located adjacent to the spinal cord, as well as the dorsal horns, represent key nociceptive loci as they contain neurons responsible for receiving and transmitting nociceptive signals (Todd, 2010). Both KOR and RGS12 are highly expressed in DRGs (Tsai et al., 2010; Willard et al., 2007), and KOR is known to mediate analgesic responses within this 
anatomical region (Xu et al., 2004). Thus, the effects of RGS12 loss on KOR-mediated analgesia may also rely, at least in part, on augmented KOR-mediated G protein signaling at the level of the spinal cord. RGS12-null mice exhibited normal morphine-induced analgesia (Fig. S6), supporting the idea that RGS12 functions selectively on KORsignaling relative to that of other opioid receptors, especially given the receptor-selectivity of morphine's analgesic actions (i.e., the anti-nociceptive effects of morphine are completely lost in MOR knockout mice (Sora et al., 1997; Pasternak, 2010) yet preserved in mice lacking KOR (Simonin et al., 1998)).

Prior evidence suggests that the DA-lowering effects of KOR agonists in the vSTR underlie their aversive/dysphoric properties (Knoll and Carlezon, 2010; Shippenberg et al., 1993); thus, attenuated U50,488-induced CPA in RGS12-null mice might be related to a constitutively elevated DA reuptake in the vSTR of these mice (Gross et al., 2018), resulting in reduced extracellular DA and causing a 'floor effect' whereby KOR-mediated reductions in vSTR DA are unable to manifest aversion in the absence of RGS12 expression. However, this possibility is unlikely, as even DA-deficient mice display KORinduced CPA (Land et al., 2009). Reduced KOR-induced CPA in RGS12-null mice is also unlikely to reflect a learning deficit given that these mice exhibit normal conditioned-placepreference to both amphetamine and cocaine (Gross et al., 2018).

RGS12 over-expression was seen to reduce G protein-dependent signaling and increase $\beta$-arrestin recruitment downstream of KOR activation (Fig. 3). Consistent with these findings, Rgs12 ablation enhances KOR-stimulated G protein activation and sensitivity to U50,488-induced hypolocomotion (Fig. 2). KOR-induced hypolocomotion is 
unaffected by $\beta$-arrestin-2 knockout (White et al., 2015), suggesting that reduced locomotion upon KOR activation is G protein-dependent. RGS12-null mice also exhibit increased KOR binding sites (a measure of protein expression) (Fig. 2) despite normal Oprk1-mRNA levels (Fig. S3), suggesting that elevated KOR levels/binding sites are not due to Oprk1 transcriptional upregulation. Increased KOR-protein levels and/or sensitivity, and not dynorphin expression levels (Fig. S3), likely underlie the increased vSTR DAT-mediated DA-uptake and resultant reduction in AMPH-stimulated hyperlocomotion seen in RGS12-null mice (Gross et al., 2018), given that these two effects are reversed by KOR inhibition (Fig. 1).

In light of augmented $\beta$-arrestin-recruitment to activated KOR upon RGS12 overexpression (Fig. 3), we speculated that RGS12 loss reduces $\beta$-arrestin-dependent internalization and/or downregulation of KOR -- a hypothesis strongly-supported by our observation of increased vSTR, but not dSTR, KOR-binding in $\beta$-arrestin-2 knockouts (Fig. 3). In contrast, [ $\left.{ }^{3} \mathrm{H}\right] \mathrm{DA}$-uptake is unaffected in $\beta$-arrestin-2 knockouts (Fig. S7); as others have demonstrated that KOR-mediated increases in [ $\left.{ }^{3} \mathrm{H}\right] \mathrm{DA}$-uptake are sensitive to PTX (Kivell et al., 2014), these findings collectively suggest that basal and KORstimulated DA uptake are $\beta$-arrestin-independent and G protein-dependent, respectively. Enhanced KOR-dependent [ $\left.{ }^{3} \mathrm{H}\right] \mathrm{DA}$-uptake in the vSTR of RGS12-null-mice (Fig. 1) is thus likely mediated by increased G-protein-signaling downstream of KOR (Fig. 5). Under conditions of low accumbal DA tone, RGS12-null mice displayed an exaggerated response to KOR antagonist-mediated reductions in DA reuptake in the NAc core, but not dSTR (Figs. 1 \& S2), further supporting that RGS12 loss engenders hypersensitivity to 
the effects of KOR on DAT function selectively in the mesolimbic DA system. Augmented KOR-mediated G protein signaling upon RGS12-loss is further supported by increased sensitivity of RGS12-null mice to U50,488-induced supraspinal analgesia (Fig. 4), considered a G protein-dependent outcome of KOR agonism (Schattauer et al., 2017; White et al., 2015). Conversely, RGS12-null mice display reduced aversion to U50,488 (Fig. 4), a behavioral outcome of KOR activation considered to be reliant on $\beta$-arrestin signaling (Chavkin et al., 2014; Ehrich et al., 2015), consistent with observations that RGS12 over-expression augments KOR-mediated $\beta$-arrestin-recruitment (Fig. 3). Together, our data demonstrate that (i) RGS12 and KOR functionally interact in the vSTR, but not dSTR, (ii) RGS12 exerts specificity for KOR over other opioid receptors, (iii) RGS12 differentially regulates signaling cascades downstream of KOR via independent mechanisms, and (iv) RGS12 is a critical determinant of KOR-mediated behavioral outcomes. 
Funding and Disclosure: The authors declare no competing financial interests. These studies were supported in part by the WVU E.J. Van Liere Endowed Medicine Professorship (to D.P.S.) and K01 AA023555 (to Z.A.M.) J.D.G. and S.W.K. each acknowledge prior support from an NIH/NIGMS Behavioral \& Biomedical Sciences training grant (T32 GM081741) and current support from NIDA predoctoral NRSA fellowships (F31 DA043331 and F30 DA044711, respectively). K.T.S. acknowledges support from P60 AA011605 and E.S.C. acknowledges support from a postdoctoral training slot on T32 AA007573; K.M.B. was supported by funding from U01 AA020911 and U24 AA025475.

Acknowledgements: We thank Dr. Gilad Barnea for furnishing HTLA cells for in-house Tango assays. 


\section{6 - Figures}

\subsection{1 - Ventral striatal dopamine transporter (DAT) dysfunction in RGS12-null mice}

\section{is kappa opioid receptor (KOR)-dependent.}

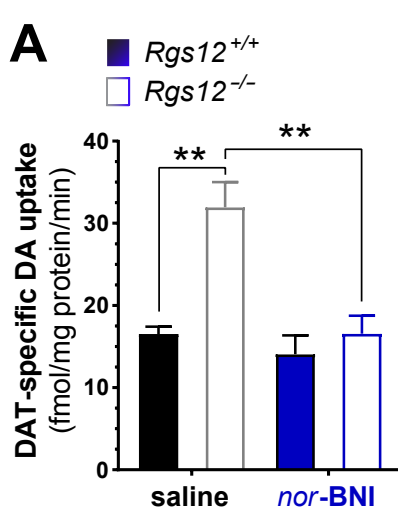

D DA release (NAc core)

- $\operatorname{Rgs} 12^{+/+}$(saline)

$\star \operatorname{Rgs}^{+/+}($nor-BNI) $\rceil$*

- Rgs12 $12^{-/}$(saline)

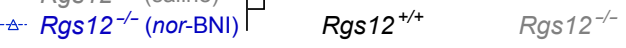

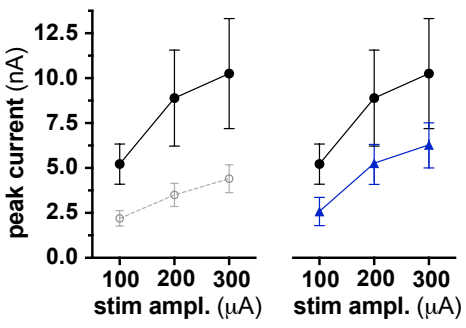

F DA reuptake (NAc core)

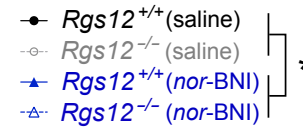

$-\triangle-$ Rgs $12^{-/-}($nor-BNI)
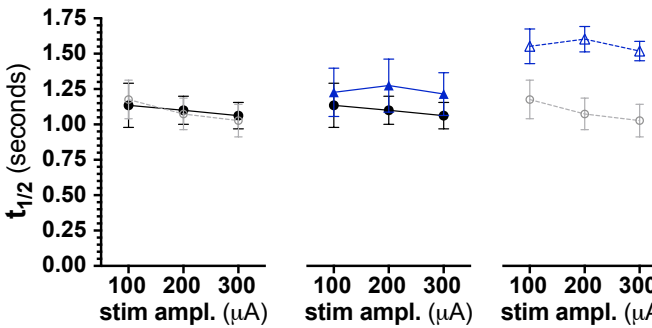

$100200300 \quad 100200300$ stim ampl. $(\mu \mathrm{A})$ stim ampl. $(\mu \mathrm{A})$
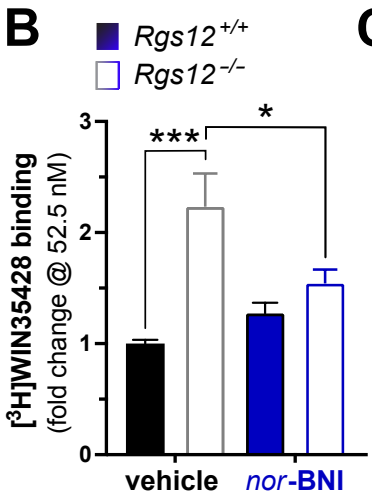

vehicle nor-BNI

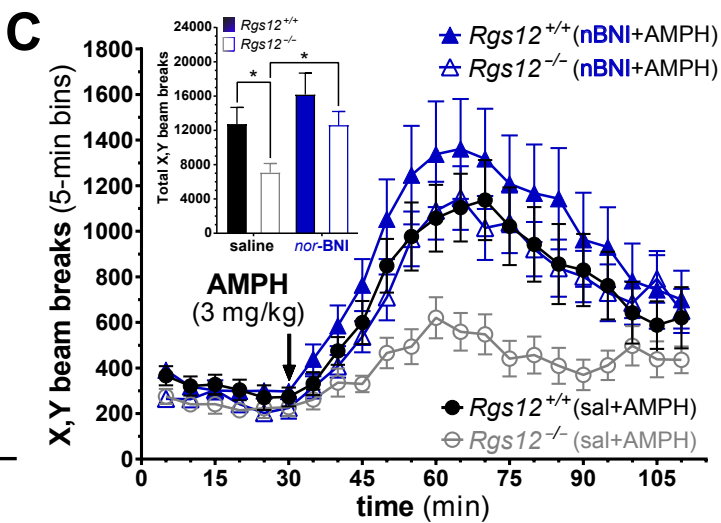

E DA release (NAc shell)

- $R g s 12^{+/+}$(saline)

$\star$ Rgs $12^{+/+}($nor-BNI) $] \mathrm{ns}$

-. Rgs12 $12^{--}$(saline)

$\triangle$ Rgs $12^{-/-}$(nor-BNI) $\quad \operatorname{Rgs}^{+/+}$
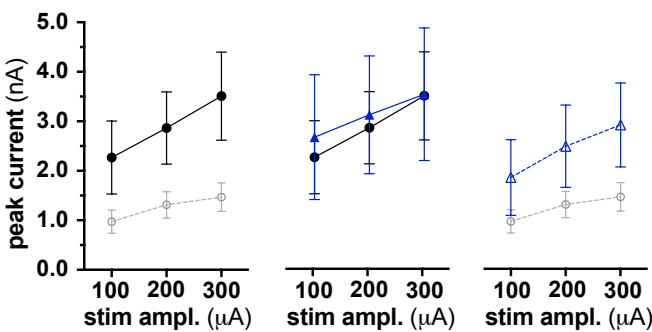

G DA reuptake (NAc shell)

- $\operatorname{Rgs} 12^{+/+}$(saline)

- Rgs $12^{-/-}$(saline) $\rceil \mathrm{ns}$

$\star R g s 12^{+/ 4}($ nor-B

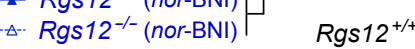

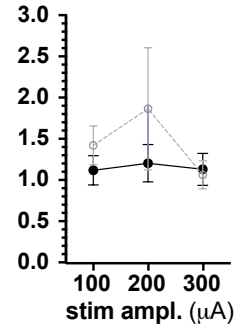

$\operatorname{Rgs} 12^{-/-}$

Figure 1. Ventral striatal DAT dysfunction in RGS12-null mice is KOR-dependent. (A) Uptake of $\left[{ }^{3} \mathrm{H}\right]$ dopamine $(8 \mathrm{nM})$ and $(\mathrm{B})$ the number of DAT binding sites are increased in vSTR synaptosomes derived from RGS12-null $\left(R_{g s 12^{-/}}\right)$mice vs WT $\left(R g s 12^{+++}\right)$littermate 
controls; this increase is lost upon prior administration to the mice of the KOR-selective antagonist nor-BNI. Mice were administered vehicle (saline) or nor-BNI (10 mg/kg, ip) 24 hours (A) or over 14 days (B) prior to sacrifice and synaptosome or membrane preparation, respectively. Non-specific binding was determined in the presence of $10 \mu \mathrm{M}$ GBR12935 (a selective DA reuptake inhibitor). Data are the mean \pm SEM and tested by two-way ANOVA with Sidak's post hoc test $\left(n=4-8\right.$ mice) $\left({ }^{*}, p<0.05,{ }^{\star \star}, p<0.01,{ }^{* \star *}, p\right.$ $<0.001)$. (C) Suppression of AMPH-induced hyperlocomotion by RGS12-null mice is reversed upon prior administration of nor-BNI. AMPH (3 mg/kg, ip)-induced changes to locomotion behavior are shown in RGS12-null mice (open symbols) and WT littermate controls (closed symbols) following 30 min acclimation to activity chambers. Mice were treated with either vehicle (saline; circles) or nor-BNI (10 mg/kg delivered ip; triangles) 24 hours prior to the experiment. Data are the mean \pm SEM $(n=10-13$ mice per group). (C, inset) Total locomotion (over $80 \mathrm{~min}$ ) by RGS12-null mice and WT littermate controls (derived from data in panel C) treated with saline or nor-BNI following injection of AMPH (3 $\mathrm{mg} / \mathrm{kg}$, ip). Data are the mean \pm SEM and tested by two-way ANOVA with Sidak's post hoc test $\left(n=10-13\right.$ mice per group) $\left({ }^{*}, p<0.05\right)$. (D) Electrically-stimulated DA release (peak DA current, $n A$ ) is attenuated in the NAc core of RGS12-null mice. (E) Electricallystimulated DA release in the NAc shell. RGS12-null mice exhibit a trend towards altered nor-BNI-dependent DA release at select stimulation amplitudes (stimulation $\mathrm{x}$ genotype $\mathrm{x}$ antagonist treatment interaction). (F) nor-BNI treatment reduces DA reuptake $\left(\mathrm{t}_{1 / 2}\right)$ in RGS12-null, but not wildtype, mice. (G) Baseline and nor-BNI-dependent DA reuptake in the NAc shell is not altered in RGS12-null mice relative to wildtype mice. All FSCV data are mean \pm SEM ( $n=6-11$ mice per group) and were analyzed by general linear mixed model ANOVA $\left({ }^{*}, p<0.05\right)$. 


\subsection{2 - RGS12 interacts with KOR and RGS12 loss results in elevated KOR sensitivity and binding sites in the vSTR.}

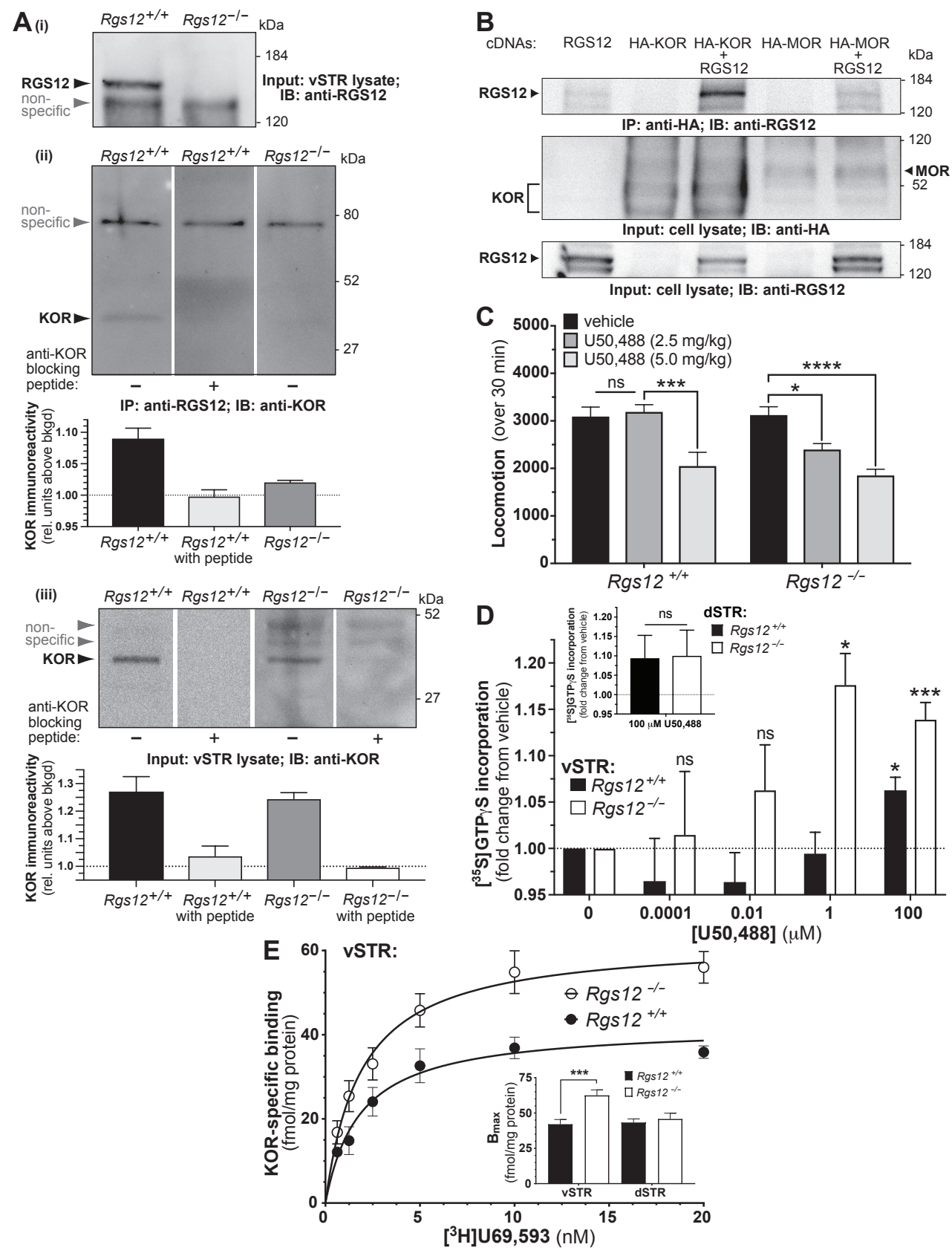

Figure 2. RGS12 interacts with KOR and RGS12 loss results in elevated KOR sensitivity and binding sites in the vSTR. (A) Representative immunoblots indicating that KOR and RGS12 co-immunoprecipitate in the vSTR of wildtype mice ( $N=2$ experiments). 
Subpanel (i) indicates loss of RGS12 immunoreactivity within whole lysates of ventral striatum from Rgs12-null mice. Subpanel (ii) demonstrates that endogenous KOR protein is co-immunoprecipitated from ventral striatal lysate upon immunoprecipitation of endogenous RGS12 protein. Subpanels (ii) and (iii) indicate that immunoblots probed with a mixture of anti-KOR and an anti-KOR blocking peptide yield no KOR immunoreactivity, confirming antibody specificity. Immunoprecipitation of RGS12 in RGS12-null vSTR results in greatly reduced signal of KOR immunoreactivity (see densitometric quantitation below immunoblot of subpanel (ii)), supporting that KOR immunoreactivity in wildtype IP samples is not due to non-specific pull down. (B) Co-immunoprecipitation analyses of HEK293T cells transiently transfected with human opioid receptor (with N-terminal HA-tag) and/or full-length RGS12 vector DNA. Robust content of RGS12 is seen in the anti-HA antibody immunoprecipitate when RGS12 is coexpressed with KOR, whereas co-expression of the related opioid receptor MOR yields only non-specific binding signal (i.e., compare first vs last lanes). Parallel immunoblots containing whole cell lysates resolved by SDS-PAGE demonstrate the presence or absence of RGS12, KOR, and/or MOR expression in appropriate conditions. (C) Total locomotion (over $30 \mathrm{~min}$ ) by RGS12-null mice and wildtype littermate controls following administration of U50,488. RGS12-null, but not wildtype, mice exhibit a hypolocomotor effect to $2.5 \mathrm{mg} / \mathrm{kg}$ U50,488 relative to vehicle controls. At $5 \mathrm{mg} / \mathrm{kg}$ U50,488, RGS12-null and wildtype controls both display reduced locomotor activity relative to vehicle controls. Data are the mean \pm SEM and tested by two-way ANOVA with Dunnet's post hoc test ( $\mathrm{n}$ $=7-13$ mice per group) (ns, $p>0.05 ;{ }^{*}, p<0.05,{ }^{* *}, p<0.001,{ }^{* * *}, p<0.0001$ ). (D) [35S]GTP $\gamma$ incorporation into vSTR membranes from RGS12-null mice and wildtype littermate controls upon activation with KOR agonist U50,488. Data are normalized to 
vehicle (saline) control (expressed as fold change). vSTR membranes from RGS12-null mice exhibit increased sensitivity to $\mathrm{U} 50,488$ relative to wildtype controls. Inset, ${ }^{35}$ S]GTP $\gamma$ binding (at $100 \mu \mathrm{M}$ U50,488) by dSTR membranes from RGS12-null mice and wildtype littermate controls. All data are the mean \pm SEM and tested by two-way ANOVA with Sidak's post hoc test $\left(n=13-19\right.$ mice per group) $\left({ }^{*}, p<0.05,{ }^{* * *} p<0.001\right)$. (E) $\left[{ }^{3} \mathrm{H}\right]$ U69,593 saturation binding analysis of vSTR membranes from RGS12-null $\left(R_{\left.g s 12^{-/}\right)}\right.$mice and wildtype $\left(R_{g s} 12^{+++}\right)$littermate controls. Non-specific binding was determined in the presence of $10 \mu \mathrm{M}$ nor-BNI (KOR antagonist). Inset, As derived from data in panel B and parallel binding data from dSTR membrane samples, $B_{\max }$ was quantified and seen to be increased in vSTR (but not dSTR) of RGS12-null mice (RGS12null vSTR $B_{\max }=62.5 \pm 3.9 \mathrm{fmol} / \mathrm{mg}$ protein vs wildtype vSTR $B_{\max }=42.1 \pm 3.3 \mathrm{fmol} / \mathrm{mg}$ protein). The $\mathrm{K}_{\mathrm{D}}$ for $\left[{ }^{3} \mathrm{H}\right] \mathrm{U} 69,593$ did not differ across genotypes (RGS12-null vSTR: 1.8 $\pm 0.4 \mathrm{nM}$; WT vSTR: $1.8 \pm 0.4 \mathrm{nM})$. Data are the mean \pm SEM and tested by two-way ANOVA with Sidak's post hoc test $\left(n=9-12\right.$ mice per group) $\left({ }^{* \star *}, p<0.001\right)$. 


\subsection{3 - RGS12 differentially regulates KOR agonist-mediated G protein versus $\beta$ -} arrestin signaling cascades and exerts considerable selectivity for KOR over other opioid receptors.
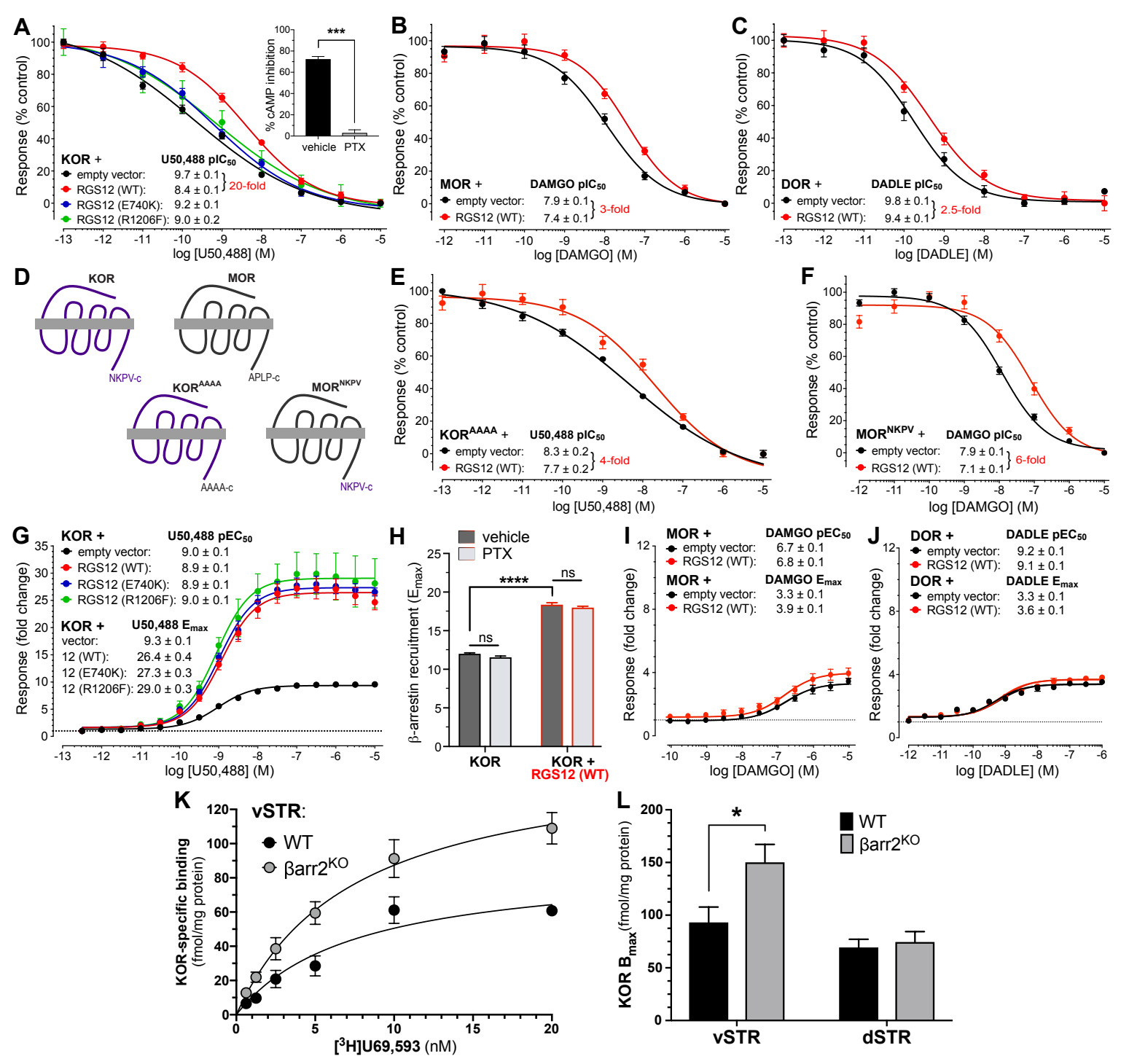

Figure 3. RGS12 expression reduces potency of the KOR agonist U50,488, yet augments agonist-stimulated recruitment of $\beta$-arrestin to KOR via independent mechanisms. (A-C) RGS12 expression reduces potency of the KOR agonist U50,488 to a greater extent than for the MOR agonist DAMGO or the DOR agonist DADLE. GloSensor-22F (Promega) luciferase-based measurements of cAMP levels within 
HEK293T cells stimulated with $100 \mathrm{nM}$ isoproterenol and simultaneously treated with opioid receptor-selective agonists following transient co-expression of (A) KOR cDNA plus indicated RGS12 expression plasmids, (B) MOR cDNA with or without wildtype (WT) RGS12, or (C) DOR cDNA with or without WT RGS12. (A, inset) PTX (200 ng/mL) pretreatment abolished KOR agonist-driven cAMP inhibition, confirming that the assay is dependent on $\mathrm{G}_{\mathrm{i} / \mathrm{o}}$-mediated signaling. Wildtype RGS12 expression reduced U50,488 potency by 20-fold, i.e. 6- to 8-fold more than its effects on DAMGO (3-fold) and DADLE (2.5-fold) potency. Loss-of-function point mutants of RGS12 curtailed U50,488 potency reductions from 20-fold down to 3-to-4-fold. Data were normalized to vehicle control conditions and are expressed as the mean \pm SEM from multiple experiments $(N=3)$. Concentration-response curves were fit by four-parameter non-linear regression (Prism 7). (D-F) The PDZ domain docking site of KOR (-NKPV-c) is necessary, but not sufficient, to completely account for the specificity of RGS12 for KOR over MOR in assays of GPCRmediated G protein signaling. (D) Schematic representing creation of KOR expression cDNA containing mutation to the C-terminus (-NKPV-c to -AAAA-c) and MOR expression cDNA containing mutation of its wildtype C-terminus (MOR: -APLP-C) to KOR's wildtype C-terminus (-NKPV-C). (E) Mutation to the C-terminus of KOR curtailed RGS12-mediated U50,488 potency reductions from 20-fold (e.g., panel A) to 4-fold. (F) RGS12 reduced MOR agonist potency by 6-fold following substitution of the MOR C-terminus with the wildtype KOR C-terminus, relative to a 3-fold potency reduction observed with wildtype MOR (e.g., panel B). Data are normalized to vehicle control and expressed as mean \pm SEM from $\mathrm{N}=3$ experiments. Dose-response curves fit by four parameter non-linear regression (Prism). (G-J) RGS12 expression augments agonist-stimulated recruitment of $\beta$-arrestin to KOR, but not MOR nor DOR, in a G protein-independent manner. Tango 
assays of $\beta$-arrestin recruitment within HTLA cells (Barnea et al., 2008; Allen et al., 2011) stimulated with indicated agonists following transient co-expression of $(\mathbf{G})$ KOR cDNA plus indicated RGS12 expression plasmids, (H) KOR cDNA with or without WT RGS12 following pretreatment with PTX or vehicle, (I) MOR cDNA with or without WT RGS12, or (J) DOR cDNA with or without WT RGS12. Agonist potency (pEC50 values) did not differ between conditions. U50,488-induced $\beta$-arrestin recruitment efficacy was $\sim 3$-fold greater when either WT RGS12, or loss-of-function point mutants of RGS12, was co-expressed with KOR, whereas WT RGS12 only increased $\beta$-arrestin recruitment to MOR by 1.2 -fold and DOR by 1.1 -fold. PTX pretreatment did not affect U50,488-induced $\beta$-arrestin recruitment to KOR (panel $H$ ) in the presence or absence of WT RGS12. Data were normalized to vehicle control conditions (fold change) and are expressed as the mean \pm SEM from multiple experiments $(\mathrm{N}=3)$. Curves were analyzed by three-parameter nonlinear regression and panel $\mathrm{H}$ was analyzed by two-way ANOVA with Sidak's post hoc test. (K) $\left[{ }^{3} \mathrm{H}\right] \cup 69,593$ saturation binding analysis of vSTR membranes from $\beta$-arrestin-2 knockout ( $\beta$ arr2 ${ }^{\mathrm{KO}}$ ) mice and wildtype (WT) controls. (L) As derived from data in panel $\mathrm{K}$ and parallel binding data from dSTR membrane samples, $B_{\max }$ was increased in vSTR (but not dSTR) of $\beta$-arrestin-2 knockout ( $\beta$ arr2 ${ }^{\mathrm{KO}}$ vSTR $\mathrm{B}_{\max }=150.1 \pm 17.1 \mathrm{fmol} / \mathrm{mg}$ protein vs wildtype vSTR $B_{\max }=93.1 \pm 14.6 \mathrm{fmol} / \mathrm{mg}$ protein; $\beta$ arr2 ${ }^{\mathrm{KO}} \mathrm{dSTR} \mathrm{B}_{\max }=74.5$ $\pm 9.8 \mathrm{fmol} / \mathrm{mg}$ protein vs wildtype dSTR $B_{\max }=69.3 \pm 7.7 \mathrm{fmol} / \mathrm{mg}$ protein). The $\mathrm{K}_{D}$ for $\left[{ }^{3} \mathrm{H}\right]$ U69,593 did not differ across genotypes ( $\beta$ arr2 ${ }^{\mathrm{KO}}$ vSTR: $7.1 \pm 1.8 \mathrm{nM}$; WT vSTR: 8.4 $\pm 2.9 \mathrm{nM}$; $\beta$ arr2 ${ }^{\mathrm{KO}}$ dSTR: $7.8 \pm 2.3 \mathrm{nM}$; WT dSTR: $6.6 \pm 1.7 \mathrm{nM}$;). Data are the mean \pm SEM and panel $L$ was analyzed by two-way ANOVA with Sidak's post hoc test $(n=12$ mice per group) $\left({ }^{*}, p<0.05\right)$. 


\subsection{4 - RGS12-null mice display differential behavioral responses to KOR agonists.}

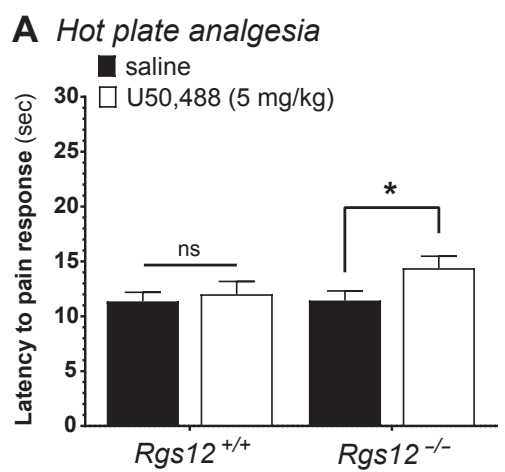

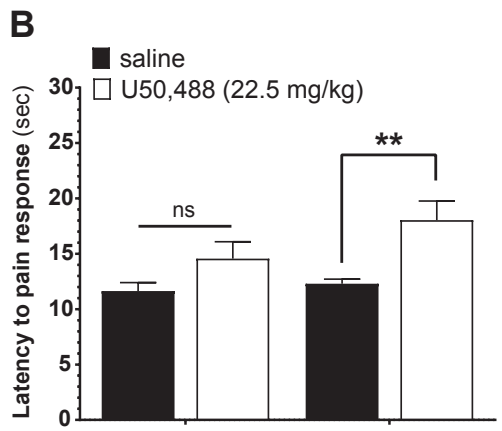

Rgs12 ${ }^{+/+} \quad$ Rgs12 $^{-/-}$

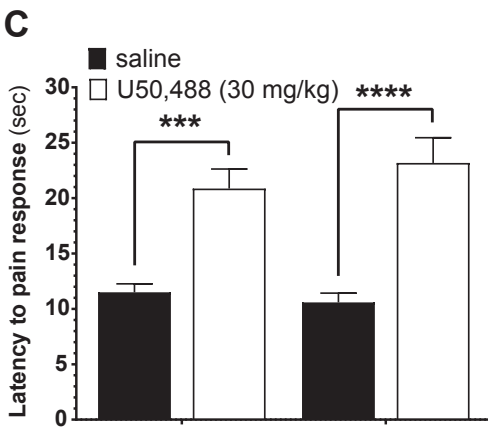

Rgs $12^{+/+}$

Rgs12-/-

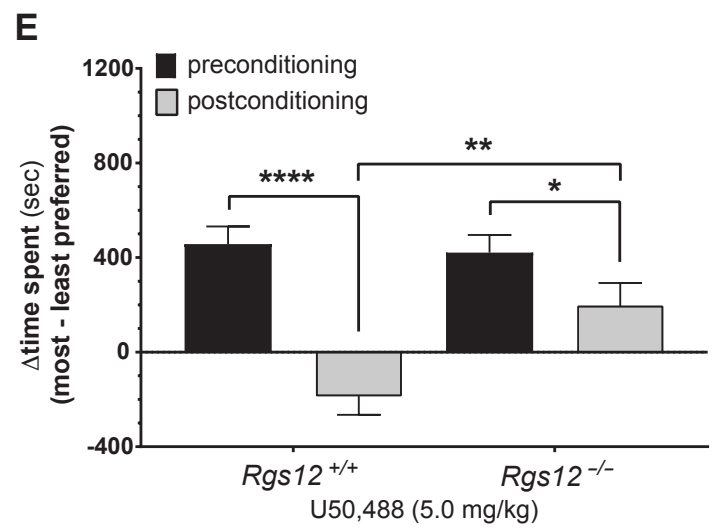

Figure 4. RGS12-null mice exhibit a heightened sensitivity to the analgesic effect of U50,488 administration but attenuated conditioned place aversion (CPA) to the aversive effects of U50,488. U50,488-induced analgesia at a dose of (A) $5 \mathrm{mg} / \mathrm{kg}$, (B) $22.5 \mathrm{mg} / \mathrm{kg}$, or (C) $30 \mathrm{mg} / \mathrm{kg}$ was measured in RGS12-null $\left(\mathrm{Rgs}_{12^{\prime /}}\right)$ mice vs WT $\left(R g s 12^{+/+}\right)$littermate controls using a hot plate latency test. Data are the mean \pm SEM and tested by two-way repeated-measures (within-subjects design) ANOVA followed by Sidak's post hoc test (n $=8-10$ mice per group) (ns, not significantly different; ${ }^{*}, \mathrm{p}<0.05 ;{ }^{* *}, \mathrm{p}<0.01 ;{ }^{* \star *}, \mathrm{p}<$ $\left.0.001{ }^{* * * *}, p<0.0001\right)$. (D-E) RGS12-null mice exhibit attenuated conditioned place aversion (CPA) to the aversive effects of U50,488. $2.5 \mathrm{mg} / \mathrm{kg}$ (D) or $5.0 \mathrm{mg} / \mathrm{kg}$ (E) of

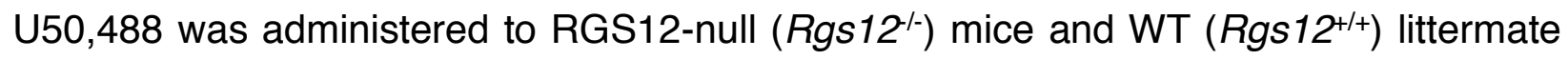
controls to test for conditioned place aversion (a measure of the dysphoric property of 
KOR agonism). Data are the mean \pm SEM and tested by two-way repeated-measures ANOVA (for within-subjects comparisons) and between-subjects ANOVA (for betweensubjects comparisons) each followed by Sidak's post hoc test ( $n=8-15$ mice per group; $\left.{ }^{*}, p<0.05 ;{ }^{* *}, p<0.01 ;{ }^{* * * *}, p<0.0001\right)$. 


\subsection{5 - Proposed model of RGS12 action in the differential outputs of KOR-activated} signaling.
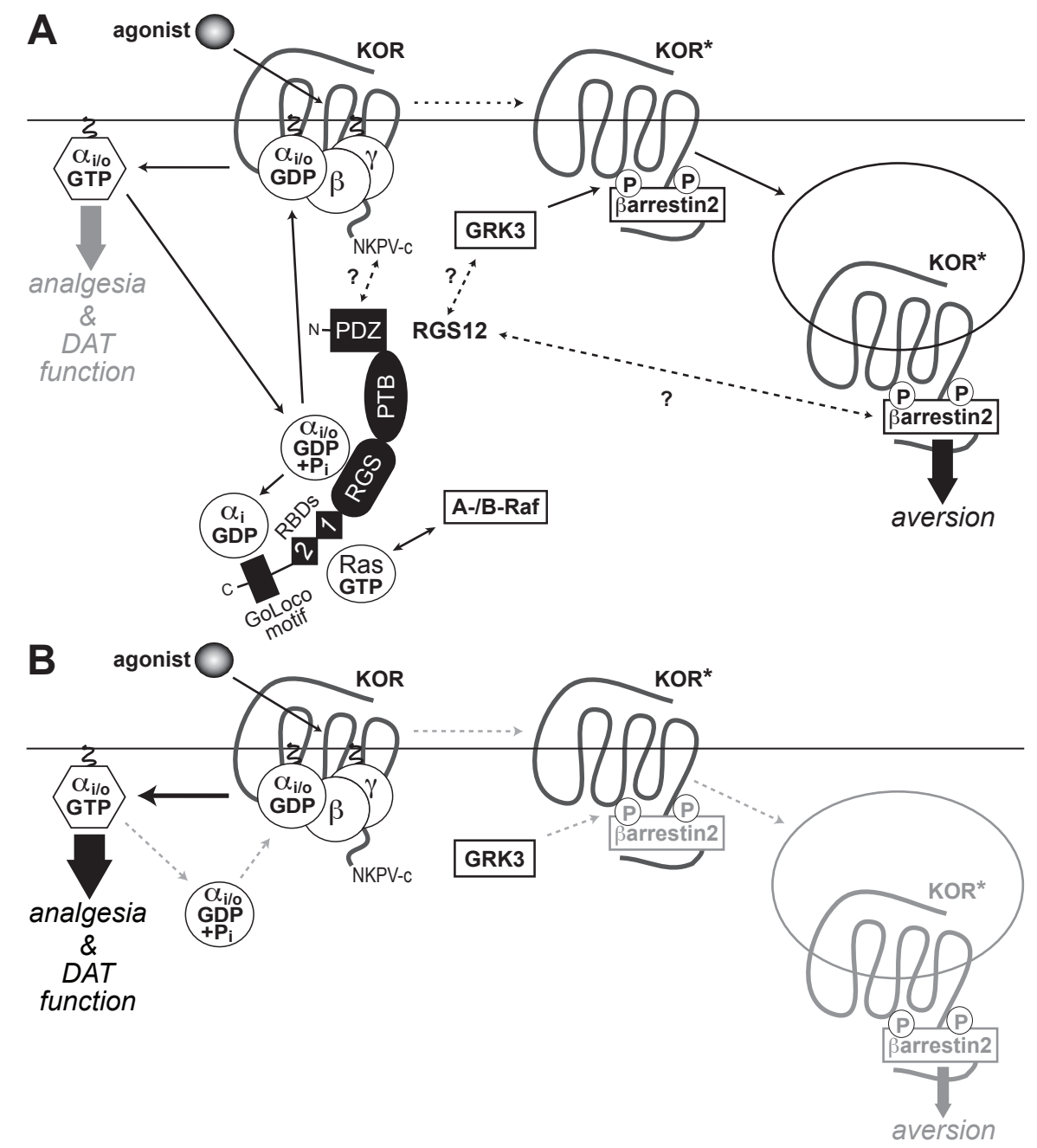

Figure 5. Proposed model of RGS12 action in the differential outputs of KOR-activated

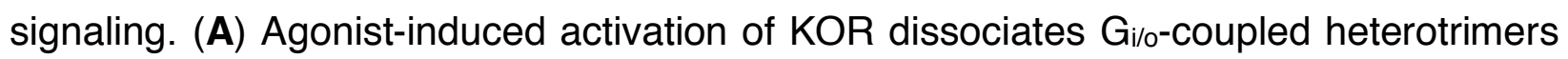
into free $\mathrm{G}$ protein subunits, evokes $\mathrm{G}$ protein-dependent signal transduction (thick grey arrow) and, ultimately, produces analgesia and regulates DAT function. RGS12 expression is seen to reduce KOR-mediated G protein signaling via its central RGS 
domain (by accelerating GTP hydrolysis of Goi/o.GTP) and its C-terminal GoLoco motif (by binding $\mathrm{G}_{\mathrm{i}} \cdot \mathrm{GDP}$ ). RGS12 also contains an N-terminal PDZ domain that interacts with MEK2 (Willard et al., 2007) and findings from this study suggest interaction with the C-terminal PDZ domain docking site of KOR (NKPV-c). RGS12 also contains tandem Ras-binding domains (RBDs) that interact with activated H-Ras and A-/B-Raf to enable MAPK/ERK scaffolding properties (Willard et al., 2007). Agonist-stimulated KOR activation is also known to drive GRK3-dependent $\beta$-arrestin-2 recruitment (Bruchas and Chavkin, 2010), resulting in receptor internalization, $\beta$-arrestin-dependent signal transduction (thick black arrow) and, ultimately, aversive behavior. RGS12 expression is seen to augment KOR agonist-stimulated $\beta$-arrestin recruitment independent of its GAP and GDI activity, suggesting that RGS12 may modulate GRK3 activity on activated KOR $\left(\mathrm{KOR}^{\star}\right)$ and/or enhance $\beta$-arrestin-2 recruitment and/or function by as yet undetermined molecular mechanisms (represented by question marks over dashed arrows). (B) Loss of RGS12 in mice results in concomitant increases in KOR-mediated G protein signaling and decreases in $\beta$-arrestin-2 recruitment, thus resulting in enhanced KOR agoniststimulated analgesia and disrupted DAT function (thicker black arrow), as well as an attenuation of KOR-stimulated aversion (thinner grey arrow), respectively. 


\section{7 - References}

1. Crowley NA, Kash TL. Kappa opioid receptor signaling in the brain: Circuitry and implications for treatment. Prog Neuropsychopharmacol Biol Psychiatry 2015;62:51-60.

2. Chavkin C, Koob GF. Dynorphin, Dysphoria, and Dependence: the Stress of Addiction. Neuropsychopharmacology 2016;41:373-374.

3. Schindler AG, Messinger DI, Smith JS, Shankar H, Gustin RM, Schattauer SS, et al. Stress produces aversion and potentiates cocaine reward by releasing endogenous dynorphins in the ventral striatum to locally stimulate serotonin reuptake. J Neurosci 2012;32:17582-17596.

4. Van't Veer A, Carlezon WA, Jr. Role of kappa-opioid receptors in stress and anxiety-related behavior. Psychopharmacology (Berl) 2013;229:435-452.

5. Schenk S, Partridge B, Shippenberg TS. U69593, a kappa-opioid agonist, decreases cocaine self-administration and decreases cocaine-produced drug-seeking. Psychopharmacology (Berl) 1999;144:339-346.

6. Chartoff EH, Ebner SR, Sparrow A, Potter D, Baker PM, Ragozzino ME, et al. Relative Timing Between Kappa Opioid Receptor Activation and Cocaine Determines the Impact on Reward and Dopamine Release. Neuropsychopharmacology 2016;41:989-1002.

7. Chavkin C. The therapeutic potential of kappa-opioids for treatment of pain and addiction. Neuropsychopharmacology 2011;36:369-370.

8. Carlezon WA, Jr., Krystal AD. Kappa-Opioid Antagonists for Psychiatric Disorders: From Bench to Clinical Trials. Depress Anxiety 2016;33:895-906.

9. Kolodny A, Courtwright DT, Hwang CS, Kreiner P, Eadie JL, Clark TW, et al. The prescription opioid and heroin crisis: a public health approach to an epidemic of addiction. Annu Rev Public Health 2015;36:559-574.

10. Koh H. Community Approaches to the Opioid Crisis. JAMA 2015;314:1437-1438.

11. Volkow ND, Collins FS. The Role of Science in Addressing the Opioid Crisis. N Engl J Med 2017.

12. Kaski SW, Brooks S, Wen S, Haut MW, Siderovski DP, Berry JH, et al. Four single nucleotide polymorphisms in genes involved in neuronal signaling are associated with Opioid Use Disorder in West Virginia. J Opioid Manag 2019;15:103-109. 
13. Bohn LM, Aube J. Seeking (and Finding) Biased Ligands of the Kappa Opioid Receptor. ACS Med Chem Lett 2017;8:694-700.

14. Ehrich JM, Messinger DI, Knakal CR, Kuhar JR, Schattauer SS, Bruchas MR, et al. Kappa Opioid Receptor-Induced Aversion Requires p38 MAPK Activation in VTA Dopamine Neurons. J Neurosci 2015;35:12917-12931.

15. White KL, Robinson JE, Zhu H, DiBerto JF, Polepally PR, Zjawiony JK, et al. The G proteinbiased kappa-opioid receptor agonist RB-64 is analgesic with a unique spectrum of activities in vivo. J Pharmacol Exp Ther 2015;352:98-109.

16. Brust TF, Morgenweck J, Kim SA, Rose JH, Locke JL, Schmid CL, et al. Biased agonists of the kappa opioid receptor suppress pain and itch without causing sedation or dysphoria. Sci Signal 2016;9:ra117.

17. Liu JJ, Sharma K, Zangrandi L, Chen C, Humphrey SJ, Chiu YT, et al. In vivo brain GPCR signaling elucidated by phosphoproteomics. Science 2018;360.

18. Urban JD, Clarke WP, von Zastrow M, Nichols DE, Kobilka B, Weinstein $\mathrm{H}$, et al. Functional selectivity and classical concepts of quantitative pharmacology. J Pharmacol Exp Ther 2007;320:1-13.

19. Rankovic Z, Brust TF, Bohn LM. Biased agonism: An emerging paradigm in GPCR drug discovery. Bioorg Med Chem Lett 2016;26:241-250.

20. Che T, Majumdar S, Zaidi SA, Ondachi P, McCorvy JD, Wang S, et al. Structure of the Nanobody-Stabilized Active State of the Kappa Opioid Receptor. Cell 2018;172:55-67 e15.

21. Siderovski DP, Willard FS. The GAPs, GEFs, and GDIs of heterotrimeric G-protein alpha subunits. Int J Biol Sci 2005;1:51-66.

22. Karkhanis A, Holleran KM, Jones SR. Dynorphin/Kappa Opioid Receptor Signaling in Preclinical Models of Alcohol, Drug, and Food Addiction. Int Rev Neurobiol 2017;136:53-88.

23. Schoffelmeer AN, Rice KC, Jacobson AE, Van Gelderen JG, Hogenboom F, Heijna MH, et al. Mu-, delta- and kappa-opioid receptor-mediated inhibition of neurotransmitter release and adenylate cyclase activity in rat brain slices: studies with fentanyl isothiocyanate. Eur J Pharmacol 1988;154:169-178.

24. Tallent M, Dichter MA, Bell GI, Reisine T. The cloned kappa opioid receptor couples to an $\mathrm{N}$-type calcium current in undifferentiated PC-12 cells. Neuroscience 1994;63:1033-1040. 
25. Henry DJ, Grandy DK, Lester HA, Davidson N, Chavkin C. Kappa-opioid receptors couple to inwardly rectifying potassium channels when coexpressed by Xenopus oocytes. Mol Pharmacol 1995;47:551-557.

26. McLaughlin JP, Xu M, Mackie K, Chavkin C. Phosphorylation of a carboxyl-terminal serine within the kappa-opioid receptor produces desensitization and internalization. J Biol Chem 2003;278:34631-34640.

27. Bruchas MR, Macey TA, Lowe JD, Chavkin C. Kappa opioid receptor activation of p38 MAPK is GRK3- and arrestin-dependent in neurons and astrocytes. J Biol Chem 2006;281:1808118089.

28. Chavkin C, Schattauer SS, Levin JR. Arrestin-mediated activation of p38 MAPK: molecular mechanisms and behavioral consequences. Handb Exp Pharmacol 2014;219:281-292.

29. Hernandez A, Soto-Moyano R, Mestre C, Eschalier A, Pelissier T, Paeile C, et al. Intrathecal pertussis toxin but not cyclic AMP blocks kappa opioid-induced antinociception in rat. Int J Neurosci 1995;81:193-197.

30. Schattauer SS, Kuhar JR, Song A, Chavkin C. Nalfurafine is a G-protein biased agonist having significantly greater bias at the human than rodent form of the kappa opioid receptor. Cell Signal 2017;32:59-65.

31. Soundararajan M, Willard FS, Kimple AJ, Turnbull AP, Ball U, Schoch GA, et al. Structural diversity in the RGS domain and its interaction with heterotrimeric $G$ protein alpha-subunits. Proc Natl Acad Sci U S A 2008;105:6457-6462.

32. Snow BE, Hall RA, Krumins AM, Brothers GM, Bouchard D, Brothers CA, et al. GTPase activating specificity of RGS12 and binding specificity of an alternatively spliced PDZ (PSD95/Dlg/ZO-1) domain. J Biol Chem 1998;273:17749-17755.

33. Lambert NA, Johnston CA, Cappell SD, Kuravi S, Kimple AJ, Willard FS, et al. Regulators of G-protein signaling accelerate GPCR signaling kinetics and govern sensitivity solely by accelerating GTPase activity. Proc Natl Acad Sci U S A 2010;107:7066-7071.

34. Han $\mathrm{MH}$, Renthal W, Ring RH, Rahman Z, Psifogeorgou K, Howland D, et al. Brain region specific actions of regulator of $\mathrm{G}$ protein signaling 4 oppose morphine reward and dependence but promote analgesia. Biol Psychiatry 2010;67:761-769.

35. Traynor J. mu-Opioid receptors and regulators of $G$ protein signaling (RGS) proteins: from a symposium on new concepts in mu-opioid pharmacology. Drug Alcohol Depend 2012;121:173180. 
36. Anderson GR, Posokhova E, Martemyanov KA. The R7 RGS protein family: multi-subunit regulators of neuronal G protein signaling. Cell Biochem Biophys 2009;54:33-46.

37. Shu FJ, Ramineni S, Hepler JR. RGS14 is a multifunctional scaffold that integrates G protein and Ras/Raf MAPkinase signalling pathways. Cell Signal 2010;22:366-376.

38. Willard MD, Willard FS, Li X, Cappell SD, Snider WD, Siderovski DP. Selective role for RGS12 as a Ras/Raf/MEK scaffold in nerve growth factor-mediated differentiation. EMBO J 2007;26:2029-2040.

39. Webb CK, McCudden CR, Willard FS, Kimple RJ, Siderovski DP, Oxford GS. D2 dopamine receptor activation of potassium channels is selectively decoupled by Galpha-specific GoLoco motif peptides. J Neurochem 2005;92:1408-1418.

40. Gross JD, Kaski SW, Schroer AB, Wix KA, Siderovski DP, Setola V. Regulator of G protein signaling-12 modulates the dopamine transporter in ventral striatum and locomotor responses to psychostimulants. J Psychopharmacol 2018;32:191-203.

41. Chao J, Nestler EJ. Molecular neurobiology of drug addiction. Annu Rev Med 2004;55:113132.

42. Russo SJ, Nestler EJ. The brain reward circuitry in mood disorders. Nat Rev Neurosci 2013;14:609-625.

43. Bruijnzeel AW. kappa-Opioid receptor signaling and brain reward function. Brain Res Rev 2009;62:127-146.

44. Knoll AT, Carlezon WA, Jr. Dynorphin, stress, and depression. Brain Res 2010;1314:56-73.

45. Chefer VI, Backman CM, Gigante ED, Shippenberg TS. Kappa opioid receptors on dopaminergic neurons are necessary for kappa-mediated place aversion. Neuropsychopharmacology 2013;38:2623-2631.

46. Di Chiara G, Imperato A. Opposite effects of mu and kappa opiate agonists on dopamine release in the nucleus accumbens and in the dorsal caudate of freely moving rats. J Pharmacol Exp Ther 1988;244:1067-1080.

47. Donzanti BA, Althaus JS, Payson MM, Von Voigtlander PF. Kappa agonist-induced reduction in dopamine release: site of action and tolerance. Res Commun Chem Pathol Pharmacol 1992;78:193-210.

48. Thompson AC, Zapata A, Justice JB, Jr., Vaughan RA, Sharpe LG, Shippenberg TS. Kappaopioid receptor activation modifies dopamine uptake in the nucleus accumbens and opposes the effects of cocaine. J Neurosci 2000;20:9333-9340. 
49. Kivell B, Uzelac Z, Sundaramurthy S, Rajamanickam J, Ewald A, Chefer V, et al. Salvinorin $A$ regulates dopamine transporter function via a kappa opioid receptor and ERK1/2-dependent mechanism. Neuropharmacology 2014;86:228-240.

50. Schmidt KT, Makhijani VH, Boyt KM, Cogan ES, Pati D, Pina MM, et al. Stress-Induced Alterations of Norepinephrine Release in the Bed Nucleus of the Stria Terminalis of Mice. ACS Chem Neurosci 2018.

51. Zhou L, Stahl EL, Lovell KM, Frankowski KJ, Prisinzano TE, Aube J, et al. Characterization of kappa opioid receptor mediated, dynorphin-stimulated [35S]GTPgammaS binding in mouse striatum for the evaluation of selective KOR ligands in an endogenous setting. Neuropharmacology 2015;99:131-141.

52. Jordan M, Schallhorn A, Wurm FM. Transfecting mammalian cells: optimization of critical parameters affecting calcium-phosphate precipitate formation. Nucleic Acids Res 1996;24:596601.

53. Barnea G, Strapps W, Herrada G, Berman Y, Ong J, Kloss B, et al. The genetic design of signaling cascades to record receptor activation. Proc Natl Acad Sci U S A 2008;105:64-69.

54. Allen JA, Yost JM, Setola V, Chen X, Sassano MF, Chen M, et al. Discovery of beta-arrestinbiased dopamine D2 ligands for probing signal transduction pathways essential for antipsychotic efficacy. Proc Natl Acad Sci U S A 2011;108:18488-18493.

55. Bohn LM, Lefkowitz RJ, Gainetdinov RR, Peppel K, Caron MG, Lin FT. Enhanced morphine analgesia in mice lacking beta-arrestin 2. Science 1999;286:2495-2498.

56. Yorgason JT, Espana RA, Jones SR. Demon voltammetry and analysis software: analysis of cocaine-induced alterations in dopamine signaling using multiple kinetic measures. J Neurosci Methods 2011;202:158-164.

57. Threlfell S, Lalic T, Platt NJ, Jennings KA, Deisseroth K, Cragg SJ. Striatal dopamine release is triggered by synchronized activity in cholinergic interneurons. Neuron 2012;75:58-64.

58. Melchior JR, Ferris MJ, Stuber GD, Riddle DR, Jones SR. Optogenetic versus electrical stimulation of dopamine terminals in the nucleus accumbens reveals local modulation of presynaptic release. J Neurochem 2015;134:833-844.

59. Castellano C, Ammassari-Teule M, Libri V, Pavone F. Effects of kappa-opioid receptor agonists on locomotor activity and memory processes in mice. Pol J Pharmacol Pharm 1988;40:507-513. 
60. Bohn LM, Zhou L, Ho JH. Approaches to Assess Functional Selectivity in GPCRs: Evaluating G Protein Signaling in an Endogenous Environment. Methods Mol Biol 2015;1335:177-189.

61. Pan ZZ. mu-Opposing actions of the kappa-opioid receptor. Trends Pharmacol Sci 1998;19:94-98.

62. Al-Hasani R, Bruchas MR. Molecular mechanisms of opioid receptor-dependent signaling and behavior. Anesthesiology 2011;115:1363-1381.

63. Sambi BS, Hains MD, Waters CM, Connell MC, Willard FS, Kimple AJ, et al. The effect of RGS12 on PDGFbeta receptor signalling to p42/p44 mitogen activated protein kinase in mammalian cells. Cell Signal 2006;18:971-981.

64. Kimple RJ, Kimple ME, Betts L, Sondek J, Siderovski DP. Structural determinants for GoLoco-induced inhibition of nucleotide release by Galpha subunits. Nature 2002;416:878-881.

65. Li JG, Chen C, Liu-Chen LY. Ezrin-radixin-moesin-binding phosphoprotein-50/Na+/H+ exchanger regulatory factor (EBP50/NHERF) blocks U50,488H-induced down-regulation of the human kappa opioid receptor by enhancing its recycling rate. J Biol Chem 2002;277:27545-27552.

66. Sora I, Takahashi N, Funada M, Ujike H, Revay RS, Donovan DM, et al. Opiate receptor knockout mice define mu receptor roles in endogenous nociceptive responses and morphineinduced analgesia. Proc Natl Acad Sci U S A 1997;94:1544-1549.

67. Pasternak GW. Molecular insights into mu opioid pharmacology: From the clinic to the bench. Clin J Pain 2010;26 Suppl 10:S3-9.

68. Land BB, Bruchas MR, Schattauer S, Giardino WJ, Aita M, Messinger D, et al. Activation of the kappa opioid receptor in the dorsal raphe nucleus mediates the aversive effects of stress and reinstates drug seeking. Proc Natl Acad Sci U S A 2009;106:19168-19173.

69. Vien TN, Gleason CA, Hays SL, McPherson RJ, Chavkin C, Juul SE. Effects of neonatal stress and morphine on kappa opioid receptor signaling. Neonatology 2009;96:235-243.

70. Karkhanis AN, Rose JH, Weiner JL, Jones SR. Early-Life Social Isolation Stress Increases Kappa Opioid Receptor Responsiveness and Downregulates the Dopamine System. Neuropsychopharmacology 2016;41:2263-2274.

71. Yorgason JT, Calipari ES, Ferris MJ, Karkhanis AN, Fordahl SC, Weiner JL, et al. Social isolation rearing increases dopamine uptake and psychostimulant potency in the striatum. Neuropharmacology 2016;101:471-479. 
72. Martin-McCaffrey L, Hains MD, Pritchard GA, Pajak A, Dagnino L, Siderovski DP, et al. Differential expression of regulator of G-protein signaling R12 subfamily members during mouse development. Dev Dyn 2005;234:438-444.

73. Butko MT, Savas JN, Friedman B, Delahunty C, Ebner F, Yates JR, 3rd, et al. In vivo quantitative proteomics of somatosensory cortical synapses shows which protein levels are modulated by sensory deprivation. Proc Natl Acad Sci U S A 2013;110:E726-735.

74. Sialana FJ, Wang AL, Fazari B, Kristofova M, Smidak R, Trossbach SV, et al. Quantitative Proteomics of Synaptosomal Fractions in a Rat Overexpressing Human DISC1 Gene Indicates Profound Synaptic Dysregulation in the Dorsal Striatum. Front Mol Neurosci 2018;11:26.

75. Saunders A, Macosko EZ, Wysoker A, Goldman M, Krienen FM, de Rivera H, et al. Molecular Diversity and Specializations among the Cells of the Adult Mouse Brain. Cell 2018;174:1015-1030 e1016.

76. Calipari ES, Bagot RC, Purushothaman I, Davidson TJ, Yorgason JT, Pena CJ, et al. In vivo imaging identifies temporal signature of D1 and D2 medium spiny neurons in cocaine reward. Proc Natl Acad Sci U S A 2016;113:2726-2731.

77. Tejeda HA, Wu J, Kornspun AR, Pignatelli M, Kashtelyan V, Krashes MJ, et al. Pathwayand Cell-Specific Kappa-Opioid Receptor Modulation of Excitation-Inhibition Balance Differentially Gates D1 and D2 Accumbens Neuron Activity. Neuron 2017;93:147-163.

78. Melchior JR, Jones SR. Chronic ethanol exposure increases inhibition of optically targeted phasic dopamine release in the nucleus accumbens core and medial shell ex vivo. Mol Cell Neurosci 2017;85:93-104.

79. Mansour A, Fox CA, Akil H, Watson SJ. Opioid-receptor mRNA expression in the rat CNS: anatomical and functional implications. Trends Neurosci 1995;18:22-29.

80. Resendez SL, Keyes PC, Day JJ, Hambro C, Austin CJ, Maina FK, et al. Dopamine and opioid systems interact within the nucleus accumbens to maintain monogamous pair bonds. Elife 2016;5.

81. Nirenberg MJ, Chan J, Pohorille A, Vaughan RA, Uhl GR, Kuhar MJ, et al. The dopamine transporter: comparative ultrastructure of dopaminergic axons in limbic and motor compartments of the nucleus accumbens. J Neurosci 1997;17:6899-6907.

82. Chen N, Reith ME. Substrates and inhibitors display different sensitivity to expression level of the dopamine transporter in heterologously expressing cells. J Neurochem 2007;101:377388. 
83. Robinson DL, Venton BJ, Heien ML, Wightman RM. Detecting subsecond dopamine release with fast-scan cyclic voltammetry in vivo. Clin Chem 2003;49:1763-1773.

84. Phillips PE, Hancock PJ, Stamford JA. Time window of autoreceptor-mediated inhibition of limbic and striatal dopamine release. Synapse 2002;44:15-22.

85. McGinnis MM, Siciliano CA, Jones SR. Dopamine D3 autoreceptor inhibition enhances cocaine potency at the dopamine transporter. J Neurochem 2016;138:821-829.

86. Bermingham DP, Blakely RD. Kinase-dependent Regulation of Monoamine Neurotransmitter Transporters. Pharmacol Rev 2016;68:888-953.

87. Richardson BD, Saha K, Krout D, Cabrera E, Felts B, Henry LK, et al. Membrane potential shapes regulation of dopamine transporter trafficking at the plasma membrane. Nat Commun 2016;7:10423.

88. Gowrishankar R, Gresch PJ, Davis GL, Katamish RM, Riele JR, Stewart AM, et al. RegionSpecific Regulation of Presynaptic Dopamine Homeostasis by D2 Autoreceptors Shapes the In Vivo Impact of the Neuropsychiatric Disease-Associated DAT Variant Val559. J Neurosci 2018;38:5302-5312.

89. Gray AM, Rawls SM, Shippenberg TS, McGinty JF. The kappa-opioid agonist, U-69593, decreases acute amphetamine-evoked behaviors and calcium-dependent dialysate levels of dopamine and glutamate in the ventral striatum. J Neurochem 1999;73:1066-1074.

90. Marcott PF, Gong S, Donthamsetti P, Grinnell SG, Nelson MN, Newman AH, et al. Regional Heterogeneity of D2-Receptor Signaling in the Dorsal Striatum and Nucleus Accumbens. Neuron 2018;98:575-587 e574.

91. Lein ES, Hawrylycz MJ, Ao N, Ayres M, Bensinger A, Bernard A, et al. Genome-wide atlas of gene expression in the adult mouse brain. Nature 2007;445:168-176.

92. Lipp J. Possible mechanisms of morphine analgesia. Clin Neuropharmacol 1991;14:131147.

93. Jensen TS. Opioids in the brain: supraspinal mechanisms in pain control. Acta Anaesthesiol Scand 1997;41:123-132.

94. Altier N, Stewart J. The role of dopamine in the nucleus accumbens in analgesia. Life Sci 1999;65:2269-2287.

95. Gear RW, Aley KO, Levine JD. Pain-induced analgesia mediated by mesolimbic reward circuits. J Neurosci 1999;19:7175-7181. 
96. Hylden JL, Nahin RL, Traub RJ, Dubner R. Effects of spinal kappa-opioid receptor agonists on the responsiveness of nociceptive superficial dorsal horn neurons. Pain 1991;44:187-193.

97. Cai X, Huang H, Kuzirian MS, Snyder LM, Matsushita M, Lee MC, et al. Generation of a KOR-Cre knockin mouse strain to study cells involved in kappa opioid signaling. Genesis 2016;54:29-37.

98. Todd AJ. Neuronal circuitry for pain processing in the dorsal horn. Nat Rev Neurosci 2010;11:823-836.

99. Tsai NP, Tsui YC, Pintar JE, Loh HH, Wei LN. Kappa opioid receptor contributes to EGFstimulated neurite extension in development. Proc Natl Acad Sci U S A 2010;107:3216-3221.

100. Xu M, Petraschka M, McLaughlin JP, Westenbroek RE, Caron MG, Lefkowitz RJ, et al. Neuropathic pain activates the endogenous kappa opioid system in mouse spinal cord and induces opioid receptor tolerance. J Neurosci 2004;24:4576-4584.

101. Simonin F, Valverde O, Smadja C, Slowe S, Kitchen I, Dierich A, et al. Disruption of the kappa-opioid receptor gene in mice enhances sensitivity to chemical visceral pain, impairs pharmacological actions of the selective kappa-agonist $\mathrm{U}-50,488 \mathrm{H}$ and attenuates morphine withdrawal. EMBO J 1998;17:886-897.

102. Shippenberg TS, Bals-Kubik R, Herz A. Examination of the neurochemical substrates mediating the motivational effects of opioids: role of the mesolimbic dopamine system and D-1 vs. D-2 dopamine receptors. J Pharmacol Exp Ther 1993;265:53-59.

103. Bruchas MR, Chavkin C. Kinase cascades and ligand-directed signaling at the kappa opioid receptor. Psychopharmacology (Berl) 2010;210:137-147. 


\section{8 - Supplementary Information}

\subsection{1 - Supplementary Methods}

\subsection{1a - $\beta$-Arrestin-2 deficient animals}

Male and female $\beta$-arrestin-2 knockout ( $\beta$ arr2 ${ }^{\mathrm{KO}}$ ) (JAX Stock 023852) and wildtype C57BL/6 control mice (JAX Stock 000664) were purchased from The Jackson Laboratory (Bar Harbor, ME) and housed under identical conditions to RGS12-null and wildtype littermates.

\subsection{1b - Synaptosomal [ $\left.{ }^{3} \mathrm{H}\right] \mathrm{DA}$ uptake}

Synaptosomal $\left[{ }^{3} \mathrm{H}\right] \mathrm{DA}$ uptake was performed as described (Gross et al., 2018) with minor modifications. Briefly, RGS12-null mice and wildtype littermates were administered vehicle $(0.9 \% \mathrm{NaCl})$ or nor-BNI $(10 \mathrm{mg} / \mathrm{kg}$, ip) 24 hours prior to dissection. Ventral striata were then extracted and synaptosomes prepared as described (Gross et al., 2018). Synaptosomal fractions were incubated with $0.8 \mu \mathrm{M}$ DA (with $\left[{ }^{3} \mathrm{H}\right] \mathrm{DA}$ content diluted to 8 nM final concentration) in Krebs-Ringer buffer (Gross et al., 2018) for 10 minutes. Nonspecific uptake was determined in the presence of DAT-selective reuptake inhibitor GBR12935. Uptake reactions were terminated by filtration over Whatman GF/B filters with ice-cold Krebs-Ringer buffer, washed three times, and measured via liquid scintillation counting. $\left[{ }^{3} \mathrm{H}\right] \mathrm{DA}$ uptake analyses in tissue samples from $\beta$ arr ${ }^{\mathrm{KO}}$ and wildtype control mice were performed identically to RGS12-null and wildtype littermates, except that these mice did not receive vehicle or nor-BNI pretreatment before testing.

\subsection{1c - Locomotor activity}

AMPH-induced locomotor activity was measured as described (Gross et al., 2018) with the following modifications: RGS12-null mice and wildtype littermates received vehicle $(0.9 \% \mathrm{NaCl})$ or nor-BNI (10 mg/kg, ip) 24 hours prior to quantification of $\mathrm{AMPH}$-induced 
hyperlocomotion. For U50,488-induced locomotion, RGS12-null mice and wildtype littermates were administered vehicle ( $0.9 \%$ saline, ip) or U50,488 (2.5 or $5 \mathrm{mg} / \mathrm{kg}$, ip), immediately placed into open-field chambers (San Diego Instruments), and $X, Y$ coordinate beam breaks measured in five-min bins for 30 minutes.

\subsection{1d - Fast-scan cyclic voltammetry (FSCV)}

RGS12-null and wildtype littermates were injected with $10 \mathrm{mg} / \mathrm{kg}$ nor-BNI or saline (i.p.). 24 hours later, brain slices were prepared and FSCV performed as described (Schmidt et al., 2018). Briefly, mice under deep anesthesia were decapitated, and brain tissue was submerged in oxygenated ice-cold sucrose. $300 \mu \mathrm{m}$ slices were cut with a Leica VT1000 vibratome and placed in oxygenated artificial cerebral spinal fluid (aCSF) (Schmidt et al., 2018) for at least $30 \mathrm{~min}$ prior to electrochemical testing. Striatal slices were transferred to an electrochemistry rig and perfused at $2 \mathrm{~mL} / \mathrm{min}$ with oxygenated aCSF. Slices were stimulated at 100,200, and $300 \mu \mathrm{A}$ with a bipolar nichrome electrode (single pulse, $4 \mathrm{~ms}$ duration). DA signals were recorded with an in house fabricated $100 \mu \mathrm{m} \times 7 \mu \mathrm{m}$ carbon fiber microelectrode placed $\sim 100$ um from the stimulating electrode (Kile et al., 2012); a custom built potentiostat (University of Washington, Seattle) and TarHeel CV written in LabVIEW (National Instruments) were used to apply a triangle waveform (-0.4 to $1.3 \mathrm{~V}$ ) cycling at $10 \mathrm{~Hz}$. Cyclic voltammograms (CVs) were analyzed with HDCV (UNC Chapel Hill) to create IVT (current vs time) plots that were analyzed with Clampfit 10.6 software (Molecular Devices, Sunnyvale, CA).

\subsection{1e - Radioligand binding assays}

[ $\left.{ }^{3} H\right]$ WIN35428 binding to DAT

Evaluation of DAT binding sites was performed as described (Gross et al., 2018), with minor modifications. As KOR-mediated changes to DAT levels requires prolonged drug 
treatment (Thompson et al., 2000), mice were treated with vehicle or the long-lasting, irreversible KOR antagonist nor-BNI (10 mg/kg, saline, ip) for 14 days (Patkar et al., 2013) before DAT binding was assessed. Mice received two injections of nor-BNI, first on day 0 and then on day 7 . On day 14 , mice were sacrificed, vSTR microdissected, and extracts frozen on dry ice. Crude membrane fractions were prepared and incubated with $\left[{ }^{3} \mathrm{H}\right]$ WIN35428 $(52.5 \mathrm{nM})$ in the presence or absence of $10 \mu \mathrm{M}$ GBR12935 to determine DAT-specific binding; as we previously found that RGS12-null mice do not exhibit complete DAT saturation in assays of vSTR DAT binding (Gross et al., 2018), therefore, the relative number of DAT binding sites was determined using a single, high concentration of [ $\left.{ }^{3} \mathrm{H}\right]$ WIN35428 $(52.5 \mathrm{nM})$, as previously described (Gross et al., 2018). Binding reactions proceeded for 1 hour at RT and then terminated by rapid filtration over PEI (0.5\%)-soaked Whatman GF/B filters with ice-cold Tris buffer. Protein contentadjusted data (in fmol/mg protein) were normalized to the wildtype vehicle condition and expressed as fold change to control for variability in the efficacy of [ $\left.{ }^{3} \mathrm{H}\right]$ WIN35428 binding to DAT across experiments. Data are displayed as mean \pm SEM across multiple experiments and statistical analyses performed with two-way ANOVA followed by Sidak's post-hoc test ( $\mathrm{n}=6$ mice per group).

$\left[{ }^{3} \mathrm{H}\right] \mathrm{U} 69,593$ binding to KOR and $\left.{ }^{35} \mathrm{~S}\right] \mathrm{GTP} \gamma \mathrm{S}$ incorporation upon KOR activation KOR saturation binding and GTPyS incorporation assays were performed as described (Zhou et al., 2015) with modifications. Ventral and dorsal striatal brain regions were dissected, immediately frozen on dry ice, homogenized with a polytron homogenizer in 10 volumes of buffer (10 mM Tris- $\mathrm{HCl} \mathrm{pH} \mathrm{7.4,} 100 \mathrm{mM} \mathrm{NaCl}, 5 \mathrm{mM} \mathrm{MgCl} 2,1 \mathrm{mM}$ DTT), and passed through a 27-gauge needle eight times. Homogenates were centrifuged twice at $20,000 \times g$ for $30 \mathrm{~min}$; pellets were resuspended in KOR assay buffer: either $50 \mathrm{mM}$ Tris- $\mathrm{HCl} \mathrm{pH} 7.4$ for $\left[{ }^{3} \mathrm{H}\right] \mathrm{U} 69,593$ binding, or $50 \mathrm{mM}$ Tris- $\mathrm{HCl} \mathrm{pH} 7.4,100 \mathrm{mM} \mathrm{NaCl}, 5 \mathrm{mM}$ 
$\mathrm{MgCl}_{2}, 1 \mathrm{mM}$ EDTA, $20 \mu \mathrm{M}$ GDP, $1 \mathrm{mM}$ DTT for GTP $\gamma \mathrm{S}$ incorporation. For saturation binding, resuspensions were added to $\left[{ }^{3} \mathrm{H}\right] \mathrm{U} 69,593$ (from $0.63-20 \mathrm{nM}$ ) and incubated for $2 \mathrm{hr}$ at room temperature. Nonspecific binding was determined in the presence of $10 \mu \mathrm{M}$ nor-BNI. For GTP $\gamma$ S incorporation, resuspensions were added to $\left.{ }^{35} \mathrm{~S}\right] \mathrm{GTP} \gamma \mathrm{S}(0.1 \mathrm{nM})$ and several independent concentrations of the KOR agonist U50,488 $(0.0001,0.01,1$, and $100 \mu \mathrm{M}$; dissolved in saline). Binding was terminated by filtration over Whatman GF/B filters with ice-cold deionized water (washed three times) and measured via liquid scintillation counting after overnight drying.

\subsection{1f - Co-immunoprecipitations}

Co-immunoprecipitation (co-IP) analyses in brain tissue were performed with the Pierce co-IP Kit (Waltham, MA) according to manufacturer's instructions with minor modifications. Briefly, anti-RGS12 (UNC60-26.2.1; DSHB, lowa City, IA) was immobilized on the kit's AminoLink Plus-coupled resin. Ventral striata were dissected, immediately frozen on dry ice, and then homogenized with a polytron homogenizer in co-IP lysis buffer (Pierce), followed by addition of CHAPS detergent ( $1 \%$ final concentration). Homogenates were incubated for $1 \mathrm{hr}$ at $4^{\circ} \mathrm{C}$ (with rotation) to facilitate KOR solubilization (Xia et al., 2003). Solubilized lysates were precleared with quenched resin and then added to the anti-KOR-immobilized resin for overnight incubation $\left(4^{\circ} \mathrm{C}\right.$ with rotation). Immunoprecipitates were washed, eluted, and denatured with Laemmli buffer containing $100 \mathrm{mM}$ DTT (Pierce) for 30 minutes at $37^{\circ} \mathrm{C}$. IP and whole lysate (input) samples were then subjected to SDS-PAGE, transferred to nitrocellulose, and incubated overnight at $4^{\circ} \mathrm{C}$ with anti-KOR (\#AOR-012; Alomone Labs, Jerusalem, Israel), a control mixture of anti-KOR plus blocking peptide (AOR-012 immunizing peptide/control antigen; Alomone), or anti-RGS12. Immunoblots were then washed, incubated with the appropriate HRP- 
conjugated secondary antibodies for $1 \mathrm{hr}$ at $\mathrm{RT}$, and visualized with enhanced chemiluminescence.

Co-IP analyses in HEK293T cells were performed with the Pierce HA-Tag IP/CoIP Kit according to manufacturer's instructions with minor modifications. Briefly, HEK293T cells were transiently transfected (via $\mathrm{CaPO}_{4}$ (Jordan et al., 1996)) with wildtype human RGS12 (hRGS12-WT) alone or co-transfected with hRGS12-WT and 3XHA-hKOR or 3XHA-hMOR HA-tagged human opioid receptors (www.cdna.org). Forty-eight hours later, transfected cells were lysed with co-IP lysis buffer (Pierce), CHAPS added (1\% final concentration), and lysates solubilized for $1 \mathrm{hr}\left(4^{\circ} \mathrm{C}\right.$ with rotation). Solubilized lysates were then added to pre-coupled anti-HA agarose spin columns and incubated overnight $\left(4^{\circ} \mathrm{C}\right.$ with rotation) to immunoprecipitate 3 XHA-KOR or 3XHA-MOR proteins. Immunoprecipitates were washed, eluted, and denatured in 2X Sample Buffer with 100 mM DTT (Pierce). IP and whole lysate (input) samples were then subjected to SDSPAGE, transferred to nitrocellulose, and incubated overnight at $4^{\circ} \mathrm{C}$ with anti-RGS12 (sc398545, Santa Cruz, Dallas, TX) or anti-HA (Cat. 3725, Cell Signaling Technology, Danvers, MA). Immunoblots were then washed, incubated with the appropriate HRPconjugated secondary antibodies for $1 \mathrm{hr}$ at RT, and visualized with enhanced chemiluminescence.

\subsection{1g - cAMP inhibition}

HEK293T cells were transfected via $\mathrm{CaPO}_{4}$ (Jordan et al., 1996) with vectors expressing GloSensor-22F cAMP biosensor (Promega) and HA-tagged human opioid receptor (3XHA-hKOR, 3XHA-hMOR, or 3XHA-hDOR; www.cdna.org), with or without wildtype human RGS12, RGS domain loss-of-function RGS12 (Rgs12 ${ }^{E 740 K}$ ), or GoLoco motif lossof-function RGS12 (Rgs12 R1206F). Twenty-four hours later, transfected cells were seeded onto white, clear bottom, 96-well plates $\left(8 \times 10^{6}\right.$ cells/plate). Next morning, cells were 
incubated with D-luciferin in buffer (20 mM HEPES, $140 \mathrm{mM} \mathrm{NaCl}, 5 \mathrm{mM} \mathrm{KCl} 250 \mu \mathrm{M}$ $\mathrm{NaPO}_{4}, 0.1 \mathrm{mM}$ glucose, $0.5 \mathrm{mM} \mathrm{KH}_{2} \mathrm{PO}_{4}, 1.3 \mathrm{mM} \mathrm{CaCl}_{2}, 1 \mathrm{mM} \mathrm{MgSO}_{4}, 5 \mathrm{mM} \mathrm{NaHCO}_{3}$,

$\mathrm{pH}$ 7.4) for 2 hours at room temperature. Cells were then treated with various agonist concentrations (U50,488 for KOR, DAMGO for MOR, and DADLE for DOR) for 15 minutes at RT. Then, cells were treated with isoproterenol for 15 minutes to stimulate $\mathrm{G}_{\mathrm{s}}$ signaling and adenylyl cyclase activation. Luminescence was measured with a FlexStation3 platereader (Molecular Devices). In pertussis toxin (PTX) pre-treatment assays, to uncouple Gi/o-coupled GPCRs via Ga ADP-ribosylation (Katada and Ui, 1982; Moss and Vaughan, 1988), cells were pretreated with $200 \mathrm{ng} / \mathrm{mL}$ PTX (or vehicle) for 24 hours (Pack et al., 2018) prior to luminescence measurement.

\subsection{1h - $\beta$-arrestin recruitment}

Agonist-induced $\beta$-arrestin recruitment was determined using 'Tango' assay (Barnea et al., 2008; Allen et al., 2011). HTLA cells, stably expressing $\beta$-arrestin-TEV protease fusion and tetracycline transactivator-driven luciferase reporter (Barnea et al., 2008), were transiently transfected via $\mathrm{CaPO}_{4}$ (Jordan et al., 1996) with opioid receptor-Tango vectors (FLAG-KOR-Tango, FLAG-MOR-Tango, or FLAG-DOR-Tango; contributed to Addgene by Dr. Bryan Roth) with or without WT hRGS12, Rgs12E740K, or Rgs12R1206F vectors. Twenty-four hours later, transfected cells were seeded onto white, clear bottom, 384 well plates $\left(8 \times 10^{6}\right.$ cells/plate). Next morning, cells were serum starved for 6 hours, then stimulated with various agonist concentrations (U50,488 for KOR, DAMGO for MOR, or DADLE for DOR). The following morning, cells were lysed with BrightGlo (Promega) and luminescence measured with a FlexStation3. In Tango assays performed with PTX, cells were pretreated with $200 \mathrm{ng} / \mathrm{mL}$ PTX or vehicle 24 hours prior to lysis and luminescence measurement. 


\subsection{1 $\mathrm{i}$ - In silico single cell RNAseq analysis}

The DropViz single cell RNAseq database (Saunders et al., 2018) was analyzed to determine the mouse brain neuronal cell populations that co-express Rgs12 and Oprk1 mRNA. Data displayed are the output ( Table) derived from a query with Rgs12 and Oprk1 (Gene) and Neuron (Limit by Class) set as query parameters. Results were sorted by the neuronal single cell populations expressing the highest levels of Oprk1 (Oprk1 Amount) and constrained to corticostriatal circuitry (frontal cortex, striatum, substantia nigra, globus pallidus, and thalamus) given the relevance of these regions to the behavioral effects of KOR agonism (Tejeda et al., 2017; Trifilieff and Martinez, 2013; Tejeda et al., 2013).

\subsection{1j - In situ hybridization}

In situ hybridization on mouse brain slices was performed as previously described (Gross et al., 2018); dual-label detection of Rgs12 and Oprk1 expression in the claustrum was performed by the RNA In Situ Hybridization Core at Baylor College of Medicine, which is, in part, supported by a Shared Instrumentation grant from the NIH (1S10OD016167).

\subsection{1k - Quantitative reverse transcription-polymerase chain reaction (qRT-PCR)}

Ventral striatum (VSTR) and midbrain were rapidly dissected, immediately frozen on dry ice, and then homogenized on ice in TRlzole reagent (Invitrogen ${ }^{\mathrm{TM}}$ ). RNA was extracted according to manufacturer's instructions (Direct-zol RNA MiniPrep, Zymo); genomic DNA was eliminated with the QuantiTech Reverse Transcription Kit (Qiagen). RNA quantity was assessed by QIAexpert bioanalyzer (Qiagen) and cDNA synthesized with QuantiTech Reverse Transcription (Qiagen). Published primers (Du et al., 2016) for Oprk1/KOR (F: 5'-TCCCCAACTGGGCAGAATC-3', R: 5'GACAGCGGTGATGATAACAGG-3') and Pdyn (F: 5'- CAGTGAGGATTCAGGATGGG3', R: 5'-CGTCAGGGTGAGAAAAGATGA-3') were obtained from Invitrogen. Data were 
normalized to averaged $\mathrm{Ct}$ values from three housekeeping genes: $\beta$-Actin ( $\mathrm{F}$ : 5 GGCTGTATTCCCCTCCATCG-3', R: 5'-CCAGTTGGTAACAATGCCATGTT-3'), 18S rRNA (Qiagen), and $\beta$-Tubulin (F: 5'-GGGAGGTGATAAGCGATGA-3', R: 5'CCCAGGTTCTAGATCCACCA). Two $\mu \mathrm{L}$ of CDNA template was used in each qRT-PCR reaction with SYBR Green PCR Master Mix (Qiagen). qRT-PCR was performed with a Qiagen Rotor Gene-Q; melt curves were analyzed after each run to ensure primer specificity.

\subsubsection{I - Hot plate analgesia test}

To detect sensitivity to painful stimuli, the hot plate test of nociception was performed as previously described (Bohn et al., 1999) with slight modifications. Mice were placed on a hot plate $\left(53^{\circ} \mathrm{C}\right)$ and prevented from escape by a tall plastic cylinder. Latency to lick a hindlimb, flinch/flick, jump, or other first sign of nociception was recorded. On day 1 , RGS12-null mice and wildtype littermates were administered saline $(0.9 \% \mathrm{NaCl}) 30$ minutes prior to the test and nociceptive latency recorded. On day 2, all mice were administered $U 50,488(5,22.5$, or $30 \mathrm{mg} / \mathrm{kg}$, ip) 30 minutes prior to the test and nociceptive latency was recorded.

\subsection{1m - Hot plate analgesia with KOR antagonist treatment}

Hot plate analgesia assays with nor-BNI-treated mice were performed identically to all other hot plate analgesia assays (Fig. 4A-C) except that mice were administered nor-BNI (10 mg/kg, ip, dissolved in $0.9 \% \mathrm{NaCl}$ ) following their baseline measurement; thus, mice underwent a 24 hour pretreatment of nor-BNI prior to the administration of $30 \mathrm{mg} / \mathrm{kg}$ U50,488 (ip) and subsequent hot plate latency testing.

\subsection{1n - Conditioned place aversion (CPA)}

CPA was performed as described (Schindler et al., 2012) with modifications denoted below. Mice were free to acclimate to a two-chambered place preference apparatus (Med 
Associates) on day 1 for $30 \mathrm{~min}$; time spent in each compartment was recorded to determine the most-preferred chamber (preconditioning). In the morning of days 2 and 3 , all RGS12-null mice and wildtype littermates were administered saline $(0.9 \% \mathrm{NaCl})$ and confined to their least-preferred chamber. In the afternoon of days 2 and 3 , all mice received U50,488 (2.5 or $5.0 \mathrm{mg} / \mathrm{kg}$, ip) and were confined to their most-preferred chamber for $30 \mathrm{~min}$. On day 4 (postconditioning), CPA was determined by allowing mice to freely explore. Pre- and post (U50,488)-conditioning were computed by subtracting the time spent (seconds) in the most-preferred chamber (drug-paired during conditioning) minus the least-preferred chamber (saline-paired during conditioning). 


\subsection{2 - Supplementary Figures}

\subsection{2a - Rgs12 and Oprk1 (KOR) mRNAs show similar expression patterns in mouse brain.}

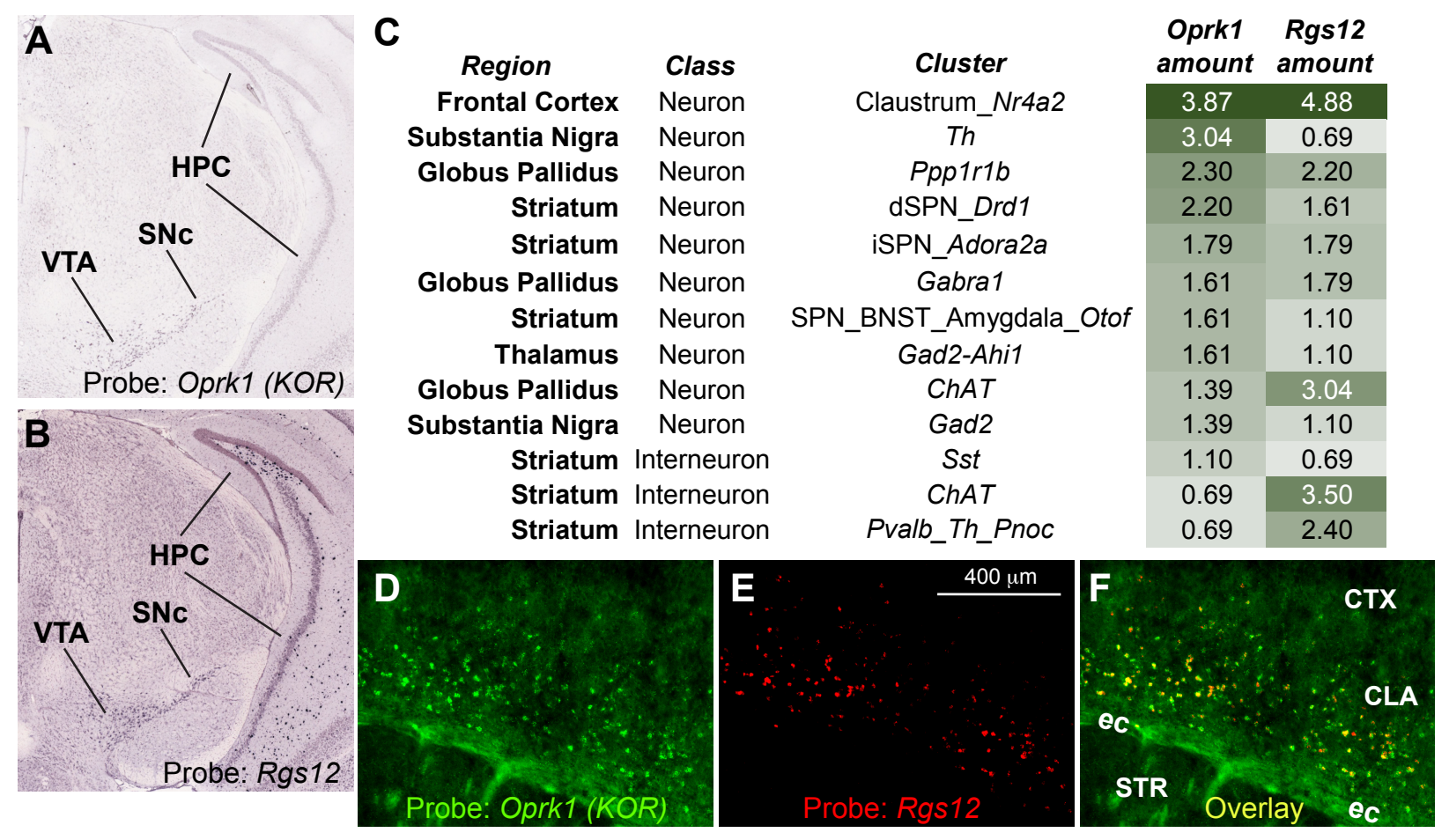

Figure S1. Rgs12 and Oprk1 (KOR) mRNAs show similar expression patterns in mouse brain. Coronal in situ hybridization (ISH) from the Allen Brain Atlas highlighting coincident Oprk1 (A) and Rgs12 (B) mRNA expression in hippocampus (HPC), and the ventral tegmental area (VTA) and substantia nigra pars compacta (SNc), with the latter two regions being beds of mesolimbic and nigrostriatal dopaminergic soma, respectively.

(C) In silico analysis of a single cell RNAseq dataset (DropViz) shows co-expression of Rgs12 with Oprk1 (KOR) in neuronal cell populations across several brain regions. Data are sorted and displayed by the neuronal cell populations expressing the highest 
levels of Oprk1 (Oprk1 amount). Rgs12 exhibits co-expression with Oprk1 in many of the top Oprk1-expressing neurons, particularly within brain regions composing the corticostriatal circuit (e.g., frontal cortex, striatum, substantia nigra, globus pallidus, thalamus). The highest expressing neuronal cell type for both Rgs12 and Oprk1 are $\mathrm{Nr} 4 \mathrm{a} 2+$ cells within the claustrum (a subregion of the frontal cortex), as observed in duallabel ISH below. (D-F) Epifluorescence images of dual-label ISH of a coronal brain slice of a wildtype mouse with antisense RNA probes directed to Oprk1 mRNA (panel D, green) and Rgs12 mRNA (panel E, red); overlay of both signals is presented in yellow in panel F (CLA, claustrum; CTX, cortex; ec, external capsule; STR, striatum). Parallel dual-label ISH of a brain slice from an RGS12-null $\left(\mathrm{Rgs}^{2 / 2^{-}}\right)$mouse resulted in no signal in the red channel (data not shown). 


\subsection{2b - Baseline and KOR-dependent DA release and DA reuptake are normal in the dSTR of RGS12-null mice.}
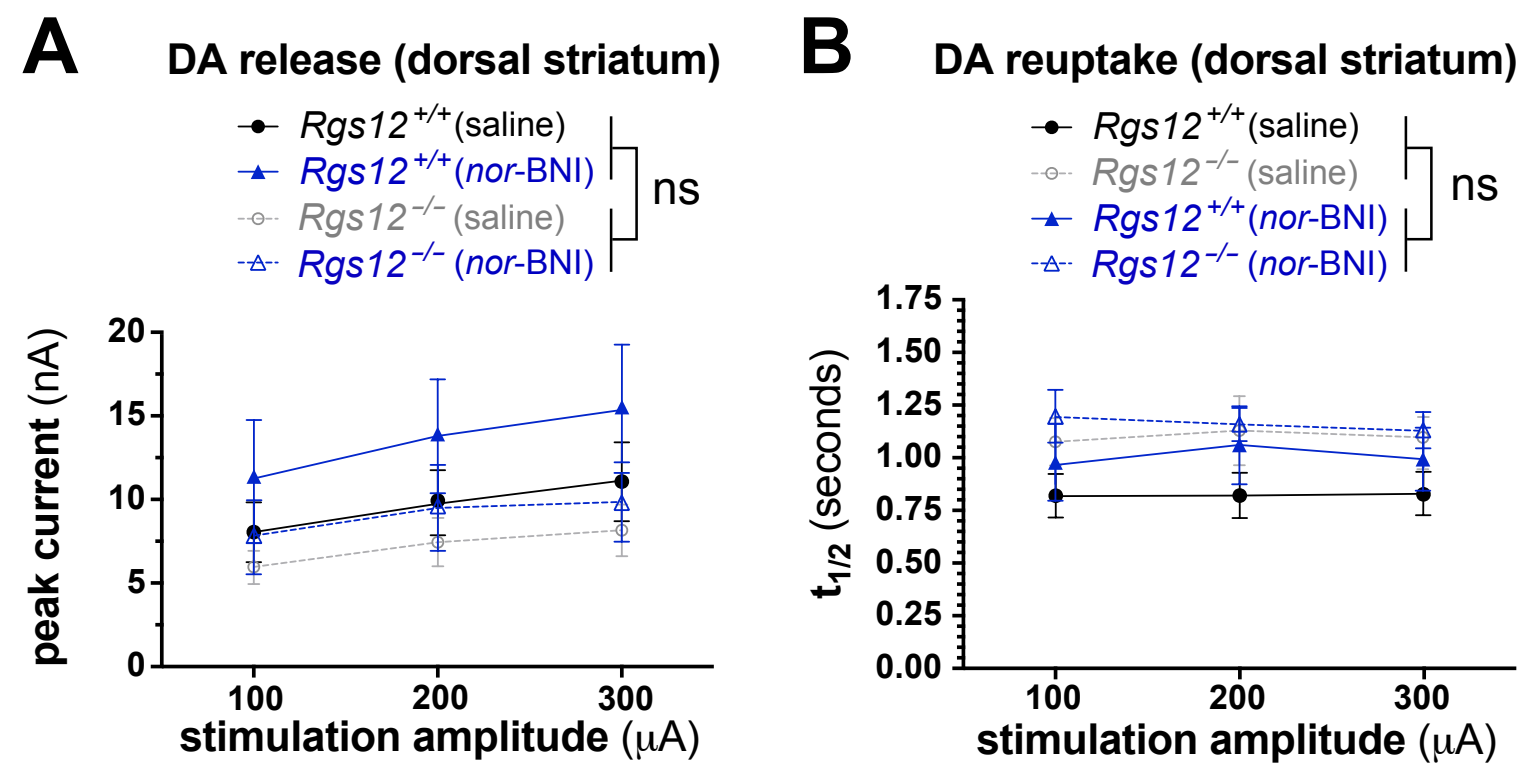

Figure S2. Baseline and KOR-dependent DA release and DA reuptake are normal in the dSTR of RGS12-null mice. (A) Electrically-stimulated DA release (peak DA current, nA) and (B) DA reuptake ( $\left.t_{1 / 2}\right)$ in the dSTR of brain slices from RGS12-null and wildtype mice pretreated with vehicle (saline) or nor-BNI (10 mg/kg, ip) 24 hours prior to FSCV measurements. Analyses reveal an effect of stimulation amplitude on DA release $(p<$ 0.0001); however, no genotype, treatment, or interaction effects were observed in measures of DA release or DA reuptake $(p>0.05)$. All FSCV data are mean \pm SEM $(n=$ 6 - 11 mice per group) and were analyzed by general linear mixed model ANOVA (ns, not significantly different). 
3.8.2c - Oprk1 (KOR) and prodynorphin (Pdyn) mRNA levels are unchanged in the vSTR and midbrain of RGS12-null mice.

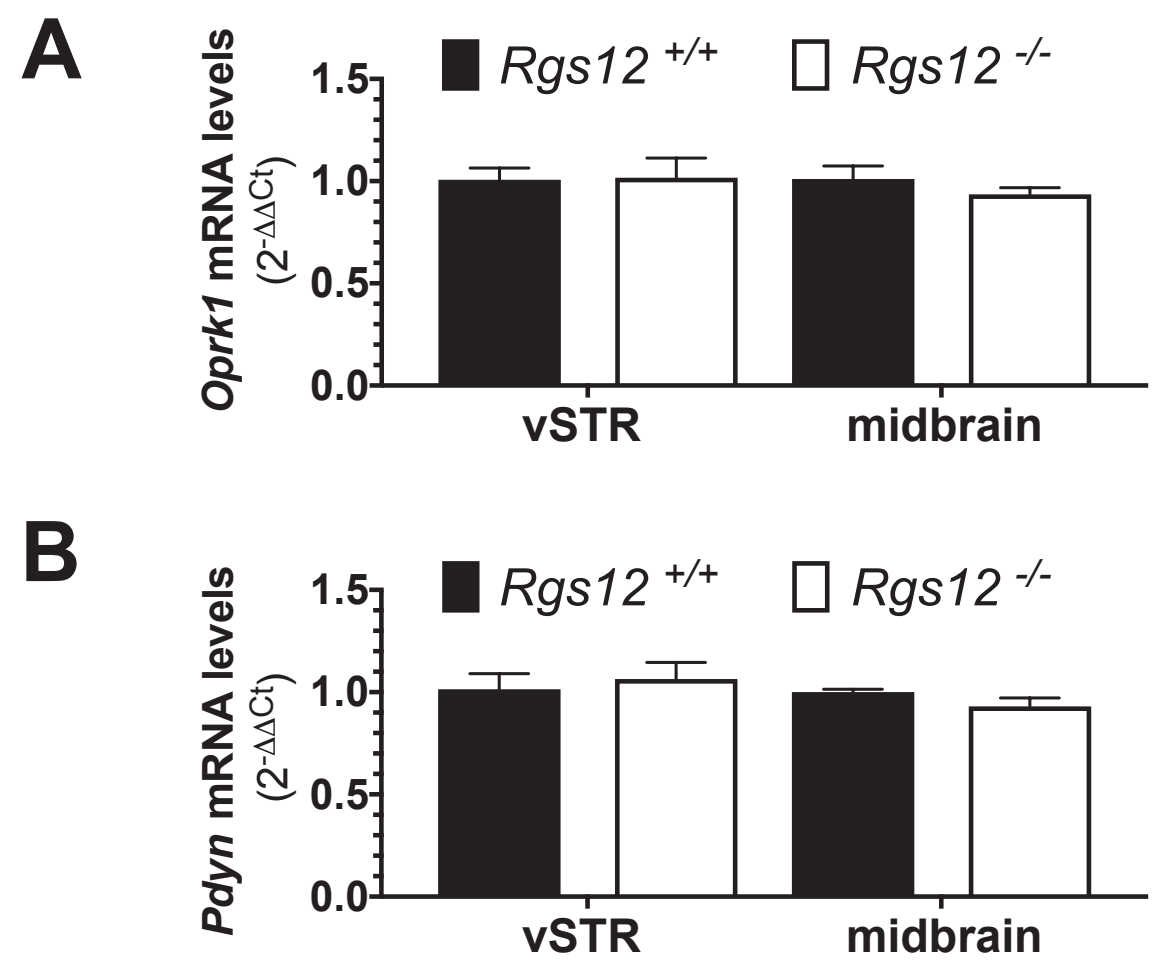

Figure S3. Oprk1 and prodynorphin mRNA levels are unchanged in the vSTR and midbrain of RGS12-null mice. (A) Measurement of Oprk1 (KOR) mRNA levels in ventral striatum (vSTR) and midbrain by qRT-PCR. RGS12-null and wildtype mice exhibited similar Oprk1 mRNA levels in both regions (omnibus: genotype, $F(1,20)=0.2, p=0.624$; region, $F(1,20)=0.4, p=0.567$; interaction, $F(1,20)=0.4, p=0.536$ ) (multiple comparisons: Oprk1-vSTR: RGS12-null vs wildtype: $p=0.994$, Oprk1-midbrain: RGS12null vs wildtype: $p=0.680)$. (B) Measurement of dynorphin precursor prodynorphin $(P d y n)$ mRNA levels in vSTR and midbrain by qRT-PCR. Analysis revealed that prodynorphin 
mRNA levels in vSTR and midbrain were comparable between RGS12-null mice and wildtype littermates (omnibus: genotype, $F(1,19)=0.02, p=0.885$; region, $F(1,19)=1.4$, $\mathrm{p}=0.255$; interaction, $F(1,19)=0.9, \mathrm{p}=0.351$ ) (multiple comparisons: Pdyn-vSTR: RGS12-null vs wildtype: $\mathrm{p}=0.809$, Pdyn-midbrain: RGS12-null vs wildtype: $\mathrm{p}=0.703$ ). All data are the mean \pm SEM and tested by two-way ANOVA with Sidak's post hoc test (n $=6$ mice per group). 


\subsection{2d - The selective effect of RGS12 on KOR-mediated G protein signaling is preserved in rodent RGS12 variants.}

A

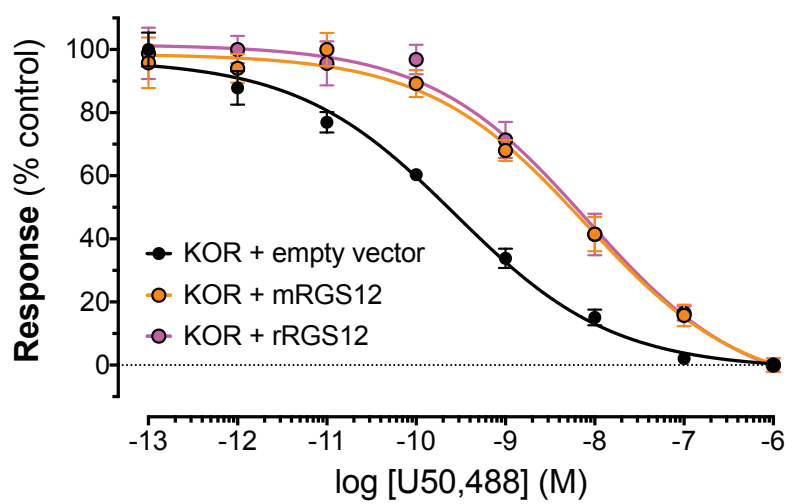

B

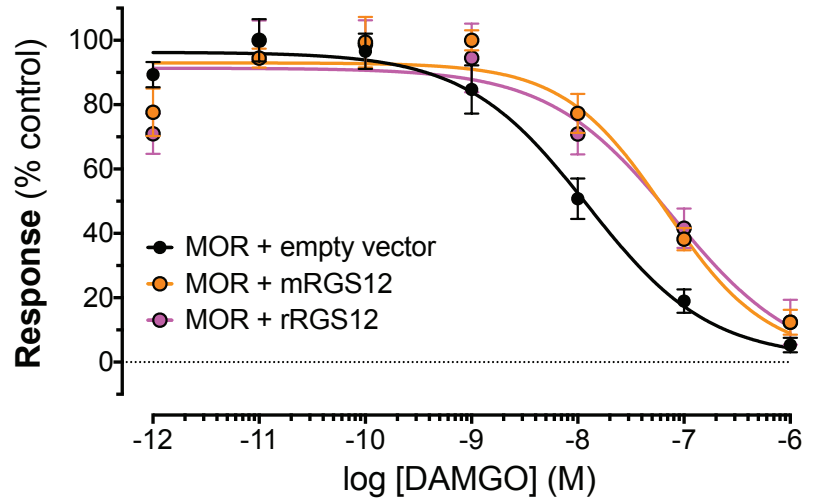

Figure S4. The selective effect of RGS12 on KOR-mediated G protein signaling is preserved in rodent RGS12 variants. Glo-Sensor luciferase-based measurements of cAMP levels in HEK293T cells stimulated with $100 \mathrm{nM}$ isoproterenol and simultaneously inhibited with indicated receptor-selective agonists following transient co-expression (A) 3XHA-hKOR or (B) 3XHA-hMOR cDNA plus empty vector, untagged wildtype mouse RGS12 (mRGS12), or myc-tagged wildtype rat RGS12 (rRGS12) expression plasmids. Co-expression of mRGS12 or rRGS12 each reduced KOR agonist potency by $\sim 30$-fold (Fig. S4A) (mRGS12: $F(1,56)=14.1, \mathrm{p}=0.0004 ; \mathrm{KOR}+\mathrm{mRGS12}^{\mathrm{pIC}} \mathrm{F}_{50}=8.1 \pm 0.2$ vs KOR only pIC $50=9.6 \pm 0.1)\left(r R G S 12: F(1,56)=12.0, \mathrm{p}=0.001 ; \mathrm{KOR}+\mathrm{rRGS} 12 \mathrm{plC}_{50}=\right.$ $8.1 \pm 0.2$ vs KOR only $\left.\mathrm{plC}_{50}=9.6 \pm 0.1\right)$. In contrast, $\mathrm{mRGS} 12$ and $\mathrm{rRGS} 12$ each attenuated MOR agonist potency by only $\sim 6$-fold (Fig. S4B) ( $m R G S 12: F(1,56)=10.7, p$ $=0.001 ; \mathrm{MOR}+\mathrm{mRGS} 12 \mathrm{plC}_{50}=7.1 \pm 0.1$ vs MOR only plC $\left.50=7.9 \pm 0.1\right)(r R G S 12: F(1$, 
$56)=7.5, p=0.008 ; \mathrm{MOR}+\mathrm{rRGS} 12^{\mathrm{WT}} \mathrm{plC}_{50}=7.1 \pm 0.2$ vs MOR only $\left.\mathrm{pIC}_{50}=7.9 \pm 0.1\right)$.

Data were normalized to vehicle control conditions and are expressed as the mean \pm SEM from multiple experiments. Concentration-response curves were fit by fourparameter non-linear regression (Prism 7). 
3.8.2e - The analgesic effect of $30 \mathrm{mg} / \mathrm{kg}$ U50,488 is lost, in both RGS12-null mice and wildtype littermate controls, following pretreatment with nor-BNI.

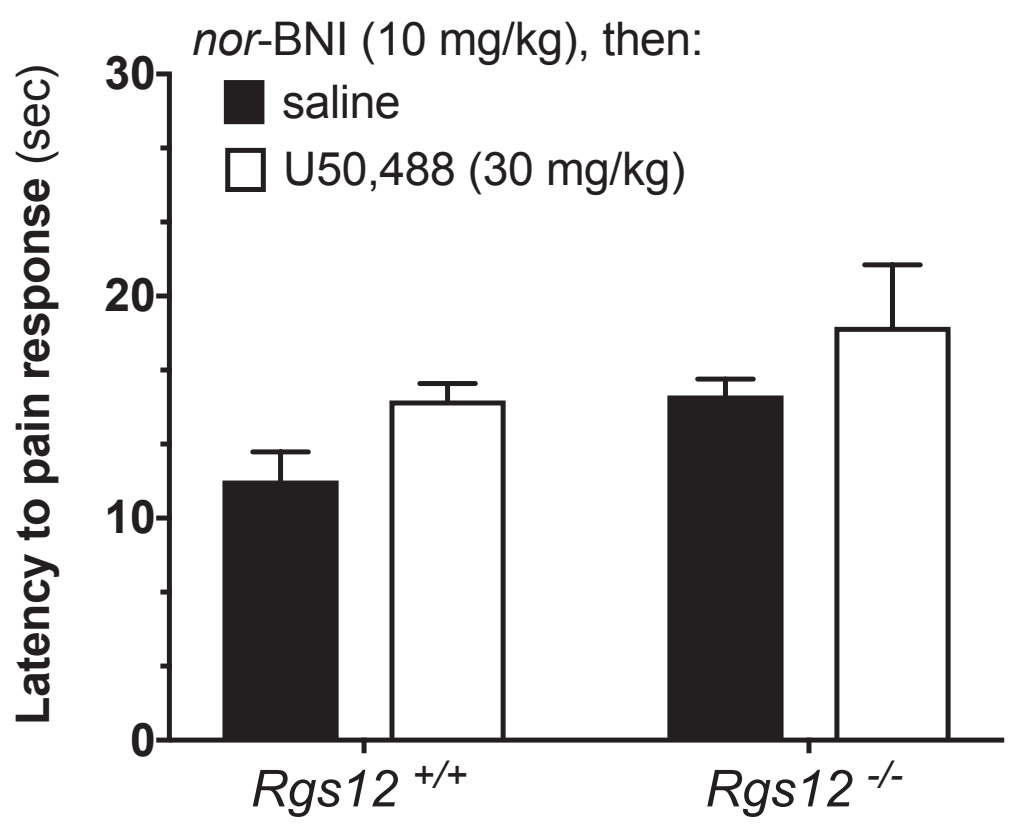

Figure S5. The analgesic effect of $30 \mathrm{mg} / \mathrm{kg} \mathrm{U50,488} \mathrm{is} \mathrm{lost,} \mathrm{in} \mathrm{both} \mathrm{RGS12-null} \mathrm{mice}$ and wildtype littermate controls, following pretreatment with nor-BNI. U50,488 (30 mg/kg)induced supraspinal analgesia is KOR-dependent. Omnibus ANOVA analysis revealed no effects of genotype, drug treatment (U50,488 + nor-BNI), or genotype $\mathrm{x}$ drug treatment $(p>0.05)$. Data are the mean \pm SEM $(n=8-10$ mice per group) and tested by two-way ANOVA. 


\subsection{2f - Responses to morphine at doses of either $5 \mathrm{mg} / \mathrm{kg}$ (A) or $10 \mathrm{mg} / \mathrm{kg}$ (B) are similar in RGS12-null mice and wildtype littermate controls.}
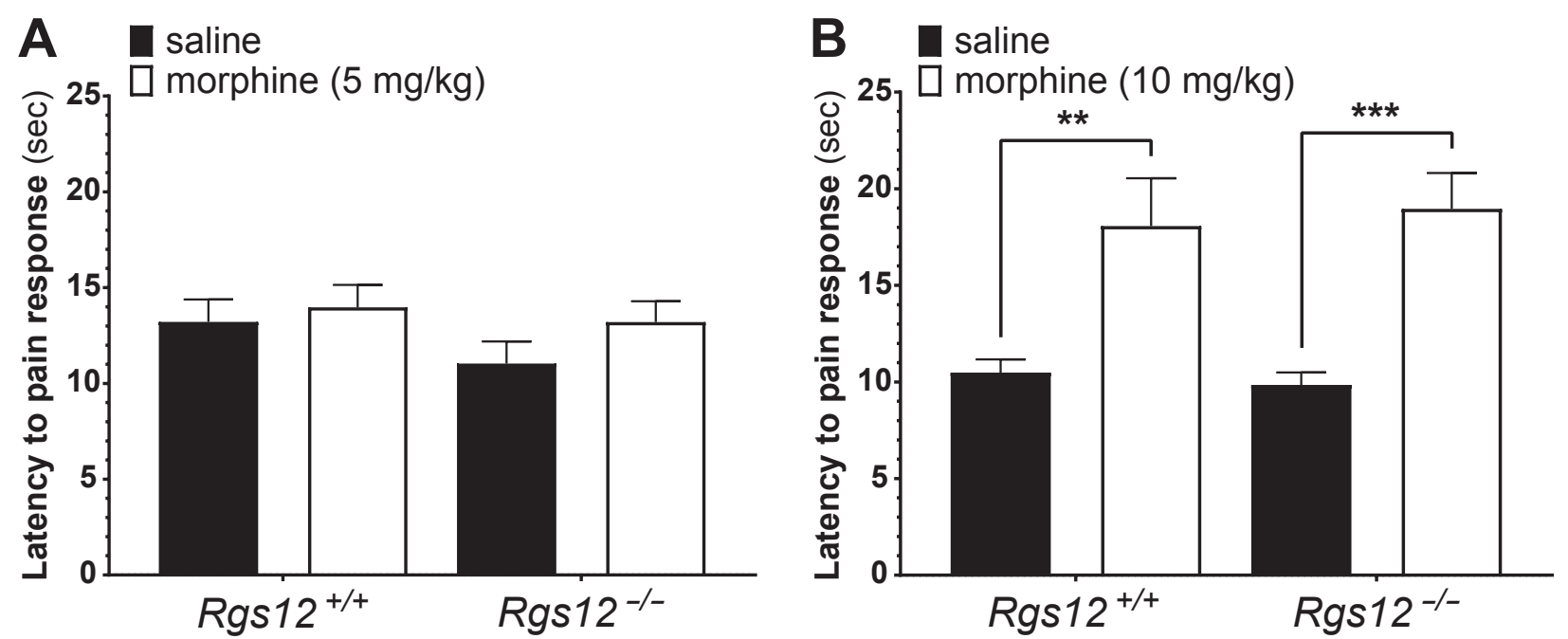

Figure S6. Responses to morphine at doses of either $5 \mathrm{mg} / \mathrm{kg}(\mathrm{A})$ or $10 \mathrm{mg} / \mathrm{kg}$ (B) are similar in RGS12-null mice and wildtype littermate controls. (A) Omnibus ANOVA analysis revealed no effects of genotype, morphine treatment, or genotype $x$ drug treatment $(p>$ 0.05). (B) Omnibus ANOVA analysis revealed only an effect of morphine treatment $(F(1,27)=29.1, \mathrm{p}<0.001) ;$ multiple comparisons: RGS12-null saline $v s 10 \mathrm{mg} / \mathrm{kg}$ morphine: $p=0.0005$; wildtype saline $v s 10 \mathrm{mg} / \mathrm{kg}$ morphine: $p=0.004$. Data are the mean \pm SEM ( $n=7-14$ mice per group) and tested by two-way ANOVA followed by Sidak's post hoc test $\left({ }^{* *}, p<0.01 ;{ }^{* \star *}, p<0.001\right)$. 


\subsection{2g - $\beta$-arrestin-2 is not required for $\left[{ }^{3} \mathrm{H}\right] \mathrm{DA}$ uptake in the vSTR and dSTR.}

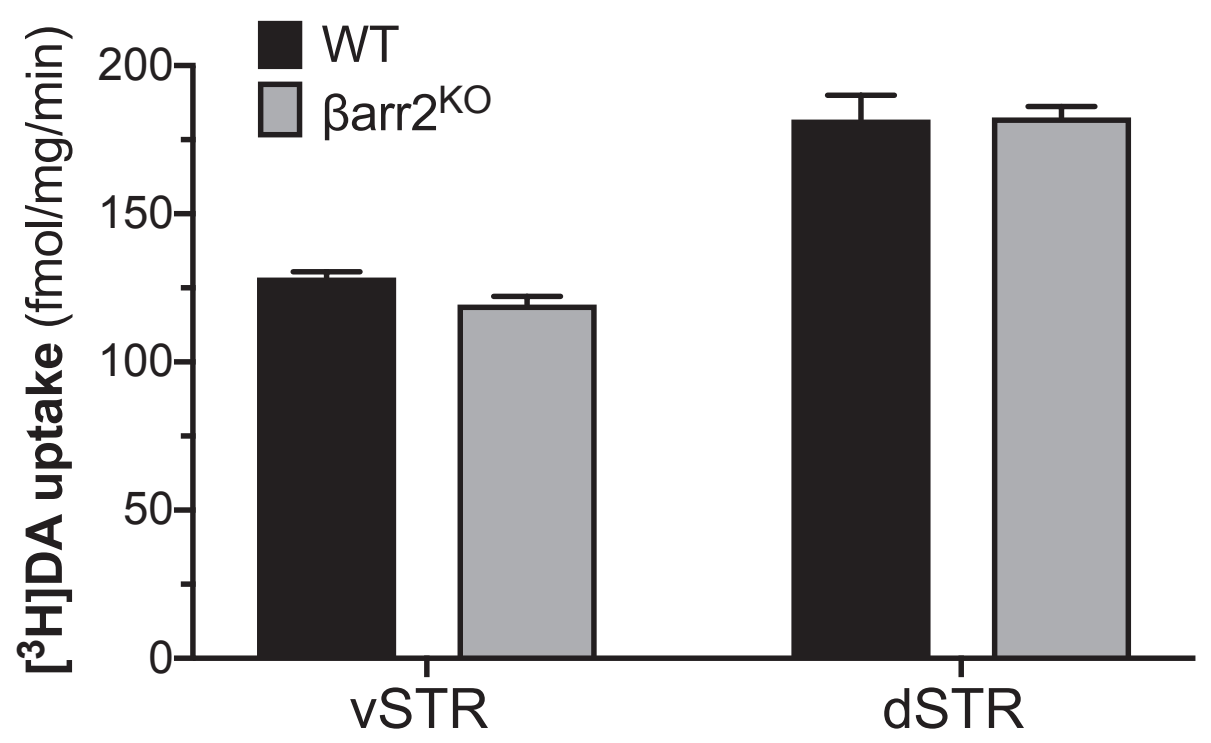

Figure S7. $\beta$-arrestin-2 is not required for [ $\left.{ }^{3} \mathrm{H}\right] \mathrm{DA}$ uptake in the vSTR and dSTR. Uptake of $\left[{ }^{3} \mathrm{H}\right] \mathrm{DA}(8 \mathrm{nM})$ in synaptosomes prepared from vSTR and dSTR brain tissue from $\beta a r r 2^{\mathrm{KO}}$ and wildtype mice. Non-specific binding was determined in the presence of 10 $\mu M$ GBR12935. Data shown are the mean \pm SEM ( $n=4$ mice per group) from a representative experiment and tested by two-way ANOVA $(p>0.05) .\left[{ }^{3} \mathrm{H}\right] \mathrm{DA}$ uptake in the vSTR and dSTR of $\beta$ arr2 ${ }^{\mathrm{KO}}$ and wildtype mice was performed twice $(\mathrm{n}=8$ mice per group over 2 independent experiments). 


\subsection{3 - Supplementary References}

1. Gross JD, Kaski SW, Schroer AB, Wix KA, Siderovski DP, Setola V. Regulator of G protein signaling-12 modulates the dopamine transporter in ventral striatum and locomotor responses to psychostimulants. J Psychopharmacol 2018;32:191-203.

2. Schmidt KT, Makhijani VH, Boyt KM, Cogan ES, Pati D, Pina MM, et al. StressInduced Alterations of Norepinephrine Release in the Bed Nucleus of the Stria Terminalis of Mice. ACS Chem Neurosci 2018.

3. Kile BM, Walsh PL, McElligott ZA, Bucher ES, Guillot TS, Salahpour A, et al. Optimizing the Temporal Resolution of Fast-Scan Cyclic Voltammetry. ACS Chem Neurosci 2012;3:285-292.

4. Saunders A, Macosko EZ, Wysoker A, Goldman M, Krienen FM, de Rivera H, et al. Molecular Diversity and Specializations among the Cells of the Adult Mouse Brain. Cell 2018;174:1015-1030 e1016.

5. Tejeda HA, Wu J, Kornspun AR, Pignatelli M, Kashtelyan V, Krashes MJ, et al. Pathway- and Cell-Specific Kappa-Opioid Receptor Modulation of Excitation-Inhibition Balance Differentially Gates D1 and D2 Accumbens Neuron Activity. Neuron 2017;93:147-163.

6. Trifilieff $P$, Martinez D. Kappa-opioid receptor signaling in the striatum as a potential modulator of dopamine transmission in cocaine dependence. Front Psychiatry 2013;4:44.

7. Tejeda HA, Counotte DS, Oh E, Ramamoorthy S, Schultz-Kuszak KN, Backman CM, et al. Prefrontal cortical kappa-opioid receptor modulation of local neurotransmission and conditioned place aversion. Neuropsychopharmacology 2013;38:1770-1779.

8. Du C, Duan Y, Wei W, Cai Y, Chai H, Lv J, et al. Kappa opioid receptor activation alleviates experimental autoimmune encephalomyelitis and promotes oligodendrocyte-mediated remyelination. Nat Commun 2016;7:11120. 


\section{CHAPTER FOUR}

\section{Conclusions and Future Directions}

\section{1 - General Conclusions}

The principal findings from this work support RGS12 as an important regulator of DAergic and KOR-dependent signal transduction, neurotransmission, and behavior in mice. Moreover, these studies identify a region-specific role for RGS12, particularly within the vSTR. Specifically, this work highlights an integral role for RGS12 in constitutive and psychostimulant-dependent DAT expression and function. We demonstrate that RGS12 mediates its effects on DAT expression/function via a functional interaction with KOR. Further elucidation of this novel functional interaction between RGS12 and KOR revealed that RGS12 is a key determinant of proper KOR signaling (in vitro and in vivo) and behavior. Notably, our finding that RGS12 differentially modulates $\mathrm{G}$ protein versus ßarr signaling downstream of KOR is a relatively novel concept for the GPCR signaling field. Namely, we reveal that interaction of a GPCR with an intracellular signaling protein, rather than a pharmacological agent (e.g., a biased agonist) per se, affects GPCR functional selectivity.

There are some limitations and unanswered questions remaining after this work, particularly with respect to the physical and functional interaction(s) between RGS12 and KOR. The Future Directions and Experimental Approaches section below is thus intended to provide a roadmap for navigating at least some of the residual questions following the conclusion of my dissertation work. Given that the functional interaction between RGS12 and KOR appears to underlie the preponderance of biochemical and behavioral effects that I have identified in RGS12null mice, the experimental pursuits proposed below will be focused predominantly on further elucidating the intricate biological relationship between these proteins. 


\section{2 - Future Directions and Experimental Approaches}

\subsection{1 - Question 1: Does RGS12 affect KOR signaling and behaviors solely in KOR- expressing neurons?}

Rationale: mRNA and protein expression data (Gross et al., 2018) suggest that Rgs12 mRNA is synthesized in DAergic projection neurons of the ventral tegmental area (VTA) and substantia nigra pars compacta $(\mathrm{SNc})$, and the protein trafficked to presynaptic terminals of the striatum. Similar mRNA and protein distribution is observed with KOR: KOR-encoding Oprk1 mRNA is enriched within DAergic VTA projections, and KOR is enriched on presynaptic terminals of the NAc within the vSTR (Crowley and Kash, 2015; Britt and McGehee, 2008; Bruijnzeel, 2009). These correlations suggest that RGS12 may be co-expressed with KOR in dopaminergic striatal neurons, and RGS12 loss in these specific neurons engenders the observed disruptions of KOR expression and function, and DA homeostasis, seen in global RGS12 knockout (RGS12-null) mice.

Approach: We recently established (Gross et al., 2018) that CMV::Cre-driven Rgs12 excision $\left(\operatorname{Rgs} 12^{\Delta 5-6 / \Delta 5-6}\right)$ throughout the organism recapitulates the augmented DAT-mediated DA reuptake and reduced hyperlocomotion to psychostimulants as observed in our global $\operatorname{Rgs} 12^{\Delta 5-8 / \Delta 5-8}$ strain. Given this specific validation of our conditional RGS12 knockout (floxed) strain $\left(R g s 12^{\Delta 5-6 / \Delta 5-6}\right)$ (Gross et al., 2018), we are now positioned to cross it with strains expressing Cre downstream of neuron subtype-specific promoters to identify those RGS12-expressing cell populations necessary and sufficient to engender the KOR signaling dysfunction observed in constitutive RGS12-null mice. We will first cross our Rgs12 f/fll mice with KOR::Cre C57BL/6 mice (which we have obtained from Dr. Sarah Ross; (Cai et al., 2016; Snyder et al., 2018)) and initially assess for Oprk1 promoter-driven Cre-mediated elimination of RGS12 expression in established KOR- and RGS12-expressing brain regions (e.g., vSTR, dSTR, prefrontal cortex, midbrain, hippocampus) by immunoblotting, as previously performed (Gross et al., 2018). We will quantify RGS12 levels 
within microdissected brain regions from Oprk ${ }^{\mathrm{Cre} /+} ; R g s 12^{\mathrm{fl/fl}}$ mice (tissue-restricted knockouts) as compared with Oprk $1^{\mathrm{Cre} /+} ; \mathrm{Rgs}_{12}{ }^{+/+}$(wildtype control) mice. For example, if RGS12 is expressed in non-KOR-expressing vSTR neurons in addition to KOR-expressing vSTR neurons, we are still likely to observe significant (albeit incomplete) reductions in RGS12 levels relative to wildtype controls, given the predominant expression of Oprk1 in this region, especially in the NAc (Mansour et al., 1987; Svingos et al., 2001). Rgs12 loss from Cre-expressing tissue should also be assessed using dual-label fluorescence in situ hybridization and validated $R g s 12$ riboprobes, as previously performed (Fig. 3.8.2a).

Once significant reduction or loss of RGS12 is verified, we would need to perform many, if not all, of the biochemical assays of KOR expression and function (e.g., KOR saturation binding with $\left[{ }^{3} \mathrm{H}\right] \mathrm{U} 69,593,\left[{ }^{35} \mathrm{~S}\right] \mathrm{GTP} \gamma \mathrm{S}$ binding, etc.) and DAergic neurotransmission (e.g., DAT saturation binding with $\left[{ }^{3} \mathrm{H}\right]$ WIN35,438; $\left[{ }^{3} \mathrm{H}\right] \mathrm{DA}$ uptake). We would also likely require the use of the tissuerestricted knockout strain in all behavioral assays previously performed with global RGS12-null mice (e.g., hot plate analgesia and CPA elicited by multiple KOR agonists [Fig. 3.6.4]). If the alterations to KOR signaling seen in global RGS12-null mice are due to loss of RGS12 function within KOR-expressing neurons, we would expect that Oprk $1^{\mathrm{Cre} /+} ; \mathrm{Rgs} 12^{\mathrm{fl/fl}}$ mice should recapitulate many, if not all, of the biochemical and behavioral phenotypes observed upon global RGS12 loss.

\subsection{2 - Question 2: Does RGS12 loss during neurodevelopment contribute to} the observed biochemical and behavioral disruptions in adult RGS12-null mice?

Rationale: If the biochemical and behavioral phenotypes observed in Oprk $1^{\mathrm{Cre} /+} ; R g s 12^{f / f l}$ mice do not resemble those of global RGS12-null mice (or if only some phenotypes are recapitulated), we would next need to probe whether alterations in KOR signaling and KOR activation-dependent behaviors result from neurodevelopmental disruptions caused by RGS12 loss -- disruptions that 
may perturb the dynorphin/KOR system. This notion is supported by prior findings from the Siderovski group that primary DRG neurons lacking RGS12 exhibit attenuated NGF-induced axonogenesis (Willard et al., 2007), from the Tsien group that RGS12 levels are altered during synaptogenesis by sensory deprivation (Butko et al., 2013), and from the Siderovski group that Rgs12 is strongly expressed throughout CNS regions integral to early embryonic neurodevelopment (Martin-McCaffrey et al., 2005).

Approach: To evaluate this hypothesis, we would cross $R g s 12^{f / f t}$ mice with tamoxifen-inducible, CAGG::Cre mice to induce Rgs12 excision conditionally in the adult mouse, obviating the confound that pre- and/or post-natal neurodevelopmental adaptations and/or compensations may occur across the lifespan in the absence of RGS12 within the global RGS12-null strains. In another project within our laboratory, we demonstrated successful tamoxifen-induced, Cremediated homologous recombination at the adult stage of a different floxed $\mathrm{Rgs}$ allele, namely that encoding RGS21, which is expressed in lingual chemosensory tissue (Schroer et al., 2018). Thus, we are confident that we can successfully evaluate whether RGS12 loss produces KOR dysfunction and altered DA homeostasis via a neurodevelopmental mechanism by crossing tamoxifen-inducible Cre mice with our $R g s 12^{f / / f l}$ mice (i.e., inducing Cre-mediated $R g s 12$ excision in adulthood). As an independent alternative approach (i.e., independent of either Oprk $1^{\mathrm{Cre} /+}$ or tamoxifen-inducible driver lines), we could breed our Rgs $12^{f / f l}$ mice with the DAT-iCre driver strain (Turiault et al., 2007; Rocchetti et al., 2015), thereby restricting RGS12 loss to DAT-expressing dopaminergic neurons.

Alternative IHC-based approach in parallel: Along with cross-breeding Rgs $12^{f / / f l}$ mice to tissueand temporally-restricted Cre drivers and phenotyping the resultant desired progeny, we could quantify downstream signaling events in situ, beginning with the global RGS12-null mice, to help establish the region-specific nature of RGS12 function(s) on KOR signaling in the brain. KOR activation reportedly leads to phosphorylation of select kinases in the striatum, cortex, 
hippocampus, and amygdala (Robles et al., 2014; Bruchas et al., 2007a; Heinsbroek et al., 2018). KOR-mediated pERK induction is preserved in GRK3-null mice (Bruchas et al., 2007a) and thus likely a Barr-independent, G protein-dependent output. Conversely, p38 MAPK phosphorylation following KOR activation is lost in GRK3-null mice (Bruchas et al., 2007a); thus, p-p38 MAPK induction is considered GRK3-//Barr-dependent and G protein-independent (Bruchas et al., 2006). Thus, we will perform IHC to test whether RGS12-deficient mice exhibit altered pERK and p-p38 induction upon KOR activation (and if this occurs in a region-specific manner). pERK and p-p38 content can be measured in brain slices of RGS12-deficient mice and matched wildtype littermates treated systemically with unbiased/full KOR agonists (e.g., U50,488 in saline, ip) using established IHC techniques (Gross et al., 2018) and validated anti-pERK / ERK and anti-p-p38 / p38 MAPK antibodies (CST). pERK- and p-p38-positive cells will be counted and normalized to ERK- and p38-positive cells (and expressed as fold induction) across multiple regions (e.g., vSTR [in particular, NAc core \& shell], dSTR, amygdala, hippocampus, prefrontal cortex, claustrum/deep cortical layers) to determine if RGS12 loss (by global or tissue-restricted knockout) perturbs outcomes of KOR-mediated G protein-dependent and -independent signaling. If no IHC differences are seen in pERK and p-p38 levels between RGS12-deficient and wildtype mice upon a single, high dose of KOR agonist, such a result may not preclude the possibility that RGS12 loss produces a potency shift in KOR sensitivity upstream of ERK and p38 phosphorylation (i.e., any differences between genotypes may be masked by high drug dose); we would then perform dose-response trials (e.g., U50,488 at 5, 10, 15, 20, $30 \mathrm{mg} / \mathrm{kg}$ ). Moreover, in vitro studies of KOR-stimulated ERK and p38 activation (Schattauer et al., 2017; Schattauer et al., 2012) have shown that maximal kinase phosphorylation is achieved in a temporally distinct fashion. Thus, we would begin by testing RGS12-deficient and wildtype mice at both 5 and 30 minutes to capture the predicted maximal activation of pERK and p-p38, respectively (Schattauer et al., 2017; Schattauer et al., 2012); we will establish time-course data for phosphorylation of 
both kinases if required. We would also likely benefit by evaluating a 2-hour timepoint in later analyse of KOR-stimulated pERK induction to assess whether RGS12 loss affects the late phase (McLennan et al., 2008) of ßarr-dependent ERK phosphorylation following KOR activation.

KOR activation is reported to induce amygdala-related anxiogenesis (Crowley and Kash, 2015; Bruchas et al., 2009; Knoll et al., 2011), frontal cortex- and hippocampal-dependent learning deficits (Carey et al., 2009; Paris et al., 2011), depression-like and stress-related behaviors involving mesolimbic structures (VTA, NAc (Bruchas et al., 2008; Chartoff et al., 2009; Berube et al., 2013)), and psychotomimesis and sensory gating deficits that may be related to KOR action in the claustrum and/or deep layers of the cerebral cortex (Ruderman et al., 2009; Stiefel et al., 2014; Patru and Reser, 2015). Given that RGS12 is expressed along with KOR in virtually all of these brain regions (Gross et al., 2018) (Allen Brain Atlas), these planned IHC studies for identifying particular CNS regions of RGS12 action should surely aid in selecting future behavioral experiments to better understand the extent to which RGS12 modulates behavioral outcomes of KOR signaling.

\subsection{3 - Question 3: Does RGS12 play a role in KOR-mediated signaling and behavior involving the spinal cord?}

Rationale: Our findings show that global RGS12-null mice have increased sensitivity to the analgesia elicited by KOR agonism in the hot plate assay (Fig. 3.6.4), a test of supraspinal analgesia (Hull et al., 1994; Sora et al., 1997). RGS12 may also regulate KOR-mediated spinal antinociception via similar mechanisms, especially with evidence that both RGS12 and KOR are expressed in spinal neurons that mediate nociception ((Willard et al., 2007; Cai et al., 2016; Hylden et al., 1991), and see also GENSAT strain Tg(Rgs12-EGFP)HW332Gsat/Mmucd). For example, RGS12 is highly expressed in dorsal root ganglion (DRG) neurons, and the Siderovski group has previously shown that RGS12 is a key regulator of NGF-stimulated axonogenesis in 
these neurons (Willard et al., 2007; Lewin and Mendell, 1993; Lewin et al., 2014). DRGs located adjacent to the spinal cord, as well as the dorsal horns, represent key nociceptive loci (Todd, 2010). Notably, KOR is also highly expressed in DRG neurons and contributes to growth factorstimulated neurite extension (Tsai et al., 2010) and to anti-nociceptive responses via its action within this anatomical region (Xu et al., 2004).

Hypotheses: RGS12 loss in the spinal cord drives altered nociception given KOR-mediated G protein hypersensitivity and ßarr hyposensitivity; RGS12 loss increases sensitivity to the antinociceptive and anti-pruritic effects of KOR agonism; RGS12 loss prevents the development of tolerance to the antinociceptive effects of repeated KOR agonism (as elicited by either chronic exogenous applications of KOR agonist or the induction of neuropathic injury).

Approaches:

4.2.3a - (i) Antinociception: To assess if RGS12 regulates KOR activity in the spinal cord, we will perform the tail immersion test (McLaughlin et al., 2004) (i.e., spinal nociception to thermal stimulus). Like antinociceptive behaviors in the hot-plate test, increased tail withdrawal latency following acute KOR agonist administration is considered G protein-dependent but ßarrindependent (Schattauer et al., 2017; McLaughlin et al., 2004). If RGS12 regulates spinal KOR signaling, we expect RGS12 deficiency to potentiate KOR agonist-induced antinociception relative to wildtype controls. In the tail withdrawal test, the distal $1 \mathrm{~cm}$ of the tail is immersed in 55 ${ }^{\circ} \mathrm{C}$ water for up to $10 \mathrm{~s}$, and tail withdrawal latency is monitored. Increased tail withdrawal latency in drug-treated mice can be used to infer the drug's antinociceptive efficacy. Dose ranges of full KOR agonists (e.g., U50,488 at 1, 2.5, 7.5, 15, or 30 mg/kg, ip; (Schattauer et al., 2017)) or vehicle will be separately administered to RGS12-deficient (global RGS12-null and tissue-restricted knockout) mice and wildtype controls $30 \mathrm{~min}$ prior to testing. Initial data with the unbiased/full KOR agonist U50,488 (Fig. 4.2.3a-1 below) suggest that global RGS12-null mice do have augmented KOR-induced tail withdrawal latencies, albeit dose-dependently. 


\subsection{3a-1 - RGS12-null mice exhibit augmented spinal antinociception to the KOR agonist in a dose-dependent manner.}

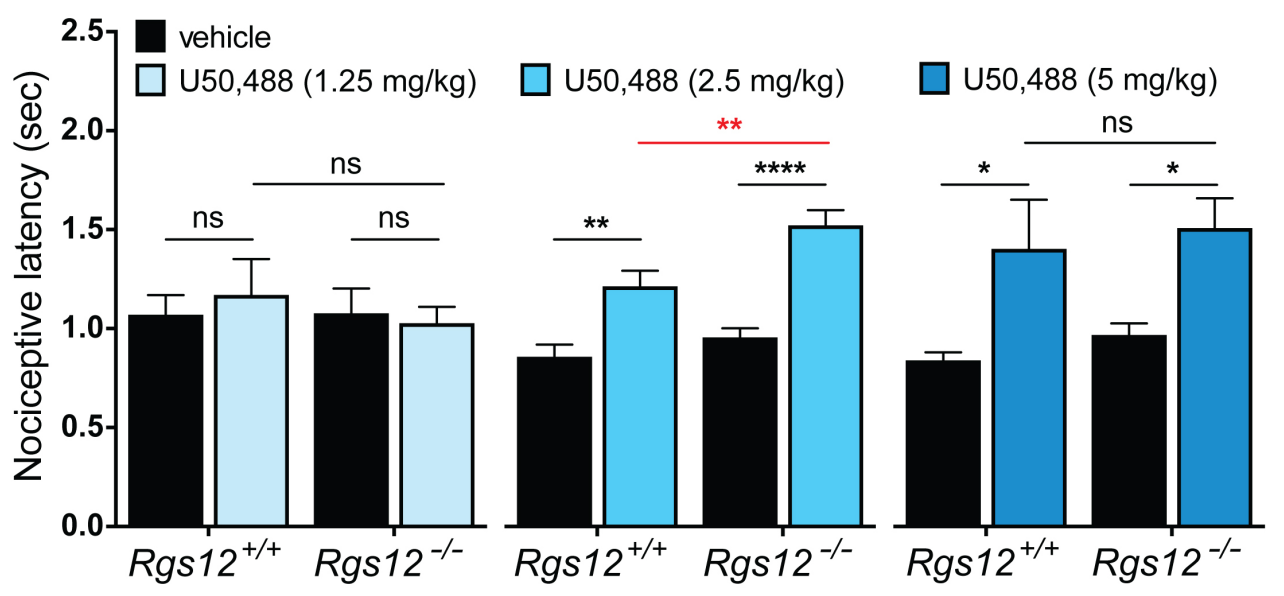

Fig. 4.2.3a-1. RGS12-null mice exhibit augmented spinal antinociception to the KOR agonist $\mathrm{U} 50,488$ at the $2.5 \mathrm{mg} / \mathrm{kg}$ dose. Indicated single doses of U50,488 were administered to global RGS12-null and WT mice prior to the warm water tail immersion test. Data are the mean \pm SEM; two-way repeated-measures ANOVA (for within-subjects comparisons) and betweensubjects ANOVA (for between-subjects comparisons) each followed by Sidak's post hoc test were performed ( $n=5-10$ mice/group; ${ }^{*}, p<0.05 ;{ }^{* *}, p<0.01 ;{ }^{* * *}, p<0.0001$ vs baseline). Unpublished preliminary data.

4.2.3b - (ii) Antinociceptive tolerance: Opioid-induced antinociception is limited by the development of tolerance following repeated administration -- a process facilitated by $\beta$ arrdependent downregulation of opioid receptors (Raehal and Bohn, 2014). For example, antinociceptive tolerance to the MOR agonist morphine is lost in $\beta$ arr-2 knockout mice (Bohn et al., 2000). Similarly, tolerance to U50,488 is attenuated in GRK3 knockout mice (McLaughlin et al., 2004), suggesting that KOR-mediated tolerance also relies on a GRK3-/ßarr-dependent mechanism. Given our findings that acute KOR-stimulated analgesia (G protein-dependent) is augmented, yet KOR-induced CPA (ßarr-dependent) is attenuated in RGS12-null mice (see 
Chapter 3), we hypothesize that RGS12-deficient and ßarr-2-deficient mouse strains will exhibit reduced tolerance to repeated KOR agonism.

Approaches: To begin to assess this hypothesis, we would repeatedly administer an unbiased/full KOR agonist to RGS12-deficient and ßarr-2-deficient mice (and wildtype littermate controls), as previously described (McLaughlin et al., 2004). For example, mice will receive escalating doses of $\mathrm{U} 50,488$ (in saline; ip) twice daily for days $1-4$ (i.e., $10 \& 15,25 \& 30,50$ \& 60 , and $70 \& 75 \mathrm{mg} / \mathrm{kg}$, AM/PM), then given a challenge dose of $25 \mathrm{mg} / \mathrm{kg}$ on day 5 . Control groups for both genotypes (gene-deficient and wildtype mice) will receive saline injections, then acute saline or $U 50,488$ on day 5 . Tolerance will be evaluated by decreased nociceptive latency per the tail immersion test (as above), performed 30 min after each day's AM injection.

Potential Confounds and Future Pursuits for 4.2.3a and 4.2.3b: It would be advantageous to also evaluate tolerance in the hot plate assay to assess $\beta$ arr-dependent supraspinal analgesia in light of our initial data that RGS12-null mice exhibit enhanced sensitivity to acute KOR-induced analgesia in this assay (Fig. 3.6.4). However, we anticipate that an ascending dose schedule of an unbiased/full KOR agonist may acutely produce profound motoric dysfunction and lack of coordination. In the hot plate assay, mice are placed on a $53{ }^{\circ} \mathrm{C}$ metal surface and latency to nociception (licking/shaking of a hindlimb or jumping) recorded. In this way, the behavior indicative of nociception relies upon motoric action. We have observed motor dysfunction in some mice receiving $30 \mathrm{mg} / \mathrm{kg} \mathrm{U} 50,488$; others report that KOR agonists produce dysfunction in coordination tests, such as rotarod (White et al., 2015). Conversely, tail withdrawal is a spinal-mediated (reflexive) response (Janssen et al., 1963; Bohn et al., 2002) and, thus, is unaffected by repeated and/or high doses of KOR agonists (McLaughlin et al., 2004). It is possible that we may not see differences in tail withdrawal tolerance between RGS12-deficient and wildtype mice if RGS12 regulates KOR-initiated signaling predominantly in supraspinal (e.g., vSTR), and not spinal, regions. If this outcome manifests, it will be even more important to use data generated by planned 
IHC studies (see Question \#2 - Alternative IHC-based approach in parallel) to better predict those specific CNS regions in which RGS12 modulates KOR signaling, and then correlate those findings to observed behaviors following KOR agonism relevant to the regions identified.

\subsection{3c - Anti-pruritus:}

Rationale: KOR activation produces anti-pruritic effects via action within DRG neurons of the spinal cord (Ross et al., 2010; Kardon et al., 2014). Intractable itch can occur secondary to disease (e.g., chronic renal failure (Simonsen et al., 2017)) or after neuraxial opioid administration (Ko, 2015) and often requires clinical intervention. KOR agonists mitigate itch in humans and rodents (Kumagai et al., 2012; Morgenweck et al., 2015). Conversely, KOR antagonists induce itch (Kamei and Nagase, 2001; Inan et al., 2009), but this effect is only partially attenuated in KOR-knockout mice, suggesting that KOR-independent mechanisms also contribute (Morgenweck et al., 2015). The KOR-selective G protein-biased (Schattauer et al., 2017) agonist nalfurafine is approved in Japan to treat pruritus in hemodialysis patients (Kumagai et al., 2012); the newer G protein-biased KOR agonist, triazole 1.1, also retains the anti-pruritic efficacy of unbiased KOR agonists (Brust et al., 2016), underscoring the concept that KOR-induced antipruritus may be $\mathrm{G}$ protein-dependent and ßarr-independent.

Hypothesis: RGS12-deficient mouse strains will exhibit increased anti-pruritic responses to a conventional (unbiased) KOR agonist relative to controls, given our findings that RGS12 loss engenders KOR-mediated G protein signaling hypersensitivity and ßarr signaling hyposensitivity (see Chapter 3)

Approach: We would evaluate KOR-induced anti-pruritus as previously described (Brust et al., 2016; Schlosburg et al., 2009; Schlosburg et al., 2011). Briefly, RGS12-deficient and wildtype control mice will be injected with an unbiased KOR agonist (see dose considerations below), and injected 10 min later with either vehicle or the pruritus-inducing agent chloroquine phosphate (CP, 
$40 \mathrm{mg} / \mathrm{kg}$, sc midscapular (Kuraishi et al., 1995) or nape of neck (Morgenweck et al., 2015)). Hindlimb scratching bout frequency and duration will be quantified in 5-min bins over $1 \mathrm{hr}$ by a genotype-blinded investigator. Given the potentially subjective nature of these scoring procedures, a subset of videos will need to be re-scored by an independent investigator to ensure intra- and inter-observer reliability.

Potential Confounds and Methods Considerations for Anti-Pruritus Testing: Studies of KOR agonist-induced anti-pruritus often precipitate scratching with the KOR antagonists nor-BNI or 5'GNTI (Brust et al., 2016; Schattauer et al., 2017; Morgenweck et al., 2015). KOR antagonistinduced itch is preserved (albeit reduced) in KOR-deficient mice, and is attenuated in ßarr-2deficient mice (Morgenweck et al., 2015), suggesting that itch produced by KOR antagonists is, at least in part, KOR-independent and ßarr-2-dependent. Conversely, CP-induced itch (KORindependent) is robustly inhibited by G protein-biased KOR agonists, and this effect of KOR agonism is unaltered in $\beta$ arr-2-deficient mice (Brust et al., 2016), supporting the notion that the anti-pruritic effect of KOR agonism on CP-stimulated itching is G protein-dependent. Thus, we will evaluate (at least initially) KOR agonist-induced anti-pruritus to CP (i.e., not to KOR antagonism) to assess whether RGS12-deficient mouse strains exhibit KOR-mediated G protein hypersensitivity in this spinal-dependent behavior. We will also consider the polycationic mast cell degranulator compound $40 / 80$ to precipitate scratching behavior (via localized histamine release (Schlosburg et al., 2009; Schlosburg et al., 2011), as an additional alternative to avoid using KOR antagonists.

U50,488 administration prior to CP injection robustly suppresses CP-induced itch (Brust et al., 2016) at doses as low as $1 \mathrm{mg} / \mathrm{kg} U 50,488$. Thus, $1 \mathrm{mg} / \mathrm{kg}$ will be the highest dose in initial U50,488 dose-response trials, systematically decreased until we identify the lowest U50,488 dose that does not affect wildtype littermate controls. We will then test whether matched RGS12deficient mice display reduced scratching at this lowest U50,488 dose, which would suggest that 
RGS12 loss increases KOR-mediated G protein signaling sensitivity, as first seen in previous experiments (Fig. 3.6.2 \& Fig. 3.6.4). Future studies should seek to replicate the effect using nalfurafine instead of $U 50,488$, because nalfurafine is approved in Japan for treatment of pruritus and is a G protein-biased KOR agonist (Schattauer et al., 2017; Kumagai et al., 2012).

\subsection{3d - Neuropathic pain}

Rationale: Peripheral nerve damage causes neuropathic pain (Zimmermann, 2001) by producing hyperalgesia (increased pain response to noxious stimuli), allodynia (pain response to innocuous stimuli), and spontaneous pain. Such neuropathic pain increases acute and prolonged dynorphin release and increases KOR activation within the dorsal horn (Xu et al., 2004; Wagner et al., 1993; Wang et al., 2001). Antagonism or genetic deletion of KOR enhances hyperalgesia (Xu et al., 2004; Obara et al., 2003) and allodynia (Xu et al., 2004) following chronic constriction injury (CCl) of the sciatic nerve, an established rodent model of neuropathic pain (Jaggi et al., 2011). These data suggest that neuropathic injury-induced KOR activation in the spinal cord by endogenous dynorphins helps mitigate increased nociception following damage.

Approach: To test whether RGS12 functions in the spinal cord to modulate dynorphin/KORrelated reductions of neuropathic pain, we will perform $\mathrm{CCl}$ surgeries (in collaboration with the Kinsey lab) on RGS12-deficient mouse strains (both global and tissue-restricted knockouts), and compare resultant hyperalgesia (e.g., Hargreaves' plantar stimulator test), and mechanical (e.g., von Frey filament) and cold (acetone-induced) allodynia vs wildtype littermate controls using established techniques in measuring rodent neuropathic pain (Crowe et al., 2017; Crowe et al., 2015; Kinsey et al., 2010; Kinsey et al., 2013; Wilkerson et al., 2016). Unpublished pilot data (from the Kinsey lab) suggest that global RGS12 deficiency indeed leads to reduced allodynia post$\mathrm{CCl}$; this finding supports the notion that RGS12 loss may reduce sciatic nerve injury-induced allodynia by augmenting KOR-mediated antinociception. 
Fig. 4.2.3d-1. RGS12-null mice exhibit attenuated allodynia after CCI.

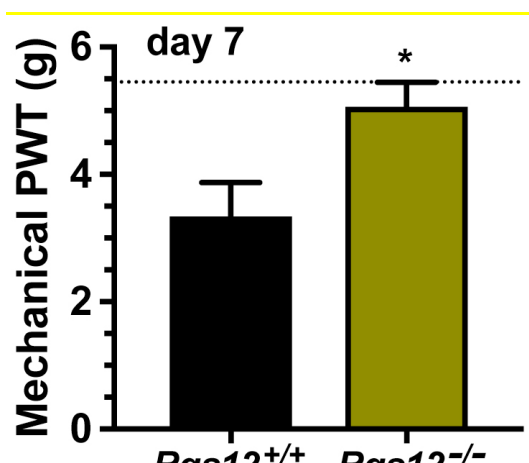

Rgs12 ${ }^{+/+}$Rgs12 ${ }^{-/-}$

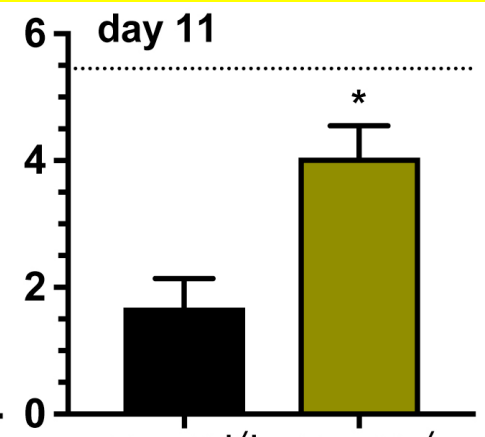

$\operatorname{Rgs}^{+/+}$Rgs12 $^{-/-}$

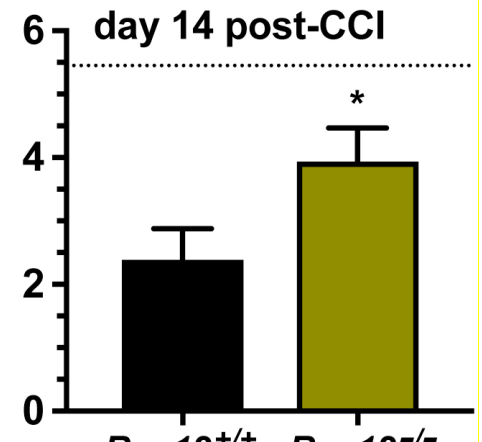

$\operatorname{Rgs12}^{+/+}$Rgs12 $^{-/-}$

Fig. 4.2.3d-1. RGS12-null mice exhibit attenuated allodynia after CCl. Wildtype mice (Rgs $12^{+/+}$; $\mathrm{n}=16)$ and RGS12-null mice (Rgs12-- $\mathrm{n}=20)$ each received a chronic constriction injury of the right sciatic nerve. After the indicated elapsed time, resultant mechanical allodynia (paw withdrawal threshold $[\mathrm{PWT}]$ ) was assessed at the right hind paw using a series of von Frey filaments as previously described (Kinsey et al., 2010; Kinsey et al., 2013; Crowe et al., 2015; Crowe et al., 2017; Wilkerson et al., 2016); mean contralateral (left paw control) withdrawal thresholds are graphically represented as the horizontal dotted line. ${ }^{*}, p<0.05$, from unpaired ttest comparing right hind paw PWT between genotypes. Unpublished preliminary data produced by Floyd Steele, PhD candidate in the Kinsey lab, using mice provided by the Siderovski and Setola labs.

To first test KOR mediation of post-CCI nociception differences in RGS12-deficient mice, we will pretreat mice with KOR antagonist (e.g., the long-lasting, irreversible KOR antagonist nor$\mathrm{BNI}$ ) prior to testing hyperalgesia (Hargreaves' plantar stimulator test) and allodynia (e.g., as performed in Fig. 4.2.3d-1 above) at 7, 11, and 14 days post $\mathrm{CCl}$ injury. Systemic nor-BNI is seen to reverse KOR-mediated antinociception for up to 14-21 days post-injection (Bruchas et al., 2007b; Patkar et al., 2013); thus, a single administration of nor-BNI $(10 \mathrm{mg} / \mathrm{kg}$, ip, dissolved in saline) 24 hours prior (i.e., day 1 ) to $\mathrm{CCl}$ surgery (day 0 ) should suffice to ascertain whether any effects engendered by RGS12 deficiency are dynorphin/KOR-mediated. As an alternative to the 
use of nor-BNI, we could also consider JDTic (Bruchas et al., 2007b; Munro et al., 2012); however, we would avoid employing 5'-GNTI owing to its off-target PAM effect at the $\alpha 1 \mathrm{~A}$-adrenergic receptor (Munro et al., 2013).

$\mathrm{CCl}$ is reported (Xu et al., 2004) to reduce the ability of exogenous KOR agonists to attenuate the hyperalgesia and allodynia that result after nerve injury; this phenomenon of reduced KOR agonism affecting post- $\mathrm{CCl}$ is considered consistent with the development of tolerance to KOR agonism-induced antinociception observed in the tail immersion test (McLaughlin et al., 2004). Moreover, this reduced KOR agonism effect post-CCI is lost in GRK3-deficient mice and thus considered $\beta$ arr-dependent (Xu et al., 2004). Therefore, our initial observation of reduced CClinduced allodynia in global RGS12-null mice may be due, at least in part, to attenuated KORmediated $\beta$ arr signaling in the absence of RGS12 and, therefore, reduced development of KOR tolerance that normally occurs in response to prolonged dynorphin release elicited by $\mathrm{CCl}$ (Xu et al., 2004; Kajander et al., 1990; Malan et al., 2000; Gardell et al., 2004). This notion is consistent with our observation that RGS12 deficiency attenuates KOR agonist-induced CPA (considered a ßarr-dependent behavior; Fig. 3.6.4) and, conversely, RGS12 over-expression greatly enhances $\beta$ arr recruitment to activated KOR in vitro (Fig. 3.6.3).

Thus, to evaluate whether global or tissue-restricted RGS12-deficient mice exhibit diminished ßarr-dependent KOR tolerance related to neuropathic pain, we will perform $\mathrm{CCl}$ (and sham) surgeries on RGS12-deficient and wildtype littermate mice, and then assess at 7, 11, and 14 days post-CCl hyperalgesia and mechanical/cold allodynia following acute administration of KOR agonists (e.g., U50,488 in escalating doses). We would suspect that RGS12 deficiency will attenuate (or abolish) the potency reduction (rightward $\mathrm{EC}_{50}$ shift) normally seen in KOR agonistinduced antinociception post-CCI (i.e., as seen in GRK3-null mice (Xu et al., 2004)); such observations would support a role for RGS12 in facilitating $\beta$ arr-dependent KOR tolerance. 
Potential Confounds and Future Directions for Neuropathic Pain Assessment: Peripheral nerve injury can also lead to supraspinal KOR activation (Abraham et al., 2000; Narita et al., 2006; Cahill et al., 2014), which may modulate spinally mediated nociceptive behaviors. For example, some evidence (Cahill et al., 2014) suggests that chronic pain is regulated by KOR-dependent modulation of mesolimbic DA, proposed to govern the negative affect experienced during pain and thus contribute to nociceptive responsiveness following neuropathic injury. Because we have evidence that the disrupted mesolimbic DAergic neurotransmission observed in RGS12-null mice is KOR-mediated (Fig. 3.6.1), it is plausible that any behavioral effects observed in neuropathic pain assays may be due, at least in part, to central effects of KOR (e.g., in the mesolimbic DA system), rather than direct spinal cord effects. Thus, if systemically administered KOR antagonist blocks the attenuation of CCl-induced nociceptive responses in RGS12-deficient mice (e.g., Fig. 4.2.3d-1 above), we will then test whether this reversal is due specifically, or in part, to changes in KOR signaling in the ventral striatum caused by RGS12 loss. To test this, we would locally deliver KOR antagonist (e.g., $100 \mathrm{nM}$ nor-BNI) or saline into the vSTR by reverse dialysis, as previously described (Gray et al., 1999; Yang et al., 2015; Virk et al., 2016). Briefly, we would perform stereotaxic surgery on RGS12-deficient mice and wildtype littermates to implant dialysis probes into the vSTR. Following surgical recovery, we would administer KOR antagonist or vehicle via reverse dialysis 24 hours prior to $\mathrm{CCl}$ surgery. Following 7, 11, and 14 days post-CCI, we would perform nociceptive testing of hyperalgesia (as above for experiments using systemically administered KOR antagonist) and allodynia (e.g., as in Fig. 4.2.3d-1 above). Like systemic administration, nor-BNI delivered directly into the CNS remains detectable (Patkar et al., 2013) in mouse brain for up to 21 days. Thus, a single administration of nor-BNI by reverse dialysis should be sufficient to antagonize KOR for the duration of the experiment. 


\subsection{4 - Question 4: Do RGS12 and KOR associate via a PDZ-mediated interaction?}

Rationale: An early paper on RGS12 from the Siderovski lab (Snow et al., 1998) described the binding specificity of its PDZ domain and noted a high degree of sequence similarity between the RGS12 PDZ domain and the first PDZ domain of NHERF1. Subsequent work (Li et al., 2002) has shown that NHERF1 directly binds a PDZ-recognition site at the KOR C-terminus (amino acids 376-380: -NKPV), but does not bind MOR (which lacks this C-terminal sequence; e.g., Fig. 10); furthermore, NHERF1 over-expression is reported (Li et al., 2002) to impact both KOR agonistinduced signaling and KOR trafficking/recycling. Thus, the first plausible candidate for investigating the molecular determinant(s) of selectivity of RGS12 action on KOR is a PDZ domain/C-terminal interaction, similar to that of the NHERF1/KOR interaction (Li et al., 2002). Our initial evidence using a KOR mutant with the last four amino acids of the wildtype KOR C-terminus mutated to alanines (NKPV $\rightarrow$ AAAA), as well as a gain-of-function MOR mutant containing KOR's wildtype C-terminus in substitution of its native C-terminal sequence (MOR ${ }^{A P L P>N K P V}$ ), supports that the effects of RGS12 on KOR-mediated G protein signaling are PDZ-dependent (Fig. 3.6.3). Approach: Bioluminescence resonance energy transfer (BRET): To help visualize potential interactions between RGS12 and KOR in a real-time, cellular context, we would initiate BRET analyses using Promega's NanoBRET system (Machleidt et al., 2015), similar to prior studies from the Siderovski lab (Giguere et al., 2012; Giguere et al., 2014) interrogating GPSM3 interactions with NLRP3, 14-3-3, and G protein subunits. The Siderovski group has previously established (Willard et al., 2007) that RGS12 can be modified at either the $\mathrm{N}$ - or C-terminus with a fusion protein (e.g., YFP or CFP) while retaining normal subcellular localization and cellular function. To leave the KOR C-terminus unperturbed*, we would likely engineer the NanoLuc or HaloTag fusion in the receptor's third intracellular loop (Wu et al., 2012). We should also test placing the NanoLuc or HaloTag fusion in the first or second intracellular loops, or within the Cterminus (prior to the final -NKPV sequence). To test interaction specificity, MOR, DOR, and D2R would need to be tagged in the same fashion as the optimized KOR construct. Initial experiments 
will test whether RGS12 is located in close proximity to KOR under basal and/or KOR agoniststimulated conditions. Mutagenesis studies (subaim (i) above) will inform further BRET construct development to elucidate those key determinants underlying any observed intracellular BRET between RGS12 and KOR.

Potential Confounds and Future Pursuits: *Caveat: To facilitate the Tango assay (Barnea et al., 2008) GPCR ORFs like that of KOR are cloned with C-terminal fusions: i.e., the vasopressin V2R tail, a TEV protease cleavage site, and a tTa transcription factor; this C-terminal extension prevents the KOR NKPV PDZ sequence from being displayed at the extreme C-terminus of the resultant GPCR fusion protein. However, there is ample evidence (Gee et al., 1998; Penkert et al., 2004; Wong et al., 2003; London et al., 2004) that PDZ domains also recognize internal peptide sequences (e.g., PDZ domains of syntrophin, Par-6, and Dishevelled).

One possible outcome is that a PDZ-mediated interaction between RGS12 and KOR is established that critically depends on the free -NKPV C-terminus of KOR and, thereby, only affects $G$ protein-dependent signaling and not $\beta$ arr interaction. RGS12 might augment $\beta$ arr interaction with KOR through a PDZ domain-independent protein segment, or alternatively, through regulating a specific signaling process (independent of the RGS domain and GoLoco motif; Fig. 10A) that is unique to KOR relative to other receptors. ßarr recruitment can engage myriad kinases, including tyrosine kinases (e.g., c-Src (Fan et al., 2001; Ribas et al., 2007)) and Ras-dependent MAPKs (Eishingdrelo and Kongsamut, 2013; Claing, 2013). Thus, RGS12 may augment $\beta$ arr recruitment by enhancing tyrosine phosphorylation- and/or Ras-dependent signaling events via its PTB domain and/or tandem RBDs, respectively. Dissecting these particular molecular determinants would proceed in a similar fashion to what is articulated above for the "PDZ domain hypothesis." For example, the Siderovski group previously characterized (Uhlik et al., 2005) the RGS12 PTB domain as belonging to a new subclass with unique electrostatics, and also established (Willard et al., 2007) a loss-of-function 
mutation (H995L) to the first RBD of RGS12 that reduces binding to $\mathrm{H}$-Ras without abrogating Raf association. If required, unbiased determinations of previously unidentified RGS12-interacting partners would be performed to generate additional hypotheses as to the nature of the selective RGS12 / KOR interaction, similar to the proteomics and yeast two-hybrid screens that the Siderovski group has successfully performed for RGS12 and GPSM3 interactants (Willard et al., 2007; Giguere et al., 2012; Giguere et al., 2014).

If the effect of RGS12 on KOR-mediated signaling is dependent on a PDZ-mediated interaction, we could consider using CRISPR / Cas9-based genome editing to induce a quadruple-alanine mutation to the KOR C-terminus $\left(K O R^{\text {NKPV }>A A A A}\right)$ within the mouse Oprk1 gene and thereby assess whether abrogating PDZ-dependent interactions with the KOR C-terminus will reproduce the KOR signaling and DA homeostasis imbalance phenotypes observed upon global loss of RGS12 (e.g., Figs. 7-9, 12, and other phenotypes as described (Gross et al., 2018)). This pursuit would not be able to directly implicate RGS12 alone in any KOR-and/or DA-related phenotypes we observe in KOR ${ }^{\mathrm{NKPV}>A A A A}$ mice, given that NHERF1 and GEC1 are also assumed to bind KOR using this motif (Huang et al., 2004; Chen et al., 2006). However, if we were to demonstrate that KOR ${ }^{\mathrm{NKPV}>A A A A}$ mice phenocopy some of the deficiencies/perturbations of one or more RGS12-deficient mouse strains, it will nonetheless provide strong correlative evidence that PDZ domain-dependent interactions between KOR and RGS12 account for at least some of the behavioral and biochemical disruptions observed upon RGS12 loss.

\subsection{5 - Question 5: Which specific brain regions and protein domains are responsible for the disruptions to DA and KOR function observed with global RGS12-null mice?}

Rationale: To make the case for RGS12 as a valid target for future drug discovery towards small molecule-mediated modulation of KOR agonist functional selectivity, a demonstration of reversal of mouse biochemical and behavioral deficits elicited by RGS12 deficiency is a required milestone. To date, no validated chemical probe for RGS12 modulation has yet been established. 
Thus, a genetic rescue strategy is required for a proof-of-principle demonstration of the region specificity of RGS12 in select biochemical and/or behavioral outcomes: i.e., viral transduction of RGS12 into select CNS regions of RGS12-deficient mouse strains.

Hypothesis: (1) Targeted re-expression of wildtype RGS12 will reverse or attenuate one or more of the behavioral deficits elicited by Rgs12 ablation; (2) re-expression of RGS12 loss-of-function mutants will ascertain the importance of select protein-protein interactions to such function by RGS12 in vivo.

Approach: Given the $<5 \mathrm{~kb}$ packaging restriction of adeno-associated viruses (Shevtsova et al., 2005) vs the $>4 \mathrm{~kb}$ size of the Rgs12 open-reading frame (NCBI NM_173402), lentiviruses expressing epitope-tagged, wildtype RGS12 will need to be constructed, purified, and titered. The Siderovski group has previously found that fluorescent protein-tagging RGS12 at either N-or C-termini has no effect on RGS12 expression or function (Willard et al., 2007); GFP onlyexpressing lentivirus will be used as a negative control. To evaluate RGS12 function in select neuronal populations, lentivirus transducing Rgs12 from cell type-specific promoters (e.g., DAT promoter for striatal DA neurons) will be constructed pending success in reversing behavioral deficits with RGS12 expressed from a more global PGK or synapsin1A promoter.

Expectations and Future Pursuits - For one or more of the observed, CNS-centered, behavioral deficits seen upon global RGS12 loss (see Chapter 2 \& Chapter 3), we expect viral-mediated restoration of vSTR RGS12 expression to normalize these behaviors. While we cannot overlook the possibility that constitutive RGS12 loss causes aberrant mouse behavior owing to a pleiotropy of dysfunctions (e.g., across multiple CNS regions and circuits; across a lengthy neurodevelopmental time-span), our expectation above arises from the unique effects that RGS12 loss (and ßarr-2 loss) is seen to engender for KOR specifically within the vSTR (Fig. 3.6.13.6.3). If reversal by viral-mediated RGS12 re-expression in the vSTR is seen for deficits attributable to RGS12 deficiency, the mesolimbic circuitry and DAT-dependent functions of virally 
infected mice will then be assessed biochemically to test whether behavior reversal by RGS12 re-expression is correlated with normalization of mesolimbic DA neurotransmission (i.e., particularly DAT function and expression). Furthermore, evidence of reversal by wildtype RGS12 re-expression would allow subsequent delivery of loss-of-function point mutants of RGS12 in head-to-head comparison with wildtype RGS12 to identify particular protein functions critical to RGS12 action in this context. These loss-of-function mutants will come from results of the experimental pursuits from Question 4 above, as well as prior studies of the Siderovski lab that have validated several loss-of-function point mutations, including a charge reversal (E740K) that eliminates RGS domain GAP activity (Sambi et al., 2006), an Arg-to-Phe change (R1206F) to the GoLoco motif which eliminates $\mathrm{G} \alpha$ binding and endosomal targeting of RGS12 (Sambi et al., 2006), and a His-to-Leu change (H995L) to the first Ras-binding domain that reduces RGS12 binding to activated H-Ras without abrogating Raf kinase association (Willard et al., 2007).

\subsection{6 - Question 6: How does RGS12 regulate psychostimulant-evoked DA levels in vivo?}

Rationale: Reduced hyperlocomotion in RGS12-null mice to psychostimulants (Fig. 2.6.2) suggests that RGS12 is involved in drug-induced increases in extracellular DA levels in the live organism. These behavioral outcomes are correlated with disruptions in DAT radioligand binding, $\left[{ }^{3} \mathrm{H}\right] \mathrm{DA}$ uptake, and $\left[{ }^{3} \mathrm{H}\right] \mathrm{DA}$ efflux (Chapter 2) -- all measures of ex vivo transporter function/activity. Although drug-induced $\left[{ }^{3} \mathrm{H}\right] \mathrm{DA}$ release in synaptosomes provides valuable information for ascertaining biochemical processes disrupted upon RGS12 loss, it cannot reflect neurotransmission in the animal with intact neurocircuitry. Thus, future studies should employ in vivo microdialysis -- continuous sampling of extracellular contents (e.g., monoaminergic neurotransmitters such as DA, 5-HT, norepinephrine [NE]) in live, awake RGS12-null and wildtype animals, rather than post-mortem preparations.

Approach: - Psychostimulant (e.g., AMPH, METH)-induced DA release should be assessed by in vivo microdialysis as previously performed by members of our lab (Doly et al., 2008). Specifically, 
mice would undergo stereotaxic surgery to implant microdialysis probes in dSTR and vSTR with coordinates from the Paxinos atlas. Upon recovery from surgery, mice would be injected with releasing agents (e.g., AMPH, METH) and dialysate collected every 10 minutes over 190 minutes. DA concentrations in dialysates would then be determined by HPLC with electrochemical detection. Additional studies with other psychostimulants that produce deficient hyperlocomotor responses in RGS12-null mice (e.g., cocaine) should also be examined.

Expectations and Future Plans: AMPH- and METH-induced DA release is likely significantly attenuated in RGS12-null mice, given reduced hyperlocomotion to these drugs (Fig. 2.6 .2 \& unpublished observations for METH). However, AMPH and METH-also exhibit appreciable affinity for the 5-HT (SERT) and NE transporter (NET), and induce transport reversal through these transporters (Steinkellner et al., 2011). To rule out any contribution of altered 5-HT or NE release to reduced hyperlocomotion of RGS12-null mice, we would need to also employ the microdialysis outlined here to evaluate SERT and NET function in RGS12-null mice (i.e., drug-induced changes in 5-HT and NE levels in relevant brain regions) and thereby assess the possible contribution of this molecular target to reduced AMPH-/METH--induced hyperlocomotion.

Potential Limitations and Control Experiment(s): Microdialysis is limited by poor temporal resolution (10 min collection intervals are most often employed) vs other techniques like voltammetry (Chefer et al., 2009). Thus, microdialysis may not fully reflect real-time monoamine neurotransmitter dynamics. However, we have found RGS12-null mice have reduced hyperlocomotion to AMPH-like drugs over an $80 \mathrm{~min}$ period (e.g., post-drug; Fig. 2.6.2). Therefore, dialysate collection in 10-min intervals should still inform whether perturbations in monoamine neurotransmitter dynamics are related to the reduced hyperlocomotion to AMPH-like drugs of RGS12-null mice. Also, stereotaxic implantation of a probe is invasive and can damage tissue, which could result in disrupted behavioral responses independent of drug-treatment. To verify that behaviorally-salient damage has not occurred, spontaneous locomotor activity ought 
to be measured in probe implanted, saline-treated RGS12-null and wildtype mice and compared to saline-treated mice that have not undergone stereotaxic surgery.

\subsection{7 - Question 7: Does RGS12 modulate SERT expression/function and serotonergic behaviors via KOR-dependent mechanism(s)?}

Rationale: We have shown that increased DAT expression and DA uptake, as well as reduced AMPH-induced hyperlocomotion, are reversed following antagonism of KOR (Fig. 3.6.1). Similarly, RGS12-null mice exhibit increased SERT expression and 5-HT uptake in a regiondependent manner, and these effects correlate with disrupted MDMA-induced hyperlocomotion (unpublished observations) and several other 5-HT-dependent behaviors (stresscoping/depression-like behavior, anxiety, and social interaction -- unpublished observations). Chronic stress (with concomitantly increased endogenous dynorphin release and KOR activation) and KOR agonists have been shown to increase plasmalemmal SERT expression and SERTmediated 5-HT uptake in a region-dependent manner and these changes are proposed to underlie a 'depression-like' phenotype (Schindler et al., 2012). Thus, it is reasonable to suspect that augmented SERT function and expression in RGS12-null mice is related to increased KOR expression/sensitivity and that these alterations to the serotonergic system underlies the observed disruptions to 5-HT-dependent behaviors (i.e., MDMA-induced locomotor activity, forced swim stress, tail suspension stress, elevated zero/plus maze, and social interaction).

Hypothesis: KOR blockade is sufficient to reverse or rescue SERT dysfunction and perturbation of 5-HT-dependent behaviors in RGS12-null mice.

Approach: Experiments will be designed exactly as described for studies evaluating DAT expression, $\left[{ }^{3} \mathrm{H}\right] \mathrm{DA}$ uptake, and $\mathrm{AMPH}$-induced hyperlocomotion (Fig. 3.6.1), except that KOR antagonist (nor-BNI, 10 mg/kg, 24-hour pretreatment, ip)-treated RGS12-null and wildtype mice will be evaluated for $(1)\left[{ }^{3} \mathrm{H}\right]$ citalopram saturation binding to SERT, (2) SERT-mediated $\left[{ }^{3} \mathrm{H}\right] 5-\mathrm{HT}$ uptake, (3) MDMA-induced $\left[{ }^{3} \mathrm{H}\right] 5-\mathrm{HT}$ efflux, (4) MDMA (10 and $30 \mathrm{mg} / \mathrm{kg}$ )-induced locomotor 
activity, (5) forced swim stress, (6) tail suspension stress, (7) elevated zero and/or plus maze, and (8) social interaction as per methods employed previously (Doly et al., 2008; Jin et al., 2017; Bey et al., 2018). Additionally, future studies of serotonergic neurotransmission and behavior should employ the use of the KOR::Cre-Rgs12 floxed mouse strain described above (in section 4.2.1), as this strategy could help determine whether RGS12 impacts serotonergic function via action specifically within KOR-expressing neurons.

Expectations and Future Pursuits: Given our observations with the effect of RGS12 on DAT (Fig. 3.6.1) and prior work by others demonstrating that KOR induces similar effects on SERT (Schindler et al., 2012), we would suspect that KOR antagonism would reverse the SERT dysfunction (i.e., SERT radioligand binding, 5-HT uptake, 5-HT efflux, and MDMA-induced locomotor activity) observed in RGS12-null mice (unpublished observations). Given that the disruptions to 5-HT-dependent behavioral outcomes (i.e., forced swim stress, tail suspension stress, elevated zero and/or plus maze, and social interaction) in RGS12-null mice (unpublished observations) is drug-independent (i.e., these are basal phenotypes of the mouse strain absence any drug application), it is reasonable to suspect that these phenotypes may manifest via one or more different neurobiological perturbations, even if these behaviors all are strongly associated with serotonergic neurotransmission. Thus, if KOR antagonism is not sufficient to reverse or rescue any of these behavioral perturbations, future studies will require additional pharmacological intervention, including (but not limited to) direct manipulation of the serotonergic system (i.e., KOR-independent 5-HT neurotransmission) with selective serotonin reuptake inhibitors (SSRIs) and/or specific 5-HT receptor agonists/antagonists. With respect to the latter, initial studies should employ the use of agonists/antagonists selective for Goilo-coupled 5-HT receptors (e.g., 5-HT receptor 1A [HTR1A]), given the specificity of RGS12 for this Ga subunit subtype. 


\section{3 - References}

Abraham KE, Brewer KL and McGinty JF. (2000) Opioid peptide messenger RNA expression is increased at spinal and supraspinal levels following excitotoxic spinal cord injury. Neuroscience 99: 189-197.

Barnea G, Strapps W, Herrada G, et al. (2008) The genetic design of signaling cascades to record receptor activation. Proc Natl Acad Sci U S A 105: 64-69.

Berube P, Laforest S, Bhatnagar S, et al. (2013) Enkephalin and dynorphin mRNA expression are associated with resilience or vulnerability to chronic social defeat stress. Physiol Behav 122: 237-245.

Bey AL, Wang X, Yan H, et al. (2018) Brain region-specific disruption of Shank3 in mice reveals a dissociation for cortical and striatal circuits in autism-related behaviors. Transl Psychiatry 8: 94.

Bohn LM, Gainetdinov RR, Lin FT, et al. (2000) Mu-opioid receptor desensitization by betaarrestin-2 determines morphine tolerance but not dependence. Nature 408: 720-723.

Bohn LM, Lefkowitz RJ and Caron MG. (2002) Differential mechanisms of morphine antinociceptive tolerance revealed in (beta)arrestin-2 knock-out mice. J Neurosci 22: 10494-10500.

Britt JP and McGehee DS. (2008) Presynaptic opioid and nicotinic receptor modulation of dopamine overflow in the nucleus accumbens. J Neurosci 28: 1672-1681.

Bruchas MR, Land BB, Aita M, et al. (2007a) Stress-induced p38 mitogen-activated protein kinase activation mediates kappa-opioid-dependent dysphoria. J Neurosci 27: 11614-11623.

Bruchas MR, Land BB, Lemos JC, et al. (2009) CRF1-R activation of the dynorphin/kappa opioid system in the mouse basolateral amygdala mediates anxiety-like behavior. PLoS One 4: e8528.

Bruchas MR, Macey TA, Lowe JD, et al. (2006) Kappa opioid receptor activation of p38 MAPK is GRK3- and arrestin-dependent in neurons and astrocytes. J Biol Chem 281: 18081-18089.

Bruchas MR, Xu M and Chavkin C. (2008) Repeated swim stress induces kappa opioid-mediated activation of extracellular signal-regulated kinase 1/2. Neuroreport 19: 1417-1422.

Bruchas MR, Yang T, Schreiber S, et al. (2007b) Long-acting kappa opioid antagonists disrupt receptor signaling and produce noncompetitive effects by activating c-Jun N-terminal kinase. J Biol Chem 282: 29803-29811.

Bruijnzeel AW. (2009) kappa-Opioid receptor signaling and brain reward function. Brain Res Rev 62: 127-146.

Brust TF, Morgenweck J, Kim SA, et al. (2016) Biased agonists of the kappa opioid receptor suppress pain and itch without causing sedation or dysphoria. Sci Signal 9: ra117.

Butko MT, Savas JN, Friedman B, et al. (2013) In vivo quantitative proteomics of somatosensory cortical synapses shows which protein levels are modulated by sensory deprivation. Proc Natl Acad Sci U S A 110: E726-735.

Cahill CM, Taylor AM, Cook C, et al. (2014) Does the kappa opioid receptor system contribute to pain aversion? Front Pharmacol 5: 253.

Cai X, Huang H, Kuzirian MS, et al. (2016) Generation of a KOR-Cre knockin mouse strain to study cells involved in kappa opioid signaling. Genesis 54: 29-37. 
Carey AN, Lyons AM, Shay CF, et al. (2009) Endogenous kappa opioid activation mediates stressinduced deficits in learning and memory. J Neurosci 29: 4293-4300.

Chartoff EH, Papadopoulou M, MacDonald ML, et al. (2009) Desipramine reduces stress-activated dynorphin expression and CREB phosphorylation in NAc tissue. Mol Pharmacol 75: 704712.

Chefer VI, Thompson AC, Zapata A, et al. (2009) Overview of brain microdialysis. Curr Protoc Neurosci Chapter 7: Unit7 1.

Chen C, Li JG, Chen Y, et al. (2006) GEC1 interacts with the kappa opioid receptor and enhances expression of the receptor. J Biol Chem 281: 7983-7993.

Claing A. (2013) beta-Arrestins: modulators of small GTPase activation and function. Prog Mol Biol Transl Sci 118: 149-174.

Crowe MS, Leishman E, Banks ML, et al. (2015) Combined inhibition of monoacylglycerol lipase and cyclooxygenases synergistically reduces neuropathic pain in mice. Br J Pharmacol 172: $1700-1712$.

Crowe MS, Wilson CD, Leishman E, et al. (2017) The monoacylglycerol lipase inhibitor KML29 with gabapentin synergistically produces analgesia in mice. Br J Pharmacol 174: 4523-4539.

Crowley NA and Kash TL. (2015) Kappa opioid receptor signaling in the brain: Circuitry and implications for treatment. Prog Neuropsychopharmacol Biol Psychiatry 62: 51-60.

Doly S, Valjent E, Setola V, et al. (2008) Serotonin 5-HT2B receptors are required for 3,4methylenedioxymethamphetamine-induced hyperlocomotion and 5-HT release in vivo and in vitro. J Neurosci 28: 2933-2940.

Eishingdrelo $\mathrm{H}$ and Kongsamut S. (2013) Minireview: Targeting GPCR Activated ERK Pathways for Drug Discovery. Curr Chem Genom Transl Med 7: 9-15.

Fan G, Shumay E, Malbon CC, et al. (2001) c-Src tyrosine kinase binds the beta 2-adrenergic receptor via phospho-Tyr-350, phosphorylates G-protein-linked receptor kinase 2, and mediates agonist-induced receptor desensitization. J Biol Chem 276: 13240-13247.

Gardell LR, Ibrahim M, Wang R, et al. (2004) Mouse strains that lack spinal dynorphin upregulation after peripheral nerve injury do not develop neuropathic pain. Neuroscience 123: 43-52.

Gee SH, Sekely SA, Lombardo C, et al. (1998) Cyclic peptides as non-carboxyl-terminal ligands of syntrophin PDZ domains. J Biol Chem 273: 21980-21987.

Giguere PM, Gall BJ, Ezekwe EA, Jr., et al. (2014) G Protein signaling modulator-3 inhibits the inflammasome activity of NLRP3. J Biol Chem 289: 33245-33257.

Giguere PM, Laroche G, Oestreich EA, et al. (2012) G-protein signaling modulator-3 regulates heterotrimeric G-protein dynamics through dual association with Gbeta and Galphai protein subunits. J Biol Chem 287: 4863-4874.

Gray AM, Rawls SM, Shippenberg TS, et al. (1999) The kappa-opioid agonist, U-69593, decreases acute amphetamine-evoked behaviors and calcium-dependent dialysate levels of dopamine and glutamate in the ventral striatum. J Neurochem 73: 1066-1074.

Gross JD, Kaski SW, Schroer AB, et al. (2018) Regulator of G protein signaling-12 modulates the dopamine transporter in ventral striatum and locomotor responses to psychostimulants. J Psychopharmacol 32: 191-203. 
Heinsbroek JA, Furbish AB and Peters J. (2018) A single, extinction-based treatment with a kappa opioid receptor agonist elicits a long-term reduction in cocaine relapse. Neuropsychopharmacology 43: 1492-1497.

Huang P, Steplock D, Weinman EJ, et al. (2004) kappa Opioid receptor interacts with $\mathrm{Na}(+) / \mathrm{H}(+)-$ exchanger regulatory factor-1/Ezrin-radixin-moesin-binding phosphoprotein-50 (NHERF1/EBP50) to stimulate $\mathrm{Na}(+) / \mathrm{H}(+)$ exchange independent of $\mathrm{G}(\mathrm{i}) / \mathrm{G}(\mathrm{o})$ proteins. J Biol Chem 279: 25002-25009.

Hull KM, Tolland DE and Maher TJ. (1994) L-tyrosine potentiation of opioid-induced analgesia utilizing the hot-plate test. J Pharmacol Exp Ther 269: 1190-1195.

Hylden JL, Nahin RL, Traub RJ, et al. (1991) Effects of spinal kappa-opioid receptor agonists on the responsiveness of nociceptive superficial dorsal horn neurons. Pain 44: 187-193.

Inan S, Dun NJ and Cowan A. (2009) Inhibitory effect of lidocaine on pain and itch using formalininduced nociception and 5'-guanidinonaltrindole-induced scratching models in mice: behavioral and neuroanatomical evidence. Eur J Pharmacol 616: 141-146.

Jaggi AS, Jain V and Singh N. (2011) Animal models of neuropathic pain. Fundam Clin Pharmacol 25: 1-28.

Janssen PA, Niemegeers CJ and Dony JG. (1963) The inhibitory effect of fentanyl and other morphine-like analgesics on the warm water induced tail withdrawl reflex in rats. Arzneimittelforschung 13: 502-507.

Jin ZL, Chen XF, Ran YH, et al. (2017) Mouse strain differences in SSRI sensitivity correlate with serotonin transporter binding and function. Sci Rep 7: 8631.

Kajander KC, Sahara Y, ladarola MJ, et al. (1990) Dynorphin increases in the dorsal spinal cord in rats with a painful peripheral neuropathy. Peptides 11: 719-728.

Kamei J and Nagase H. (2001) Norbinaltorphimine, a selective kappa-opioid receptor antagonist, induces an itch-associated response in mice. Eur J Pharmacol 418: 141-145.

Kardon AP, Polgar E, Hachisuka J, et al. (2014) Dynorphin acts as a neuromodulator to inhibit itch in the dorsal horn of the spinal cord. Neuron 82: 573-586.

Kinsey SG, Long JZ, Cravatt BF, et al. (2010) Fatty acid amide hydrolase and monoacylglycerol lipase inhibitors produce anti-allodynic effects in mice through distinct cannabinoid receptor mechanisms. J Pain 11: 1420-1428.

Kinsey SG, Wise LE, Ramesh D, et al. (2013) Repeated low-dose administration of the monoacylglycerol lipase inhibitor JZL184 retains cannabinoid receptor type 1-mediated antinociceptive and gastroprotective effects. J Pharmacol Exp Ther 345: 492-501.

Knoll AT, Muschamp JW, Sillivan SE, et al. (2011) Kappa opioid receptor signaling in the basolateral amygdala regulates conditioned fear and anxiety in rats. Biol Psychiatry 70: 425-433.

Ko MC. (2015) Neuraxial opioid-induced itch and its pharmacological antagonism. Handb Exp Pharmacol 226: 315-335.

Kumagai H, Ebata T, Takamori K, et al. (2012) Efficacy and safety of a novel k-agonist for managing intractable pruritus in dialysis patients. Am J Nephrol 36: 175-183.

Kuraishi Y, Nagasawa T, Hayashi K, et al. (1995) Scratching behavior induced by pruritogenic but not algesiogenic agents in mice. Eur J Pharmacol 275: 229-233.

Lewin GR, Lechner SG and Smith ES. (2014) Nerve growth factor and nociception: from experimental embryology to new analgesic therapy. Handb Exp Pharmacol 220: 251-282. 
Lewin GR and Mendell LM. (1993) Nerve growth factor and nociception. Trends Neurosci 16: 353359.

Li JG, Chen C and Liu-Chen LY. (2002) Ezrin-radixin-moesin-binding phosphoprotein-50/Na+/H+ exchanger regulatory factor (EBP50/NHERF) blocks U50,488H-induced down-regulation of the human kappa opioid receptor by enhancing its recycling rate. J Biol Chem 277: $27545-27552$.

London TB, Lee HJ, Shao Y, et al. (2004) Interaction between the internal motif KTXXXI of Idax and mDvl PDZ domain. Biochem Biophys Res Commun 322: 326-332.

Machleidt T, Woodroofe CC, Schwinn MK, et al. (2015) NanoBRET--A Novel BRET Platform for the Analysis of Protein-Protein Interactions. ACS Chem Biol 10: 1797-1804.

Malan TP, Ossipov MH, Gardell LR, et al. (2000) Extraterritorial neuropathic pain correlates with multisegmental elevation of spinal dynorphin in nerve-injured rats. Pain 86: 185-194.

Mansour A, Khachaturian H, Lewis ME, et al. (1987) Autoradiographic differentiation of mu, delta, and kappa opioid receptors in the rat forebrain and midbrain. $J$ Neurosci 7: 2445-2464.

Martin-McCaffrey L, Hains MD, Pritchard GA, et al. (2005) Differential expression of regulator of G-protein signaling R12 subfamily members during mouse development. Dev Dyn 234: 438-444.

McLaughlin JP, Myers LC, Zarek PE, et al. (2004) Prolonged kappa opioid receptor phosphorylation mediated by G-protein receptor kinase underlies sustained analgesic tolerance. J Biol Chem 279: 1810-1818.

McLennan GP, Kiss A, Miyatake M, et al. (2008) Kappa opioids promote the proliferation of astrocytes via Gbetagamma and beta-arrestin 2-dependent MAPK-mediated pathways. J Neurochem 107: 1753-1765.

Morgenweck J, Frankowski KJ, Prisinzano TE, et al. (2015) Investigation of the role of betaarrestin2 in kappa opioid receptor modulation in a mouse model of pruritus. Neuropharmacology 99: 600-609.

Munro TA, Berry LM, Van't Veer A, et al. (2012) Long-acting kappa opioid antagonists nor-BNI, GNTI and JDTic: pharmacokinetics in mice and lipophilicity. BMC Pharmacol 12: 5.

Munro TA, Huang XP, Inglese C, et al. (2013) Selective kappa opioid antagonists nor-BNI, GNTI and JDTic have low affinities for non-opioid receptors and transporters. PLoS One 8: e70701.

Narita M, Kaneko C, Miyoshi K, et al. (2006) Chronic pain induces anxiety with concomitant changes in opioidergic function in the amygdala. Neuropsychopharmacology 31: 739-750.

Obara I, Mika J, Schafer MK, et al. (2003) Antagonists of the kappa-opioid receptor enhance allodynia in rats and mice after sciatic nerve ligation. Br J Pharmacol 140: 538-546.

Paris JJ, Reilley KJ and McLaughlin JP. (2011) Kappa Opioid Receptor-Mediated Disruption of Novel Object Recognition: Relevance for Psychostimulant Treatment. J Addict Res Ther S4.

Patkar KA, Wu J, Ganno ML, et al. (2013) Physical presence of nor-binaltorphimine in mouse brain over 21 days after a single administration corresponds to its long-lasting antagonistic effect on kappa-opioid receptors. J Pharmacol Exp Ther 346: 545-554.

Patru MC and Reser DH. (2015) A New Perspective on Delusional States - Evidence for Claustrum Involvement. Front Psychiatry 6: 158. 
Penkert RR, DiVittorio HM and Prehoda KE. (2004) Internal recognition through PDZ domain plasticity in the Par-6-Pals1 complex. Nat Struct Mol Biol 11: 1122-1127.

Raehal KM and Bohn LM. (2014) beta-arrestins: regulatory role and therapeutic potential in opioid and cannabinoid receptor-mediated analgesia. Handb Exp Pharmacol 219: 427443.

Ribas C, Penela P, Murga C, et al. (2007) The G protein-coupled receptor kinase (GRK) interactome: role of GRKs in GPCR regulation and signaling. Biochim Biophys Acta 1768: 913-922.

Robles CF, McMackin MZ, Campi KL, et al. (2014) Effects of kappa opioid receptors on conditioned place aversion and social interaction in males and females. Behav Brain Res 262: 84-93.

Rocchetti J, Isingrini E, Dal Bo G, et al. (2015) Presynaptic D2 dopamine receptors control longterm depression expression and memory processes in the temporal hippocampus. Biol Psychiatry 77: 513-525.

Ross SE, Mardinly AR, McCord AE, et al. (2010) Loss of inhibitory interneurons in the dorsal spinal cord and elevated itch in Bhlhb5 mutant mice. Neuron 65: 886-898.

Ruderman MA, Powell SB and Geyer MA. (2009) A Kappa Opioid Model of Atypical Altered Consciousness and Psychosis: U50488, DOI, AC90179 Effects on Prepulse Inhibition and Locomotion in Mice. J Young Investig 19: 1-7.

Sambi BS, Hains MD, Waters CM, et al. (2006) The effect of RGS12 on PDGFbeta receptor signalling to p42/p44 mitogen activated protein kinase in mammalian cells. Cell Signal 18: 971-981.

Schattauer SS, Kuhar JR, Song A, et al. (2017) Nalfurafine is a G-protein biased agonist having significantly greater bias at the human than rodent form of the kappa opioid receptor. Cell Signal 32: 59-65.

Schattauer SS, Miyatake M, Shankar H, et al. (2012) Ligand directed signaling differences between rodent and human kappa-opioid receptors. J Biol Chem 287: 41595-41607.

Schindler AG, Messinger DI, Smith JS, et al. (2012) Stress produces aversion and potentiates cocaine reward by releasing endogenous dynorphins in the ventral striatum to locally stimulate serotonin reuptake. J Neurosci 32: 17582-17596.

Schlosburg JE, Boger DL, Cravatt BF, et al. (2009) Endocannabinoid modulation of scratching response in an acute allergenic model: a new prospective neural therapeutic target for pruritus. J Pharmacol Exp Ther 329: 314-323.

Schlosburg JE, O'Neal ST, Conrad DH, et al. (2011) CB1 receptors mediate rimonabant-induced pruritic responses in mice: investigation of locus of action. Psychopharmacology (Berl) 216: 323-331.

Schroer AB, Gross JD, Kaski SW, et al. (2018) Development of Full Sweet, Umami, and Bitter Taste Responsiveness Requires Regulator of G protein Signaling-21 (RGS21). Chem Senses 43: 367-378.

Shevtsova Z, Malik JM, Michel U, et al. (2005) Promoters and serotypes: targeting of adenoassociated virus vectors for gene transfer in the rat central nervous system in vitro and in vivo. Exp Physiol 90: 53-59.

Simonsen E, Komenda P, Lerner B, et al. (2017) Treatment of Uremic Pruritus: A Systematic Review. Am J Kidney Dis 70: 638-655. 
Snow BE, Hall RA, Krumins AM, et al. (1998) GTPase activating specificity of RGS12 and binding specificity of an alternatively spliced PDZ (PSD-95/DIg/ZO-1) domain. J Biol Chem 273: 17749-17755.

Snyder LM, Chiang MC, Loeza-Alcocer E, et al. (2018) Kappa Opioid Receptor Distribution and Function in Primary Afferents. Neuron 99: 1274-1288 e1276.

Sora I, Takahashi N, Funada M, et al. (1997) Opiate receptor knockout mice define mu receptor roles in endogenous nociceptive responses and morphine-induced analgesia. Proc Natl Acad Sci U S A 94: 1544-1549.

Steinkellner T, Freissmuth $\mathrm{M}$, Sitte $\mathrm{HH}$, et al. (2011) The ugly side of amphetamines: short- and long-term toxicity of 3,4-methylenedioxymethamphetamine (MDMA, 'Ecstasy'), methamphetamine and D-amphetamine. Biol Chem 392: 103-115.

Stiefel KM, Merrifield A and Holcombe AO. (2014) The claustrum's proposed role in consciousness is supported by the effect and target localization of Salvia divinorum. Front Integr Neurosci 8: 20.

Svingos AL, Chavkin C, Colago EE, et al. (2001) Major coexpression of kappa-opioid receptors and the dopamine transporter in nucleus accumbens axonal profiles. Synapse 42: 185-192.

Todd AJ. (2010) Neuronal circuitry for pain processing in the dorsal horn. Nat Rev Neurosci 11: 823-836.

Tsai NP, Tsui YC, Pintar JE, et al. (2010) Kappa opioid receptor contributes to EGF-stimulated neurite extension in development. Proc Natl Acad Sci U S A 107: 3216-3221.

Turiault M, Parnaudeau S, Milet A, et al. (2007) Analysis of dopamine transporter gene expression pattern -- generation of DAT-iCre transgenic mice. FEBS J 274: 3568-3577.

Uhlik MT, Temple B, Bencharit S, et al. (2005) Structural and evolutionary division of phosphotyrosine binding (PTB) domains. J Mol Biol 345: 1-20.

Virk MS, Sagi Y, Medrihan L, et al. (2016) Opposing roles for serotonin in cholinergic neurons of the ventral and dorsal striatum. Proc Natl Acad Sci U S A 113: 734-739.

Wagner R, DeLeo JA, Coombs DW, et al. (1993) Spinal dynorphin immunoreactivity increases bilaterally in a neuropathic pain model. Brain Res 629: 323-326.

Wang Z, Gardell LR, Ossipov MH, et al. (2001) Pronociceptive actions of dynorphin maintain chronic neuropathic pain. J Neurosci 21: 1779-1786.

White KL, Robinson JE, Zhu H, et al. (2015) The G protein-biased kappa-opioid receptor agonist RB-64 is analgesic with a unique spectrum of activities in vivo. J Pharmacol Exp Ther 352: 98-109.

Wilkerson JL, Ghosh S, Bagdas D, et al. (2016) Diacylglycerol lipase beta inhibition reverses nociceptive behaviour in mouse models of inflammatory and neuropathic pain. $\mathrm{Br} J$ Pharmacol 173: 1678-1692.

Willard MD, Willard FS, Li X, et al. (2007) Selective role for RGS12 as a Ras/Raf/MEK scaffold in nerve growth factor-mediated differentiation. EMBO J 26: 2029-2040.

Wong HC, Bourdelas A, Krauss A, et al. (2003) Direct binding of the PDZ domain of Dishevelled to a conserved internal sequence in the C-terminal region of Frizzled. Mol Cell 12: 12511260.

Wu H, Wacker D, Mileni M, et al. (2012) Structure of the human kappa-opioid receptor in complex with JDTic. Nature 485: 327-332. 
Xu M, Petraschka M, McLaughlin JP, et al. (2004) Neuropathic pain activates the endogenous kappa opioid system in mouse spinal cord and induces opioid receptor tolerance. $J$ Neurosci 24: 4576-4584.

Yang H, Sampson MM, Senturk D, et al. (2015) Sex- and SERT-mediated differences in stimulated serotonin revealed by fast microdialysis. ACS Chem Neurosci 6: 1487-1501.

Zimmermann M. (2001) Pathobiology of neuropathic pain. Eur J Pharmacol 429: 23-37. 


\section{APPENDIX A}

\section{RGS12 and Prepulse Inhibition}

\section{Appendix A.1 - Deletion of schizophrenia-associated gene RGS12 in mice results in} baseline prepulse inhibition deficiencies that are not reversed by antipsychotics

A

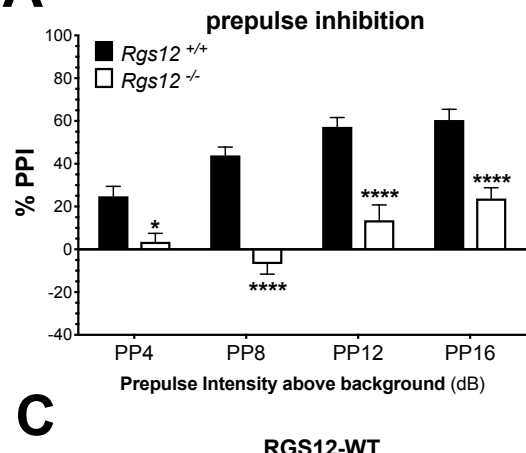

prototypical:

$1^{\text {st }}$ gen. antipsychotic

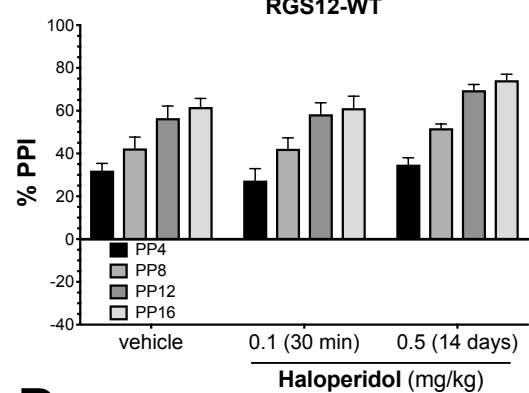

D

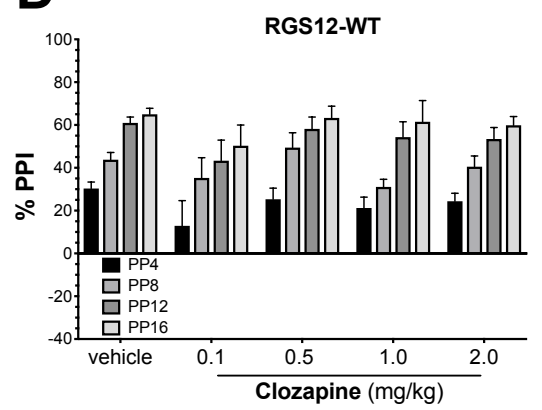

E

$3^{\text {rd }}$ gen. antipsychotic

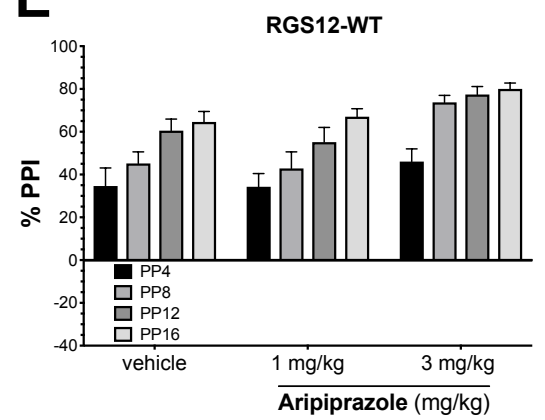

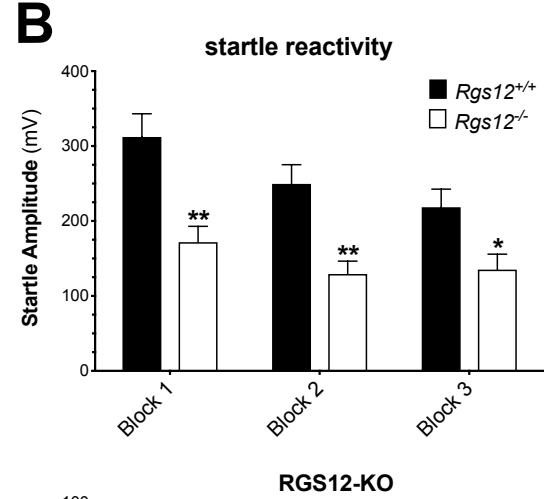
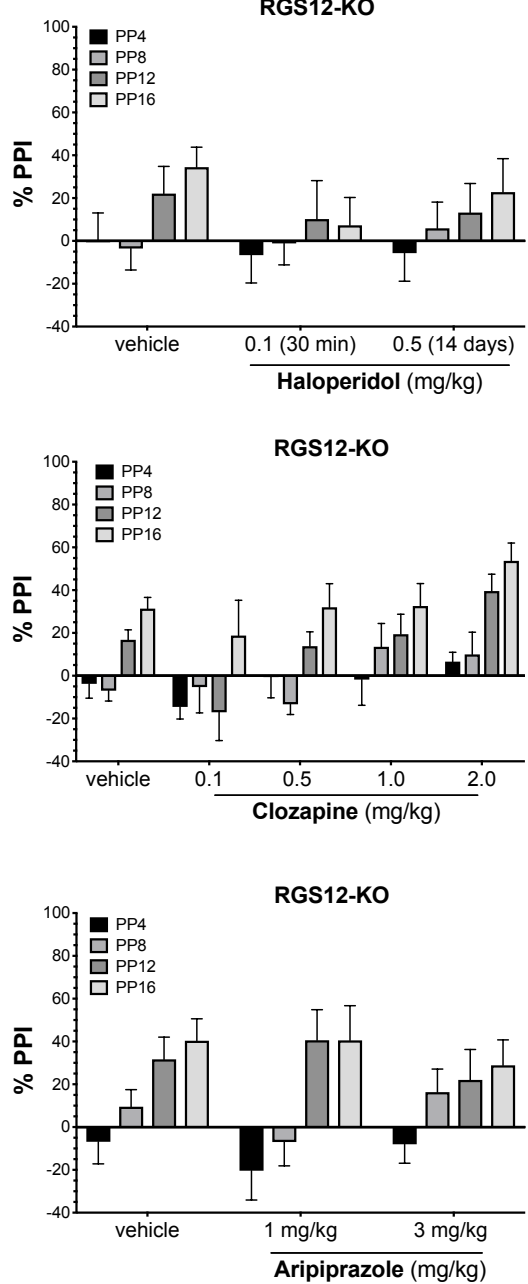
Figure Appx. A.1. Deletion of the schizophrenia-associated gene RGS12 (Xu et al., 2011; Guipponi et al., 2014) in mice produces baseline deficiencies in prepulse inhibition that are not reversed by several different antipsychotics. (A) Baseline prepulse inhibition of acoustic startle (\% PPI) in RGS12-null (Rgs12\% - open bars) and wildtype littermate control $\left(R g s 12^{+/+}\right.$- closed bars) mice to four different prepulse intensities: 4 (PP4), 8 (PP8), 12 (PP12), and 16 (PP16) decibels $(\mathrm{dB})$ above background noise $(65 \mathrm{~dB})$. Data were analyzed by two-way ANOVA ( $\mathrm{n}=14-$ 19 mice per group). (B) Average baseline startle amplitude (millivolts, mV) (a measure of startle reactivity) across three blocks of a complete PPI session in RGS12-null and wildtype littermate controls. Block 1 consisted of 6 sequential startle pulse-only (120 dB) white noise bursts at the beginning of the session, Block 2 consisted of 12 startle pulse-only exposures interspersed pseudorandomly throughout the PPI session, and Block 3 consisted of 6 sequential startle pulseonly exposures at the end of the PPI session. Data were analyzed by two-way ANOVA ( $n=18$ mice per group) (C) PPI following vehicle, acute $(0.1 \mathrm{mg} / \mathrm{kg}, 30-\mathrm{min}$ pretreatment, ip), or repeated $\left(0.5 \mathrm{mg} / \mathrm{kg}, 14\right.$ consecutive days, once/day, ip) administration of the prototypical $1^{\text {st }}$ generation antipsychotic haloperidol (a dopamine D2 receptor antagonist) in wildtype (left panel) and RGS12null (right panel) littermate controls. Data were analyzed by two-way ANOVA ( $\mathrm{n}=8-10$ mice per group) (D) PPI following vehicle or acute administration of the prototypical $2^{\text {nd }}$ generation antipsychotic clozapine (a serotonin 5-HT2A and dopamine D2 receptor antagonist) at various doses $(0.5,1.0$, or $2.0 \mathrm{mg} / \mathrm{kg}, 30$-min pretreatment, ip) in wildtype (left panel) and RGS12-null (right panel) littermate controls. Data were analyzed by two-way ANOVA ( $n=4-18$ mice per group) (E) PPI following vehicle or acute administration of the prototypical $3^{\text {rd }}$ generation antipsychotic aripiprazole (a serotonin 5-HT2A and dopamine D2 receptor partial agonist) at various doses (1.0 or $3.0 \mathrm{mg} / \mathrm{kg}, 30-\mathrm{min}$ pretreatment, ip) in wildtype (left panel) and RGS12-null (right panel) littermate controls. Data were analyzed by two-way ANOVA ( $n=6-7$ mice per group) All data are the mean $+/$ - SEM. ${ }^{*} p<0.05,{ }^{* *} p<0.01, p<0.0001$. 
Appendix A.2 - Deletion of schizophrenia-associated gene RGS6 in mice does not alter baseline prepulse inhibition or startle reactivity
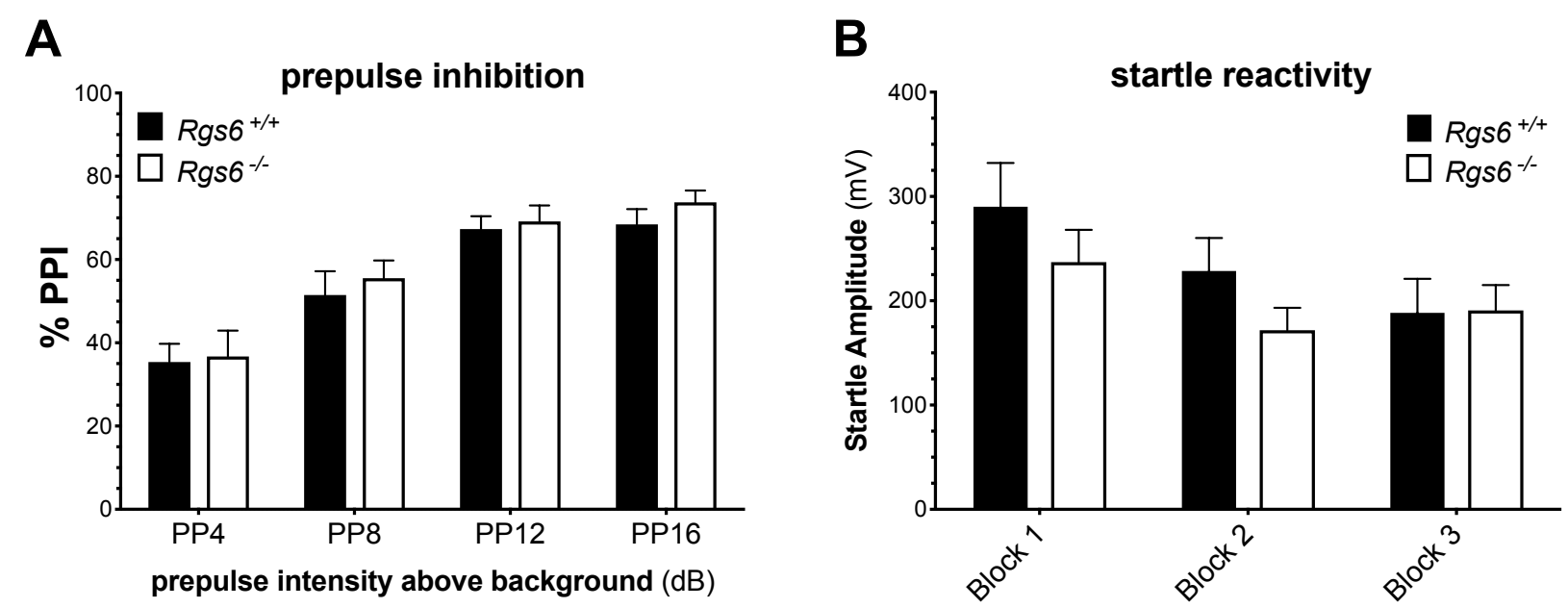

Figure Appx. A.2. Deletion of schizophrenia-associated gene RGS6 (Schizophrenia Working Group of the Psychiatric Genomics, 2014) in mice does not alter prepulse inhibition or startle reactivity. (A) Baseline prepulse inhibition of acoustic startle (\% PPI) in constitutive RGS6-null (Rgs $12^{-/-}$- open bars) and wildtype littermate control $\left(R g s 6^{+/+}\right.$- closed bars) mice to four different prepulse intensities: 4 (PP4), 8 (PP8), 12 (PP12), and 16 (PP16) decibels (dB) above background noise $(65 \mathrm{~dB})$. Analysis by two-way ANOVA revealed no significant differences between genotypes ( $n=10-12$ mice per group; $p>0.05)$. (B) Average baseline startle amplitude (millivolts, $\mathrm{mV}$ ) (a measure of startle reactivity) across three blocks of a complete PPI session in RGS12null and wildtype littermate controls. Analysis by two-way ANOVA revealed no significant differences between genotypes $(n=10-12$ mice per group; $p>0.05)$. 


\section{Appendix A.3 - References}

Guipponi M, Santoni FA, Setola V, et al. (2014) Exome sequencing in 53 sporadic cases of schizophrenia identifies 18 putative candidate genes. PLoS One 9: e112745.

Schizophrenia Working Group of the Psychiatric Genomics C. (2014) Biological insights from 108 schizophrenia-associated genetic loci. Nature 511: 421-427.

Xu B, Roos JL, Dexheimer P, et al. (2011) Exome sequencing supports a de novo mutational paradigm for schizophrenia. Nat Genet 43: 864-868. 